\title{
Growing out of hunger: \\ Towards an improved understanding of the water and nutrient limited yield of cassava
}
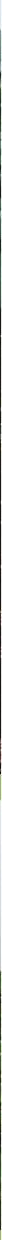

\section{Joy G. Adiele}





\section{Growing out of hunger: Towards an improved understanding of the water and nutrient limited yield of cassava}

Joy G. Adiele 


\section{Thesis committee}

\section{Promotor}

Prof. Dr K.E. Giller

Professor of Plant Production Systems

Wageningen University \& Research

\section{Co-promotor}

Dr A.G.T. Schut

Assistant professor, Plant Production Systems Group

Wageningen University \& Research

\section{Other members}

Prof. Dr L.O. Fresco, Wageningen University \& Research

Dr G. Byju, Central Tuber Crops Research Institute, Bhubaneshwar, India

Dr I. Supit, Water Systems and Global Change, Wageningen University \& Research

Dr H.A. Webber, Leibniz Centre for Agricultural Landscape Research, Müncheberg, Germany

This research was conducted under the auspices of the C.T. de Wit Graduate School of Production Ecology and Resource Conservation (PE\&RC). 


\title{
Growing out of hunger: Towards an improved understanding of the water and nutrient limited yield of cassava
}

\author{
Joy G. Adiele
}

Thesis

Submitted in fulfilment of the requirements for the degree of doctor

at Wageningen University

by the authority of the Rector Magnificus,

Prof. Dr A.P.J. Mol,

in the presence of the

Thesis Committee appointed by the Academic Board

to be defended in public

on Tuesday 30 June 2020

at 1:30 p.m. in the Aula. 


\section{Joy G. Adiele}

Growing out of hunger: Towards an improved understanding of the water and nutrient limited yield of cassava

146 pages

PhD Thesis, Wageningen University, Wageningen, The Netherlands (2020)

With references, with summary in English and Dutch

ISBN: 978-94-6395-420-4

DOI: https://doi.org/10.18174/523048 


\begin{abstract}
Cassava is an important staple crop for the rural population but also more and more used as a cash and industrial crop, contributing to economic development of sub-Saharan Africa (SSA). Therefore, sustainable intensification of cassava has become necessary, but the crop's yield potential is unknown. This study aimed to understand the yield potential of cassava and the dynamics of nutrient limitations in relation to water availability, to obtain better insight and a theoretical understanding of how the crop responds to nutrient availability and application of fertilizers in different agro-ecologies. Field experiments were conducted in different agro-ecologies: in Cross River (Tropical Rainforest), Edo (Forest Transition Savanna) and Benue (Guinea Savanna) in 2016 and 2017. Treatments included NPK fertilizers in four application rates, $\mathrm{N}, \mathrm{P}$ and $\mathrm{K}$ omission plots and plots combining the highest rates of $\mathrm{N}$ and $\mathrm{P}\left(300 \mathrm{~kg} \mathrm{~N} \mathrm{ha}^{-1}, 100 \mathrm{~kg} \mathrm{P} \mathrm{ha}^{-1}\right)$ with respectively $60,120,180,240$ and $300 \mathrm{~kg} \mathrm{~K} \mathrm{ha}^{-1}$, and highest rate of $\mathrm{N}, \mathrm{P}$ and $\mathrm{K}$ combined with secondary and micronutrients. Fresh and dry biomass and nutrient contents of leaves, stems and storage roots were recorded at 4 and 8 months after planting and at final harvest. At set times, light interception and detailed plant characteristics were measured, including canopy dimensions, number of leaves and leaf scars. The measured values were used to calculate other variables, including leaf angle distribution, light extinction coefficient, leaf area index $(L A I)$ and radiation use efficiency $(R U E)$. The LINTUL-Cassava model was recalibrated and tested for accuracy of water limited yield predictions. Further, model components were added that allowed us to compute $\mathrm{N}, \mathrm{P}$ and $\mathrm{K}$ limited growth.
\end{abstract}

Foremost, we evaluated the cassava yield potential and nutrient use efficiency when supplied with various $\mathrm{N}, \mathrm{P}$ and $\mathrm{K}$ rates and at high $\mathrm{N}$ and $\mathrm{P}$ rates with increasing rates of $\mathrm{K}$. Measured storage root dry matter (DM) yields ranged between 11 and $35 \mathrm{t} \mathrm{DM} \mathrm{ha}^{-1}$. The largest yields were obtained at the largest rates of $\mathrm{K}$ with a mean agronomic efficiency of 60,162 and $51 \mathrm{~kg}$ DM of storage roots per $\mathrm{kg}$ of $\mathrm{N}, \mathrm{P}$ and $\mathrm{K}$ applied. Increasing the supply of $\mathrm{K}$ improved yields and therefore also the agronomic efficiency of $\mathrm{N}$ and P. Storage root yield responses to applied N, P and K fertilizers $(2-18,3-16$ and $3-22 \mathrm{t}$ $\mathrm{DM} \mathrm{ha}{ }^{-1}$, respectively) varied across the agro-ecologies, reflecting variability in potential yields and applied NPK ratios. Addition of secondary and micronutrients did not affect cassava storage root yield. We found that the caloric energy yield of cassava per $\mathrm{kg}$ of $\mathrm{N}$ applied is 2.7 times larger than the value reported for maize. For the nutrient uptake dynamics in cassava, on average, 67, 61 and $52 \%$ of total $\mathrm{N}, \mathrm{P}$ and $\mathrm{K}$ uptake were already taken up at four months after planting (MAP), respectively. The maximum uptake rates for $\mathrm{N}, \mathrm{P}$ and $\mathrm{K}$ were $0.21,0.03$ and $0.12 \mathrm{~g} \mathrm{~m}^{-2} \mathrm{~d}^{-1}$ respectively at about four MAP. Nutrient dilution curves for $\mathrm{N}, \mathrm{P}$ and $\mathrm{K}$ at different application rates were quantified for the first time in cassava, with obtained nutrient dilution coefficients higher than most other reported crops. Under optimum conditions, nutrient dilution curves of the concentrations of $\mathrm{N}, \mathrm{P}$ and $\mathrm{K}$ in the crop were determined using a power function model with $\mathrm{Nc}=82 \mathrm{DM}^{-0.61}, \mathrm{Pc}=7.4 \mathrm{DM}^{-0.54}$ and $\mathrm{Kc}=43 \mathrm{DM}^{-0.54}$, when total biomass was between 5 and $57 \mathrm{t} \mathrm{DM} \mathrm{ha}^{-1}$. Our study provides insights in the dynamics of nutrient uptake and uptake rates, $\mathrm{N}, \mathrm{P}$ and $\mathrm{K}$ dilution curves and nutrition indices for cassava under West African conditions.

The average measured fraction of light intercepted during the season was $80 \%$, with a light extinction coefficient of 0.67 and an $R U E$ of $2.8 \mathrm{~g} \mathrm{DM} \mathrm{MJ}^{-1}$ intercepted photosynthetically active radiation. After calibration with data from the 2016 experiment in Edo only, the LINTUL-Cassava model described the crop growth and observed patterns of $L A I$ well, also for the other experiments in Cross River and Edo. The 2016 season in Benue was not well described, likely due to rooting depth limitations early in the season. Simulated storage root yield at 4 MAP (vegetative period), 8 MAP (mid-season) and at harvest were strongly correlated to observed storage root yields ( $R^{2}$ of 0.92 ), with a RMSE of $4.93 \mathrm{t} \mathrm{DM} \mathrm{ha-1}$. We ascertained that $R U E$ of cassava was much higher than previously observed in Africa, resulting in an average storage root yield of $39 \pm 7 \mathrm{t} \mathrm{DM} \mathrm{ha}^{-1}$ for a 14-month growing season (in Edo 2016) Consequently, potential yields are higher and yield gaps larger than expected or previously reported. 
We conclude that the LINTUL-Cassava model can provide an adequate estimate of storage root yield across major cassava growing agroecological zones in Nigeria under rainfed conditions. Finally, we integrated all the acquired knowledge to develop and test a dynamic model for cassava (LINTULCassava-NPK) that simulates N, P and K limited growth. The model captured the uptake patterns of N, $\mathrm{P}$ and $\mathrm{K}$ well in both the calibration and the test dataset. The prediction accuracy of $\mathrm{N}, \mathrm{P}$ and $\mathrm{K}$ uptake for the test dataset was also high, with small root mean squared error of prediction (RMSEP) of $5.5 \mathrm{~g} \mathrm{~N}$ $\mathrm{m}^{-2}, 0.8 \mathrm{~g} \mathrm{P} \mathrm{m}^{-2}, 4.0 \mathrm{~g} \mathrm{~K} \mathrm{~m}^{-2}$, respectively. The model predicted storage root yields accurately (RMSEP

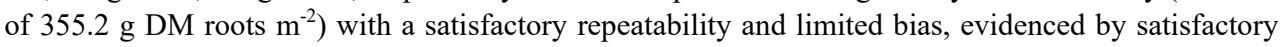
linear relationships between simulated and observed values $\left(\mathrm{R}^{2}\right.$ of $\left.0.7-0.8\right)$ with slope values close to 1 and only a small offset. The model provided insight in the need to balance especially $\mathrm{N}$ and $\mathrm{K}$ for cassava. To our knowledge, this is the first tested crop growth model for a field crop that simulates uptake and growth limitations of the three major macro-nutrients $\mathrm{N}, \mathrm{P}$ and $\mathrm{K}$. Although promising, the model concepts require further testing, especially under a range of water- and nutrient-limited conditions.

Keywords: Root crops; potential yield; nitrogen; potassium; phosphorus; secondary nutrients; micronutrients; light interception, radiation use efficiency, dry matter partitioning, crop growth models; relative biomass; Relative biomass; nutrient uptake rate; cassava plant parts; dilution coefficients; nutrient dynamics; critical nutrient concentration; nutrient uptake; nutrient demand; nutrient stress. 


\section{Contents}

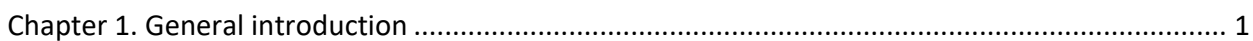

Chapter 2. Towards closing cassava yield gap in West Africa: Agronomic efficiency and

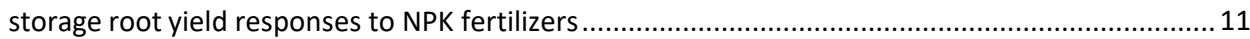

Chapter 3. Evaluating cassava yield potential using the LINTUL-Cassava model 31

Chapter 4. Dynamics of nutrient uptake, dilution and nutrition indices for cassava 53

Chapter 5. LINTUL-Cassava-NPK: a simulation model for nutrient-limited cassava growth 79

Chapter 6. General discussion 105

References

Summary 129

Samenvatting

Acknowledgements. 133

PE\&RC Training and Education Statement

About the author 

Chapter 1. General introduction 


\subsection{Background}

Food demand is predicted to increase substantially in sub Saharan Africa (SSA) where more than half of the anticipated growth between now and 2050 is expected to occur, with most of the projected increase concentrated in Nigeria (UNDESA, 2017). The current world population of 7.8 billion is expected to reach 8.5 billion by 2030, 9.7 billion in 2050 and 11.2 billion in 2100 (Worldometers, 2020). In SSA, children under age 15 account for $41 \%$ of the population, while young persons of age 15 to 24 account for a further $19 \%$ (UNDESA, 2017). With such young growing population and over 54 percent of the working force based on the agricultural sector for livelihoods, income and employment (FAO-DG, 2018), the need to increase crop productivity for food, industrial uses and other purposes that will improve the living standard becomes paramount. However, only a small proportion of the required increase in food production can come from expansion of the area cultivated (Koning et al., 2008; Hall and Richards, 2013; Barnosky et al., 2016). There is increased awareness of the impacts of $\mathrm{CO}_{2}$ release and decrease in biodiversity, resulting from the conversion of grassland or forest to arable lands (Haberl, 2015). Moreover, it is expected that there will be losses of good quality agricultural lands for urban development and other non-agricultural uses. In addition, the likelihood of expanding irrigated agriculture in Africa is limited (Viala, 2008; Strzepek and Boehlert, 2010). Therefore, $90 \%$ of the increase in crop production will have to be from improved crop varieties and management (Hall and Richards, 2013; Ray et al., 2013).

The ultimate challenge becomes to provide the growing population in SSA with a sustainable, secure supply of safe, nutritious, and affordable high-quality food; using less land, with lower inputs, in the context of global climate and environmental changes. Sustainable agricultural intensification especially in SSA, resulting in increased yields per unit of land has been identified as the most promising approach towards food security (Godfray et al., 2010; Tscharntke et al., 2012). The food scarcity of 2008 may be a warning of what is to come. Staple food prices increased rapidly and caused unrest in 36 countries (BBC-News, 2008; Mittal, 2009). Therefore, food self-sufficiency has become a necessity. Cassava (Manihot esculenta Crantz) is a major staple food in SSA and has been vital to food security in despite the low productivity in the area (Howeler et al., 2013; Senkoro et al., 2018). There is a large potential to sustainably increase the crop's productivity. Subsequently, increasing food availability and provision of other by-products for industrial uses.

\subsection{Cassava: a crop of hope for meeting the food needs of sub Saharan Africa}

Cassava is extensively cultivated for its edible storage roots which is rich in starch and has high energy content of about 16.5 MJ kg-1 DM (Montagnac et al., 2009). It is more resilient to adverse conditions and climate change than other crops, like grains (Rosenthal and Ort, 2012; De Souza et al., 2017) or other cereals, and seems a better option for various reasons. It has the ability to survive on poor soils, with a high yield per hectare. The flexibility of planting and harvesting times makes it a farmer's friendly crop, reduces cost and price risks (Fresco, 1986). Cassava could provide SSA with options for food security in the face of increasing population, dwindling resources, and changing climate.

The global area cropped with cassava has expanded considerably over the past decades (Howeler, 2017; Shackelford et al., 2018), with over 26 million hectares of land cultivated in 2017, of which approximately $78 \%$ was in Africa (FAOSTAT, 2020a). Nigeria is the largest cassava-producing country in the world with about $60 \mathrm{Mt}$ of fresh cassava roots produced yearly from 2015 to 2018 (FAOSTAT, 2020a). Therefore, an in-depth study of the crop is essential to understand it's growth and yield potentials in the region, so as to explore ways of maximizing its benefits for food security and economic growth. 


\subsection{Cassava physiology}

Cassava is propagated from the stems. Emergence of new sprouts from the stem cuttings begins at 5 15 days after planting (DAP) and is fully achieved at 30 DAP. Until 30 DAP, shoot and root growth depends on the reserves of the stem cutting. The first adventitious roots are replaced by fibrous roots (Cock et al., 1979; Alves, 2002). These new roots take up water and nutrients, only a few of them (between 3 and 14) become storage roots, which can be distinguished from the fibrous roots from 60 to 90 DAP (Alves, 2002). Cassava shows simultaneous shoot and storage root development in which photo assimilates are partitioned between shoots and storage root growth (Fukai et al., 1984; Alves, 2002). However, photo assimilates are preferentially partitioned to shoot until c. 6 months after planting (Fig. 1.1). Maximum growth rates of stems and leaves are achieved within 90-180 DAP, which is the most active vegetative growth stage for cassava. In the absence of Western Africa (WA) seasonal dry period, cassava leaf area index (LAI) attains its peaks at c. 120 to 150 DAP, when senescence of lower leaves begins to counteract further leaf production at the top of the canopy. LAI typically begins to decline at 270 DAP when senescence outpaces new leaf production (El-Sharkawy et al., 1990; El-Sharkawy and De Tafur, 2010). The fastest rates of dry matter (DM) accumulation in storage roots occur between 180 300 DAP. At 300-360 DAP, (referred to as the dormancy period or end of a growth cycle), the leaf production decreases while starch accumulation in storage roots continues (Alves, 2002). The plant completes its 12-month cycle, and this could be followed by a new cycle (Fig. 1.1). To obtain high storage root yields, the crop should reach a leaf area index of 3-3.5 as quickly as possible and maintain that LAI for as long as possible (El-Sharkawy, 2003). Leaf life varies between 60-80 days during the first four months of growth and increases to about 120 days at later plant stage (El-Sharkawy, 2003). However, patterns of dry matter partitioning among the plant's organs are affected by growth conditions and could show different trends, particularly with changes in soil nutrient level, water regime, solar radiation, length of the day (photoperiod), and temperature.

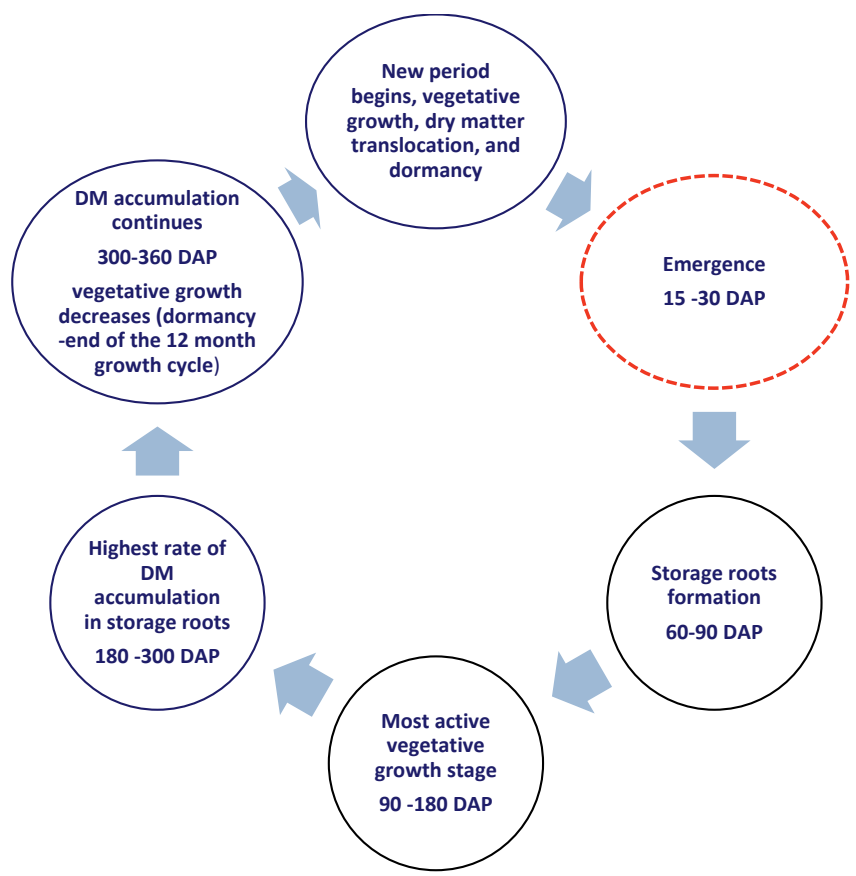

Fig. 1.1. Cassava growth cycle begins with emergence at 15 - 30 DAP and matures 300 - 360 DAP, depending on variety, environment and climatic conditions. 


\subsection{Attaining cassava yield potential}

Cassava, though grown mostly as a subsistence crop by smallholder farmers is becoming increasingly important as a commercial crop and now cultivated on large scale in order to meet the growing demand. Average fresh storage root yield of cassava varies between 1.1 and $32.1 \mathrm{t} \mathrm{ha}^{-1}$ with a global average yield of $11.3 \mathrm{t} \mathrm{ha}^{-1}$ fresh roots among 104 cassava growing countries. Current average root yield in smallholder farmers' fields in SSA is estimated at only $7.2 \mathrm{t} \mathrm{ha}^{-1}$ fresh roots (FAOSTAT, 2020b). Yields in research trials varied from 8.6 to 55.5 tons $^{-1}{ }^{-1}$ of fresh root yield (Fermont et al., 2009; EkeOkoro and Njoku, 2012; Howeler, 2017). These values are far below the potential yield of 80-100t ha ${ }^{-1}$ (Cock et al., 1979; El-Sharkawy et al., 1990; Byju and Suja, 2020), when growth conditions and management are optimal. Hence, it is possible to further increase cassava yields through improved fertilizer management.

Improving crop yield with fertilizers must be considered alongside nutrient use efficiency (NUE) (Janssen, 2011; Norton, 2014), for sustainable crop production. NUE is an important concept for evaluating crop production systems and depends on fertilizer management (Norton, 2014; Fixen et al., 2015). However, if the pursuit of improved NUE impairs current or future productivity, the need for cropping fragile or preserved lands will likely increase. At the same time, as nutrient rates increase towards an optimum, productivity continues to increase but at a decreasing rate, and NUE typically declines (Barbieri et al., 2008). Though, the extent of the decline will be determined by factors including soil and climatic conditions. Improvements in agronomic practices including balanced fertilizer $(\mathrm{N}, \mathrm{P}$ and K) application can markedly improve NUE and, when implemented concurrently with increased nutrient rates, can result in simultaneous increase of both crop yields and NUE (de Wit, 1968; Fixen et al., 2015). Yield response, nutrient uptake, agronomic efficiency, internal utilization efficiency, apparent recovery efficiency and nutrient harvest index are used in agronomic research to assess the efficiency of fertilizer application and such studies should be included in cassava production for better understanding of the system.

\subsection{Cassava crop characteristics for potential yield}

The physiological and phenological traits of a crop determines its potential yield. These traits are influenced by genotype, environment and management (Byju and Suja, 2020). In cassava, some variables related to the canopy, such as LAI, leaf retention etc, are strongly positively correlated with storage root yield (El-Sharkawy and De Tafur, 2010). Improvement of resource use efficiency is an important approach towards achieving the potential yield. It depends on the efficiencies with which the crop converts intercepted light into biomass over the course of the growing season (De Souza et al., 2017). Light interception is affected by canopy size, duration and speed of ground coverage after planting. Values of intercepted light from improved cassava cultivars ranged between $52.3-64.1 \%$, these are below values recorded from modern cultivars of major grains and seed crops, as well as the theoretical limit of $100 \%$ (De Souza et al., 2017). Therefore, increasing seasonal light interception of cassava to approach theoretical maximum could greatly improve cassava storage root yield. Further, improving the radiation use efficiency appears to present the greatest opportunity for improving cassava yield potential. For instance, average RUE of $1.16 \mathrm{~g} \mathrm{DM} \mathrm{MJ}{ }^{-1}$ IPAR (Ezui et al., 2017b) recorded from experiments in West Africa is only $36 \%$ of the RUE of other $\mathrm{C}_{3}$ plants such a potato (Rezig et al., 2013; Zhou et al., 2017). Understanding the basic physiology of cassava and relations among or between parameters and crop growth rate (CGR) will enable us to optimize crop management and improve crop growth simulation models (Kiniry et al., 1999; De Souza et al., 2017). 


\subsection{Understanding cassava nutrient dynamics}

The growth rates of cassava are inextricably related to cumulative nutrient uptake (Howeler, 2002; Byju and Suja, 2020) and they determine fertilizer requirements. Nutrients uptake occurs during the entire growth cycle, with the maximum at about 4 MAP (Howeler, 2012). This period corresponds to maximum DM accumulation and uptake rate of cassava (when the canopy is fully developed and vegetative growth has reached its peak). Uptake rate of nutrients decreases after six months, though uptake of nutrients of the plant continues throughout the growth period (Howeler and Cadavid, 1983; Howeler, 2012). Nutrients uptake and growth rates, including the production potential of cassava are influenced by demand from the growing crop, climatic conditions, soil water availability, soil fertility and plant age (Alva et al., 2002). Also, nutrient concentration of plants decreases during the growth cycle, even when nutrient supply is sufficient (Justes et al., 1994; Lemaire, 2012). The concept of nutrient dilution and nutrition index for nitrogen $(\mathrm{N})$ have been widely used as a diagnostic tool for crop $\mathrm{N}$ sufficiency, but only few studies are available for other macronutrients (Zamuner et al., 2016; Gómez et al., 2018). To our knowledge, none exists for cassava. Therefore, it becomes important to understand the nutrient uptake of cassava as affected by fertilizer application and establish nutrient dilution curves and nutrition indices for cassava, for improved crop management.

\subsection{Modelling cassava growth and yield}

In order to provide information to farmers, policy makers and other stakeholders on approaches to sustainable agriculture, many researchers and farmers seek to estimate the yield of crops before harvest. On this basis, crop growth simulation models are used to study the system and provide relevant information for planning and managing crop production. Robust simulation models that describe the processes of cassava development and nutrients uptake can help to understand changes in crop growth in response to changes in environmental conditions and nutrient management (van Ittersum et al., 2003). A LINTUL-type of model that simulates dry matter production as a function of the amount of light intercepted and a constant radiation use efficiency $(R U E)$, can be used for this purpose. LINTUL has been developed to simulate potential and water limited crop growth of cassava (Ezui et al., 2018). However, this model has not been tested in Nigeria where cassava is cultivated across a range of environmental and climatic conditions. Further, nutrient limited growth has not been included in the LINTUL model. Hence, the need to develop and test a dynamic model for cassava that simulates N, P and $\mathrm{K}$ limited growth in the tropics.

\subsection{Study rationale and objectives}

The potential yield of cassava in SSA is not known. However, if we apply the general rule of thumb in crop production, average daily dry matter yield is about $200 \mathrm{~kg} \mathrm{DM} \mathrm{ha}^{-1}$, with a harvest index of 0.5 , the potential storage root yield of cassava could be about 36 tons ha $^{-1}$. Disturbingly, annual average yield in SSA has remained poor (FAOSTAT, 2020a). No research yet investigated the response of cassava to targeted optimized dosages of NPK fertilizer, aiming at potential yields for improved cassava production in Nigeria. Existing crop models on water limited yield (Matthews and Hunt, 1994; Gabriel et al., 2014; Ezui et al., 2018) have not been tested for cassava in Nigeria. In fact, no crop model has yet been developed to simulate cassava growth under nutrient limited conditions. Cassava simulation model will help to determine potential and economical yields in different agro-ecologies for agro advisory purposes. This study aimed to quantify cassava yield potentials and interactions with water and nutrient availability. Also, to improve the existing LINTUL-Cassava model (Ezui et al., 2018) to better accurately assess yield gaps under water- and nutrient limited conditions. These findings could inform better practises for increased productivity. 


\section{Study objectives}

The general objective was to explore the yield potential of cassava and the dynamics of nutrients limitations in relation to water availability, obtain better insight and a theoretical understanding of how the crop responds to nutrient availability and application of fertilizers in different agro-ecologies.

Specific objectives were to:

- assess cassava yield potential and response to fertilizer application, including the nutrient use efficiency and evaluate yield responses to varying K supply with steady $\mathrm{N}$ and $\mathrm{P}$ rates (Chapter 2);

- evaluate the temporal dynamics of light interception in cassava and radiation use efficiency under non-water limited conditions, calibrate, evaluate and test the LINTUL-Cassava model (Chapter 3);

- understand the biomass growth and nutrient uptake of cassava as affected by fertilizer application and establish nutrient dilution curves and nutrition indices for cassava (Chapter 4);

- develop and test a dynamic model for cassava that simulates N, P and K limited growth (Chapter $5)$.

\subsection{Study area and research methodology}

Nigeria was the prime area of study, where all agro-ecological types of the various tropical regional climate categories are present (Adejuwon, 2006). Including the moist evergreen Rain Forests, semievergreen Rain Forests (Transition Rain Forest or Derived Savannah), Guinea Savannah, Sudan Savannah, and Sahel Savannah. The Rain Forests and Transition Rain Forest covers about $25 \%$ of the country, Guinea Savannah spreads across over $40 \%$ of the land area, and the semi-arid Sudan and Sahel Savannah together constitute about $35 \%$ of the land area. The "Transition Rain Forest" was originally Rain Forest before it was converted, due to human activities (Adejuwon, 2006). A two-year study was conducted on-farm in Nigeria from 2016 to 2018. The experiments were established in 6 fields in three of the agroecological zones (AEZs) (Rain Forest - Cross River, Transition Rain Forest Edo, and Guinea Savanna - Benue), covering the major cassava-producing regions in Nigeria (Fig. 1.2). These agro-ecologies represent the major cassava-cropping environments of other countries of WA. The growing season of each region begins with the onset of rains from April - May - June for Cross River - Edo - Benue, respectively. The dry season runs from November to early April - May. Mean annual rainfall at the field locations in the years 2008 to 2017 were 2300, 2200, and $1400 \mathrm{~mm}$ for Cross River, Edo, and Benue, respectively (Ukhurebor and Abiodun, 2018). More information about the experiment sites is shown in Table 2.1 . 


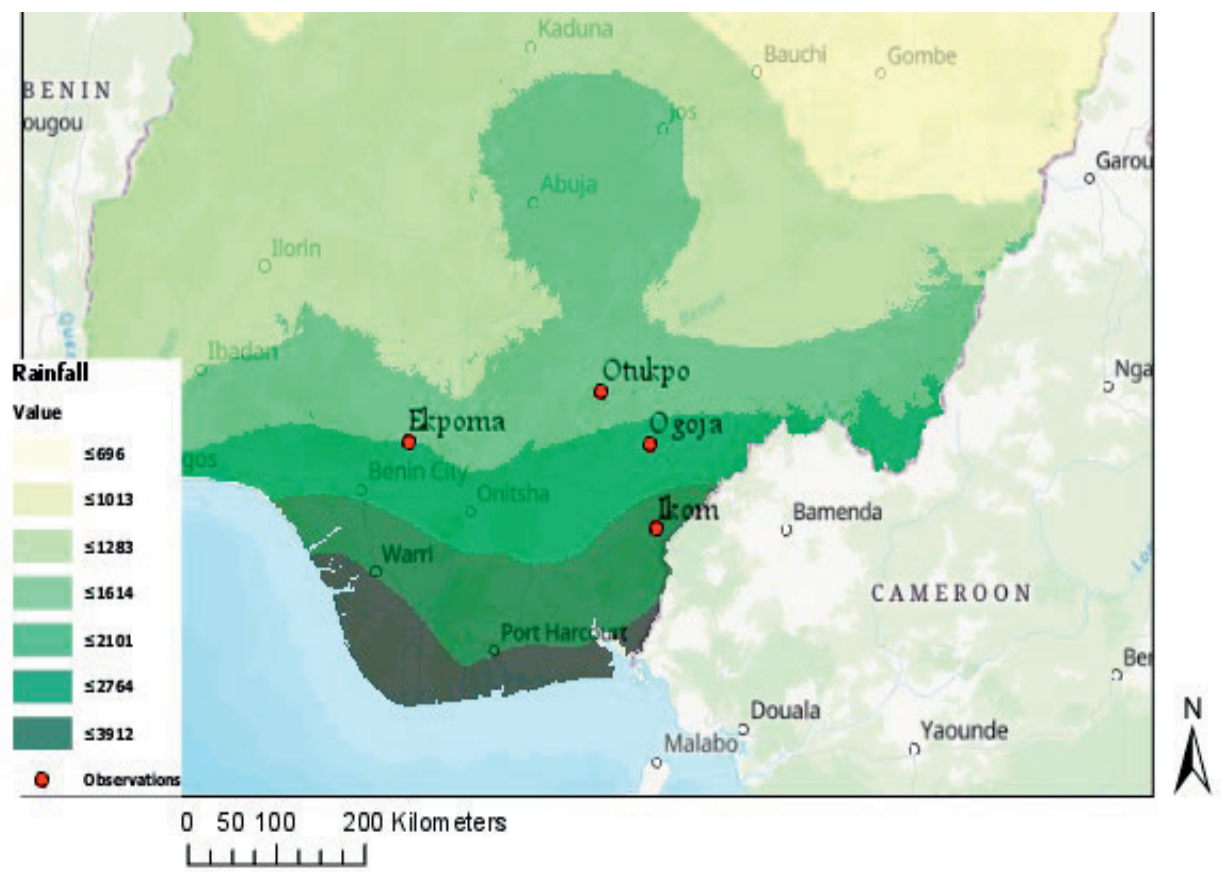

Fig. 1.2. Location of study sites and average annual rainfall in southern Nigeria.

Each experiment field contained 12 treatments replicated three times. Soil samples were taken before land preparation from $0-30 \mathrm{~cm}$ depth. The treatments were N, P, K and other nutrients (secondary and micronutrients) applied in different amounts and combinations. The twelve treatments were randomly assigned to plots within blocks, resulting in 36 plots for each experiment. TME 419, a popular cassava cultivar in Nigeria and West Africa was grown in all experiments. Fields were well managed and observations and data collection were carried out until harvest.

\subsection{Thesis outline}

Six chapters are contained in this thesis. This Chapter (1) presents the propelling issue of enhancing food security for the growing population through increased cassava production. Also, the chapter identified the constraints hampering cassava from full expression of its potentials and possible solutions. In Chapter 2, collected data from experiments were used to quantify cassava yield potentials and responses to $\mathrm{N}, \mathrm{P}$ and especially $\mathrm{K}$ in different agro-ecologies and implications for the environment, through analysis of NUE. Obtained crop parameters calculated from the observed data were used in Chapter 3 to calibrate and evaluate the performance of the LINTUL-Cassava model. Chapter 4 provides insight in the dynamics of nutrients uptake, uptake rates, N, P and K dilution curves and nutrition indices for cassava. In chapter 5 , the obtained information from the previous Chapters 3 and 4 were used to develop and test a dynamic crop growth model for cassava that simulates N, P and $\mathrm{K}$ limited growth. Chapter 6 discuses findings from chapter 2 to 5 and integrates them to solving identified issues of feeding the growing population and enhancing socioeconomic development. 



\section{Chapter 2. Towards closing cassava yield gap in West Africa: Agronomic efficiency and storage root yield responses to NPK fertilizers}

This chapter is published as:

Adiele, J.G, Schut, A.G.T., van den Beuken, R.P.M., Ezui, K.S., Pypers, P., Ano, A.O., Egesi, C.E., Giller KE., 2020. Towards closing cassava yield gap in West Africa: Agronomic efficiency and storage root yield responses to NPK fertilizers. Field Crops Res. Published online https://doi.org/10.1016/j.fcr.2020.107820. 


\begin{abstract}
Nutrient management of cassava has received little attention compared with cereal crops. We evaluated cassava yield potential and nutrient use efficiency when supplied with nitrogen, phosphorus and potassium at high rates and when supplied with increasing rates of $\mathrm{K}$. On-farm experiments were conducted at six locations in Nigeria across the major cassava growing agro-ecologies of Western Africa (Tropical Rainforest - Cross River, Forest Transition Savanna - Edo, and Guinea Savanna - Benue) during two seasons (2016-2017 and 2017-2018). Nitrogen, P and K fertilizers were applied at various rates, including treatments with and without added secondary and micronutrients. Storage root dry matter (DM) yields ranged between 11 and $35 \mathrm{t} \mathrm{DM} \mathrm{ha}^{-1}$. The largest yields were obtained with a mean agronomic efficiency of 60,162 and $51 \mathrm{~kg} \mathrm{DM}$ of storage roots per $\mathrm{kg}$ of N, P and K applied, with average uptakes of 364,44 and $242 \mathrm{~kg} \mathrm{~N}, \mathrm{P}$ and $\mathrm{K} \mathrm{ha}^{-1}$ respectively. Storage root yield responses to applied $\mathrm{N}, \mathrm{P}$ and $\mathrm{K}$ fertilizers $\left(2-18,3-16\right.$ and $3-22 \mathrm{t} \mathrm{DM} \mathrm{ha}^{-1}$, respectively) varied across the locations, reflecting variability in potential yields and applied NPK ratios. Addition of a mixture of secondary and micronutrients did not affect cassava yields. We found that the caloric energy yield of cassava per $\mathrm{kg}$ of $\mathrm{N}$ applied is 2.7 times larger than the value reported for maize. Increasing the supply of $\mathrm{K}$ gave a high agronomic efficiency of $\mathrm{N}$ even when supplied at high rates, supporting the theory of "increasing returns to scale" of de Wit (1994). We conclude that cassava has a major role in future food security of sub-Saharan Africa, with potentially larger DM yields, a better recovery of applied nutrients and larger energy yield per kg of applied $\mathrm{N}$ fertilizer when compared with grains.
\end{abstract}

Keywords: Root crops; potential yield; nitrogen; potassium; phosphorus; secondary nutrients; micronutrients. 


\subsection{Introduction}

Cassava (Manihot esculenta Crantz) is a major staple food in sub-Saharan Africa (SSA), providing an important source of calories and options for food security for the increasing population (De Souza et al., 2017). Cassava roots can be harvested throughout the year, which ensures a continuous food supply for smallholder farmers and raw materials for related processing industries (Rahman and Awerije, 2016). Cassava is currently cultivated in 40 of the 53 countries in SSA, which account for half of the total world production of cassava (FAOSTAT, 2019). Cultivation has expanded because cassava can grow in relatively marginal soils and under erratic rainfall conditions (Howeler, 2017), important characteristics especially for future more variable climates. Although cassava plays a major role in SSA, the current average root yield in smallholder farmers' fields is estimated at only $2.5 \mathrm{t} \mathrm{DM} \mathrm{ha}^{-1}$, equivalent to $7.2 \mathrm{t}$ $\mathrm{ha}^{-1}$ fresh roots (De Souza et al., 2017). This is only one third of average yields obtained in Asia (Howeler, 2017).

Results from on-station and on-farm researcher-managed trials in the region have shown that cassava yield can be improved substantially with improved crop establishment, genotype and management. Root yields up to $19 \mathrm{t} \mathrm{DM} \mathrm{ha}^{-1}$ (equivalent to $54 \mathrm{t} \mathrm{ha}^{-1}$ of fresh roots) were recorded in on-farm trials with fertilizer application in Southern Togo within 10 to 11 months after planting (Ezui, 2017). Fresh root yields of $40 \mathrm{t} \mathrm{ha}^{-1}$ were attained with improved varieties in on-station trials in Nigeria (Eke-Okoro and Njoku, 2012). Fermont et al. (2007) reported fresh root yields ranging from 14 to $59 \mathrm{t} \mathrm{ha}^{-1}$ in Uganda and western Kenya in on-farm breeding trials. The ideal plant type simulated by Cock et al. (1979) suggested that potential cassava yields could be as large as $90 \mathrm{t} \mathrm{ha}^{-1}$ of fresh roots $\left(32 \mathrm{t} \mathrm{DM} \mathrm{ha}^{-1}\right)$ in a 12month growing period. Indeed, with improved cultivars under optimal growing conditions cassava yields as high as $90 \mathrm{t} \mathrm{ha}^{-1}$ of fresh roots (equivalent to $27-32 \mathrm{t} \mathrm{DM} \mathrm{ha}^{-1}$ ) have been observed within 10 months in Cauca, Colombia (El-Sharkawy et al., 1990; El-Sharkawy, 2007). Fukai and Hammer (1987) obtained cassava yield of $23 \mathrm{t} \mathrm{DM} \mathrm{ha}^{-1}$ at 12 months in northern Australia. Thus, cassava has a very high yield potential when growth conditions and management are optimal.

Nigeria is the largest cassava-producing country in the world with about $60 \mathrm{Mt}$ of fresh cassava roots produced in 2017 (FAOSTAT, 2019). Increases in production over the years have been achieved largely by expansion of the area cropped with cassava and improved varieties. Average fresh root yield of cassava farmers from 1965 to 2017 ranged from $7-12 \mathrm{t} \mathrm{ha}^{-1}$, much below its potential productivity. Cassava yields could be increased in a sustainable manner through improved crop management and fertilizer application, thereby reducing the need for a further expansion of cropland.

Crop yield is a key measure of the response of any cropping system to changed management practices, but this response must be considered alongside nutrient use efficiency (NUE) (Janssen, 2011; Norton, 2014). Nutrient use efficiency is an important concept for evaluating crop production systems and can be greatly impacted by fertilizer management as well as soil- and plant-water relationships (Norton, 2014; Fixen et al., 2015). Only few studies have focused on increasing cassava yield and NUE in tropical rain-fed agricultural systems (Ezui et al., 2016; Ezui et al., 2017a; Senkoro et al., 2018). Improvements in agronomic practices combined with balanced fertilizer (N, P and $\mathrm{K}$ ) application can markedly improve NUE and, when implemented concurrently with increased nutrient rates, can result in simultaneous increase of both crop yields and NUE (de Wit, 1968; Fixen et al., 2015). This means that if uptake of a particular nutrient increases then uptake of other nutrients (if available) will increase too. At incremental rates of fertilizer in which all nutrients are present in proper proportions, in theory, each additional $\mathrm{kg}$ of the fertilizer will initially give a greater production increase than the preceding $\mathrm{kg}$ up to a certain optimum, followed by a decrease. Furthermore, if other essential production factors (including genetics) are improved, this optimum will be achieved at high nutrient availability (de Wit, 1994; Nijland and Schouls, 1997), a concept known as "Increasing returns to scale" (de Wit, 1994).

Strategic research should search for the minimum of each production resource that is required to allow maximum utilization of all other resources (de Wit, 1992). In this work, we aimed to quantify the yield 
potential and nutrient use efficiency of cassava in the major cassava growing agro-ecologies of Nigeria. We studied especially the effect of $\mathrm{K}$ application on storage root yield as $\mathrm{K}$ is an essential nutrient for plant physiological processes, it improves crop yield and quality and enhances stress tolerance (Krauss, 2004; Guo et al., 2019). Also, $\mathrm{K}$ is absorbed in large amounts by cassava and removed from the field through harvest of the storage roots (Howeler and Cadavid, 1983). Our objectives were to: (1) assess cassava yield potential and response to fertilizer application; (2) evaluate yield responses to varying $\mathrm{K}$ supply with steady $\mathrm{N}$ and $\mathrm{P}$ rates; (3) test the need for secondary and micro-nutrients; and (4) evaluate nutrient uptake, agronomic efficiency, internal utilization efficiency, apparent recovery efficiency and nutrient harvest index of $\mathrm{N}, \mathrm{P}$ and $\mathrm{K}$ of cassava.

\subsection{Materials and methods}

\subsubsection{The study area}

A two-year study was conducted on-farm in southern Nigeria from 2016 to 2018. Each year, experiments were established in new fields in three agroecological zones (AEZs) (Rain Forest - Cross River, Transition Rain Forest - Edo, and Guinea Savanna - Benue), covering the major cassava-producing regions in Nigeria. These agro-ecologies also encompass the major cassava-cropping environments of other countries of SSA. The growing season of each region begins with the onset of rains from April May - June for Cross River - Edo - Benue, respectively. The dry season with intermittent or no rainfall runs from November to early April - May. Mean annual rainfall at the field locations in the years 2008 to 2017 were 2300, 2200, and $1400 \mathrm{~mm}$ for Cross River, Edo, and Benue, respectively (NIMET, 2012; Ukhurebor and Abiodun, 2018). Weather data were obtained from the closest station of the Nigerian Meteorological Agency (NIMET). Detailed characteristics of the experimental fields are shown in Tables 2.1.

Table 2.1. Characteristics of experimental sites with planting and harvest dates, and the amount of rainfall $(\mathrm{mm})$ from planting to harvest.

\begin{tabular}{|c|c|c|c|c|c|c|}
\hline Year & 2016 & & & 2017 & & \\
\hline Location & Ekpoma (Edo) & $\begin{array}{l}\text { Ogoja } \\
\text { (Cross } \\
\text { River) }\end{array}$ & $\begin{array}{l}\text { Otukpo } \\
\text { (Benue) }\end{array}$ & Ekpoma (Edo) & $\begin{array}{l}\text { Ikom (Cross } \\
\text { River) }\end{array}$ & $\begin{array}{l}\text { Otukpo } \\
\text { (Benue) }\end{array}$ \\
\hline Geographic & $7.05^{\circ} \mathrm{N}$ & $6.76^{\circ} \mathrm{N}$ & $7.27^{\circ} \mathrm{N}$ & $6.80^{\circ} \mathrm{N}$ & $5.96^{\circ} \mathrm{N}$ & $7.27^{\circ} \mathrm{N}$ \\
\hline coordinates & $6.13^{\circ} \mathrm{E}$ & $8.69^{\circ} \mathrm{E}$ & $8.18^{\circ} \mathrm{E}$ & $6.23^{\circ} \mathrm{E}$ & $8.77^{\circ} \mathrm{E}$ & $8.19^{\circ} \mathrm{E}$ \\
\hline $\begin{array}{l}\text { Elevation } \\
\text { (masl) }\end{array}$ & 214 & 47 & 135 & 215 & 105 & 139 \\
\hline Planting date & May 24, 2016 & $\begin{array}{l}\text { Jun } 16 \text {, } \\
2016\end{array}$ & $\begin{array}{l}\text { Aug 16, } \\
2016\end{array}$ & May 12,2017 & Jun 3, 2017 & $\begin{array}{l}\text { Jun } 15, \\
2017\end{array}$ \\
\hline Harvest date & Aug 4, 2017 & $\begin{array}{l}\text { Aug 25, } \\
2017\end{array}$ & Oct 6,2017 & May 21, 2018 & May 3, 2018 & $\begin{array}{l}\text { Jun } 15 \text {, } \\
2018\end{array}$ \\
\hline $\begin{array}{l}\text { Crop duration } \\
\text { (MAP) }\end{array}$ & 14 & 14 & 13.5 & 12 & 11 & 12 \\
\hline $\begin{array}{l}\text { Agro } \\
\text { ecological } \\
\text { zone }\end{array}$ & $\begin{array}{l}\text { Transition } \\
\text { rainforest } \\
\text { savanna }\end{array}$ & Rainforest & $\begin{array}{l}\text { Guinea } \\
\text { savanna }\end{array}$ & $\begin{array}{l}\text { Transition } \\
\text { rainforest } \\
\text { savanna }\end{array}$ & Rainforest & $\begin{array}{l}\text { Guinea } \\
\text { savanna }\end{array}$ \\
\hline $\begin{array}{l}\text { Rainfall } \\
\text { amount (mm) }\end{array}$ & 3157 & 3067 & 1747 & 2357 & 2141 & 1359 \\
\hline $\begin{array}{l}\text { Previous } \\
\text { crop(s) }\end{array}$ & $\begin{array}{l}\text { Cassava, maize } \\
\text { intercrop }\end{array}$ & Cassava & $\begin{array}{l}\text { Cassava, } \\
\text { maize } \\
\text { intercrop }\end{array}$ & $\begin{array}{l}\text { Cassava, maize } \\
\text { intercrop }\end{array}$ & $\begin{array}{l}\text { Cassava, } \\
\text { maize } \\
\text { intercrop }\end{array}$ & Soybean \\
\hline $\begin{array}{l}\text { Max. rooting } \\
\text { depth (m) }\end{array}$ & $>3.2$ & NA & 1.6 & $>3.2$ & NA & 1.4 \\
\hline Main soil type & Nitisol & Acrisol & Acrisol & Nitisol & Nitisol & Acrisol \\
\hline
\end{tabular}

NA: rooting depth sampling was not done at the location, MAP: months after planting 


\subsubsection{Experimental treatments and management}

The experimental design for all six on-farm experiments was a randomized complete block (RCBD) with three replicates (blocks). Plot size was $10 \mathrm{~m}$ by $8 \mathrm{~m}$ and treatments were randomized within the blocks at each location. The blocks were placed perpendicular to the slope. Treatments were N, P, K, and other nutrients (secondary and micronutrients) applied in different amounts and combinations (Table 2.2). The rates applied ranged from 0 to $300 \mathrm{~kg} \mathrm{~N} \mathrm{ha}^{-1}, 0$ to $100 \mathrm{~kg} \mathrm{P} \mathrm{ha}^{-1}$, and 0 to $300 \mathrm{~kg} \mathrm{~K} \mathrm{ha-}$ ${ }^{1}$ in various combinations. One treatment received additional $\mathrm{S}, \mathrm{Ca}, \mathrm{Mg}, \mathrm{Zn}$, and $\mathrm{B}$ at the rates of 16.6, $10,10,5$, and $2.5 \mathrm{~kg} \mathrm{ha}^{-1}$, respectively. Treatment names are as shown in Table 2.2, where (f) represents full rate of the optimized nutrient and K60, K120, K180, K240, were varied at rates of K at 60, 120, 180 and $240 \mathrm{~kg} \mathrm{ha}^{-1}$ (Table 2.2). The optimized fertilizer rates and combinations for the experimental treatments were determined using the Quantitative Evaluation of the Fertility of Tropical Soils (QUEFTS) model for cassava (Ezui, 2017), aiming at a yield of $90 \mathrm{t}$ fresh roots ha-1 (equivalent to $32 \mathrm{t}$ $\mathrm{DM} \mathrm{ha}^{-1}$ ). Cassava variety TME 419 was grown in all experiments: this is a popular variety in Nigeria and West Africa because it has high dry matter and is nutrient use efficient (De Souza and Long 2018). Further, it has erect stems and minimal branching, which allows intercropping as well as higher planting densities (Eke-Okoro and Njoku, 2012; Ezui et al., 2017a). Planting was done at the onset of rains each year, except in Benue in 2016, where planting was done about 3 months after the first rains. The late planting at Benue was due to the re-establishment of the experiment in a different field as the first planting was badly damaged by soil erosion. Stem cuttings of $25 \mathrm{~cm}$ long were planted at distances of $1.0 \mathrm{~m}$ by $0.8 \mathrm{~m}$, following the recommended planting density of 12,500 plants per hectare. Phosphorus was applied at planting, while nitrogen and potassium were applied in three equal splits at $1,2.5$, and 3.5 months after planting (MAP) and secondary and micro-nutrients were applied at 2.5 MAP. The N, $\mathrm{P}$ and $\mathrm{K}$ fertilizers used were urea, triple super phosphate and muriate of potash. The fields were weeded regularly, especially before each fertilizer application and there was no observed pest or disease outbreaks. TME 419 is considered to be resistant to pests and diseases. It has high water use efficiency through its lower stomatal conductance, with higher photosynthetic rates than most improved cultivars (De Souza and Long 2018).

\subsubsection{Soil sampling and rooting depth}

Composite soil samples were collected before land preparation from five points in a "W" pattern from $0-30 \mathrm{~cm}$ depth in each plot and bulked together. The samples were air-dried and sieved through a 2 $\mathrm{mm}$ mesh sieve. The $\mathrm{pH}$ was measured in a 2.5:1 soil suspension in water. The hydrometer method was used to determine the particle size. Soil organic carbon was obtained by the combustion method and N by Kjeldahl digestion. The Mehlich-3 extraction was used for $\mathrm{Ca}, \mathrm{Mg}$ and $\mathrm{K}$, while available $\mathrm{P}$ was determined using the Olsen extraction method. All soil analyses were done at the IITA laboratory, Ibadan, Nigeria. In order to measure cassava rooting depth, several soil pits were dug in plots (NfPfKf, NOPfKf, NfP0Kf and NfPfK0), in the area where intermediate harvests were carried out. Cassava roots were clearly identified and differentiated from other roots as they were creamy-yellowish and when cut secrete a cloudy-whitish latex. The depth at which the deepest cassava roots were found were recorded at each location (Table 2.1). 
Table 2.2. Nutrient application rates per treatment, (f) represents full rate of the optimized nutrient and $\mathrm{K} 60, \mathrm{~K} 120, \mathrm{~K} 180, \mathrm{~K} 240$, were varied rates of $\mathrm{K}$ at $60,120,180$, and $240 \mathrm{~kg} \mathrm{ha}^{-1}$. S, Ca, Mg, Zn, and $\mathrm{B}$ were applied in combination.

\begin{tabular}{llllll}
\hline & Treatment & Nitrogen & Phosphorus & $\begin{array}{l}\text { Potassium } \\
\left(\mathrm{kg} \mathrm{N} \mathrm{ha}^{-1}\right)\end{array}$ & $\begin{array}{l}\text { secondary } \\
\text { micronutrients } \\
\text { S-Ca-Mg-Zn-B }\left(\mathrm{kg} \mathrm{ha}^{-1}\right)\end{array}$ \\
\hline 1. & Control & 0 & 0 & 0 & 0 \\
2. & N0PfKf & 0 & 100 & 300 & 0 \\
3. & NfP0Kf & 300 & 0 & 300 & 0 \\
4. & NfPfK0 & 300 & 100 & 0 & 0 \\
5. & NfPfK60 & 300 & 100 & 60 & 0 \\
6. & NfPfK120 & 300 & 100 & 120 & 0 \\
7. & NfPfK180 & 300 & 100 & 180 & 0 \\
8. & NfPfK240 & 300 & 100 & 240 & 0 \\
9. & NfPfKf & 300 & 100 & 300 & 0 \\
10. & NfPfKfMN & 300 & 100 & 300 & $16-10-10-5-2.5$ \\
11. & N150P40K180 & 150 & 40 & 180 & 0 \\
12. & N75P20K90 & 75 & 20 & 90 & 0 \\
\hline
\end{tabular}

\subsubsection{Yield assessment}

At physiological maturity, a net plot of $6.4 \mathrm{~m}^{2}$ containing eight consecutive plants, was harvested in each experimental plot. Plants were separated into leaves, stems and storage roots and weights of each harvested plant part (leaf with petiole, stem, and storage root) were recorded for each plot. Sub-samples of about $400 \mathrm{~g}$ fresh weight were collected in the field using a digital field scale, and oven dried at $60^{\circ} \mathrm{C}$ until constant weight, then weighed and dry matter content calculated, and fresh roots yields converted to DM yield. Dried subsamples from leaves with petioles, stems and storage roots were analysed for total N, P and K concentration. Total N in the tissue was analysed by Dumas combustion using a Carlo Erba EA1108 elemental analyser. Total P and K concentrations were measured with inductively coupled plasma (ICP) (iCAP 7400, Thermo Fisher Scientific, USA).

\subsubsection{Calculations and data analysis}

To estimate the nutrient use efficiency of cassava, parameters of yield response, nutrient uptake, agronomic efficiency (AE), apparent recovery efficiency (RE) and internal utilization efficiency (IE) were calculated using the following equations (Fixen et al., 2015; Chuan et al., 2016):

$$
\begin{aligned}
& \text { Agronomic efficiency }\left(A E_{i}\right)=\frac{Y_{f}-Y_{0, i}}{\mathrm{f}_{\mathrm{app}, \mathrm{i}}} \\
& \text { Apparent recovery efficiency }\left(R E_{i}\right)=\frac{U_{f}-U_{0, i}}{\mathrm{f}_{\mathrm{app}, \mathrm{i}}} \\
& \text { Internal utilization efficiency }\left(I E_{i}\right)=\frac{Y_{i}}{U_{i}}
\end{aligned}
$$


With $i=\mathrm{N}$, P, or K: $Y_{\mathrm{f}}=$ storage root yield for NfPfKf treatment $\left[\mathrm{kg} \mathrm{DM} \mathrm{ha}^{-1}\right] ; Y_{0, i}=$ storage root yield with either $\mathrm{N}, \mathrm{P}$, or $\mathrm{K}$ omitted $\left[\mathrm{kg} \mathrm{DM} \mathrm{ha}{ }^{-1}\right] ; \mathrm{f}_{\text {app }}=$ rate of nutrient $i$ applied $\left[\mathrm{kg} \mathrm{ha}^{-1}\right] ; U_{0}=$ nutrient uptake in below- and aboveground biomass with either $\mathrm{N}, \mathrm{P}$, or K omitted $\left[\mathrm{kg} \mathrm{ha}^{-1}\right] ; U_{f}=$ nutrient uptake in below and aboveground biomass with N, P and $\mathrm{K}$ applied at full rate. N, P and $\mathrm{K}$ uptake by the crop were calculated by multiplying each nutrient percentage with the total plant biomass dry matter. Nutrient harvest indices (NHI) were calculated as the ratio between nutrient $(\mathrm{N}, \mathrm{P}$ and $\mathrm{K})$ uptake in storage roots and N, P and K uptake in storage root plus shoot (Fageria, 2014). Energy and protein efficiencies of cassava (the quantity of calories/energy or protein produced by a kilo of $\mathrm{N}$ applied), were calculated as a product of agronomic efficiency of $\mathrm{N}$ and energy or protein content, which were derived from literature, with energy and protein content of $16.54 \mathrm{MJ} \mathrm{kg}^{-1} \mathrm{DM}$ and $33.73 \mathrm{~g} \mathrm{~N} \mathrm{~kg}^{-1} \mathrm{DM}$, respectively (Montagnac et al., 2009).

The treatment effects on DM storage root yield were analysed separately for each location and year, using a linear mixed model with DM root yield as response variable and fertilizer treatment as explanatory factor, while blocks were considered random effects. Interactions of yield response with locations and year were analysed with a mixed linear regression model. Effects were analysed with a type-III ANOVA using Satterthwaite's approximation method. Also, NUE (AE, RE, and IE) of applied $\mathrm{N}, \mathrm{P}$ and $\mathrm{K}$ fertilizers and NHI were analysed using a linear mixed model. Differences between treatment means were considered significant when probability $\leq 0.05$. R software (R Core, 2019), version 3.5 with the lme4, lmerTest, and Predictmeans packages was used for statistical analysis.

\subsection{Results}

\subsubsection{Soil nutrient status and rainfall distribution}

Average soil organic matter (SOM) was 1.4, 0.9 and 1.0 \% for Benue, Cross River and Edo, in 2016 respectively. Soil concentrations of available $\mathrm{P}, \mathrm{K}, \mathrm{Ca}$ and $\mathrm{Mg}$ were below standard critical nutrient concentrations for crop production, indicating that the soil nutrient status of all experimental sites was poor (Table 2.3). All sites used in 2017 were also deficient for $\mathrm{P}$ and $\mathrm{K}$, with a mean of $2.66 \pm 0.07$ (standard error) $\mathrm{mg} \mathrm{kg}^{-1}$ for $\mathrm{P}$, and $0.17 \pm 0.02 \mathrm{cmol} \mathrm{kg}^{-1}$ for exchangeable K. Rainfall amounts received during each cropping seasons at the experimental sites from planting to harvest were adequate for proper establishment. Benue received the least rainfall in both years (Fig. 2.1). During both years, rainfall began late March (Cross River), April (Edo) or mid-May (Benue) and continued until the start of the dry season from November to March.

Table 2.3. Soil texture and chemical characteristics for samples taken at $0-30 \mathrm{~cm}$ depth before land preparation and planting at Benue, Cross River and Edo in 2016.

\begin{tabular}{|c|c|c|c|c|c|c|c|c|c|c|c|}
\hline Location & $\mathrm{pH}$ & SOC & $\mathrm{N}$ & C:N & P Olsen & $\mathrm{K}$ & $\mathrm{Ca}$ & $\mathrm{Mg}$ & Sand & Silt & Clay \\
\hline & & $\%$ & $\%$ & & $\mathrm{mg} \mathrm{kg}^{-1}$ & $\begin{array}{l}\mathrm{cmol}_{\mathrm{c}} \\
\mathrm{kg}^{-1}\end{array}$ & $\begin{array}{l}\mathrm{cmol}_{\mathrm{c}} \\
\mathrm{kg}^{-1}\end{array}$ & $\begin{array}{l}\mathrm{cmol}_{\mathrm{c}} \\
\mathrm{kg}^{-1}\end{array}$ & $\%$ & $\%$ & $\%$ \\
\hline Benue & 5.9 & 0.8 & 0.09 & 8.9 & 4.7 & 0.10 & 1.7 & 0.8 & 60.2 & 25.5 & 14.3 \\
\hline $\begin{array}{l}\text { Cross } \\
\text { River }\end{array}$ & 5.4 & 0.5 & 0.04 & 12.5 & 2.8 & 0.10 & 1.1 & 0.7 & 65.0 & 19.0 & 16.0 \\
\hline Edo & 5.7 & 0.6 & 0.05 & 12 & 3.7 & 0.07 & 1.3 & 0.5 & 83.0 & 4.9 & 12.0 \\
\hline
\end{tabular}




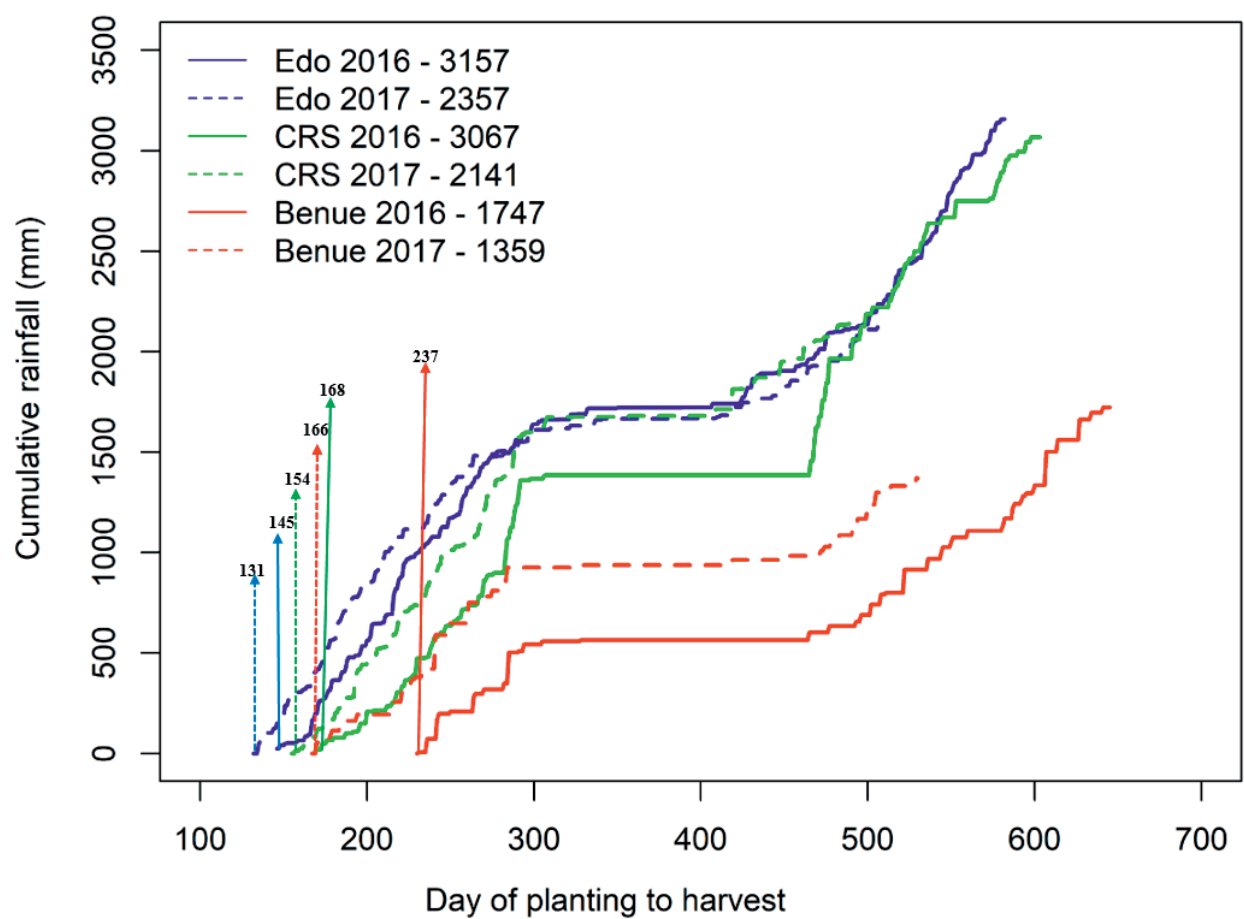

Fig. 2.1. Cumulative daily rainfall amount (mm) during the two growing seasons across the regions. The 2016 experiments were planted on day of the year (DOY) 145, 168, and 237 and the 2017 experiments were planted on DOY 131, 154, and 166 at Edo, Cross River (CRS), and Benue respectively.

\subsubsection{Yield responses to nutrients}

The crops were harvested at approximately 14 months in 2016, whereas in 2017 the experiments in Benue and Edo were harvested at $12 \mathrm{MAP}$, and at $11 \mathrm{MAP}$ at Cross River (Table 2.1), when the crops were recovering from drought. Average yields in the control treatments (NOP0K0) for both years were 10.2, 10.3, and $7.3 \mathrm{t} \mathrm{DM} \mathrm{ha}^{-1}$ in Edo, Cross River, and Benue, respectively (Table 2.4). Yield responses to $\mathrm{N}, \mathrm{P}$ and $\mathrm{K}$ were most pronounced in Edo, then Cross River and least in Benue. Generally, yields increased with fertilizer application rate. Yields differed greatly between the plots which received full rates of all three nutrients (NfPfKf) and the corresponding PK, NK, and NP plots. Cassava storage root yield in the full PK treatment plots (NOPfKf) ranged from $9-18 \mathrm{t} \mathrm{DM} \mathrm{ha}^{-1}$, with yield responses to $\mathrm{N}$ from $2-18 \mathrm{t} \mathrm{DM} \mathrm{ha}^{-1}$ across the locations (Table 2.4). Yield from NK and NP (NfP0Kf and NfPfK0) plots ranged from $8-19 \mathrm{t} \mathrm{DM} \mathrm{ha}^{-1}$ with yield responses from $3-16$ to $\mathrm{P}$ and $3-22 \mathrm{t} \mathrm{DM} \mathrm{ha}^{-1}$ to $\mathrm{K}$ respectively. Yield response to treatments within the two years and across all locations was highly significant $(\mathrm{p}<.001)$. The largest yields were obtained in the NfPfKf plot, though not significantly different from NfPfKfMN plots, with Edo recording the largest yield of 35 and $22 \mathrm{t} \mathrm{DM} \mathrm{ha}^{-1}$, Cross River 30 and $22 \mathrm{t} \mathrm{DM} \mathrm{ha}^{-1}$, and 26 and $11 \mathrm{t} \mathrm{DM} \mathrm{ha}^{-1}$ for Benue, in the 2016 and 2017 growing seasons, respectively (Table 2.4). The N150P40K180 treatments yielded less than with the full amount of nutrients with average yields of 23, 20, $16 \mathrm{DM} \mathrm{tha}^{-1}$ and 13, 12, and $8 \mathrm{tDM} \mathrm{ha}^{-1}$ in 2016 and 2017 for Edo, Cross River and Benue, respectively. 
Table 2.4. Average storage root yield with standard deviation in $t$ dry matter (DM) ha ${ }^{-1}$ for different fertilizer combinations at Benue (Guinea Savanna), Cross River (Rainforest), and Edo (Forest Transition). The $f$ denotes full ( $300 \mathrm{~kg} \mathrm{~N}$ and $\mathrm{K}, 100 \mathrm{~kg} \mathrm{P})$.

\begin{tabular}{lllllll}
\hline & Benue & \multicolumn{3}{c}{ Cross River } & Edo & \\
& 2016 & 2017 & 2016 & 2017 & 2016 & 2017 \\
\hline Control & 8.6 & 5.9 & 9.3 & 12.5 & 11.2 & 9.2 \\
N0PfKf & 10.0 & 8.9 & 10.7 & 9.9 & 17.0 & 14.5 \\
NfP0Kf & 10.0 & 7.6 & 13.1 & 13.8 & 19.4 & 11.9 \\
NfPfK0 & 19.3 & 7.6 & 11.6 & 9.9 & 12.8 & 10.6 \\
NfPfK60 & 17.3 & 6.9 & 14.3 & 14.1 & 19.7 & 13.0 \\
NfPfK120 & 19.5 & 7.4 & 16.6 & 16.6 & 21.0 & 14.3 \\
NfPfK180 & 19.3 & 7.8 & 19.2 & 12.2 & 24.1 & 16.0 \\
NfPfK240 & 14.5 & 12.3 & 25.5 & 16.0 & 24.6 & 25.2 \\
NfPfKf & 25.5 & 11.4 & 29.7 & 22.7 & 35.5 & 22.3 \\
NfPfKfMN & 27.0 & 10.8 & 28.7 & 21.5 & 34.8 & 27.6 \\
N150P40K180 & 16.1 & 7.8 & 19.5 & 12.4 & 22.5 & 12.9 \\
N75P20K90 & 11.0 & 9.3 & 13.4 & 13.2 & 16.1 & 13.7 \\
Treatment & $* * *(3.14)$ & ns & $* * *(2.54)$ & $* *(2.70)$ & $* * *(3.47)$ & $* * *(2.85)$ \\
Location & $* * *(1.29)$ & & & & & \\
Treatment*Year & $*(2.4)$ & & & & &
\end{tabular}

* Significant at $\mathrm{P}<0.05 ; \mathrm{ns}=$ not significant

** Significant at $\mathrm{P}<0.01$

$* * *$ Significant at $\mathrm{P}<0.001$

+ Standard errors (SE) in parentheses and relates only to comparisons between significant terms.

\subsubsection{Nutrient uptake}

Cassava that received fertilizer at full rate (NfPfKf) took up more nutrients across the seasons and locations and uptake was significantly different from other treatments. Average $\mathrm{N}$ uptake by cassava in both years was $416 \mathrm{~kg} \mathrm{ha}^{-1}$ (Edo), $326 \mathrm{~kg} \mathrm{ha}^{-1}$ (Cross River), and $215 \mathrm{~kg} \mathrm{ha}^{-1}$ (Benue). Average P uptake in both years was $56 \mathrm{~kg} \mathrm{ha}^{-1}$ (Edo), $38 \mathrm{~kg} \mathrm{ha}^{-1}$ (Cross River), and $24 \mathrm{~kg} \mathrm{ha}^{-1}$ (Benue) (Fig. 2.2. c and d). Potassium uptake was on average 287, 263, and $212 \mathrm{~kg} \mathrm{ha}^{-1}$, in Edo, Cross River, and Benue, respectively (Fig. 2.3. d). Treatment N150P40K180 in both years had average N uptake of 250 (Edo), 196 (Cross River), 122 (Benue) $\mathrm{kg} \mathrm{ha}^{-1}$. Phosphorus uptake was 30, 19, and $14 \mathrm{~kg} \mathrm{ha}^{-1}$, while $\mathrm{K}$ uptake was 140,159 , and $132 \mathrm{~kg} \mathrm{ha}^{-1}$ in Edo, Cross River, and Benue, respectively. Uptake of K increased with increasing rates (Fig. 2.3. b) and was higher in 2016 than 2017. A three-quadrant diagram explaining further the relation between $\mathrm{N}$ and $\mathrm{P}$ fertilizer rate and uptake, uptake and yield, and fertilizer rate and yield are included in Appendices 2.A and B. 

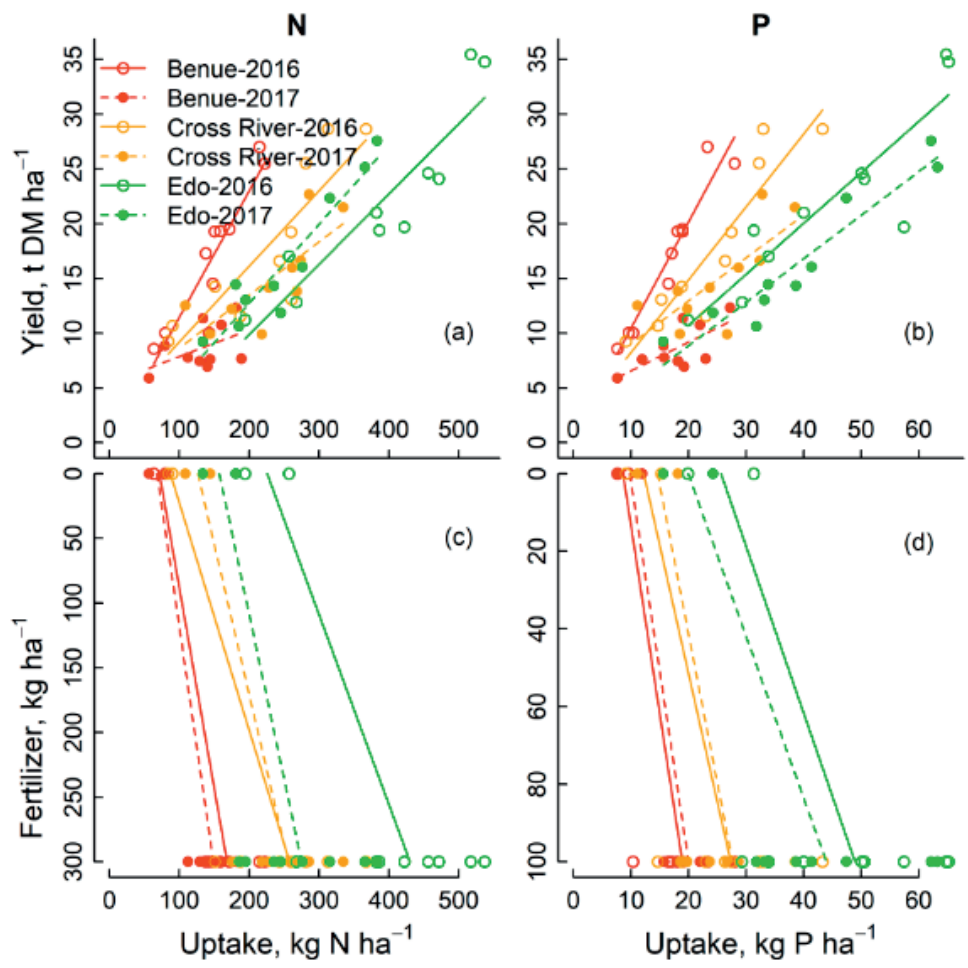

Fig. 2.2. Relationship between optimized fertilizer rate and uptake (c, d), uptake and yield (internal utilization efficiency ( $a, b)$ of nutrients N and P. Across the three states (Edo, Cross River, and Benue) during the 2016 and 2017 growing seasons. 


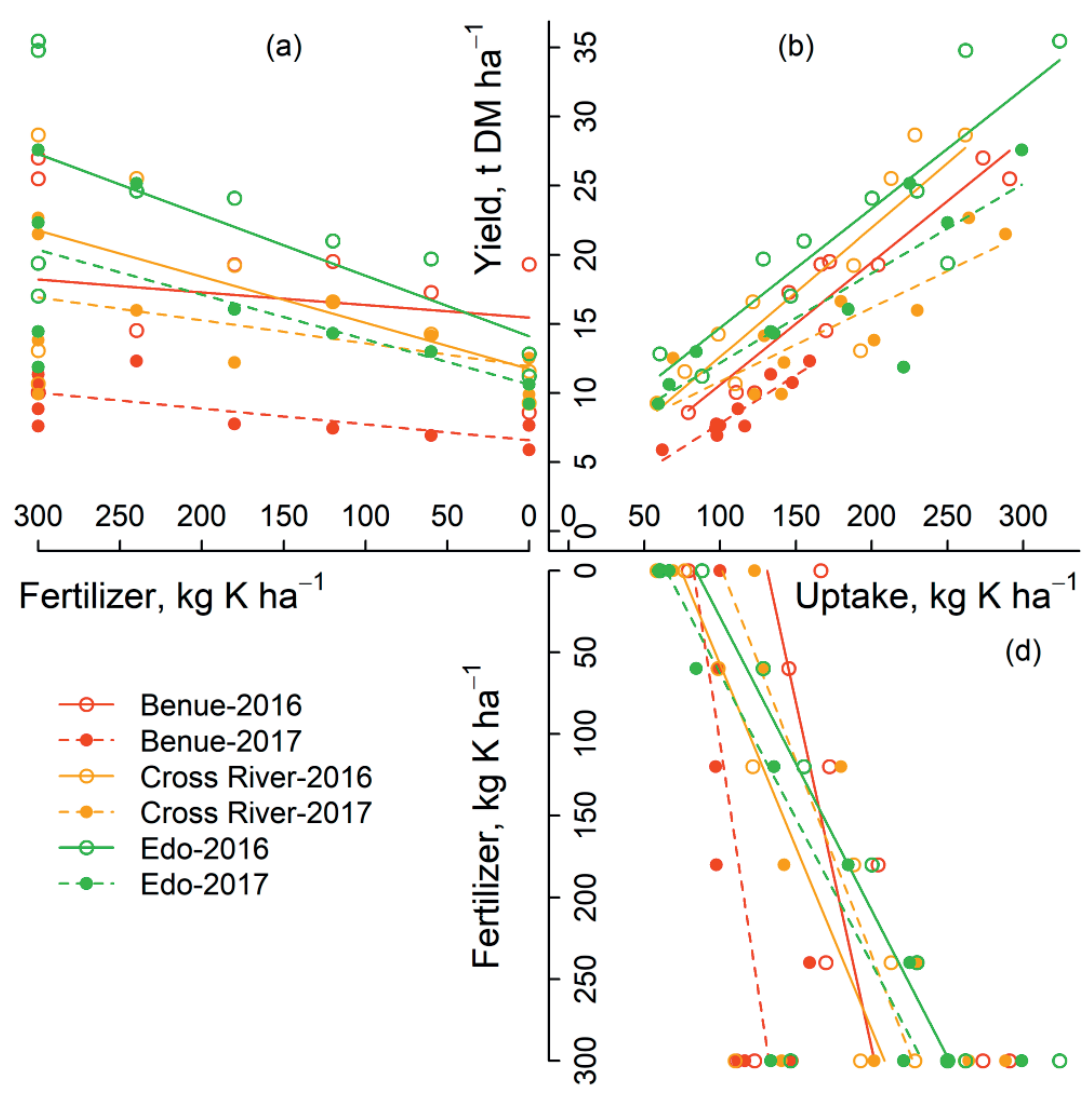

Fig. 2.3. Three-quadrant diagram showing the relation between $\mathrm{K}$ rates and uptake in quadrant (d), uptake and yield in quadrant (b) and fertilizer rate and yield in quadrant (a).

\subsubsection{Agronomic efficiency (AE)}

Agronomic efficiency of $\mathrm{N}$ and $\mathrm{P}$ was similar across the locations, but differed between the two years, while the AE of K differed only across locations (Table 2.5). Overall, the AE of all nutrients was highest with the full treatment (NfPfKf). Average AE of N, P and K were 49, 129 and $53 \mathrm{~kg} \mathrm{~kg}^{-1}$ for the 2016 and 2017 cropping season in Edo and Cross River. Benue had the lowest AE values for all treatments in both years (Table 2.5). 
Table 2.5. Agronomic efficiency (AE) of N, P, and $\mathrm{K}\left(\mathrm{kg} \mathrm{kg}^{-1}\right)$ when balanced and optimized $\mathrm{N}, \mathrm{P}, \mathrm{K}$, rates $\left(\mathrm{kg} \mathrm{ha}^{-1}\right)$ were applied to cassava in 2016 and 2017. At Benue, Cross River, and Edo Nigeria.

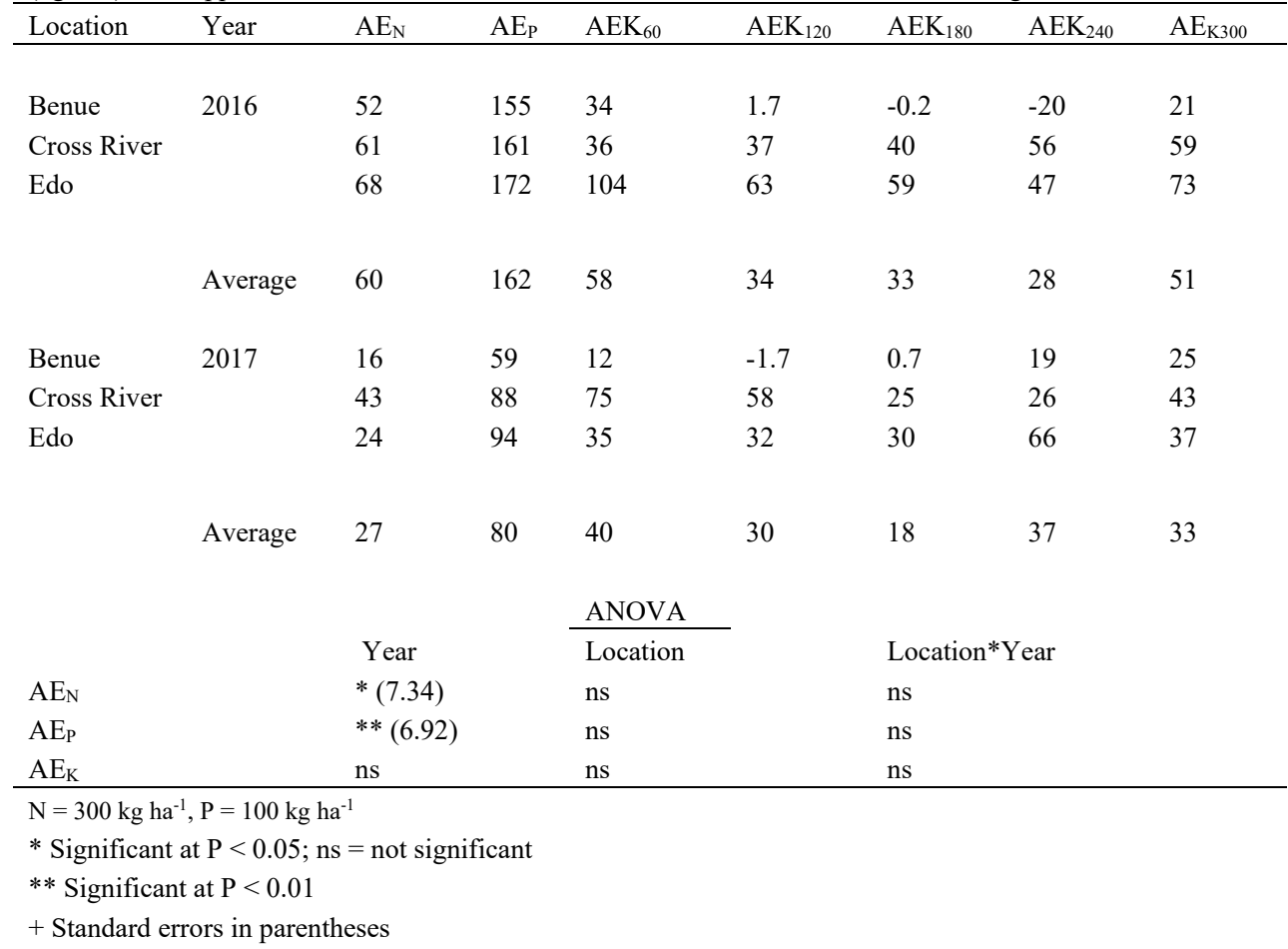

\subsubsection{Internal utilization efficiency (IE)}

Internal utilization efficiency (IE) of $\mathrm{N}, \mathrm{P}$ and $\mathrm{K}$ differed greatly between locations, with Benue recording the highest $\mathrm{IE}_{\mathrm{N}}$ and $\mathrm{IE}_{\mathrm{P}}$ (Fig 2. a, b). The largest $\mathrm{IE}_{\mathrm{K}}$ was observed in Edo. $\mathrm{IE}_{\mathrm{N}}$ was higher in the PK plots, but consistently lower in NK and NP plots, when compared with treatments that received the same rates of $\mathrm{N}$ fertilizers, across all locations and years. $\mathrm{IE}_{\mathrm{N}}$ ranged between $47-80,45-118$, and $40-126 \mathrm{~kg} \mathrm{~kg}^{-1} \mathrm{~N}$ in Edo, Cross River and Benue, respectively. The NfPfKf treatment had an $\mathrm{IE}_{\mathrm{N}}$ of 76, 89 and $115 \mathrm{~kg} \mathrm{~kg}^{-1} \mathrm{~N}$ in 2016 and 59, 78 and $59 \mathrm{~kg} \mathrm{~kg}^{-1} \mathrm{~N}$ in 2017, at Edo, Cross River and Benue, respectively. $\mathrm{IE}_{\mathrm{P}}$ ranged between $334-619,370-791$, and $400-1000 \mathrm{~kg} \mathrm{~kg}^{-1} \mathrm{P}$, in Edo, Cross River, and Benue respectively. The NfPfKf treatment had an $\mathrm{IE}_{\mathrm{P}}$ of 599,767 and $911 \mathrm{~kg} \mathrm{~kg}^{-1} \mathrm{P}$ in 2016 and 433, 653 and $405 \mathrm{~kg} \mathrm{~kg}^{-1} \mathrm{P}$ in 2017, in Edo, Cross River and Benue, respectively. Also, $\mathrm{IE}_{\mathrm{K}}$ was highest in the NP plots across locations and years. It ranged between $91-213$ (Edo), $69-150$ (Cross River), and $65-116$ (Benue) $\mathrm{kg} \mathrm{kg}^{-1} \mathrm{~K}$ in both years. The $\mathrm{IE}_{\mathrm{K}}$ of NfPfKf treatment was 150 and 91,111 and 85, and 88 and $77 \mathrm{~kg} \mathrm{~kg}^{-1} \mathrm{~K}$, in 2016 and 2017, respectively at Edo, Cross River and Benue, respectively (Fig. 2.3. b). The mean highest $\mathrm{IE}_{\mathrm{K}}$ was obtained from Edo and was significantly different from other locations. The slopes of Fig. 2.2 a, b and Fig. 2.3 b, reflect the IEs of N, P and K across treatments.

\subsubsection{Recovery efficiency (RE)}

Recoveries of N, P and K was significantly different in 2016 and 2017 and among the locations. (Table 2.6). Recovery efficiency of all nutrients was greater in 2016 at 14 MAP than in 2017 at 12 MAP. The NfPfKf treatment had average N, P and K recovery efficiencies of $0.73,0.26$ and 0.64 in 2016, respectively across the locations. Recovery of $\mathrm{N}$ was lowest in Benue in both years (Table 2.6). RE of $\mathrm{P}$ was different $(\mathrm{p}<0.05)$ and varied from 0.05 to 0.32 across locations. Also, RE of $\mathrm{K}$ differed across 
the locations and varied from 0.42 to 0.88 in 2016 and 0.24 to 0.61 in 2017 (Table. 2.6). RE of N, P and $\mathrm{K}$ was larger in Edo and Cross River than in Benue. Average RE of $\mathrm{K}$ across the locations in both years increased with higher rates with full rates of $\mathrm{N}$ and $\mathrm{P}$ and was least in the NfPfK60 treatment $\left(\mathrm{RE}_{\mathrm{K} 60}\right)$ (Table 2.6).

Table 2.6. Recovery efficiency of N, P, and $\mathrm{K}$ when balanced and optimized N, P and K, rates ( $\mathrm{kg}$ $\mathrm{ha}^{-1}$ ) were applied to cassava in 2016 and 2017. At Benue, Cross River, and Edo Nigeria.

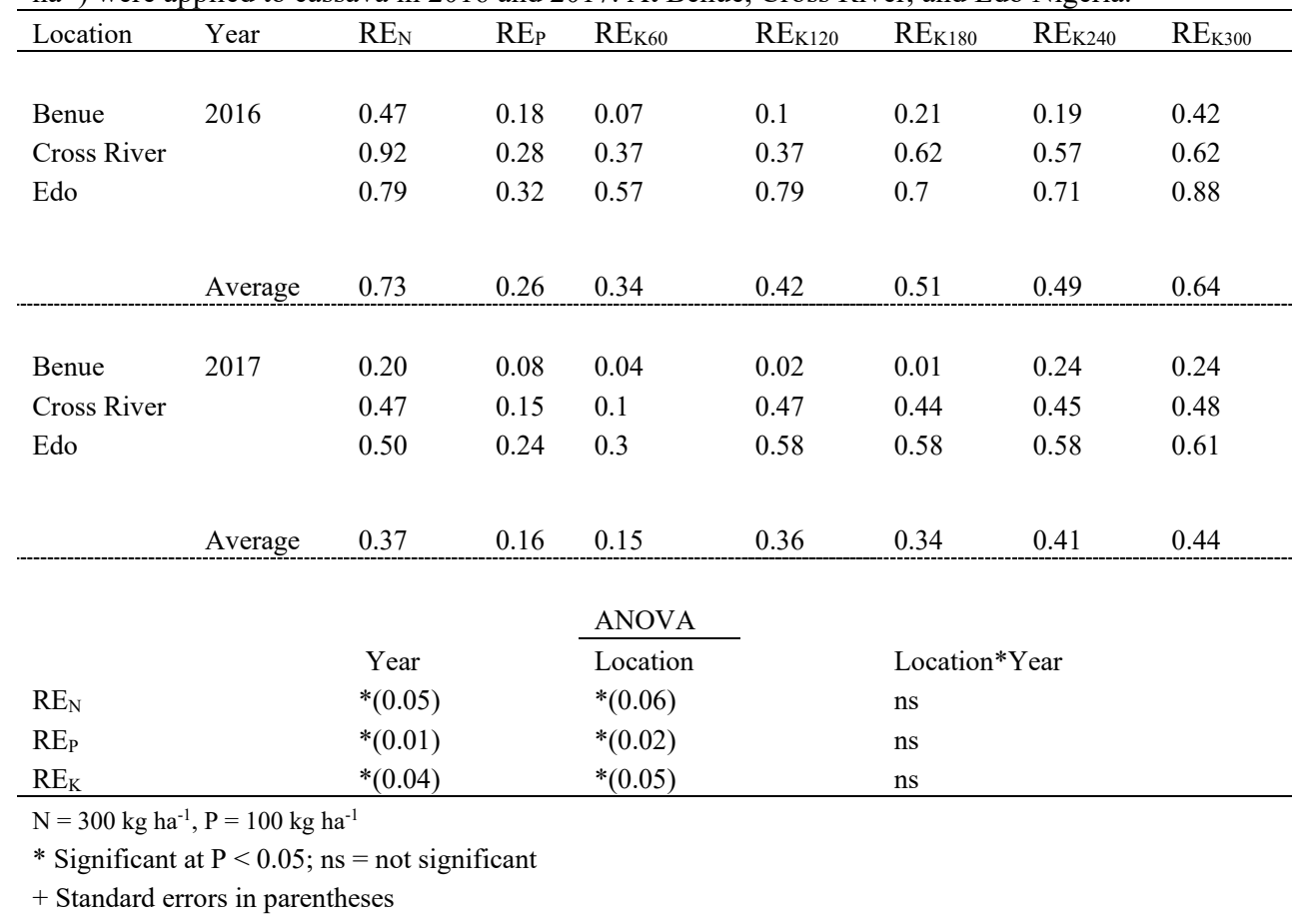

\subsubsection{Nutrient harvest index (NHI)}

Nutrient harvest index of $\mathrm{N}$ and $\mathrm{P}$ was largest in the full nutrient treatment, with averages of 0.43 for $\mathrm{HI}_{\mathrm{N}}$ and $0.54 \mathrm{HI}_{\mathrm{P}}$ across locations and years, when compared with the treatments where less $\mathrm{K}$ fertilizer was applied. These NHI values were significantly larger than what was observed in the control. By contrast, $\mathrm{HI}_{\mathrm{K}}$ did not differ among treatments but differed between locations with smallest values for Edo (Table 2.7). N, P and $\mathrm{K}$ concentration in the storage roots were highest in the NfPfKf treatment and differed significantly from other treatments and locations. Averages of N, P and $\mathrm{K}$ concentrations in both years were $3.35,0.56$, and $4.38 \mathrm{~kg} \mathrm{t}^{-1} \mathrm{DM}$. The lowest concentrations were in the control treatment, with averages of $2.55,0.43$ and $3.49 \mathrm{~kg} \mathrm{~N}, \mathrm{P}$ and $\mathrm{K} \mathrm{t}^{-1} \mathrm{DM}$. The nutrient with largest concentration in the storage root across the treatments and locations in both years was $\mathrm{K}$, except in Edo, where the $\mathrm{K}$ concentration was lower than that of $\mathrm{N}$ (Table 2.7). 
Table 2.7. Nutrient harvest index and storage roots nutrient concentration of $\mathrm{N}, \mathrm{P}$, and $\mathrm{K}\left(\mathrm{kg} \mathrm{t}^{-1} \mathrm{DM}\right)$. At Benue, Cross River, and Edo in 2016 and 2017.

\begin{tabular}{|c|c|c|c|c|c|c|}
\hline Treatment & $\mathrm{HI}_{\mathrm{N}}$ & $\mathrm{HI}_{\mathrm{P}}$ & $\mathrm{HI}_{\mathrm{K}}$ & $\begin{array}{l}\mathrm{N} \\
\left(\begin{array}{lll}\mathrm{kg} & \mathrm{N} & \mathrm{t}^{-1} \\
\text { DM roots }\end{array}\right)\end{array}$ & $\begin{array}{l}\mathrm{P} \\
\left(\begin{array}{lll}\mathrm{kg} & \mathrm{P} \quad \mathrm{t}^{-1} \\
\text { DM roots }\end{array}\right.\end{array}$ & $\begin{array}{l}\mathrm{K} \\
\left(\begin{array}{lll}\mathrm{kg} & \mathrm{K} & \mathrm{t}^{-1} \\
\text { DM roots})\end{array}\right.\end{array}$ \\
\hline & & & Benue & & & \\
\hline Control & 0.39 & 0.59 & 0.7 & 2.20 & 0.44 & 4.61 \\
\hline N150P40K180 & 0.46 & 0.61 & 0.67 & 3.12 & 0.56 & 5.50 \\
\hline NfPfK180 & 0.43 & 0.6 & 0.63 & 3.29 & 0.60 & 4.82 \\
\hline NfPfKf & 0.47 & 0.64 & $\begin{array}{l}0.69 \\
\text { Cross River }\end{array}$ & 3.77 & 0.72 & 6.17 \\
\hline Control & 0.37 & 0.52 & 0.71 & 2.57 & 0.40 & 3.30 \\
\hline N150P40K180 & 0.37 & 0.53 & 0.62 & 2.95 & 0.42 & 4.14 \\
\hline NfPfK180 & 0.33 & 0.46 & 0.57 & 2.90 & 0.46 & 3.87 \\
\hline NfPfKf & 0.39 & 0.53 & $\begin{array}{l}0.62 \\
\text { Edo }\end{array}$ & 2.96 & 0.45 & 3.88 \\
\hline Control & 0.28 & 0.39 & 0.58 & 2.88 & 0.45 & 2.57 \\
\hline N150P40K180 & 0.34 & 0.42 & 0.59 & 2.31 & 0.46 & 2.89 \\
\hline NfPfK180 & 0.31 & 0.4 & 0.49 & 3.02 & 0.47 & 2.40 \\
\hline NfPfKf & 0.42 & 0.43 & 0.54 & 3.33 & 0.56 & 3.08 \\
\hline & & & ANOVA & & & \\
\hline $\mathrm{HI}_{\mathrm{N}}$ & $\begin{array}{l}\text { Treatment } \\
*(0.02)\end{array}$ & $\begin{array}{l}\text { location } \\
* *(0.02)\end{array}$ & & $\mathrm{N}$ & $\begin{array}{l}\text { Treatment } \\
\text { ns }\end{array}$ & $\begin{array}{l}\text { location } \\
\text { ns }\end{array}$ \\
\hline $\mathrm{HI}_{\mathrm{P}}$ & $* *(0.01)$ & $* * *(0.01)$ & & $\mathrm{P}$ & ns & $*(0.04)$ \\
\hline $\mathrm{HI}_{\mathrm{K}}$ & $*(0.02)$ & $* * *(0.02)$ & & K & ns & $* * *(0.23)$ \\
\hline $\begin{array}{l}\mathrm{N}=300 \mathrm{~kg} \mathrm{ha}^{-1}, \mathrm{P}= \\
* \text { Significant at } \mathrm{P} \\
\text { ** Significant at } \mathrm{F} \\
\text { *** Significant at } \\
+ \text { Standard errors }\end{array}$ & $\begin{array}{l}100 \mathrm{~kg} \mathrm{ha}^{-1} \\
<0.05 ; \mathrm{ns}=\mathrm{n} \\
<0.01 \\
\mathrm{P}<0.001 \\
\text { in parentheses }\end{array}$ & significant & & & & \\
\hline
\end{tabular}

\subsection{Discussion}

\subsubsection{Yield potential of cassava in West Africa}

Cassava yield responded strongly to applied nutrients on very infertile soils which clearly exhibited large macro-nutrient deficiencies with soil nutrients below critical concentrations of about $10 \mathrm{mg} \mathrm{kg}^{-1}$ for $\mathrm{P}$, and $0.20 \mathrm{cmol} \mathrm{kg}^{-1}$ for exchangeable $\mathrm{K}, 5.0$ and $1.0 \mathrm{cmol} \mathrm{kg}^{-1}$ for $\mathrm{Ca}$ and $\mathrm{Mg}$ (Howeler, 2002). The rainfall distribution was adequate for establishment and growth of cassava in the selected locations; the field in Cross River experienced a short dry period in 2016 and Benue suffered from a seasonal dry period in both years. Nevertheless, a yield of $29 \mathrm{t} \mathrm{DM} \mathrm{ha}^{-1}$ was recorded in Cross River in 2016. The largest cassava yield of $35 \mathrm{t} \mathrm{DM} \mathrm{ha}^{-1}$ at 14 MAP was achieved in Edo, equivalent to $97 \mathrm{t} \mathrm{ha}^{-1}$ of fresh storage roots. No effects of drought were observed in 2016 for Edo, despite a brief dry season, due to the rooting depth of cassava in this field, which was greater than $3.2 \mathrm{~m}$. This observed yield is larger than the target yield of $90 \mathrm{tha}^{-1}$ of fresh roots which we used to determine the nutrient requirements with the QUEFTS model (Ezui, 2017). These yields are comparable to the simulated ideal yield of $32 \mathrm{t}$ $\mathrm{DM} \mathrm{ha}^{-1}$ at 12 MAP proposed by Cock et al. (1979) and to the actual recorded yields of $27-32 \mathrm{t}$ DM $\mathrm{ha}^{-1}$ at 10 MAP reported from Cauca, Colombia (El-Sharkawy et al., 1990). Cassava storage root yield responses to applied $\mathrm{N}, \mathrm{P}$ and $\mathrm{K}\left(2-18,3-16\right.$ and $\left.3-22 \mathrm{t} \mathrm{DM} \mathrm{ha}^{-1}\right)$ varied across the locations 
reflecting variability in site conditions and water availability. A linear response to $\mathrm{K}$ application was observed, without reaching the expected plateau that would result from diminishing returns Although root growth was not measured, we suspect that $\mathrm{K}$ application strongly increased root growth and increased the capacity to access water from deeper soil layers during the dry seasons and intercept leached $\mathrm{N}$ from upper soil layers. The most limiting nutrient in Edo was $\mathrm{K}$, while $\mathrm{N}$ was most limiting in Cross River, and $\mathrm{P}$ was most limiting in Benue.

\subsubsection{Nutrient uptake and nutrient use efficiency}

Nutrient use efficiency was addressed in terms of agronomic efficiency (AE), internal utilization efficiency (IE) and the apparent recovery efficiency (RE) of N, P and K of cassava. AE was lowest at Benue reflecting the poorest growth conditions with shallow soil inhibiting deeper root growth in both years, which was exacerbated by drought, reflecting the need for adjustment of fertilizer applications to water-limited potential production. High average AE values of $\mathrm{N}, \mathrm{P}$ and $\mathrm{K}\left(60,162\right.$ and $\left.51 \mathrm{~kg} \mathrm{~kg}^{-1}\right)$ were obtained in line with the ranges of recorded AEs in other studies in the region of 53-91, 84-110 and 112$124 \mathrm{~kg} \mathrm{~kg}^{-1}$ (NYI, 2014; Senkoro et al., 2018). These AE values are much greater than those found in cereal crops (maize, rice and wheat) which range from $15-30,15-40$ and $8-20 \mathrm{~kg} \mathrm{~kg}^{-1}$ for N, P and $\mathrm{K}$, under optimal management (Fixen et al., 2015; Ichami et al., 2019). The average uptakes of N, P and $\mathrm{K}$ from the NfPfKf treatments in Edo and Cross River were 364, 44 and $242 \mathrm{~kg} \mathrm{ha}^{-1}$, while that of the control (NOP0K0) treatments were 141,15 and $73 \mathrm{~kg} \mathrm{ha}^{-1}$, reflecting nutrient uptakes $\mathrm{N}>\mathrm{K}>\mathrm{P}$ for cassava (Howeler, 2014). Roots acted as storage of especially $\mathrm{K}$, with $\mathrm{K}$ concentrations and $\mathrm{HI}_{\mathrm{K}}$ declining when K supply was limited.

The high nutrient recovery of cassava and limited $\mathrm{N}$ leaching may be attributed to the longer growing period and more intensive and extensive root system when compared with cereals (Howeler, 2002; 2014). The recorded average total uptake of $\mathrm{N}, \mathrm{P}$ and $\mathrm{K}$ was $13.5-13.7,1.5-1.7$ and $7.0-9.7 \mathrm{~kg} \mathrm{~N}, \mathrm{P}$ and $\mathrm{K} \mathrm{t}^{-1} \mathrm{DM}$ and $4.3-4.8,0.52-0.53,2.4-3.1 \mathrm{~kg} \mathrm{~N}, \mathrm{P}, \mathrm{K} \mathrm{t}^{-1} \mathrm{FM}$ root yield respectively were similar to values found in the literature (Howeler and Cadavid, 1983; Howeler, 2002; Howeler, 2014; Howeler, 2017). The observed internal utilization efficiency (IE) corresponded with those reported for balanced nutrition at high yields under good management (Norton, 2014; Fixen et al., 2015) and the estimated minimum and maximum IEs of nutrients for cassava (Ezui et al., 2017a). The observed $\mathrm{IE}_{\mathrm{P}}$ in Benue was $41 \%$ higher and $\mathrm{IE}_{\mathrm{K}}$ was $25 \%$ higher in Edo than the calculated maximum $\mathrm{IE}_{\mathrm{P}}$ and $\mathrm{IE}_{\mathrm{K}}$ for cassava by Ezui et al. (2017a), reflecting P deficiency in the field at Benue and K deficiency at Edo.

The high $\mathrm{RE}_{\mathrm{N}}$ at Edo and Cross River in 2016 could be due to the long growing season of 14 months with adequate soil water availability. Ezui et al. (2016) recorded maximum $R E_{N}, R E_{P}$, and $R E_{K}$ values of $0.95,0.6$ and 0.95 , respectively for cassava under optimum management. The relatively lower $P$ recovery is typical (Janssen et al., 1990; Syers et al., 2008). Nevertheless, P recovery by cassava is much better than cereal crops with typical first-year recovery values around $0.1-0.25$ in tropical systems (Wolf and Van Keulen, 1989; Van der Eijk et al., 2006). Cassava roots form a symbiosis with native vesicular-arbuscular mycorrhiza, strongly increasing $\mathrm{P}$ uptake (Howeler, 2017). The $\mathrm{N}$ and $\mathrm{P}$ harvest index increased with increased rates. The smallest $\mathrm{HI}_{\mathrm{K}}$ was observed in Edo (Table 2.7), reflecting $\mathrm{K}$ limitations at the Edo sites in 2016 and 2017. The decline in K concentration in the storage roots may have resulted from limited supply of $\mathrm{K}$ when compared to $\mathrm{N}$ and $\mathrm{P}$. The low harvest index values indicate that most of the nutrients taken up by the plant could be recycled back to the soil by re-incorporation of the residues from the shoot, and especially the leaves (Howeler, 2014).

\subsubsection{Cassava and food security in SSA}

In SSA, expected population growth (UNDESA, 2017) demands a doubling of crop production by 2050 (Van Ittersum et al., 2016), with changing dietary preferences (Cassidy et al., 2013) and increasing 
demands from biofuel and industrial products. Cassava is more resilient to adverse conditions and climate change than maize (Rosenthal and Ort, 2012; De Souza et al., 2017) or other cereals, and seems a better option for various reasons. High-yielding cassava can play a key role towards meeting the rising food demands, because of its high energy content and efficiency. For example, the energy contents of cassava and maize are 16.5 and 14.9 $\mathrm{MJ} \mathrm{kg}^{-1} \mathrm{DM}$ (Montagnac et al., 2009). The efficiency of energy production per unit of $\mathrm{N}$ is 2.7 times greater for cassava $\left(993 \mathrm{MJ} \mathrm{kg} \mathrm{N}^{-1}\right)$ than for maize $\left(372 \mathrm{MJ} \mathrm{kg} \mathrm{N}^{-}\right.$ $\left.{ }^{1}\right)$. For proteins legumes may provide the most efficient options (Zhang et al., 2019), yet the efficiency of cassava is $2023 \mathrm{~g}$ protein $\mathrm{kg}^{-1} \mathrm{~N}$ compared to e.g. $3348 \mathrm{~g}$ protein $\mathrm{kg}^{-1} \mathrm{~N}$ for maize. Under limited $\mathrm{N}$ availability, applying fertilizer to cassava results in more energy per $\mathrm{kg} \mathrm{N}$ applied with lower environmental risks, evidenced by higher recovery and nutrient use efficiency than for maize. Furthermore, cassava is well adapted to rainfall variability and drought. However, there is an urgent need to develop value chains that can support sustainable intensification.

\subsection{Conclusion}

This study was designed to explore the yield potential of cassava under rain-fed conditions in the three major cassava growing agro-ecological zones across SSA. Strong responses to applied N, P and K fertilizers depict the inherent ability of cassava for large yields, and the need for fertilizer application. The recovery and the yield response to $\mathrm{K}$ increased with increasing rates of $\mathrm{K}$ applied when both $\mathrm{N}$ and $\mathrm{P}$ were also applied in large amounts, indicating a positive feedback mechanism through improved uptake and growth. Irrespective of the poor soil fertility, addition of secondary and micronutrients did not increase storage root yield. Our results clearly show that agronomic and internal utilization efficiency of nutrients by cassava are larger than for cereals such as maize. This indicates that environmental risks are less, but at the same time risks of mining soil nutrient reserves are larger with cassava. Also, cassava yield gaps may be larger than previously thought, providing options to increase food production on existing farmland. Investment in fertilizer for cassava gives a 2.7 times larger dietary energy return than similar fertilizer investment in maize. To realistically end hunger, achieve food security and promote sustainable crop production systems in SSA, more research to further understand cassava growth and production is required. We see a large potential to address future energy needs of the growing population with cassava, with smaller environmental risks than cereal crops.

\section{Acknowledgements}

We thank the Netherlands Fellowship Program (NUFFIC) and the African Cassava Agronomy Initiative (ACAI) of IITA for funding. We are grateful to A. Olojede and C. Ifenkwe for their assistance in the field. 


\subsection{Appendices}

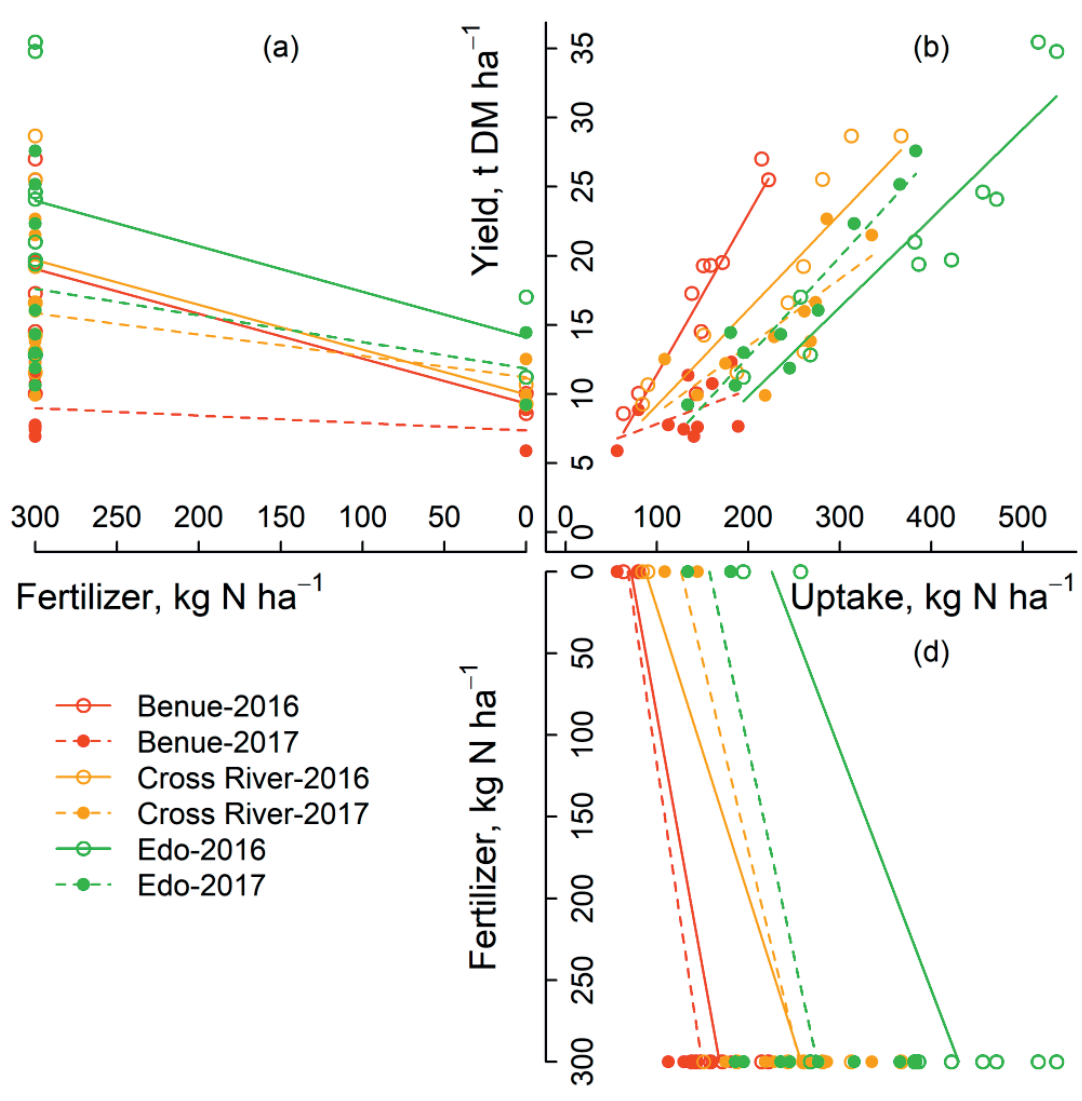

Appendix 2.A. Three-quadrant diagram showing the relation between $\mathrm{N}$ rates and uptake in quadrant (d), uptake and yield in quadrant (b) and fertilizer rate and yield in quadrant (a). 


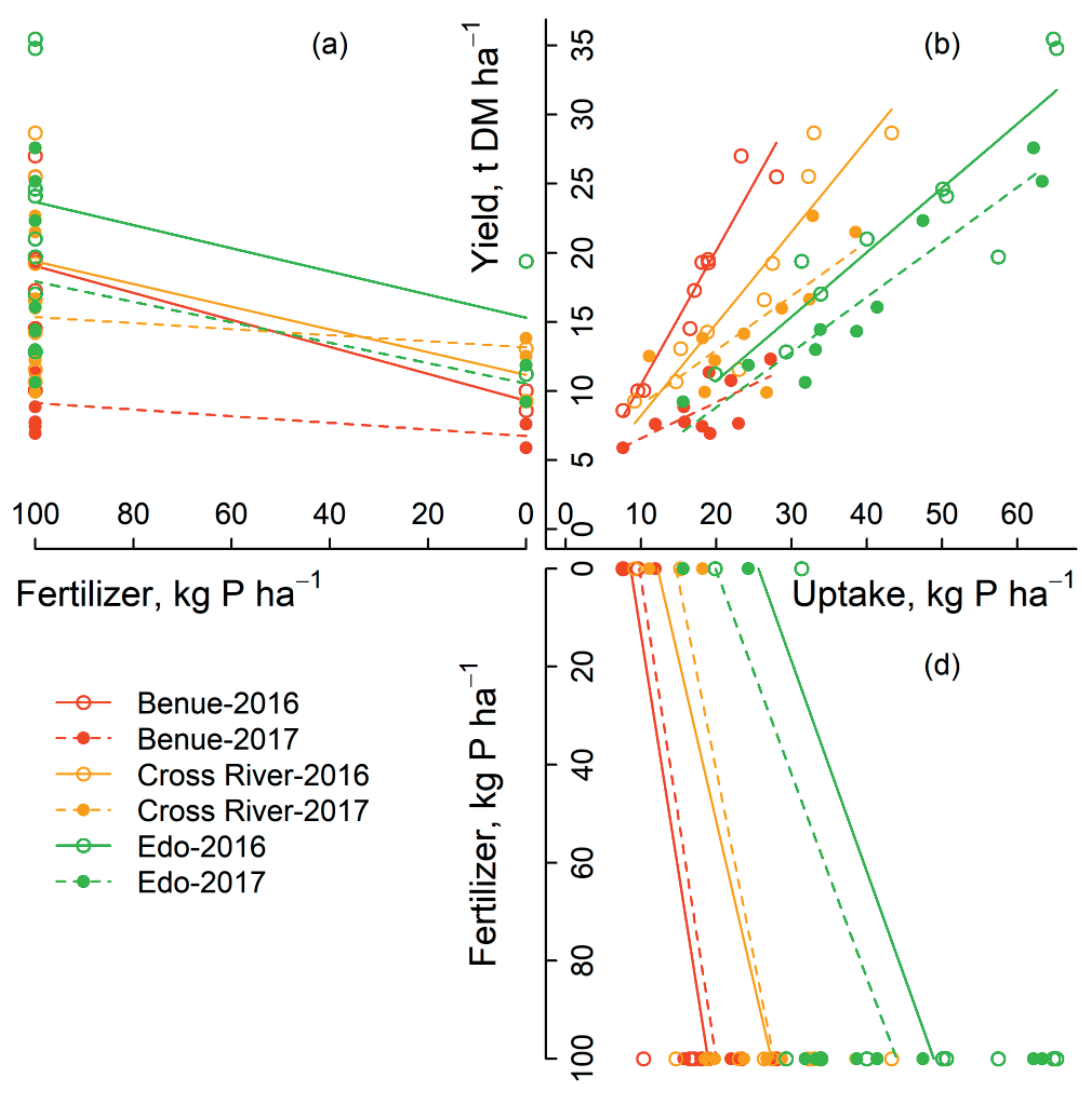

Appendix 2.B. Three-quadrant diagram showing the relation between P rates and uptake in quadrant (d), uptake and yield in quadrant (b) and fertilizer rate and yield in quadrant (a). 



\section{Chapter 3. Evaluating cassava yield potential using the LINTUL-Cassava model}

This chapter is submitted as:

Adiele, J.G, Schut, A.G.T., van den Beuken, R.P.M., Ezui, K.S., Pypers, P., Ano, A.O., Egesi, C.E., Giller KE., 2020. Evaluating cassava yield potential using the LINTUL-Cassava model. Submitted to Eur. J. Agron. Under review. 


\begin{abstract}
Accurate assessments of yield potentials of cassava are needed to analyse yield gaps, define yield targets and set benchmarks for actual yields in Nigeria. This study evaluated the crop model LINTUL-Cassava under non-water and water limited conditions in Nigeria. On-farm experiments were conducted at six locations across the three major cassava growing agro-ecologies of Western Africa (Tropical Rainforest - Ogoja and Ikom, Cross River, Rainforest Transition Savanna - Ekpoma, Edo and Guinea Savanna Otukpo, Benue) during two subsequent seasons (2016 - 2018). Treatments included fertilizer rates calculated to support non-water-limited yields of $90 \mathrm{t}$ fresh storage root yield ha ${ }^{-1} \mathrm{y}^{-1}$ (equivalent to $32 \mathrm{t}$ $\mathrm{DM} \mathrm{ha}^{-1}$, produced in a growing season of 12 months). Light interception $(L I)$ and leaf area index $(L A I)$ were measured each month. The weights of leaves, stems and storage roots were measured at 4 and 8 months after planting and at harvest, and radiation use efficiency $(R U E)$ calculated. The Edo experiment from 2016 was without drought stress and was used to parameterise LINTUL-Cassava and calibrate assimilate partitioning as function of temperature sums. The average fraction of light intercepted during the season was $80 \%$, with a light extinction coefficient of 0.67 and a $R U E$ of $2.8 \mathrm{~g} \mathrm{DM} \mathrm{MJ}^{-1}$ intercepted photosynthetically active radiation (IPAR). After calibration, the LINTUL-Cassava model described the crop growth and observed patterns of $L A I$ well in the experiments in Cross River and Edo (2017). Simulated and observed storage root yield at 4 MAP (vegetative period), 8 MAP (mid-season) and at harvest were strongly correlated ( $R^{2}$ of 0.92 ), with a RMSE of $4.93 \mathrm{t} \mathrm{DM} \mathrm{ha}^{-1}$. We ascertained that $R U E$ of cassava was much higher than previously observed in Africa, with average non-water limited storage root yield of $39 \pm 7 \mathrm{t} \mathrm{DM} \mathrm{ha} \mathrm{a}^{-1}$. Consequently potential yields are greater and yield gaps larger than expected or previously reported. We conclude that the LINTUL-Cassava model can provide an adequate estimate of storage root yield across major cassava growing agroecological zones in Nigeria under rainfed conditions.
\end{abstract}

Keywords: light interception, radiation use efficiency, dry matter partitioning, crop growth models. 


\subsection{Introduction}

Cassava (Manihot esculenta Crantz) is an important food crop and animal feed in tropical and subtropical Africa, Asia, and Latin America. The area cropped with cassava has expanded considerably over the past decades (Howeler et al., 2013), with over 26 million hectares of land cultivated in 2017, of which approximately $78 \%$ was in Africa (FAOSTAT, 2017). Cassava is a warm season crop with unique and useful environmental physiological traits, including the ability to produce in poor soils and yield even under conditions of extreme drought (Angelov et al., 1993; Alves, 2002; El-Sharkawy, 2009). There is wider recognition of cassava as a crop of choice for climate change adaptation strategies, particularly in sub-Saharan Africa (SSA) (FAO, 2018). Tropical root crops such as cassava or tuber crops like yams may provide new options to feed the growing population with lower nutrient requirements than cereals (Howeler, 2017). Nutrient use efficiency (NUE) of cassava is much higher than that of cereals (Adiele et al. Chapter 1; Howeler, 2017)). Further, cassava may make better use of suitable growing days, especially under seasonal drought conditions that characterise rain-fed agriculture in SSA (Ezui et al., 2018). Observed yields from experiments in the region ranged between 11 and $35 \mathrm{t}$ dry matter (DM) ha ${ }^{-1}$ (Adiele et al. Chapter 1) and were larger than simulated potential yields (Matthews and Hunt, 1994; Gabriel et al., 2014; Ezui et al., 2018). This suggests that some crop parameters used currently in cassava growth simulation models require modification. Good estimates of potential yields provide important benchmarks for realistic yield targets and understanding of yield gaps with local relevance (Van Ittersum et al., 2013).

The validity of crop models relies on an accurate estimation of parameters that describe key crop growth processes. The amount of light intercepted $(L I)$ by a crop and radiation use efficiency $(R U E)$ are key parameters for estimating potential yield (Sinclair and Muchow, 1999; Kiniry et al., 2005; De Souza et al., 2017). Therefore, $L I$ and $R U E$ have been used to investigate the interaction between crops and management, and to explain yield differences in diverse production environments (Shah et al., 2004). Seasonal $L I$ values of cassava from different studies in Colombia ranged from 52.3-64.1\% (De Souza et al., 2017). Similar values were also observed for cultivars in e.g. Thailand and Indonesia, where the largest increases in yield per unit land area $\left(\sim 24 \mathrm{t}\right.$ fresh storage root ha ${ }^{-1}$, equivalent to $\left.8.4 \mathrm{t} \mathrm{DM} \mathrm{ha}{ }^{-1}\right)$ have been achieved in the recent years, between 2005 and 2017 (De Souza et al., 2017; FAOSTAT, 2019). Previous studies have reported huge variation in $R U E$ with values ranging from 0.55 to $2.3 \mathrm{~g} D M$ $\mathrm{MJ}^{-1}$ intercepted photosynthetically active radiation (IPAR) (Veltkamp, 1985; Pellet and El-Sharkawy, 1997; Ezui et al., 2017b). A calibrated value of $2.9 \mathrm{~g} \mathrm{DM} \mathrm{MJ}^{-1}$ IPAR was used in the modified GUMCAS model to simulate potential yield (Gabriel et al., 2014). By contrast, the seasonal average RUE recorded in experiments in West Africa was $1.16 \mathrm{~g} \mathrm{DM} \mathrm{MJ}^{-1}$ IPAR (Ezui et al., 2017b).

$R U E$ is cultivar-specific, and the highest values can only be achieved under optimal agronomic practises. For instance, with good management, $R U E$ values for potatoes (a $\mathrm{C}_{3}$ species as is cassava) range between 2.6 and 3.1 $\mathrm{g} \mathrm{DM} \mathrm{MJ}^{-1}$ IPAR (Sinclair and Muchow, 1999; Rezig et al., 2013; Zhou et al., 2016). Furthermore, reported light extinction coefficient $(k)$ values of cassava from literature are similar to those of other crops $(0.50-0.88)$, while maximum leaf area index $(L A I)$ ranges from 3 to $11 \mathrm{~m}^{2} \mathrm{~m}^{-2}$ (Veltkamp, 1985; Pellet and El-Sharkawy, 1997; Ezui et al., 2017b). Assessment of these key parameters ( $R U E$ and $k$ ) under SSA conditions is needed for proper simulation of crop growth and yield gap assessments.

LINTUL-Cassava, a relatively simple and robust model, can simulate biomass growth and yield of cassava for potential and water-limited conditions (Ezui et al., 2018). LINTUL-Cassava uses tabulated values for dry matter partitioning and biomass growth rate as a function of the amount of light intercepted multiplied with the (invariable) $R U E$ parameter value. However, this model has not been 
tested in Nigeria where cassava is cultivated across a range of environmental and climatic conditions which can be considered typical of the humid tropics. The objectives of our study were to: (1) understand the temporal dynamics of light interception in cassava; (2) determine radiation use efficiency and photoassimilate partitioning of cassava under non-water limited conditions; (3) calibrate and evaluate the LINTUL-Cassava model with field data obtained from experiments under non-water limited conditions; and (4) test this model with observations from other field experiments in three agro-ecological zones.

\subsection{Materials and methods}

\subsubsection{The study area}

On-farm experiments were conducted from 2016 to 2018. Six experimental fields were selected in three agro-ecological zones (AEZ): Rainforest, with two fields located in Cross River state; Transition Rainforest - two fields in Edo state; and Guinea Savanna with two fields in the state of Benue, covering the major cassava producing regions in Nigeria. Each year, three field trials were established, one in each AEZ. The fields in Edo were located at $7.05^{\circ} \mathrm{N}, 6.13^{\circ} \mathrm{E}$ in 2016 and $6.80^{\circ} \mathrm{N}, 6.13^{\circ} \mathrm{E}$ in 2017 . For Cross River, field locations were at $7.27^{\circ} \mathrm{N}, 8.18^{\circ} \mathrm{E}$ in 2016 and $5.96^{\circ} \mathrm{N}, 8.77^{\circ} \mathrm{E}$ in 2017 . In Benue, fields were located at $6.76^{\circ} \mathrm{N}, 8.69^{\circ} \mathrm{E}$ in 2016 and $7.27^{\circ} \mathrm{N}, 8.19^{\circ} \mathrm{E}$ in 2017 . The growing season begins with the onset of rains in the south from April (Cross River), gradually moving north, with first rains in Edo by mid-April and June in Benue. The dry season starts early November in the north (Benue), later the dry season extends southwards through Edo and Cross River with intermittent rainfall and ends late March at Cross River, early to mid-April at Edo and May at Benue. The Harmattan wind (cold, dry, dusty northeasterly trade wind) blows during the dry season across all regions.

The experiment locations (Cross River and Edo) fall within the Niger delta, which contains deep deposits of relatively young material, rich in clay, resulting in mostly Nitisols or Ferralsols, while Benue is located within the rift basin, with Acrisols or Lixisols as dominant soil types. Weather data were obtained from nearby weather stations, with mean annual rainfall of about 2300, 2200, and $1400 \mathrm{~mm}$ for Cross River, Edo, and Benue respectively (Ukhurebor and Abiodun, 2018).

\subsubsection{Experiment design, crop establishment and management}

The selected treatments used in this study were part of a larger experiment, described earlier (Adiele et al. Chapter 1). Each experiment contained three blocks, with fertilizer treatments randomized within these blocks. Only three treatments with abundant NPK supply and comparable yields were included in this study, targeting yields of $90 \mathrm{t}$ fresh storage root yield $\mathrm{ha}^{-1} \mathrm{y}^{-1}$ (equivalent to $32 \mathrm{t} \mathrm{DM} \mathrm{ha}{ }^{-1}$, produced in a growing season of 12 months), based on the calibrated QUEFTS model (Ezui et al., 2016). The N, $\mathrm{P}, \mathrm{K}$, secondary and micronutrient rates for these selected treatments are provided in Table 3.1. The plot size was $10 \mathrm{~m}$ by $8 \mathrm{~m}$. Planting was done at the onset of rains each year, except at Benue in 2016, where planting was delayed due to search for an adequate location. Dates of planting were May 24, June 16 and August 16 in 2016 and May 12, June 3 and June 15, in 2017 for Edo, Cross River and Benue respectively. Stem cuttings of $25 \mathrm{~cm}$ long from cassava cv. TME 419 were planted at a distance of 1.0 $\mathrm{m}$ by $0.8 \mathrm{~m}$, resulting in the recommended planting density of 12,500 plants per hectare. The selected TME 419 cultivar has high storage root dry matter and starch contents, and is characterised by erect stems with minimal branching, which facilitates intercropping as well as higher planting densities (EkeOkoro and Njoku, 2012; Ezui, 2017). Phosphorus (P) was applied by placement at planting, while nitrogen $(\mathrm{N})$ and potassium $(\mathrm{K})$ were also placed near the roots in three splits at 1, 2.5, and 3.5 months after planting (MAP). The secondary and micronutrients were applied at 2.5 MAP. The N, P and K fertilizers used were urea, triple super phosphate (TSP) and muriate of potash (MOP). The experimental plots were weeded regularly, especially before each fertilizer application and light interception measurements. 
Table 3.1. Nutrient application rates per treatment, (f) represents full rate of the nutrient $(\mathrm{N}=300, \mathrm{P}=$ 100 and $\mathrm{K}=300 \mathrm{~kg} \mathrm{ha}^{-1}$ ), $\mathrm{K} 240$ the $\mathrm{K}$ rate of $240 \mathrm{~kg} \mathrm{ha}^{-1}$. Secondary and micronutrients (MN) S, Ca, $\mathrm{Mg}, \mathrm{Zn}$, and $\mathrm{B}$ were applied at the rates of $16.6-10-10-5$ and $2.5 \mathrm{~kg} \mathrm{ha}^{-1}$, respectively.

\begin{tabular}{llllll}
\hline & Treatment & Nitrogen & $\begin{array}{l}\text { Phosphorus } \\
\left(\mathrm{kg} \mathrm{ha}^{-1}\right)\end{array}$ & Potassium & $\begin{array}{l}\text { Secondary and Micro } \\
\text { nutrients }\end{array}$ \\
\hline 1. & NfPfK240 & 300 & 100 & 240 & None \\
2. & NfPfKf & 300 & 100 & 300 & None \\
3. & NfPfKfMN & 300 & 100 & 300 & Included \\
\hline
\end{tabular}

\subsubsection{Soil sampling, rooting depth and plant available water (PAW)}

Composite soil samples were collected before land preparation from five points in a "W" pattern from $0-30 \mathrm{~cm}$ depth in each plot and bulked together. The samples were air-dried and sieved through a 2 $\mathrm{mm}$ mesh sieve. The hydrometer method was used to determine the particle size. In order to measure cassava rooting depth, several soil pits were dug in the middle of the plots where the intermediate harvests were carried out at 4 and $8 \mathrm{MAP}$ in Edo and Benue, without tampering with the net plots for final harvest. Cassava roots were easily identified and differentiated from other roots as they were creamy-yellowish and when cut secrete a cloudy-whitish latex. The depth at which the deepest cassava roots were found was recorded for two locations (Edo and Benue). The soil pits were filled up again immediately after measurement. For PAW, soil samples were taken from different layers using soil core rings and from different locations within the fields, in order to account for spatial heterogeneity and heterogeneity in soil depths. The samples were taken at 0, 20, 40, 80, 120 and $160 \mathrm{~cm}$ depth. Actual saturation (SAT), field capacity (FC), wilting point (WP) and air dry (AD) soil moisture content were determined from these samples and measurements averaged to obtain one parameter for the whole profile (van den Beuken, 2018). PAW was determined by subtracting soil water content at wilting point from field capacity (PAW = FC-WP). Pedotransfer functions (PTF's) were selected to determine WP soil moisture content based on texture, bulk density and/or SAT percentage. Soil classification and climate types were compared to the ones used to derive the PTF to check fitness and the PTF which predicted the observed FC soil moisture content best was chosen as a predictor for WP soil moisture content (van den Beuken, 2018). The AD soil moisture content was assumed to be $1 / 3$ of the WP soil moisture content (Penning de Vries, 1989). The rooting depth and soil moisture content measurements were not done at Cross River due to insecurity in the field location area when this study was done. However, the experiment fields in Cross River had similar soil type and properties with experiment fields in Edo. Soil samples were processed and textural analysis done at the IITA laboratory, Ibadan, Nigeria.

\subsubsection{Yield assessment}

Plant establishment was counted at $1 \mathrm{MAP}$ and all missing cassava stands were replaced to ensure good plant stands $(>90 \%)$. Non-destructive morphological assessments, including canopy dimensions (width, length and depth) were made on plants at 1, 2.5, 4, 6, and 8 MAP at Edo and up till 10 MAP at Benue. Beyond these stages, canopy dimension assessments were impossible due to the height of the plant. In each plot, light interception measurements were recorded at 1, 2.5, 4, 8, 10, 12 and 14 MAP. These measurements were done around solar noon (from about 11:00 to 14:00 hrs) with an AccuPAR LP-80 Ceptometer (Decagon Devices Inc. Pullman, Washington, USA). This equipment allows simultaneous measurement of photosynthetically active radiation (PAR) above and below the canopy. A tripod stand was placed on a level platform and readings below the canopy were taken at six different locations in 
each plot, at soil level, with the $80 \mathrm{~cm}$ probe positioned diagonally between two ridges. Average values of PAR above and below, zenith angle of the sun $(\theta)$ and the beam fraction $(\mathrm{fb})$ were measured directly by AccuPAR per plot with a default leaf angle distribution $(x)$ parameter value of 1 . Canopy dimension measurements were used to estimate the $x$ parameter and this was used to derive the light extinction coefficient ( $k$ ) and LAI of cassava (Veltkamp, 1985; Pellet and El-Sharkawy, 1997; Ezui et al., 2017b). The general value of $k$ was determined as a slope of simple linear regression of $L A I$ vs log transformed fraction of light intercepted, following (Zhou et al., 2016; Ezui et al., 2017b; Tripathi et al., 2018).

Harvests were done three times at all locations in both growing seasons, except at 4 MAP in Cross River 2017. Eight plants were harvested from a net area of $6.4 \mathrm{~m}^{2}$ per experimental plot at each harvest. First and second intermediate harvests were done at approximately 4 and 8 MAP. Final harvest for the first year planting took place on Aug 4, Aug 25 and Oct 6, 2017 in Edo, Cross River and Benue, respectively. Final harvest for the second year was on May 4, May 21 and June 15, 2018, in Cross River, Edo and Benue, respectively. At each harvest, fresh weight of leaves and petioles, lignified stems and storage roots of each plant were recorded separately, Sub-samples were oven dried at $60^{\circ} \mathrm{C}$ and dry matter yield was determined gravimetrically. Total biomass was calculated by summation of the all plant parts, including the fallen leaves. Cassava fine roots were not measured in this study.

\subsubsection{Parameter calculations for data analysis}

The daily fraction of light intercepted $(f L I)$ was calculated using the model in equation 1 .

$f L I=1-\frac{I_{t}}{I_{0}}$

Where $I_{t}$ is the measured photosynthetic active radiation (PAR) below the canopy and $I_{o}$ is the incident photosynthetic active radiation (PAR) above the canopy, both in $\mathrm{MJ} \mathrm{m}^{-2} \mathrm{~d}^{-1}$. Daily total radiation (DTR) was calculated from daily hours of sunshine measurements, from nearby weather stations, using the Angstrom-Prescott model (Bamiro, 1983).

$D T R=H_{0}\left(a+b *\left(\frac{n}{N}\right)\right)$

Where $H_{0}$ is the daily mean value of global radiation at the top of the atmosphere ( $\left.\mathrm{MJ} \mathrm{m}^{-2} \mathrm{~d}^{-1}\right), N$; the daily maximum sunshine duration (day length), $n$; the hours of bright sunshine and the ' $a$ ' and ' $b$ ' values are known as Angstrom constants. The Ångstrom constants were determined using the latitude of each field location. The intercepted PAR by the crop (IPAR) was calculated as the product of the fraction of light intercepted $(f L I)$ and $D T R$ and the fraction of photosynthetically active radiation $(f P A R)$, estimated

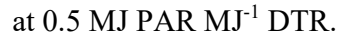

$$
I P A R=f L I * D T R * f P A R
$$

The light extinction coefficient $\left(k_{A P}\right)$ was calculated from each AccuPAR measurement assuming an ellipsoidal leaf angle distribution, following procedures of Campbell (1986) and Ezui et al. (2017b).

Canopy dimensions and AccuPAR measurements (light interception) were done concurrently. Derivation of $x, k_{A P}$ and $L A I$ values followed standard procedures (Eq. 3.A.1 - 3). Average leaf weight was determined from the total weight of leaves without petioles and the counted number of leaves at each harvest. These average leaf weights were then multiplied with the number of leaf scars to determine the weight of fallen leaves. Specific leaf area $(S L A)$ was calculated at each harvest as the ratio of estimated $L A I$ and measured green leaf weight, excluding petioles. Leaf petioles of cassava account for 20 to $30 \%$ of total leaf weight (El-Sharkawy, 2003). 
$S L A=\frac{L A I\left(m^{2} \text { leaf } m^{-2} \text { soil }\right)}{\text { Green leaf dry weight }\left(\mathrm{g} \mathrm{m}^{-2}\right)}$

Light interception was recorded at approximately $37,78,120,242,305,363$ and 415 days after planting (DAP) for both years in Benue and 40, 78, 120, 244, 318, 361 and 435 DAP in Edo. Measured values of $L I$ were interpolated and cumulative IPAR $\left(\mathrm{MJ} \mathrm{PAR} \mathrm{m}^{-2}\right)$ was estimated for each harvest, and plotted against the total biomass to determine the $R U E$ of cassava at non-water limited conditions, using only observed data from the Edo experiment in 2016. The fields at Edo experienced no drought effects as there was abundant and well distributed rainfall during the 2016 growing season (approx. $3000 \mathrm{~mm}$ ), with measured rooting depth of over $3.2 \mathrm{~m}$, ensuring sufficient soil moisture supply during the short dry season.

\subsubsection{New parameters and LINTUL-Cassava model}

The LINTUL-Cassava model was calibrated and tested for the cassava cultivar TME 419, which is a widely used variety in the region (Ezui et al., 2018). LINTUL-Cassava simulates cassava growth based on the RUE approach of Monteith (1977), with plant development governed by temperature sums and a descriptive definition of assimilate partitioning. The model uses a simple tipping bucket approach to describe plant-available water, enabling simulation of growth under rainfed conditions. The parameter set, as reported by Ezui et al. (2018) was calibrated with experimental data from the plots from Edo (with fertilizer addition at full rate) in 2016 where water did not limit growth. First, measured values of RUE and $k$ were used to set parameters values for potential conditions. Second, the description of assimilate partitioning (Fig. 3.A. a, b) was adjusted to match model calculations of $L A I$ with the observed patterns, using forcing functions of the measured $L I$. Accurate simulation of $L A I$ dynamics throughout the growing season of a crop, determines to a large extent the validity of any crop growth model (Gabriel et al., 2014). To test/evaluate the performance of the model, independent data from the other five experiments; Edo 2017, Benue and Cross River in 2016 and 2017 (Table 3.2) were used. These experiments received similar crop management, but differed in crop growth and development and experienced different degrees of water limitation.

Table 3.2. Locations used for calibration and evaluation of LINTUL-Cassava model

\begin{tabular}{lllll}
\hline & Agro-ecology & State/Location & Year & Calibration/evaluation \\
\hline 1 & Transition Rainforest & Edo/Ekpoma & 2016 & Calibration \\
2 & Transition Rainforest & Edo/Ekpoma & 2017 & Evaluation \\
3 & Tropical Rainforest & Cross River/Ogoja & 2016 & Evaluation \\
4 & Tropical Rainforest & Cross River/Ikom & 2017 & Evaluation \\
5 & Guinea Savanna & Benue/Otukpo & 2016 & Evaluation \\
6 & Guinea Savanna & Benue/Otukpo & 2017 & Evaluation \\
\hline
\end{tabular}

\subsubsection{Statistical analysis}

Daily $L A I$ and $f L I$ were obtained through linear interpolation of measured values. In order to obtain $L A I$ estimates up to the end of the season, measured $L I$ was used to estimate $L A I$ from the known relation between $L I$ and $L A I$ using $k$ of 0.67 , after Beer-Lambert law. Simple linear regression was used to estimate $R U E$ (g DM MJ ${ }^{-1}$ IPAR) for the whole cropping season (Sinclair and Muchow, 1999). The treatment effects on $L A I$, leaf angle distribution $(x)$, and light extinction coefficient $\left(k_{A P}\right)$ were analysed separately for each location and year, using a linear mixed model with the parameter as response variable and fertilizer treatment as explanatory factor, while blocks were considered random effects. Effects were 
analysed with a type-III ANOVA using Satterthwaite's approximation method. Differences between treatment means were considered significant when probability $\leq 0.05$. For analysis, $R$ version 3.5 with the lme4, lmerTest, and Predictmeans packages was used (R Core, 2019).

\subsection{Results}

\subsubsection{Soil characteristics, soil water content and plant available water (PAW)}

The soil type in Edo was characterised as a Nitisol with clear nitic properties, with a sandy loam topsoil and good drainage. Benue was characterised as an Acrisol, also with a sandy loam topsoil. Observed rooting depths of cassava were more than $3.2 \mathrm{~m}$ in Edo and about $1.6 \mathrm{~m}$ in Benue, where rooting was restricted by a dense clay layer. The SAT, FC, WP and AD soil water content in Edo and Benue are as shown in Table 3.3. PAW was on average $0.162\left(\mathrm{~m}^{3}\right.$ water $\mathrm{m}^{-3}$ soil $)$ in Edo and $0.252\left(\mathrm{~m}^{3}\right.$ water $\mathrm{m}^{-3}$ soil) in Benue. Soil water content for Cross River was assumed to be similar to that of Edo since both states shared similar soil types. Rainfall amounts received from planting to harvest at the experimental sites in 2016 were 3157, 3067 and 1747 mm for Edo, Cross River and Benue. In 2017, Edo, Cross River and Benue received lower amounts of 2357, 2141 and $1359 \mathrm{~mm}$ of rainfall. A more detailed experimental site description can be found in Adiele et al. (Chapter 1).

\subsubsection{Leaf area index (LAI), light extinction coefficient $\left(k_{A P}\right)$ and leaf angle distribution $(x)$}

The LAI differed only with time and location, but did not differ among treatments. In 2017, average maximum $L A I$ of 6.3 was attained at 122 DAP from NPK fertilized treatments in Edo. $L A I$ was already 3 at 65 DAP, and was maintained between 3.0 and 6.3 for a duration of 145 days before decreasing to 2.8 and subsequently 1.5 at 243 DAP. A similar trend was observed in 2016 (Table 3.4).

This decrease in $L A I$ occurred during the drier part of the season with the typical Harmattan winds. During the second phase of the growing season, which begins with the onset of rains (between 10 and 11 MAP), there was a strong leaf regrowth reaching almost initial $L A I$ peak values (Table 3.4). At Benue, in 2017, the highest LAI of 3.6 was measured at 122 DAP at the peak of vegetative period in this location and reduced to 0.9 during the dry season. The LAI increased again when the rains returned from 304 DAP (Table 3.4). In 2016, the LAI development was very slow due to drought and gradually increased with the return of rainfall (Table 3.4).

Table 3.3. Soil characteristics, rooting depth, and typical soil moisture contents when soils are saturated (SAT), at field capacity (FC), wilting point (WP) or air dry (AD).

\begin{tabular}{|c|c|c|c|}
\hline & \multicolumn{3}{|c|}{ Location } \\
\hline & Benue & Cross River & Edo \\
\hline Sand $(\%)$ & 60.2 & 65.0 & 83.0 \\
\hline Silt (\%) & 25.5 & 19.0 & 4.9 \\
\hline Clay $(\%)$ & 14.3 & 16.0 & 12.0 \\
\hline Max. rooting depth (m) & 1.6 & - & 3.2 \\
\hline \multicolumn{4}{|c|}{ Water contents $\left(\mathrm{m}^{3}\right.$ water $\mathrm{m}^{-3}$ soil $)$ at: } \\
\hline Saturation (SAT, pF 0.0) & 0.487 & $0.460^{*}$ & 0.460 \\
\hline Field capacity (FC, $\mathrm{pF}$ of 2.0 ) & 0.362 & $0.310^{*}$ & 0.310 \\
\hline Wilting point (WP, $\mathrm{pF}$ of 4.2 ) & 0.110 & $0.148 *$ & 0.148 \\
\hline Air dry (AD, pF of 5.5) & 0.037 & $0.049 *$ & 0.049 \\
\hline
\end{tabular}

*Assumed values on the basis of similarity in soil types between Cross River and Edo 
Table 3.4. Leaf area index (LAI) ( $\mathrm{m}^{2}$ leaf $\mathrm{m}^{-2}$ soil) of cassava over time in Edo and Benue for 2016 and 2017 growing periods. LAI differed only by locations and days after planting in each year.

\begin{tabular}{|c|c|c|c|c|c|c|c|c|c|c|c|c|c|c|}
\hline \multirow[b]{2}{*}{ DAP } & \multicolumn{7}{|c|}{$\begin{array}{l}\text { Edo, } \\
2016\end{array}$} & \multicolumn{7}{|c|}{$\begin{array}{c}\text { Benue, } \\
2016\end{array}$} \\
\hline & 40 & 78 & 120 & 244 & 318 & 361 & 435 & 30 & 76 & 122 & 304 & 335 & 363 & 415 \\
\hline NfPfK240 & 0.3 & 2.3 & 5.2 & 1.0 & 5.4 & 5.4 & 5.1 & 0.2 & 0.8 & 0.4 & 1.5 & 1.8 & 1.9 & 2.0 \\
\hline NfPfKf & 0.4 & 3.7 & 6.6 & 1.4 & 5.1 & 5.5 & 5.5 & 0.2 & 1.0 & 0.5 & 2.0 & 2.1 & 2.2 & 2.4 \\
\hline NfPfKfMN & 0.4 & 2.2 & 6.8 & 1.6 & 5.6 & 6.5 & 6.4 & 0.3 & 1.1 & 0.6 & 2.1 & 2.2 & 2.3 & 2.6 \\
\hline \multirow[t]{2}{*}{ Average } & $0.4^{\mathrm{e}}$ & $2.6^{\mathrm{c}}$ & $6.2^{\mathrm{a}}$ & $1.4^{\mathrm{d}}$ & $5.4^{\mathrm{b}}$ & $5.8^{\mathrm{ab}}$ & $5.7^{\mathrm{ab}}$ & $0.23^{\mathrm{e}}$ & $1.0^{\mathrm{c}}$ & $0.5^{\mathrm{d}}$ & $1.8^{\mathrm{b}}$ & $2.0^{\mathrm{ab}}$ & $2.1^{\mathrm{ab}}$ & $2.3^{\mathrm{a}}$ \\
\hline & \multicolumn{7}{|c|}{2017} & \multicolumn{7}{|c|}{2017} \\
\hline DAP & $\begin{array}{r}30 \\
--1\end{array}$ & 76 & 122 & 243 & 319 & 364 & & 74 & 122 & 243 & 304 & 364 & & \\
\hline NfPfK240 & 0.3 & 2.3 & 5.2 & 1.0 & 4.5 & 5.5 & & 2.1 & 2.6 & 0.6 & 1.1 & 2.0 & & \\
\hline NfPfKf & 0.3 & 3.7 & 6.7 & 1.4 & 5.1 & 5.6 & & 1.7 & 2.3 & 0.6 & 1.1 & 2.2 & & \\
\hline NfPfKfMN & 0.4 & 2.2 & 7.0 & 1.6 & 5.8 & 6.1 & & 2.5 & 3.6 & 0.9 & 1.1 & 2.5 & & \\
\hline Average & $0.3^{\mathrm{e}}$ & $2.7^{\mathrm{c}}$ & $6.3^{\mathrm{a}}$ & $1.3^{\mathrm{d}}$ & $5.1^{\mathrm{ab}}$ & $5.7^{\mathrm{a}}$ & & $2.1^{\mathrm{b}}$ & $2.8^{\mathrm{a}}$ & $0.7^{\mathrm{c}}$ & $1.1^{\mathrm{c}}$ & $2.2^{\mathrm{b}}$ & & \\
\hline
\end{tabular}

*Different letters indicate significant differences within each location. LSD (0.05)

As expected, values of $k_{A P}$ and $x$ at Edo and Benue were similar, $k_{A P}$ values appear to increase with increasing $x$ values. The values of $k_{A P}$ ranged from 0.5 to 0.8 (Table 3.A) and were similar among the treatments. The least values of $k_{A P}(0.5)$ were observed in Edo at $4 \mathrm{MAP}$, at the peak of vegetative period. A significant linear relationship $\left(\mathrm{R}^{2}=0.99\right)$ between $L A I$ and $-\ln (1-f L I)$ was found, with overall light extinction coefficient $(k)$ estimated at 0.67 (Fig. 3.1). The $x$ value of 1.0 obtained at the peak of vegetative period of cassava in Edo did not differ from Benue at same period (Table 3.B). The higher value 3.6 was obtained at early growth stage and later (after much leaf fall). 


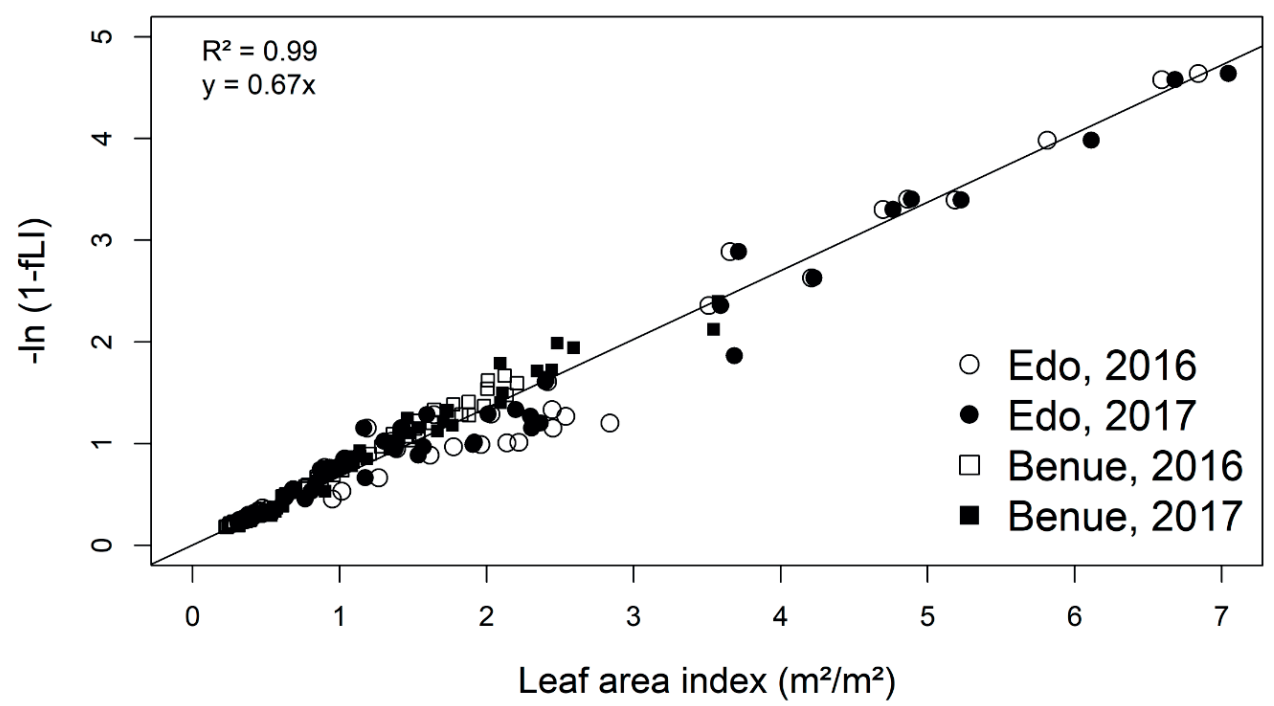

Fig. 3.1. Observed $k$, derived from the slope of linear regression of $L A I$ and - $\ln (1-\mathrm{fLI})$ of all treatments and locations in both growing years, 2016 and 2017.

\subsubsection{Fraction of light intercepted (fLI)}

In Edo 2016, cassava in the NfPfKf treatment intercepted approximately $78 \%$ of the incoming radiation as early as $78 \mathrm{DAP}$ and more than $90 \%$ at $120 \mathrm{DAP}$. The fraction of light intercepted gradually reduced to $70 \%$ during the Harmattan period at 237 DAP and increased again with the return of rains to more than $90 \%$ at 307 DAP (Fig. 3.2). In Benue 2016, only $50 \%$ of light was intercepted by cassava at 132 DAP in the NfPfKf plot, intercepted light reduced to $26 \%$ during the dry season and increased to $70 \%$ at 365 DAP. In 2017, a similar trend in light interception by treatments and locations was observed. The only difference was that light interception at Benue in 2017 at the early stage of the plant growth was larger than in 2016, due to earlier planting (Fig. 3.2). Average $f L I$ was $80 \%$ in Edo and much larger than $46 \%$ in Benue. 


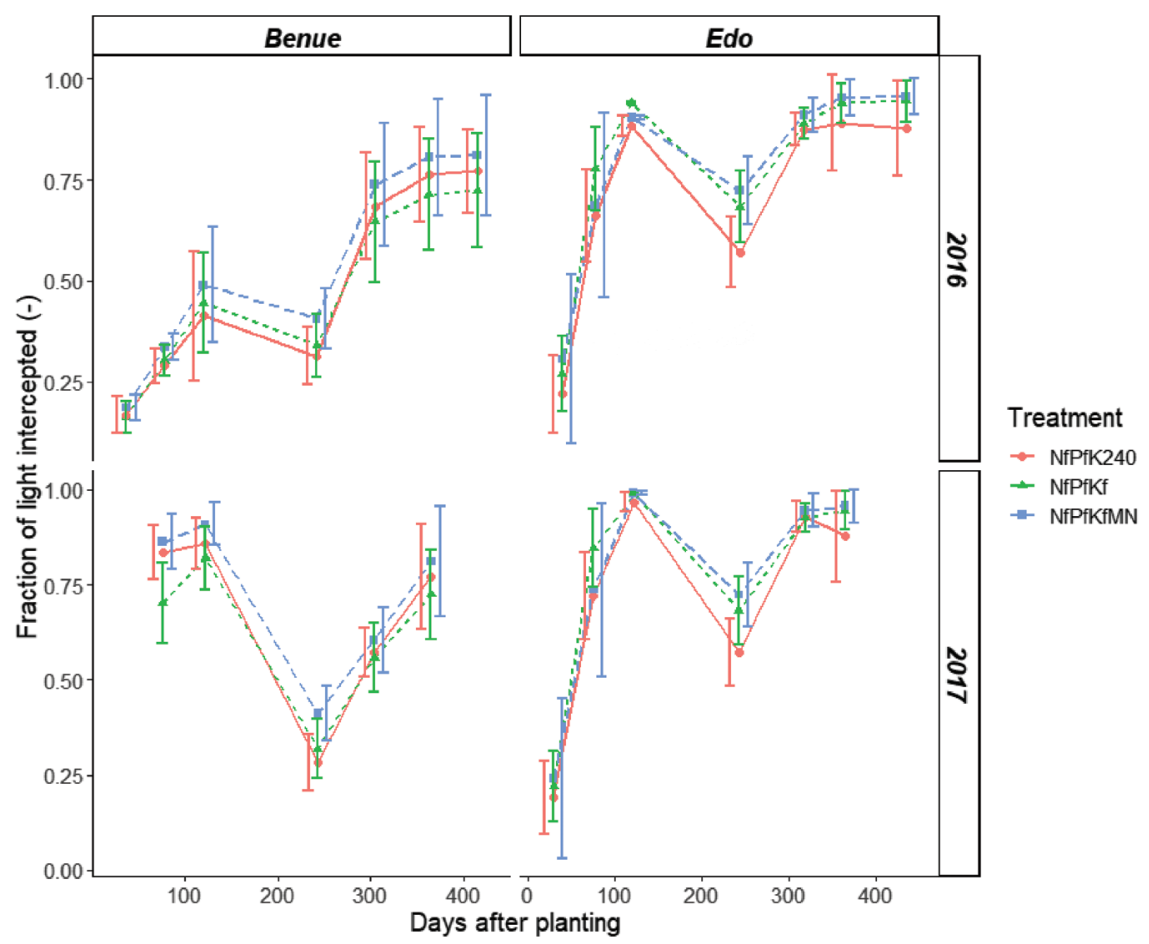

Fig. 3.2. Measured fraction of light intercepted across treatments and locations with error bars indicating one standard deviation in 2016 and 2017, showing similar trends at same periods during the growing season. Observations took place from 40 to 435 DAP in Edo 2016 and 30 to 365 DAP in Edo 2017. Observations at Benue in 2016 and 2017 took place from 37 to 415 DAP and 76 to 365 DAP, respectively. The growth duration for the experiments in 2016 growing season was longer than in 2017.

\subsubsection{Crop yield and radiation use efficiency (RUE)}

Total biomass differed significantly between Edo and Benue $(p<0.001)$ during both growing seasons (Table 3.5). Total biomass at final harvest in 2016 was 6849 and $4086 \mathrm{~g} \mathrm{~m}^{-2}$, and was 4597 and $1596 \mathrm{~g}$ $\mathrm{m}^{-2}$ in 2017 for Edo and Benue, respectively (Table 3.5). In 2016, storage root weights were 3931 and $2551 \mathrm{~g} \mathrm{~m}^{-2}$ and was 2233 and $1346 \mathrm{~g} \mathrm{~m}^{-2}$ for Edo and Benue in 2017, respectively. Also, amounts of leaves and stems at 4, 8 and 12 or 14 MAP were much larger at Edo than Benue (Table 3.5). In Edo 2016 and 2017, seasonal $R U E$ was $2.8 \mathrm{~g} \mathrm{DM} \mathrm{MJ}^{-1} \mathrm{IPAR}\left(R^{2}=0.98\right)$ (Fig. 3.3). In Benue, $R U E$ for the entire growing seasons of 2016 and 2017 were $2.1\left(R^{2}=0.95\right)$ and $1.3 \mathrm{~g} \mathrm{DM} \mathrm{MJ}^{-1} \mathrm{IPAR}\left(R^{2}=0.96\right)$, respectively. 


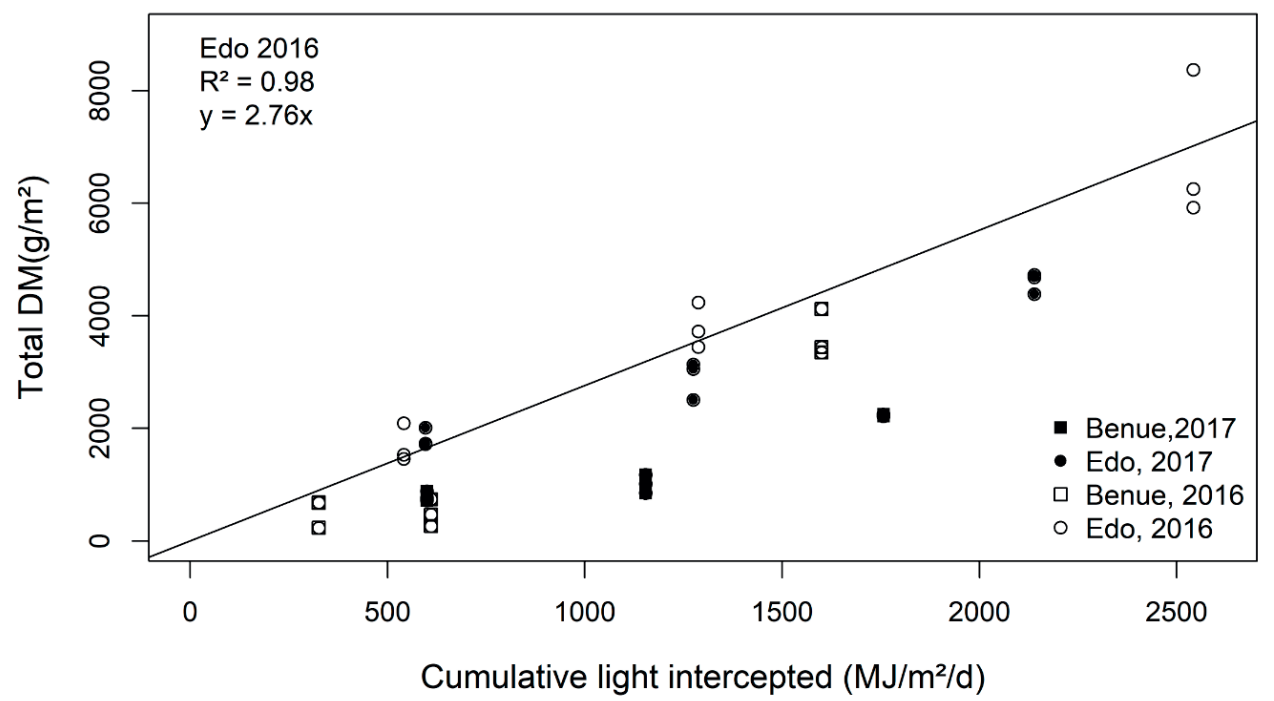

Fig. 3.3. Measured total biomass as a function of cumulative light intercepted in full treatments at Benue and Edo in 2016 and 2017 growing seasons. The slope of this relationship represents radiation use efficiency $(R U E)$. We consider that RUE at Edo 2016 represents a growing environment where water was not limiting.

The RUEs at different harvest periods varied greatly between the locations and years, with values consistently smaller at the second intermediate harvest (8 MAP), during the dry season in each location. The only exception was Edo 2016 second harvest (8 MAP), where the RUE was as high as $2.6 \mathrm{~g}$ DM $\mathrm{MJ}^{-1}$ IPAR (Table 3.5). Calculated specific leaf area ranged between 0.013 to 0.02 at Edo, and 0.012 to 0.04 at Benue during the growing seasons (Table 3.5). Specific leaf area of cassava decreased during the dry/Harmattan season and increased afterwards with the return of rainfall (Table 3.5).

\subsubsection{LINTUL-Cassava model}

The LINTUL-Cassava model with adjusted dry matter partitioning was able to describe the dynamics of leaf area index accurately throughout the growth period, especially leaf regrowth after leaf senescence that occurred in older plants during dry/Harmattan season (late December - March) (Fig. 3.A. a). Also, the amount of leaves, stems and storage roots DM $\left(\mathrm{g} \mathrm{m}^{-2}\right)$ and partitioning of assimilates under potential conditions (Fig. 3.A. b) were simulated reasonably well. The calibrated model was able to predict the observed DM leaves, stems and storage root yields for Edo 2017 under rain-fed conditions (Fig. 3.4), though with slight overestimation of storage root yield at harvest. The model simulated the water-limited yield well at Cross River and Benue, especially the end season stems and storage roots (Fig. 3.4). There was a slight overestimation of stems and storage root growth at mid-season under water limited conditions. In both years and all locations excluding Edo 2016, a significant linear relationship $\left(\mathrm{R}^{2}=\right.$ 0.92) was found between simulated and observed storage root yield at 4 MAP (vegetative period), 8 MAP (mid-season) and harvest (Fig. 3.5). Also, partitioning of DM to different plant parts simulated by the model was similar to that observed (Table 3.6). 
Table 3.5. Radiation use efficiency $(R U E)$ at different harvest periods, total biomass, cumulative light intercepted $(I P A R)$ and Specific leaf area (SLA) during 2016 and 2017 growing seasons at Benue and Edo

\begin{tabular}{|c|c|c|c|c|}
\hline $\begin{array}{l}\text { Months after } \\
\text { planting }\end{array}$ & Total biomass $\left(\mathrm{g} \mathrm{m}^{-2}\right)$ & $\operatorname{IPAR}\left(\mathrm{MJ} \mathrm{m}^{-2} \mathrm{~d}^{-1}\right)$ & $\begin{array}{l}\text { RUE (g DM } \\
\text { MJ }^{-1} \text { IPAR) }\end{array}$ & $\operatorname{SLA}\left(\mathrm{m}^{2} \mathrm{~g}^{-1}\right)$ \\
\hline & & & Edo, 2016 & \\
\hline 4 & $1694 \pm 346$ & 541 & 3.1 & 0.02 \\
\hline 8 & $3666 \pm 129$ & 1288 & 2.6 & 0.01 \\
\hline \multirow[t]{2}{*}{14} & $6849 \pm 1241$ & 2542 & 2.5 & 0.02 \\
\hline & & & Edo, 2017 & \\
\hline 4 & $1885 \pm 347$ & 596 & 3.1 & 0.02 \\
\hline 8 & $2828 \pm 364$ & 1274 & 1.6 & 0.01 \\
\hline \multirow[t]{2}{*}{12} & $4597 \pm 186$ & 2139 & 2.0 & 0.02 \\
\hline & & & Benue, 2016 & \\
\hline 4 & $344 \pm 19$ & 326 & 1.6 & 0.02 \\
\hline 8 & $437.2 \pm 96$ & 610 & 0.2 & 0.03 \\
\hline \multirow[t]{2}{*}{14} & $4085.8 \pm 1547$ & 1600 & 3.2 & 0.03 \\
\hline & & & Benue, 2017 & \\
\hline 4 & $786.1 \pm 84$ & 600 & 1.3 & 0.03 \\
\hline 8 & $1018.6 \pm 839$ & 1154 & 0.4 & 0.02 \\
\hline 12 & $1596.1 \pm 1100$ & 1757 & 1.4 & 0.02 \\
\hline
\end{tabular}



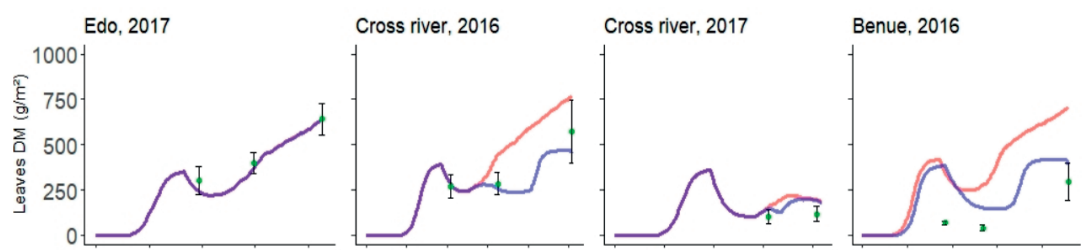

Benue, 2017
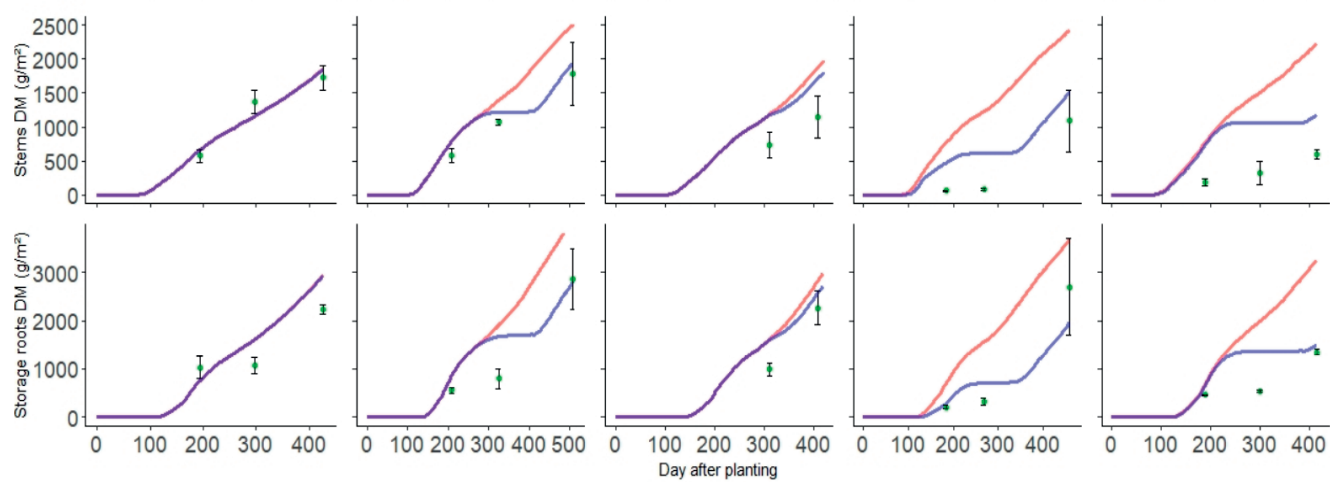

- Potential $=$ Water limited

- Observation:

Fig. 3.4. Observed and simulated leaves, stems, and storage root yield DM ( $\left.\mathrm{g} \mathrm{m}^{-2}\right)$ under water limited conditions from Edo in 2017, Cross River and Benue in both years. Error bars of the observed means are one standard deviation of the mean.

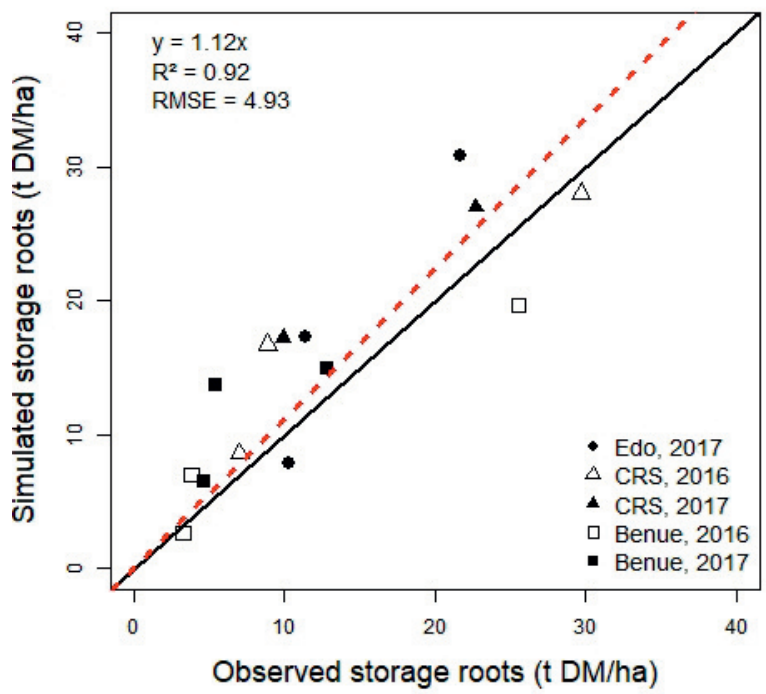

Fig. 3.5. Observed and simulated storage roots from Edo in 2017, Cross River, and Benue in 2016 and 2017. At 4 MAP (vegetative period), 8 MAP (mid-season) and harvest. The solid line is the 1:1 line, while the red dashed line is the best fit regression without intercept which has a slope of 1.12. 
Table 3.6. Dry matter partitioning to whole leaves (WLV), green leaves (WLVG), dead leaves (WLVD), stems (WST), storage roots (WSO), total Biomass $\left(\mathrm{g} \mathrm{m}^{-2}\right)$. Observed and simulated at different development stages. $\mathrm{H} 1, \mathrm{H} 2$, and $\mathrm{H} 3$ represent harvest at approx. 4,8 , and 14 MAP

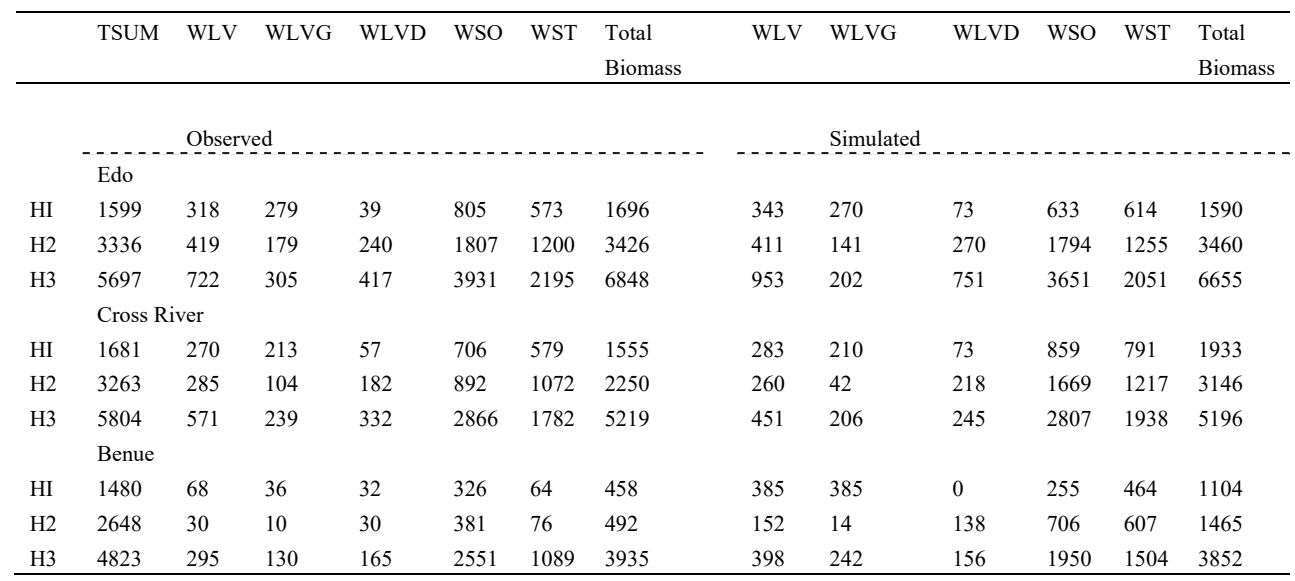

\subsection{Discussion}

\subsubsection{Cassava (almost) achieved potential growth and yield at Edo}

A yield in Edo of $39 \pm 7 \mathrm{t} \mathrm{DM} \mathrm{ha}^{-1}\left(>100 \mathrm{tha}^{-1}\right.$ fresh root) was achieved where large balanced doses of nutrients had been supplied and water did not appear to limit production. Cassava has the ability to root deeply (Lal and Maurya, 1982; El-Sharkawy et al., 1992), and cassava roots reached over $3.2 \mathrm{~m}$ depth in Edo which was why drought did not appear to constrain crop growth even during the short dry season. The soil moisture content at wilting point varied between 0.105 and $0.170 \mathrm{~m}^{3}$ water $\mathrm{m}^{-3}$ soil. Plant available water varied between 0.135 to $0.179 \mathrm{~m}^{3}$ water $\mathrm{m}^{-3}$ soil and is larger than what was reported from similar soil types in Kabete, Nairobi $\left(0.03\right.$ to $0.15 \mathrm{~m}^{3}$ water $\mathrm{m}^{-3}$ soil) and Santa Catarina, Brazil ( 0.08 to $0.12 \mathrm{~m}^{3}$ water $\mathrm{m}^{-3}$ soil) (Karuku et al., 2012; Costa et al., 2013). Knowledge of plant available water helps to determine the agricultural potential of soils (Dekker, 2003). Though the soil in Edo was infertile in terms of nutrients, it was highly suitable for cropping, as the porosity of the soils permits deep rooting. Soil moisture content was lower at Benue than Edo. The limited rooting depths observed in Benue were likely caused by subsoil constraints due to a high bulk density of the soil at $1.6 \mathrm{~m}$ depth (van den Beuken, 2018).

\subsubsection{Estimating light interception}

The values of the measured light extinction coefficient $\left(k_{A P}\right)$ ranged from 0.5 to 0.8 with changing leaf angles (Campbell, 1986), and were similar among the treatments and locations (Table 3. A and B). This is expected as light extinction coefficient values of cassava are varietal specific (Pellet and El-Sharkawy, 1997). At Edo, the lowest $k_{A P}$ and $x$ values of 0.5 and 1.0 were obtained at peak vegetative stage when the $L A I$ was 6.7 and this would have allowed deeper penetration of light. Though Veltkamp (1985) suggested that cultivars with vertically orientated leaves should have a higher yielding ability than cultivars with more horizontally oriented leaves, Cock et al. (1979) found that there was little, if any advantage of a more vertical leaf orientation for clones that had $L A I$ up to 4 . Therefore, vertically oriented leaves show a clear advantage only in crops with high $L A I$ values of 6 and more. In this study, 
the value of the seasonal light extinction coefficient $(k)$ was 0.67 (Fig. 3.1). The $S L A$ (leaf thickness) influences canopy expansion through its effect on total leaf area per plant, thereby affecting light interception and radiation use efficiency (Kumar et al., 2012). We observed fairly consistent reduction of $S L A$ at mid-stage of crop growth, which coincided with the dry/Harmattan period. In the relatively dry period of the year when these typical Harmattan winds occur, plant growth is reduced and leaves fall from plants including deciduous trees. The decreased $S L A$ may have resulted from reduction in leaf area expansion and reallocation of extra assimilates to already thick leaves, resulting in increased leaf mass with reduced $S L A$ values. Previous studies at Redland bay, Australia, recorded SLA values in cassava between 0.022 and $0.028 \mathrm{~m}^{2} \mathrm{~g}^{-1}$ (Fukai et al., 1984), which are comparable to measured SLA values in this study. The leaf angle distribution $(x)$ is a very important crop specific parameter required to estimate $L A I$ directly in the field using a ceptometer. The assumption that $x$ equates one for ceptometer reading (Devices, 2014), was also reasonable for cassava at least around full field cover. The use of ceptometer for $L A I$ measurements directly in the field saves labour, time and cost.

In this study, the cassava developed vigorously and provided early and rapid canopy cover, which intercepted more light needed for optimum growth and development. Also, due to the presence of many green leaves, effects of leaf shedding was reduced and optimum levels of $L A I$ and $f L I$ were maintained for a long period. On average, $L A I$ of 3 and $80 \% f L I$ were maintained throughout the growing season at Edo. This is the highest recorded season average light intercepted for cassava - well above the $52.3-$ $64.1 \%$ obtained from different high yielding cultivars in Colombia (De Souza et al., 2017). Light interception fluctuated throughout the season across locations but did not fall below $60 \%$ at the peak of the dry season at Edo (Fig. 3.2). At Benue, $L A I$ and light intercepted were much less than in Edo and differed between the two years due to time of planting, soil types and weather conditions. Our results corroborate the findings of De Souza et al. (2017), that increasing the season-long intercepted light towards the theoretical maximum $(100 \%)$ can give a large increase in cassava yield.

\subsubsection{Radiation use efficiency}

Radiation use efficiency values of cassava in SSA are sparsely documented. We observed a positive and strong linear relationship between the cumulative amount of photosynthetically active radiation and total biomass, which is consistent with other previous studies (Veltkamp, 1985; Pellet and El-Sharkawy, 1997; Sinclair and Muchow, 1999; Ezui et al., 2017b). The crop intercepted more radiation and produced more biomass at Edo than other locations with seasonal $R U E$ of $2.8 \mathrm{~g} \mathrm{DM} \mathrm{MJ}^{-1}$ IPAR. This is the largest $R U E$ value for cassava reported to date. It was obtained under near-optimal conditions for high yields, with ample N, P and $\mathrm{K}$ and sufficient soil water supply throughout the growing season. The obtained high $R U E$ is comparable to $R U E$ values of potatoes with good management (Sinclair and Muchow, 1999; Rezig et al., 2013; Zhou et al., 2016). Values of $R U E$ at 8 MAP, which coincided with the peak of dry season throughout this study, and $R U E$ values from Benue were similar to other reported values of 0.69 to $1.6 \mathrm{~g} \mathrm{DM} \mathrm{MJ}^{-1}$ IPAR (Pellet and El-Sharkawy, 1997; Ezui et al., 2017b). In Benue 2016, planting was done late in the season, thereby exposing the young plants to drought (from 2.5 MAP) resulting in lower $R U E$ compared with the other sites. Nevertheless, $R U E$ in Benue increased strongly after the dry period and the yield at harvest was $26 \mathrm{t} \mathrm{DM} \mathrm{ha}^{-1}$. This could be due to that newly expanded leaves of previously stressed cassava exhibit higher photosynthetic capacity rates when drought stress is alleviated, resulting in good yields (El-Sharkawy, 2007; Rosenthal and Ort, 2012). Final harvest in Benue 2016 was done at 14 MAP in 2016, when the crops were fully recovered from drought effects. Observed differences in $R U E$ were due to differences in soil water availability and rooting conditions. The highest $R U E$ values ( $\left.3.1 \mathrm{~g} \mathrm{DM} \mathrm{MJ}^{-1} \mathrm{IPAR}\right)$ occurred at peak vegetative stage in Edo. 


\subsubsection{Simulating cassava growth and yields using LINTUL-Cassava}

After parameterization and calibration of DM partitioning, the LINTUL-Cassava model was able to describe the observed patterns of $L A I$ and growth of leaves, stems and storage roots (Fig. 3.A. a, b). There was good agreement between measured and simulated dry matter production in Edo, under nonwater limited conditions (Fig. 3.B). LINTUL-Cassava slightly overestimated mid-season DM yield of storage roots under water-limited conditions at Cross River and Benue (Fig. 3.4). During this stage the crop growth rate in the field was significantly less than earlier in the season. Cassava reduced its canopy during the dry/Harmattan season by shedding older leaves and this resulted in less light interception. Cassava leaf stomata are sensitive and respond rapidly to changes in water status of the plant and atmosphere (Alves, 2002) and close when the vapour pressure deficit of the air increases, even without changes in the leaf water potential (El-Sharkawy, 2003). The stomatal closure decreases photosynthetic $\mathrm{CO}_{2}$ assimilation and subsequently growth. At Benue, the overestimation was exacerbated by shallow soil with high bulk density inhibiting deeper root growth and increasing drought induced nutrient deficiency. Though storage root yield reduced at mid-season under water limited conditions, the crop recovered when rainfall resumed. Thereby, compensating for yield losses with final yields approaching those at non-water limited conditions (Fig. 3.4). Nevertheless, storage root yield at the end of the growing periods under both no water limitation (Edo 2017) and water limited conditions (Cross River and Benue) was simulated reasonably well with yield differences of $9.3 \mathrm{t} \mathrm{DM} \mathrm{ha}^{-1}$ between observed and simulated non-water limited yield in Edo, 1.6 and $4.3 \mathrm{t} \mathrm{DM} \mathrm{ha}^{-1}$ for Cross River and 5.8 and $2.1 \mathrm{t}$ $\mathrm{DM}_{\text {ha }}{ }^{-1}$ for Benue in 2016 and 2017, respectively.

The use of a seasonal average $R U E$ to calculate cassava production, whereas in reality the $R U E$ varies considerably during the growing season, is the likely cause of over-estimation of yield during the dry (or Harmattan) season. This bias could be avoided by simulating the production on the basis of actual $R U E$ obtained at each stage. However, LINTUL is a simple model that describes crop growth on the basis of light interception and utilization, and incorporates only those processes that affect major determinants of growth (Spitters and Schapendonk, 1990). Dynamics of RUE are not considered, resulting in some mismatch which is compensated at harvest. Other, more detailed models exist that simulate cassava growth and yield (Matthews and Hunt, 1994; Gabriel et al., 2014). These modelling approaches differ from LINTUL-Cassava; leaf appearance rates are modelled explicitly and assimilates that are not needed for shoot growth are translocated to both fibrous and storage roots. This is referred as a "spill over" approach. Other more detailed models, e.g. SUCROS, describe growth from daily photosynthesis and respiration. Spitters (1989) illustrates that the use of constant or seasonal average $R U E$ is a valid simplification when simulating crop growth throughout the season, but not valid when the interest is to simulate daily growth rates. Further, the choice of model depends on the aims of the study; either to predict expected effects in future scenarios or acquire insights on how crops grow depending on the environmental conditions and treatments applied (Donatelli et al., 2002; van Ittersum et al., 2003). Simple models such as LINTUL have the advantage of requiring only few parameters (Spitters, 1989). Most importantly, the $L A I$ (which is one of the most essential variables in crop growth models: (Dzotsi et al., 2013; Gabriel et al., 2014), was simulated well by LINTUL-Cassava. Thus LINTUL-Cassava was able to describe cassava growth and yield in SSA, especially at maturity using a simple and reproducible approach.

\subsection{Conclusion}

Cassava yields and the measured season average $R U E$ values of $2.8 \mathrm{~g} \mathrm{DM} \mathrm{MJ}^{-1}$ IPAR and $80 \%$ light intercepted were much larger than reported earlier for cassava. LINTUL-Cassava was able to simulate DM yields reasonably well under both non-water limited and water limited conditions. These results improve our understanding of cassava yield potential in SSA, indicating that cassava yields more than $35 \mathrm{tDM} \mathrm{ha}^{-1}$ are possible (equivalent to $97 \mathrm{t} \mathrm{ha}^{-1}$ of fresh storage root) which are much larger than earlier 
reported in Africa. Overall, the simple and robust LINTUL-Cassava model can effectively estimate the storage root yield at the end of the growing season under rainfed conditions, using tabulated partitioning values. The LINTUL-Cassava model may be used to improve crop management, yield gap assessments and breeding research for standard planting times. It is essential to test the model for other locations with other climatic conditions and crop planting times.

\section{Acknowledgements}

We thank the Netherlands Fellowship Program (NUFFIC) and the African Cassava Agronomy Initiative (ACAI) of IITA for funding. Also, we thank A. Olojede and C. Ifenkwe for supporting data collection.

\subsection{Appendices}

3.A Calculating light extinction coefficient and LAI from Accupar measurement and leaf angle distribution

\section{light extinction coefficient:}

$$
k_{A P}=\frac{\sqrt{x^{2}+\tan \theta^{2}}}{x+1.744(x+1.182)^{-0.733}}
$$

The zenith angle of the sun $(\theta)$ was measured by AccuPAR directly, $x=$ leaf angle distribution parameter calculated from cassava canopy dimension measurement as:

\section{Leaf angle distribution:}

$x=\frac{C W 1+C W 2}{2 * C T}$

Where CW1 and CW2 $(\mathrm{cm})$ are the longest and the shortest horizontal width of the canopy; CT $(\mathrm{cm})$ is the vertical thickness of the canopy. The measurements on canopy dimensions and photosynthetically active radiation were done same day. With the derivation of $x$ and $k_{A P}$ values, LAI was determined using Eq. (A3).

\section{Leaf area index:}

$L A I=\frac{\left[\left(1-\frac{1}{2 * k_{A P}}\right) f b-1\right] \ln (\tau)}{A(1-0.47 f b)}$

$f b=$ beam fraction of the incident radiation, $\tau=\frac{P A R \text { below canopy }}{P A R \text { above canopy }}$. Values of $f b$ and $\tau$ were directly measured using the AccuPAR. $A$ is a term for primary and secondary canopy absorption that is empirically related to the leaf absorptivity in the PAR band: $A=0.283+0.785 a-0.159 a^{2}$. The value used for leaf absorptivity was 0.85 (Ezui et al., 2017b). 
Table 3.A. Apparent light extinction coefficient ( $\mathrm{k}_{\mathrm{AP}}$ ) of cassava over time in Edo and Benue for 2016 and 2017 growing periods. ANOVA between treatment and DAP across locations.

\begin{tabular}{|c|c|c|c|c|c|c|c|c|c|}
\hline & Edo & 2016 & & & Benue & 2016 & & & \\
\hline DAP & 40 & 78 & 120 & 244 & 30 & 76 & 122 & 304 & 335 \\
\hline NfPfK240 & 0.8 & 0.4 & 0.5 & 0.8 & 0.8 & 0.8 & 0.7 & 0.8 & 0.7 \\
\hline NfPfKf & 0.8 & 0.5 & 0.5 & 0.8 & 0.8 & 0.7 & 0.7 & 0.8 & 0.7 \\
\hline NfPfKfMN & 0.8 & 0.4 & 0.6 & 0.8 & 0.9 & 0.8 & 0.7 & 0.8 & 0.7 \\
\hline \multirow[t]{3}{*}{$\operatorname{LSD}(0.05)$} & $\mathrm{ns}$ & $\mathrm{ns}$ & $\mathrm{ns}$ & $\mathrm{ns}$ & $\mathrm{ns}$ & $\mathrm{ns}$ & $\mathrm{ns}$ & $\mathrm{ns}$ & $\mathrm{ns}$ \\
\hline & & 2017 & & & & 2017 & & & \\
\hline & 30 & 76 & 122 & 243 & 74 & 122 & 243 & 304 & \\
\hline NfPfK240 & 0.8 & 0.5 & 0.5 & 0.8 & 0.7 & 0.7 & 0.6 & 0.8 & \\
\hline NfPfKf & 0.8 & 0.5 & 0.5 & 0.8 & 0.7 & 0.7 & 0.6 & 0.8 & \\
\hline NfPfKfMN & 0.8 & 0.5 & 0.5 & 0.8 & 0.7 & 0.7 & 0.6 & 0.8 & \\
\hline $\operatorname{LSD}(0.05)$ & ns & $\mathrm{ns}$ & ns & ns & $\mathrm{ns}$ & $\mathrm{ns}$ & ns & ns & \\
\hline
\end{tabular}

Table 3.B. Measured values of the " $x$ " variable to describe the leaf angle distribution of cassava over time in Edo and Benue for 2016 and 2017 growing periods.

\begin{tabular}{|c|c|c|c|c|c|c|c|c|c|}
\hline & Edo & 2016 & & & Benue & 2016 & & & \\
\hline DAP & 40 & 78 & 120 & 244 & 30 & 76 & 122 & 304 & 335 \\
\hline NfPfK240 & 3.0 & 0.8 & 1.0 & 2.4 & 3.6 & 1.7 & 1.6 & 2.3 & 1.7 \\
\hline NfPfKf & 2.5 & 0.8 & 1.0 & 2.6 & 2.9 & 1.6 & 1.5 & 2.4 & 1.6 \\
\hline NfPfKfMN & 2.9 & 0.7 & 1.0 & 2.4 & 3.4 & 1.8 & 1.4 & 2.3 & 1.6 \\
\hline \multirow[t]{3}{*}{$\operatorname{LSD}(0.05)$} & ns & $\mathrm{ns}$ & $\mathrm{ns}$ & $\mathrm{ns}$ & $\mathrm{ns}$ & ns & ns & ns & ns \\
\hline & & 2017 & & & & 2017 & & & \\
\hline & 30 & 76 & 122 & 243 & 74 & 122 & 243 & 304 & \\
\hline NfPfK240 & 2.3 & 0.9 & 1.0 & 2.8 & 1.6 & 1.0 & 1.2 & 2.8 & \\
\hline NfPfKf & 2.6 & 0.9 & 1.0 & 2.5 & 1.7 & 1.2 & 1.2 & 2.7 & \\
\hline NfPfKfMN & 2.4 & 1.0 & 1.0 & 3.1 & 1.7 & 1.1 & 1.1 & 2.7 & \\
\hline $\operatorname{LSD}(0.05)$ & ns & ns & ns & ns & ns & ns & ns & ns & \\
\hline
\end{tabular}



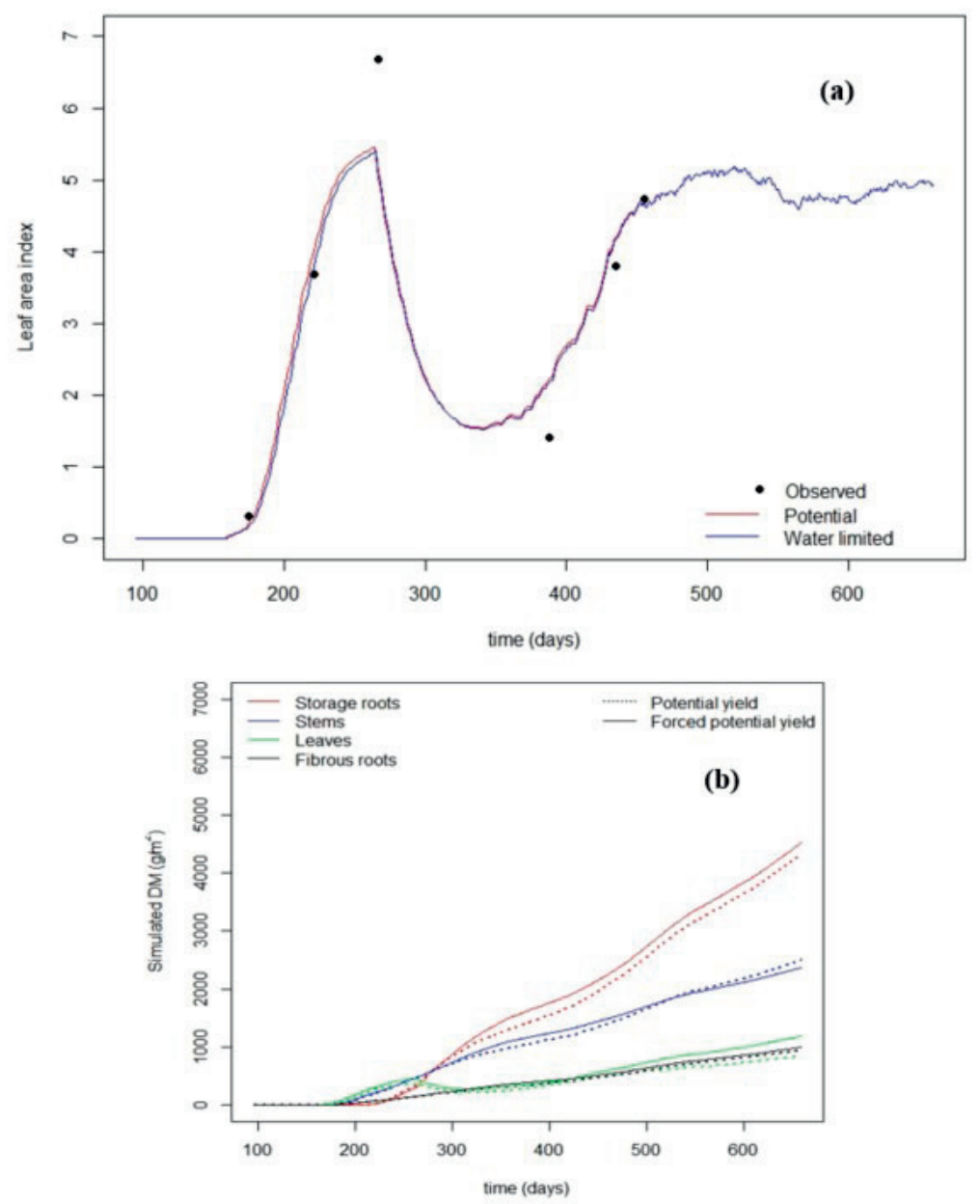

Fig. 3.A. (a) simulated and observed leaf area index (LAI) and (b) simulated DM potential yield of different cassava parts (g $\mathrm{m}^{-2}$ ) at Edo in 2016 by LINTUL-Cassava (broken lines) and LINTUL-Cassava Forced LI (solid lines) models. Time after planting to harvest is between 145 to 582 days. Model simulation time was set at 95 DOY (50 days before planting). 

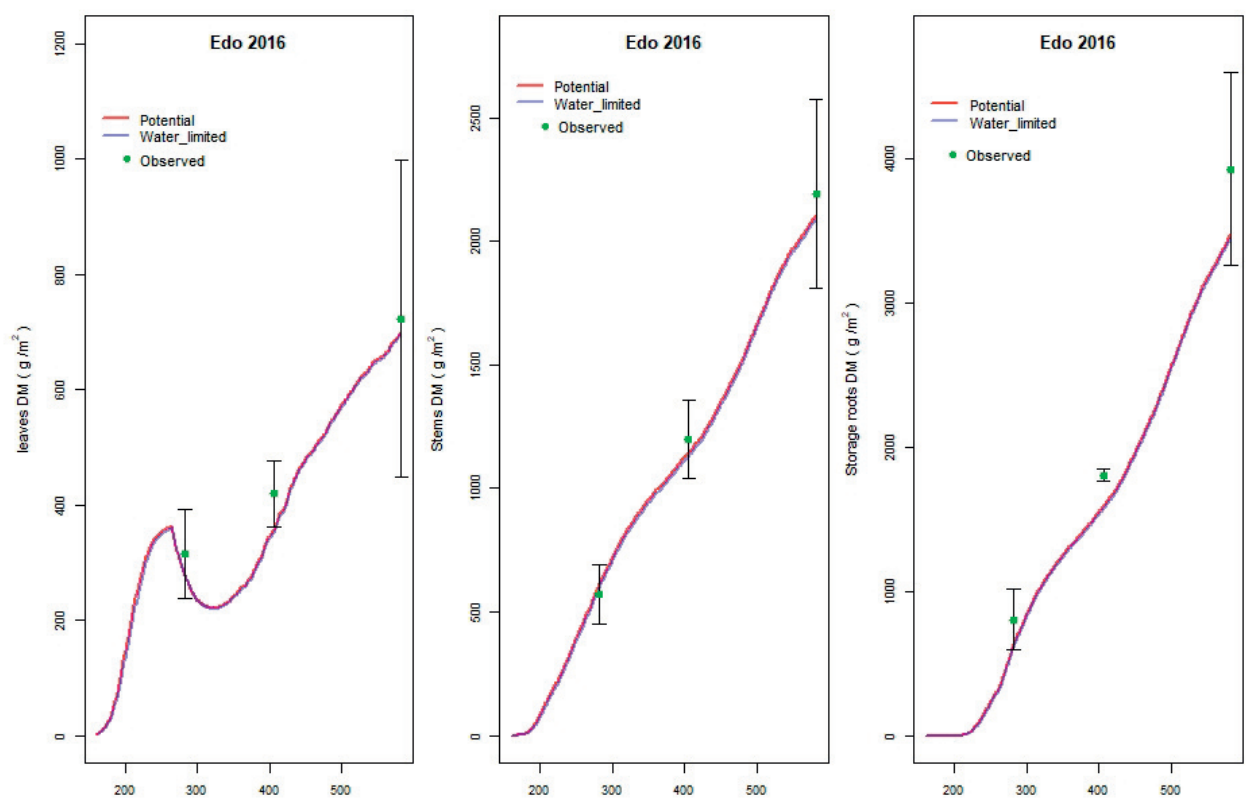

Fig. 3.B. Observed and simulated storage root, stems, and leaves DM ( $\mathrm{g} \mathrm{m}$ ) undęr potential conditions in Edo 2016.

Error bars of the observed mean are one standard deviation of the mean.

Table 3.C. Dry matter partitioning in fibrous roots, stems, leaves and storage roots, based on measured data from Edo, 2016 where water was not limiting, at early development stages and different measuring points.

\begin{tabular}{|c|c|c|c|c|c|c|}
\hline $\begin{array}{l}\text { Development } \\
\text { stage/harvest }\end{array}$ & $\begin{array}{l}\text { Tsum } \\
\left({ }^{\circ} \mathrm{Cd}\right)\end{array}$ & frt & flv & fst & fso & Source \\
\hline Sprouting & 0 & 0.11 & 0.74 & 0.15 & 0.00 & Estimated, (Fukai and Hammer, 1987) \\
\hline $\begin{array}{l}\text { Start of storage } \\
\text { roots bulking }\end{array}$ & 188 & 0.11 & 0.73 & 0.17 & 0.00 & Estimated (Fukai and Hammer, 1987) \\
\hline $\begin{array}{l}4 \text { MAP, Edo } \\
2016\end{array}$ & 1413 & 0.01 & 0.23 & 0.29 & 0.47 & Measured \\
\hline $\begin{array}{l}8 \text { MAP, Edo } \\
2016\end{array}$ & 3166 & 0.01 & 0.13 & 0.38 & 0.47 & Measured \\
\hline $\begin{array}{l}14 \text { MAP, Edo } \\
2016\end{array}$ & 5522 & 0.01 & 0.13 & 0.30 & 0.57 & Measured \\
\hline \multicolumn{7}{|c|}{ Calibrated parameter } \\
\hline Parameters codes & Unit & $\begin{array}{l}\text { Default } \\
\text { value }\end{array}$ & $\begin{array}{l}\text { New } \\
\text { value }\end{array}$ & & & \\
\hline$R U E$ & $\begin{array}{l}\text { g DM } \\
M^{-1} \\
\text { IPAR }\end{array}$ & 1.5 & 2.8 & & & \\
\hline FASTRANSLSO & & 0.45 & 0.65 & & & \\
\hline
\end{tabular}





\section{Chapter 4. Dynamics of nutrient uptake, dilution and nutrition indices for cassava}

This chapter is submitted as:

Adiele, J.G., Schut, A.G.T., Ezui, K.S., Pypers, P., Giller, K.E.

Dynamics of nutrient uptake, dilution and nutrition indices for cassava. Submitted to Agronomy for Sustainable development. 


\begin{abstract}
The use of fertilizers to improve productivity of cassava will be required to meet the increasing demand for cassava as food, feed or raw material for processing industries. We quantified the nutrient uptake of cassava in response to fertilizer application and the proportions of $\mathrm{N}, \mathrm{P}$ and $\mathrm{K}$ in plant parts to derive $\mathrm{N}$, $\mathrm{P}$ and $\mathrm{K}$ dilution curves and nutrition indices for cassava. On-farm experiments were conducted at six locations in Nigeria across the major cassava growing agro-ecologies of West Africa (Tropical Rainforest - Cross River, Forest Transition Savanna - Edo, and Guinea Savanna - Benue) during two seasons (2016-2017 and 2017-2018). Nitrogen, P and K fertilizers were applied at varying rates to obtain both nutrient-limiting and non-limiting conditions. Uptake and concentrations of nutrients were measured in leaves, stems and storage roots at 4,8 and 12 or 14 months after planting (MAP). Dilution curves and nutrition indices for $\mathrm{N}, \mathrm{P}$ and $\mathrm{K}$ were determined. On average, 67,61 and $52 \%$ of total N, P and $\mathrm{K}$ was taken up at 4 months after planting (MAP), respectively. The maximum uptake rates for $\mathrm{N}$ and $\mathrm{P}\left(0.21\right.$ and $\left.0.03 \mathrm{~g} \mathrm{~m}^{-2} \mathrm{~d}^{-1}\right)$ were observed in Edo, while the maximum $\mathrm{K}$ uptake rate $\left(0.12 \mathrm{~g} \mathrm{~m}^{-2} \mathrm{~d}^{-}\right.$ $\left.{ }^{1}\right)$ occurred in Cross River at about 4 MAP. Average leaf N, P and K concentration (45.0, 3.0 and 10.4 $\left.\mathrm{g} \mathrm{kg}^{-1}\right)$ at 4 MAP decreased by $0.15,0.5$ and $0.35 \mathrm{~g} \mathrm{~kg}^{-1}$ at 8 MAP and increased almost to the initial value at final harvest. The variation of cassava leaf $\mathrm{N}, \mathrm{P}$ and $\mathrm{K}$ concentrations was small. Nutrient dilution curves for $\mathrm{N}, \mathrm{P}$ and $\mathrm{K}$ at different application rates were quantified for the first time in cassava, with obtained nutrient dilution coefficients higher than most other reported crops. Under non-nutrient limiting conditions, nutrient dilution curves of total $\mathrm{N}, \mathrm{P}$ and $\mathrm{K}$ in the crop were determined using a power function model, when total biomass was between 5 and $57 \mathrm{t} \mathrm{DM} \mathrm{ha}^{-1}$, while storage root yield varied from 3 to $35 \mathrm{t} \mathrm{DM} \mathrm{ha}^{-1}$, from 4 MAP to final harvest. Understanding the nutrient uptake and dilution pattern during the growth cycle can help to understand the temporal nutritional demands of cassava and to identify management practices to prevent nutrient deficiency as well as excess. Further, such information could be used to develop a dynamic model for cassava that simulates nutrient-limited growth. Our study provides insights in the dynamics of nutrient uptake and uptake rates, N, P and K dilution curves and nutrition indices for cassava under West African conditions.
\end{abstract}

Keywords: Relative biomass; nutrient uptakes; concentrations; cassava plant parts; dilution coefficients 


\subsection{Introduction}

Cassava (Manihot esculenta Crantz) is an important food crop in West Africa with a high yield potential of over 90 tons ha ${ }^{-1}$ of fresh storage roots $\left(32 \mathrm{t} \mathrm{DM} \mathrm{ha}^{-1}\right)$ in a year and high nutrient use efficiency (Cock et al., 1979; El-Sharkawy et al., 1990; Howeler, 2017). Cassava contributes greatly to food security and as raw material for industrial processing. Cassava chips are effective energy substitutes for cereals in pig and poultry diets, while cassava starch is a high quality resource for the paper and textile industries (FAO, 2018). It is also used as feedstock for ethanol production (Adejuwon, 2006; Dai et al., 2006). The increasing demand for cassava offers farmers the opportunity to intensify production, earn higher incomes and boost their food supply (Howeler et al., 2013). Therefore, the use of inorganic fertilizers, following 4R nutrient stewardship (right amount, right time, right place and right source), is inevitable to sustainably improve productivity in the future (Oliveira et al., 2017). Cassava can grow under a wide range of environmental conditions, but growth rates are strongly affected by biophysical conditions and management (Howeler, 2012). Cassava is a perennial plant where vegetative and storage root growth occurs simultaneously, from the onset of storage roots initiation, with dry matter partitioned between the shoot and storage roots (Alves, 2002; El-Sharkawy, 2003). Typically, assimilates are partitioned mostly to the shoot during canopy establishment and partitioning to storage organs strongly increases from about 4 months after planting (MAP) onwards. In West Africa, a reduction in leaf growth rates usually occurs during a dry season and leaf growth resumes when rainfall returns. During this stage, the crop allocates most of the assimilates to the storage roots (Howeler and Cadavid, 1983). This poses a challenge for crop management in terms of optimizing nutrient application and uptake to allow optimum development of leaf area index (LAI) for adequate light interception and maximum growth, while regulating shoot growth to avoid lodging.

Nitrogen $(\mathrm{N})$, phosphorus $(\mathrm{P})$ and potassium $(\mathrm{K})$ uptake and partitioning in cassava have been documented in Latin America (Howeler and Cadavid, 1983; Howeler, 2002; Howeler, 2012). Orioli et al. (1967) reported that uptake of N, P and K was limited during the first two months of cassava growth, peaked during the third and fourth months before slowing again. Until six MAP, N accumulated mainly in the leaves, after which $\mathrm{N}$ in leaves declined due to leaf fall, but continued to increase in stems and remained constant in roots (Howeler, 2012). Phosphorus and especially $\mathrm{K}$ accumulated mainly in the roots, followed by stems and leaves (Howeler, 2012). The uptake and partitioning of nutrients in cassava is further influenced by demand in response to climatic conditions, soil water availability, soil fertility and plant age. Climate variability contributes to differences in plant growth rates and production potential (Alva et al., 2002). Howeler (2012) reported that in both irrigated and non-irrigated plots, the concentration of $\mathrm{N}, \mathrm{P}$ and $\mathrm{K}$ in the whole plant decreased remarkably during dry months and increased with the onset of rains. In cassava, there is usually a distinct decrease in nutrient uptake during the dry season, with or without adequate soil water (Fukai and Hammer, 1987; Howeler, 2012). This may be due to stomatal closing during day time and decreased transpiration in response to low relative humidity.

Several studies have shown that nutrient concentration of plants decreases during the growth cycle, even when nutrient supply is sufficient. Howeler (2012) found that concentrations of N, P and K decreased with increasing age of cassava in all plant parts. This has been attributed to dilution as the plant ages (Justes et al., 1994; Lemaire, 2012), directly related to increase in the proportion of structural and storage tissues (Greenwood et al., 1991). The minimum nutrient concentration required by the crop to reach its maximum growth rate at a given amount of biomass accumulation, time and field situation is referred to as critical value (c) of the mineral nutrient $\left(\mathrm{N}_{c}, \mathrm{P}_{\mathrm{c}}\right.$ and $\left.\mathrm{K}_{\mathrm{c}}\right)$. The concept of critical nutrient concentration and nutrition index have been widely used as a diagnostic tool for crop nutrient sufficiency, and to simulate crop demand for nutrients (Justes et al., 1994; Lemaire, 2012; Gómez et al., 2018). The $\mathrm{N}$ critical dilution curve based on total biomass has been established for various crops, e.g., wheat (Justes et al., 1994; Yue et al., 2012), corn (Plénet and Lemaire, 1999), rice (Sheehy et al., 1998; 
He et al., 2017), and potato (Marouani et al., 2014; Gómez et al., 2018). A few studies have established critical nutrient dilution curves of other macronutrients for potato (Zamuner et al., 2016; Gómez et al., 2018) and we are unaware of any published reports on critical concentrations of N, P and K in cassava.

Understanding the nutrient uptake and dilution pattern during the growth cycle can help to understand the temporal nutritional demands of cassava and to identify management practices to prevent nutrient deficiency as well as excess (Du Preez and Bennie, 1991). Such information can also be used to improve simulation models to predict cassava growth and storage root yield production under nutrient-limited conditions. Our objectives were to; (1) understand the nutrient uptake of cassava as affected by fertilizer application; (2) quantify the proportions of N, P and K in plant-parts across the crop growth cycle and (3) establish nutrient dilution curves and nutrition indices for cassava.

\subsection{Materials and methods}

\subsubsection{Study area}

On-farm experiments were conducted from 2016 to 2018. The six selected experimental fields were located in three agro-ecological zones (Rainforest - Cross River, Transition Rainforest - Edo, and Guinea Savanna - Benue), covering the major cassava producing regions in Nigeria. Each year, three field trials were established, one in each zone. The fields in Edo were located at $7.05^{\circ} \mathrm{N}, 6.13^{\circ} \mathrm{E}$ in 2016 and $6.80^{\circ} \mathrm{N}, 6.13^{\circ} \mathrm{E}$ in 2017 . For Cross River, field locations were at $7.27^{\circ} \mathrm{N}, 8.18^{\circ} \mathrm{E}$ in 2016 and $5.96^{\circ} \mathrm{N}$, $8.77^{\circ} \mathrm{E}$ in 2017 . In Benue, fields were located $6.76^{\circ} \mathrm{N}, 8.69^{\circ} \mathrm{E}$ in 2016 and $7.27^{\circ} \mathrm{N}, 8.19^{\circ} \mathrm{E}$ in 2017. The growing season begins with the onset of rains in the south from April (Cross River), gradually moving north, with first rains in Edo by early May and June in Benue. The dry season with intermittent or no rainfall runs from November to early April - May. The experiment locations (Cross River and Edo) fall within the Niger delta, which contains deep deposits of relatively young material, rich in clay, resulting in mostly Nitisols or Ferralsols, while Benue is located within the rift basin, with Acrisols or Lixisols as dominant soil types. Observed rooting depths of cassava were more than $3.2 \mathrm{~m}$ in Edo and about $1.6 \mathrm{~m}$ in Benue where rooting was restricted by a dense clay layer causing soil water saturation at depth after periods of heavy rainfall. Weather data were obtained from nearby weather stations at distances of approximately 2.5, 60 and $0.5 \mathrm{~km}$ (as the crow flies), with mean annual rainfall of about 2300, 2200 and $1400 \mathrm{~mm}$ for Cross River, Edo and Benue respectively (NIMET, 2012; Ukhurebor and Abiodun, 2018).

\subsubsection{Experiment design, crop establishment and management}

The larger experiment, fully described in Adiele et al. (Chapter 1), included 12 treatments from which 4 treatments were selected for this study. Each experiment contained three blocks to account for any gradient present in the field with fertilizer treatments randomized within these blocks. The N, P and $\mathrm{K}$ rates applied in the selected treatments are provided in Table 4.1. The plot size was $10 \mathrm{~m}$ by $8 \mathrm{~m}$. Planting was done at the onset of rains each year, except at Benue in 2016, where planting was done approximately three months later (mid-season). Dates of planting were May 24, June 16, and August 16, in 2016 and May 12, June 3, and June 15, in 2017 for Edo, Cross River and Benue respectively. Stem cuttings of $25 \mathrm{~cm}$ long from cassava cv. TME 419 were planted at a distance of 1.0 by $0.8 \mathrm{~m}$, resulting in the recommended planting density of 12,500 plants per hectare. The selected TME 419 cultivar has a high storage root DM and starch contents, and is characterised by erect stems with minimal branching, which facilitates intercropping as well as higher planting densities (Eke-Okoro and Njoku, 2012; Ezui, 2017). Phosphorus was applied by placement close to the cuttings at planting, while $\mathrm{N}$ and $\mathrm{K}$ were also spot-applied near the plant base in three splits at 1, 2.5 and 3.5 MAP. The N, P and K fertilizers used were urea, triple super phosphate (TSP) and muriate of potash (MOP). The experimental plots were well managed and weeded regularly, especially before each fertilizer application. 
Table 4.1. Nutrient application rates per treatment, (f) represents full rate of the nutrient $(\mathrm{N}=300$, $\mathrm{P}=100$ and $\mathrm{K}=300 \mathrm{~kg} \mathrm{ha}^{-1}$ ).

\begin{tabular}{lllll}
\hline & Treatment & Nitrogen $(\mathrm{N})$ & $\begin{array}{l}\text { Phosphorus (P) } \\
\left(\mathrm{kg} \mathrm{ha}^{-1}\right)\end{array}$ & Potassium (K) \\
\hline 1. & Control & 0 & 0 & 0 \\
2. & N150P40K180 & 150 & 40 & 180 \\
3. & NfPfK180 & 300 & 100 & 180 \\
4. & NfPfKf & 300 & 100 & 300 \\
\hline
\end{tabular}

\subsubsection{Data collection}

At the start of the experiment, just before land preparation, soil samples were collected from five points in a "W" pattern from $0-30 \mathrm{~cm}$ depth in each plot, bulked together before a composite sample was taken. The samples were air dried and sieved through a $2 \mathrm{~mm}$ mesh sieve. The $\mathrm{pH}$ was measured in water using a 2.5:1 dilution. The hydrometer method was used to determine the particle size. Soil organic carbon was obtained by the combustion method and $\mathrm{N}$ by Kjeldahl digestion. The Mehlich-3 extraction was used for $\mathrm{Ca}, \mathrm{Mg}$ and $\mathrm{K}$, while available $\mathrm{P}$ was determined in Olsen extracts. All soil analyses were done at the IITA laboratory, Ibadan, Nigeria.

\subsubsection{Yield assessment and plant nutrient content measurements}

At 4,8 and final harvest (FH) at 12 or $14 \mathrm{MAP}$, a net plot of $6.4 \mathrm{~m}^{2}$ (eight plants) was harvested in each experimental plot. Plants were separated into leaves, stems and storage roots and weights of each harvested plant part (leaf with petiole, stem, and storage root) were recorded for each plot. Sub-samples of about $400 \mathrm{~g}$ fresh weight were collected in the field using a digital field scale, and oven dried at $60^{\circ} \mathrm{C}$ until constant weight and weighed to allow dry matter (DM) yield to be calculated. Dried subsamples from leaves with petioles, stems, and storage roots were analysed for total N, P and K concentration. Total $\mathrm{N}$ in the tissue was analysed by Dumas combustion using a Carlo Erba EA1108 elemental analyser. Total $\mathrm{P}$ and $\mathrm{K}$ concentrations were measured with inductively coupled plasma (ICP) (iCAP 7400, Thermo Fisher Scientific, USA). Subsamples collected at 4 MAP in Benue in 2016, and in Cross River in 2017 were not analysed.

\subsubsection{Calculations and data analysis}

The N, P and $\mathrm{K}$ uptake in each crop component were calculated by multiplying nutrient content by the plant biomass dry matter $\left(\mathrm{g} \mathrm{m}^{-2}\right)$ (Ciampitti and Vyn, 2013; Chuan et al., 2016). Nitrogen, $\mathrm{P}$ and $\mathrm{K}$ uptake rates $\left(\mathrm{g} \mathrm{m}^{-2} \mathrm{~d}^{-1}\right)$ at 4 and $8 \mathrm{MAP}$ and at FH were calculated as the difference between plant uptake at 8 minus 4 MAP or final harvest minus 8 MAP divided by the number of days between the growth intervals. Following the approach used by Bista et al. (2018). Temperature sum (Tsum) was calculated using equation 1 , at a Tbase of $15^{\circ} \mathrm{C}$

Tsum $=\sum_{1}^{d} \max \left(\frac{\left(T_{\max , d}-T_{\min , d}\right)}{2}-T_{\text {base }}, 0\right)$ (eq. 1$)$

Where $T_{\max }$ and $T_{\min }$ are the daily maximum and minimum temperatures $\left({ }^{\circ} \mathrm{C}\right) . T_{\text {base }}$ is the base temperature below which the crop no longer develops.

\subsubsection{Establishment of nutrient dilution curves}

For this objective, only data points from Edo and Cross River were used, so as to capture the more ideal cassava growing environment considering soil conditions. The nutrient dilution curve describing the 
relationship between nutrient concentration and total biomass across locations and years, was generated by fitting a simple negative power function (eq. 2), following (Yue et al., 2012).

$C_{(N, P, K)}=a_{(N, P, K)}(D M)^{-b_{(N, P, K)}}($ eq. 2$)$

Where DM is total biomass (the sum of aboveground and storage roots biomass ( $\mathrm{t} \mathrm{DM} \mathrm{ha}^{-1}$ ), excluding fibrous roots) $C\left(\mathrm{~g} \mathrm{~kg}^{-1}\right)$ is the total concentration of $\mathrm{N}, \mathrm{P}$ or K in the plant biomass. Coefficient $a\left(\mathrm{~g} \mathrm{~kg}^{-}\right.$ $\left.{ }^{1}\right)$ represents the concentration of $\mathrm{N}, \mathrm{P}$ or $\mathrm{K}$ when the DM is exactly $1 \mathrm{tha}^{-1}$. Thus, it is related to the level of nutrient supply and the intrinsic ability of the crop to take up the nutrient during early growth stages (Lemaire et al., 2007). Parameter $b$ represents a "dilution coefficient", which describes the reduction in nutrient concentration associated with the increment in total biomass. It characterizes the pattern of decrease of the nutrient concentration with increase in DM. If $b$ is zero, the nutrient concentration remains constant. If $b=1$, there is an increase in biomass without any increase in $\mathrm{N}, \mathrm{P}$ or $\mathrm{K}$ concentration. The model in eq. 2 contains only two uncorrelated parameters, making it unbiased and preferred to explain the dynamics of nutrient concentration in plants (Justes et al., 1994). Also, nutrient dilution curves at maximum growth rates were determined using eq. 2 , following the procedure adapted from Gómez et al. (2018) for potato, Justes et al. (1994) and Lemaire (2012) for winter wheat and various crops and grasses. This required identification of values by which the evaluated nutrients do not limit crop growth (Greenwood et al., 1986; Justes et al., 1994; Marouani et al., 2014). Therefore, the highest yielding treatments across locations and years were selected to determine the parameters $a$ and $b$ for each nutrient for maximum growth rate.

Two envelope curves were defined for $\mathrm{N}, \mathrm{P}$ and $\mathrm{K}$, describing the minimum and maximum concentrations (eq. 3 and 4) following the method of Justes et al. (1994) and Yue et al. (2012) for N.

$$
\begin{aligned}
& C_{(N, P, K), \text { max }}=a_{(N, P, K), \max }(D M)^{-b_{(N, P, K)}}(\text { eq. } 3) \\
& C_{(N, P, K), \min }=a_{(N, P, K), \min }(D M)^{-b_{(N, P, K)}}(\text { eq. } 4)
\end{aligned}
$$

The $C_{\max }$ curve represents the maximum nutrient accumulation capacity of the plant (luxury consumption), corresponding to the maximum nutrient uptake rate (Justes et al., 1994; Lemaire, 2012). The $\mathrm{C}_{\min }$ curve represents the minimum nutrient concentration and is assumed as the lower limit below which metabolism ceases. Note that $\mathrm{C}_{\min }$ is probably an overestimate of the true minimum limit at which cassava growth stops, because it could be less under other growth conditions (Justes et al., 1994). The fitted values for $a$ were adjusted manually to find best values for the $a_{\max }$ and $a_{\min }$ parameters for each nutrient, such that they visually matched the dilution patterns of $\mathrm{N}, \mathrm{P}$ and $\mathrm{K}$, whereas the $b$ parameter was not adjusted. Following Greenwood et al. (1986) and Angus and Moncur (1985), the nutrition indices (NI) were calculated as:

$N I_{(N, P, K)}(D M)=\frac{C_{(N, P, K)}(D M)-C_{(N, P, K), \min }(D M)}{C_{(N, P, K), \max }(D M)-C_{(N, P, K), \min }(D M)}(e q .5)$

Where $C_{(N, P, K)}(\mathrm{DM})$ represents the nutrient concentration for N, P or K for a given amount of dry matter. The relative biomass production was calculated as a ratio of the total biomass weight (DM, $\mathrm{t} \mathrm{ha}^{-1}$ ) obtained at each harvest period to the largest total biomass (Lemaire, 2012) 


\subsubsection{Statistical analysis}

Treatment effects on nutrient uptake rate were analysed separately for each location and growth stage, using a linear mixed model with nutrient uptake rate as response variable and fertilizer treatment as explanatory factor, while years were considered random effects. The interaction of plant-parts nutrient uptake response with location and year or treatment were analysed with a mixed linear regression model. A simple linear regression was used to assess the relationship between relative biomass and nutrition indices. Effects were analysed with a type-III ANOVA using Satterthwaite's approximation method. Differences between treatment means were considered significant when probability $\leq 0.05$. $R$ software (R Core, 2019), version 3.5 with the lme4, lmerTest and Predictmeans packages was used for statistical analysis.

\subsection{Results}

\subsubsection{Dynamics of whole plant nutrient uptake and uptake rate}

The proportion of nutrients taken up at $4 \mathrm{MAP}$ in relation to the total uptake at final harvest, varied with locations and treatments. In Edo, there was no water deficiency and growth continued during the dry period between $4 \mathrm{MAP}$ and $8 \mathrm{MAP}$, while nutrient uptake during this period was minimal (Fig. 4.1a, d, $\mathrm{g}$ and $\mathrm{j}$ ). Growth ceased completely in Benue and was strongly reduced in Cross River during this period, while some loss of $\mathrm{N}$ and $\mathrm{P}$ was observed, and to a lesser extent of $\mathrm{K}$, due to leaf fall (Fig. 4.1). The proportional uptakes for the fertilized treatments were larger than the unfertilized treatments. At all locations, a larger proportion of $\mathrm{N}$ was taken up before the drought when compared to $\mathrm{P}$ and $\mathrm{K}$ (Fig. 4.1 $\mathrm{b}$, e and c). On average, cassava in Edo at 4 MAP took up 59, 60, and $60 \%$ of $\mathrm{N}, \mathrm{P}$ and $\mathrm{K}$ in the unfertilized treatment, compared to 70,62 and $56 \%$ in the fertilized treatments. At Benue, cassava in the unfertilized treatment took up 70,66, and $53 \%$ of N, P and K at 4 MAP, compared with, on average, 48,41 and $35 \%$ uptake of N, P and K in the fertilized treatments. At Cross River, these values were 56, 55 , and $50 \%$ of N, P and $\mathrm{K}$ at $4 \mathrm{MAP}$ for the unfertilized treatment and 76,73 and $65 \%$ for the fertilized treatments.

The fastest $\mathrm{N}$ uptake rate during the growing season was observed in Edo, at $4 \mathrm{MAP}$ with the NfPfKf treatment $\left(0.21 \mathrm{~g} \mathrm{~m}^{-2} \mathrm{~d}^{-1}\right.$, compared with an average of $0.15 \mathrm{~g} \mathrm{~m}^{-2} \mathrm{~d}^{1}$ across treatments), (Table 4.2). The cumulative $\mathrm{N}$ uptake from 4 MAP to FH was significantly influenced by treatment and location, except at $8 \mathrm{MAP}$ when there was no significant effect of treatment due to the dry season (Tables 4.A1-3 of the appendices). Also, phosphorus uptake rate was at its peak at 4 MAP with maximum 
Edo

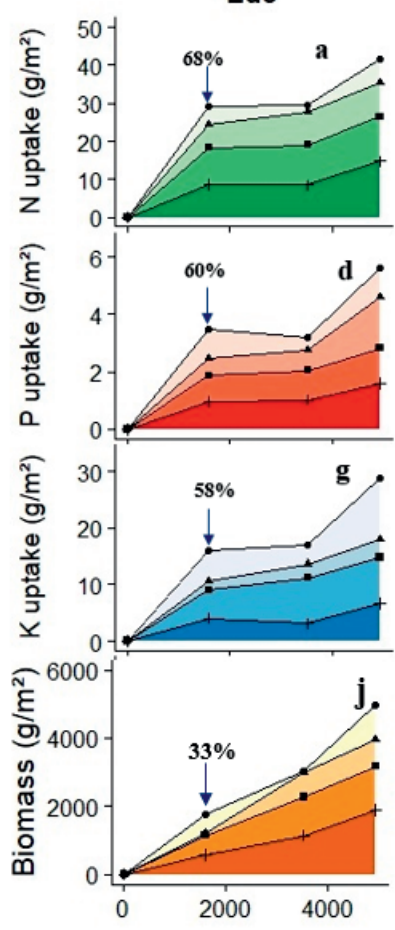

Benue

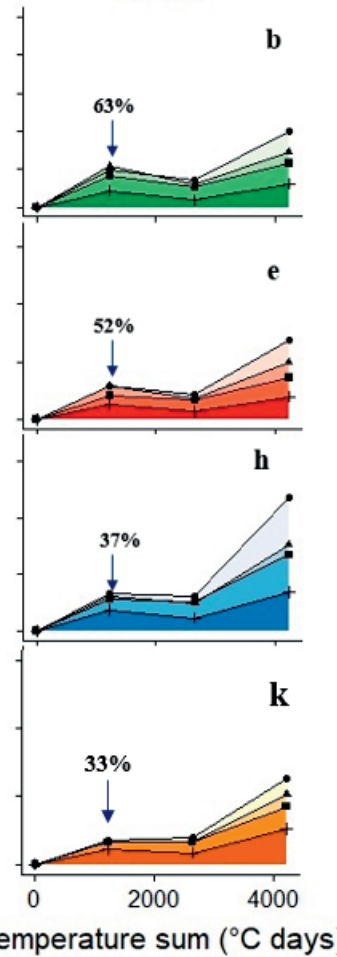

Cross river

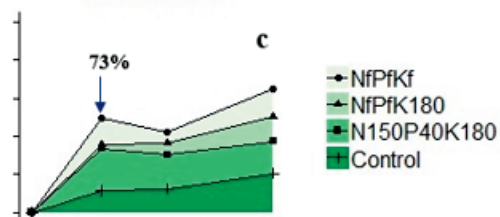

- NfPfKf

-NfPfK180

- N150P40K180

EControl

- NfPfKf

- NfPfK180

- N150P40K180

EControl

- NfPfKf

- NfPfK180

-N150P40K180

+Control

Fig. 4.1. Cassava cumulative plant nutrient uptake for $\mathrm{N}$ (panels a,b,c), $\mathrm{P}$ (panels d,e,f) and $\mathrm{K}$ (panels g,h,i) and total biomass (panels $\mathrm{j}, \mathrm{k}, \mathrm{l}$ ) as a function of cumulative temperature sum from planting through harvests at 4,8 and final harvest. Symbols indicate average values for harvests at 4,8 and final harvests across the two years. The arrows indicate average percentages (for all treatments) of N, P and $\mathrm{K}$ uptake and biomass production at 4 MAP compared with final harvest.

value of $0.03 \mathrm{~g} \mathrm{~m}^{-2} \mathrm{~d}^{-1}$ and an average of $0.02 \mathrm{~g} \mathrm{~m}^{-2} \mathrm{~d}^{-1}$ (Table. 4.2). Across locations and years, the average quantities of $P$ taken up in the unfertilized and fertilized treatments were 0.7 and $1.2 \mathrm{~g} \mathrm{~m}^{-2}$ and 1.9 and $3.2 \mathrm{~g} \mathrm{~m}^{-2}$ at $4 \mathrm{MAP}$ and FH, respectively. Similar to $\mathrm{N}$ and $\mathrm{P}$, the maximum $\mathrm{K}$ uptake rate $(0.12$ $\mathrm{g} \mathrm{m}^{-2} \mathrm{~d}^{-1}$, and average of $0.1 \mathrm{~g} \mathrm{~m}^{-2} \mathrm{~d}^{-1}$ ) was observed at 4 MAP in Cross River. The quantities of $\mathrm{K}$ taken up at $4 \mathrm{MAP}$ and FH by unfertilized plants were 3.7 and $6.9 \mathrm{~g} \mathrm{~m}^{-2}$, while the fertilized plants took up 10.7 and $20.1 \mathrm{~g} \mathrm{~m}^{-2}$ at $4 \mathrm{MAP}$ and $\mathrm{FH}$ stages, respectively. N, P and $\mathrm{K}$ uptake rates strongly decreased during the dry season to $0.07,0.004$ and $0.03 \mathrm{~g} \mathrm{~m}^{-2} \mathrm{~d}^{-1}$ on average. There was a rise in $\mathrm{N}, \mathrm{P}$ and $\mathrm{K}$ uptake rate to $0.1,0.02$ and $0.09 \mathrm{~g} \mathrm{~m}^{-2} \mathrm{~d}^{-1}$ from $8 \mathrm{MAP}$ to $\mathrm{FH}$ with the return of rainfall (Table 4.2). Nutrient uptake rates were much slower at Benue from 0-4 and 4-8 MAP than for the other locations, while uptakes rates were comparable from $8 \mathrm{MAP}$ to $\mathrm{FH}$. This suggests that nutrient uptake was reduced due to soil water limitations in the first $8 \mathrm{MAP}$, resulting in much less total nutrient uptake. 
Table 4.2. Average cassava nutrient uptake rates from 0-4, 4-8 months after planting (MAP) and from 8 MAP to final harvest $(\mathrm{FH})$ at Edo, Cross River, and Benue across the years

\begin{tabular}{|c|c|c|c|c|c|c|c|c|c|}
\hline \multirow{2}{*}{$\begin{array}{l}\text { Treatment } \\
\text { Growth period }\end{array}$} & \multicolumn{3}{|c|}{$\begin{array}{c}\mathrm{N} \\
\left(\mathrm{g} \mathrm{m}^{-2} \mathrm{~d}^{-1}\right)\end{array}$} & \multicolumn{3}{|c|}{$\begin{array}{c}\mathrm{P} \\
\left(\mathrm{g} \mathrm{m}^{-2} \mathrm{~d}^{-1}\right)\end{array}$} & \multicolumn{3}{|c|}{$\begin{array}{c}\mathrm{K} \\
\left(\mathrm{g} \mathrm{m}^{-2} \mathrm{~d}^{-1}\right)\end{array}$} \\
\hline & 0-4 MAP & $\begin{array}{c}4-8 \\
\text { MAP }\end{array}$ & $\begin{array}{l}8 \text { MAP- } \\
\text { FH }\end{array}$ & 0-4 MAP & $\begin{array}{c}4-8 \\
\text { MAP }\end{array}$ & $\begin{array}{c}8 \text { MAP- } \\
\text { FH }\end{array}$ & 0-4 MAP & $\begin{array}{c}4-8 \\
\text { MAP }\end{array}$ & $\begin{array}{c}8 \text { MAP- } \\
\text { FH }\end{array}$ \\
\hline & \multicolumn{9}{|c|}{ Edo } \\
\hline $\mathrm{NfPfKf}$ & 0.210 & 0.075 & 0.098 & 0.025 & 0.004 & 0.019 & 0.114 & 0.029 & 0.079 \\
\hline NfPfK 180 & 0.178 & 0.053 & 0.049 & 0.018 & 0.002 & 0.012 & 0.074 & 0.027 & 0.028 \\
\hline $\mathrm{N} 150 \mathrm{P} 40 \mathrm{~K} 180$ & 0.132 & 0.023 & 0.039 & 0.014 & -0.002 & 0.005 & 0.064 & 0.020 & 0.023 \\
\hline Control & 0.062 & 0.001 & 0.034 & 0.007 & 0.001 & 0.003 & 0.029 & -0.007 & 0.022 \\
\hline \multirow[t]{2}{*}{ Treatment } & $* * *(0.005)$ & $*(0.017)$ & $* *(0.007)$ & $\begin{array}{c}\text { ANOVA } \\
* *(0.001)\end{array}$ & ns & $*(0.003)$ & $* *(0.007)$ & ns & $*(0.015)$ \\
\hline & \multicolumn{9}{|c|}{ Cross River } \\
\hline NfPfKf & 0.181 & 0.034 & 0.086 & 0.019 & 0.004 & 0.014 & 0.124 & 0.025 & 0.093 \\
\hline NfPfK 180 & 0.130 & 0.028 & 0.053 & 0.015 & 0.003 & 0.005 & 0.090 & 0.022 & 0.044 \\
\hline N150P40K 180 & 0.120 & 0.025 & 0.031 & 0.013 & 0.003 & 0.004 & 0.093 & 0.019 & 0.032 \\
\hline Control & 0.042 & 0.014 & 0.030 & 0.005 & 0.001 & 0.002 & 0.093 & 0.008 & 0.025 \\
\hline \multirow[t]{2}{*}{ Treatment } & - & ns & $*(0.016)$ & $\frac{\text { ANOVA }}{-}$ & ns & $*(0.001)$ & - & ns & $*(0.012)$ \\
\hline & \multicolumn{9}{|c|}{ Benue } \\
\hline $\mathrm{NfPfKf}$ & 0.070 & 0.019 & 0.069 & 0.008 & 0.003 & 0.017 & 0.049 & 0.020 & 0.092 \\
\hline NfPfK 180 & 0.077 & 0.005 & 0.036 & 0.009 & 0.002 & 0.006 & 0.045 & 0.017 & 0.058 \\
\hline $\mathrm{N} 150 \mathrm{P} 40 \mathrm{~K} 180$ & 0.06 & 0.005 & 0.034 & 0.006 & 0.001 & 0.004 & 0.041 & 0.014 & 0.047 \\
\hline Control & 0.032 & -0.003 & 0.025 & 0.004 & 0.001 & 0.003 & 0.027 & 0.005 & 0.026 \\
\hline Treatment & - & $\mathrm{ns}$ & $\mathrm{ns}$ & $\frac{\text { ANOVA }}{-}$ & ns & $*(0.004)$ & - & $*(0.003)$ & ns \\
\hline
\end{tabular}

* Significant at $\mathrm{P}<0.05$

** Significant at $\mathrm{P}<0.01$

$* * *$ Significant at $\mathrm{P}<0.001$

+ Standard errors (SE) in parentheses and relates only to comparisons between significant terms

- : one year available data for the period, yet uptake rates differed by treatments at 4 MAP

ns: not significant

\subsubsection{Distribution of nutrients over plant organs}

Nutrient uptake of leaves, stems and storage roots at 4, 8 MAP and FH was evaluated. The amount of nutrients in the various plant organs varied among treatments and locations. There was no interaction between treatments and years (Tables 4.A1-3). The leaf N, P and K uptakes were largest at 4 MAP, while stem $\mathrm{N}, \mathrm{P}$ and $\mathrm{K}$ uptake were largest at $8 \mathrm{MAP}$. The accumulation of storage root $\mathrm{N}, \mathrm{P}$ and $\mathrm{K}$ uptake increased with plant age and biomass (Fig. 4.2). Nutrient accumulation was greater in fertilized plants than the unfertilized ones. Except increased $\mathrm{N}$ accumulation in stems, nutrients in all plant parts decreased at the 8 MAP (mid growth stage) harvest which corresponded with the seasonal dry period across the locations, and later increased again as the crop growth continued when rainfall resumed (Tables 4.A1-3). 


\subsubsection{Nitrogen, $P$ and $K$ in leaves, stems and roots}

Both unfertilized and fertilized treatments showed similar trends with the largest proportion of N (55\% of the total $\mathrm{N}$ uptake by the whole plant) in the leaves at 4 MAP (Fig. 4.2). At 8 MAP, N partitioning to the leaves decreased but increased in the stems. Shoot $\mathrm{N}$ uptake at FH in fertilized treatments was proportionally largest in the stem at $54 \%$, in contrast to the unfertilized treatment where the proportion of stem $\mathrm{N}$ in the shoot was $38 \%$ (Fig. 4.2). There was no significant difference between the fertilized and the unfertilized treatments in the partitioning of $\mathrm{N}, \mathrm{P}$ and $\mathrm{K}$ at the different growth stages $(p<0.05)$. Proportional P content was largest in the storage roots (54\%) at final harvest and was similar for fertilized and unfertilized treatments. The storage roots also accumulated the largest proportion of $\mathrm{K}$, increasing from $4 \mathrm{MAP}$ to FH for both unfertilized and fertilized treatments, in all locations and years (Fig. 4.2 and Table 4.A3 ). The proportions of $\mathrm{K}$ in storage roots across locations and years were on average 49,60 and $60 \%$ in the fertilized compared to 60,70 and $69 \%$ for unfertilized treatments at 4,8 MAP and FH, respectively.
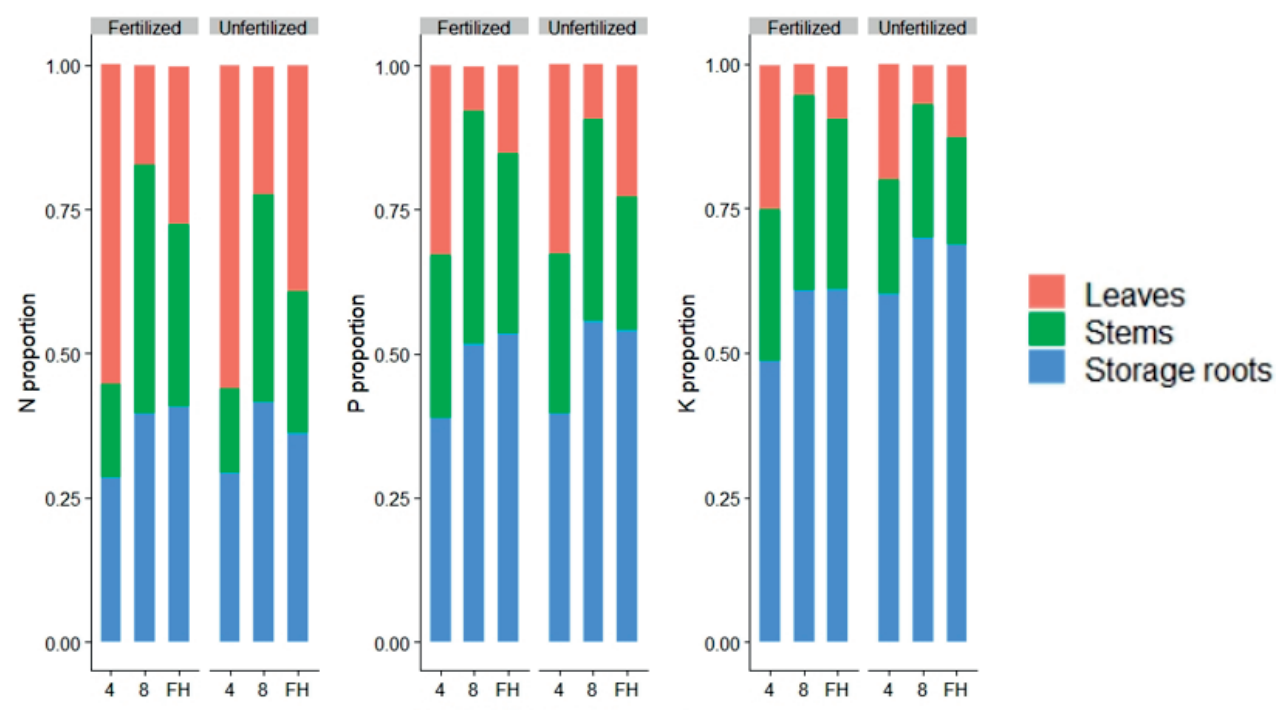

Fig. 4.2. Proportions of total uptake of N, P and $\mathrm{K}$ in leaves, stems and storage roots at different growth stages, from approximately 4 months after planting to full harvest $(\mathrm{FH})$ across location and years.

\subsubsection{Nutrient concentration in leaves, stems and storage roots}

The pattern of seasonal change in the N, P and $\mathrm{K}$ concentrations was similar for locations and years, with smaller concentrations in leaves at 8 MAP than at 4 MAP or FH. Nutrient concentrations differed only between unfertilized and fertilized treatments with a smaller leaf N, P and K concentration in unfertilized compared with the fertilized treatments (Fig. 4.3). The N, P and $\mathrm{K}$ concentration in the leaves of the unfertilized treatment at $4 \operatorname{MAP}\left(43,2.8\right.$ and $\left.8.2 \mathrm{~g} \mathrm{~kg}^{-1}\right)$ decreased to $39,2.0$ and $7.1 \mathrm{~g} \mathrm{~kg}^{-1}$ during the dry season $(8 \mathrm{MAP})$ and increased later to almost the initial value when drought stress was relieved. For the fertilized treatment, $\mathrm{N}, \mathrm{P}$ and $\mathrm{K}$ concentration of leaves $\left(46,3.1,12.5 \mathrm{~g} \mathrm{~kg}^{-1}\right)$, decreased at $8 \mathrm{MAP}$ to $39.4,2.0$ and $8.18 \mathrm{~g} \mathrm{~kg}^{-1}$. Nitrogen and $\mathrm{P}$ increased to the initial value at final harvest, while leaf $\mathrm{K}$ concentration was slightly reduced to $12.1 \mathrm{~g} \mathrm{~kg}^{-1}$ from the initial values. There was a steady decrease in 
$\mathrm{P}, \mathrm{K}$ concentration in stems and roots. Also, $\mathrm{N}$ concentration in roots decreased, but increased in stems at 8 MAP before declining towards FH (Fig. 4.3). There were no signs of dilution in the leaves, concentration increased with leaf biomass (Fig. 4.A1, panel B). The opposite pattern was found for stems, with the greatest concentration of $\mathrm{N}$ at $8 \mathrm{MAP}$. The concentrations of $\mathrm{P}$ in leaves showed a strong seasonal pattern, while $\mathrm{P}$ in stems and storage roots strongly declined during development. The concentrations of $\mathrm{K}$ in leaves varied over the growth period, while $\mathrm{K}$ in stems and storage roots declined more strongly for fertilized treatments than for unfertilized treatments (Fig. 4.3).
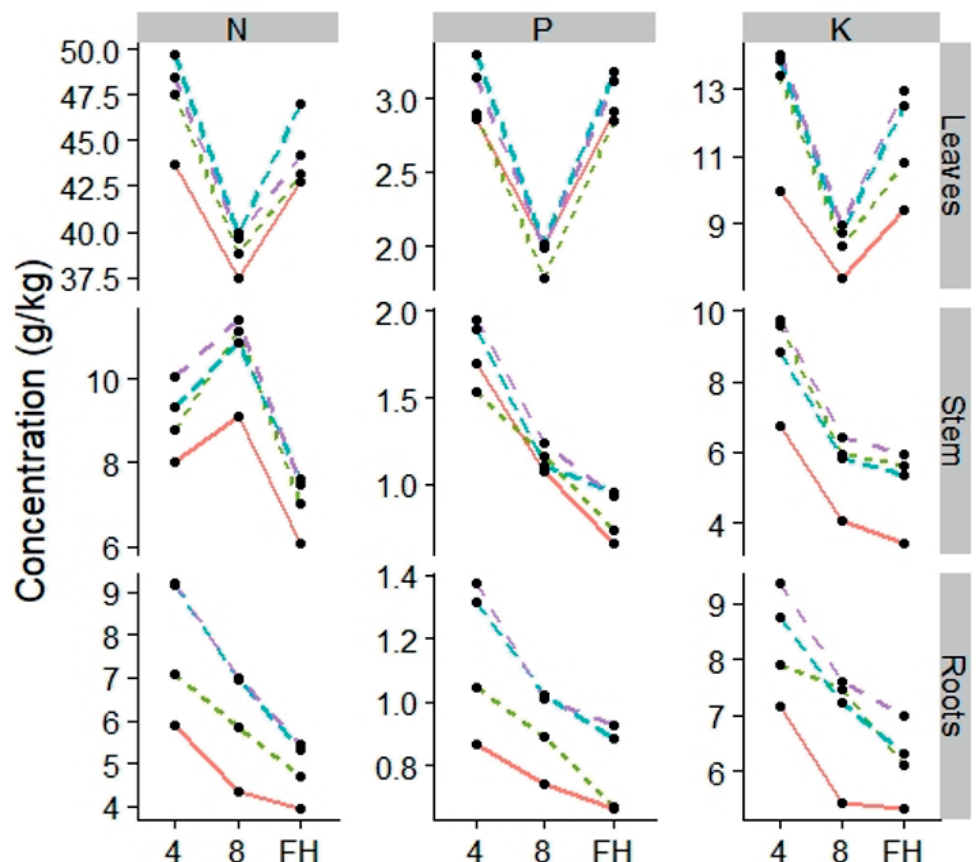

Treatment

- Control

-- N150P40K180

-- NFPfK180

- NfPfKf
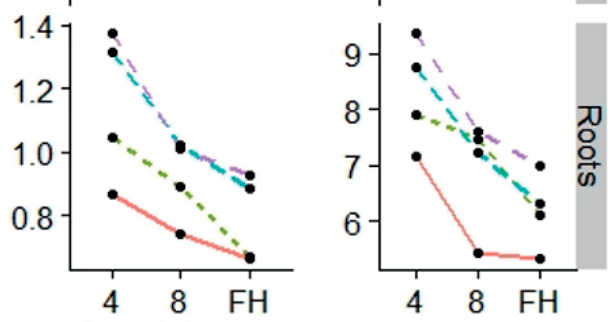

\section{Months after planting}

Fig. 4.3. Differences between treatments in average $\mathrm{N}, \mathrm{P}$ and $\mathrm{K}$ concentrations $\left(\mathrm{g} \mathrm{kg}^{-1}\right)$ across locations and years in leaves, stems and storage roots at different growth stages.

The N, P and K concentrations at 4 MAP in stems of the unfertilized treatments were 8.9, 2.1 and $5.3 \mathrm{~g}$ $\mathrm{kg}^{-1}$ compared to $9.7,2.1$ and $9.1 \mathrm{~g} \mathrm{~kg}^{-1}$ for the fertilized treatments. At about $8 \mathrm{MAP}$, stem $\mathrm{N}$ concentration increased to 10.5 and $11.7 \mathrm{~g} \mathrm{~kg}^{-1}$ in unfertilized and fertilized treatments, respectively, while $\mathrm{P}$ decreased to $1.16 \mathrm{~g} \mathrm{~kg}^{-1}$ in all treatments and $\mathrm{K}$ to 3.51 and $6.07 \mathrm{~g} \mathrm{~kg}^{-1}$ in unfertilized and fertilized treatments. At FH, there were decreases of 23,59 and $48 \%$ of stem N, P and K concentrations when compared to 4 MAP. Also, the storage root $\mathrm{N}, \mathrm{P}$ and $\mathrm{K}$ concentrations in unfertilized treatments (7.6, 1.0 and $7.4 \mathrm{~g} \mathrm{~kg}^{-1}$ ) and $10,1.5$ and $9.3 \mathrm{~g} \mathrm{~kg}^{-1}$ in the fertilized treatment decreased in concentration at FH (Fig. 4.3). The observed maximum and minimum concentrations of N, P and $\mathrm{K}$ are compared with values from the literature in Table 4.3 . 
Table 4.3. Observed vs. literature values of minimum and maximum concentration of nutrients in cassava from 4 MAP to maturity across treatments, locations and years

\begin{tabular}{|c|c|c|c|c|c|}
\hline Nutrient & $\begin{array}{l}\text { Measured } \\
\text { values } \\
\text { Minimum }\end{array}$ & Maximum & $\begin{array}{l}\text { Literature } \\
\text { values } \\
\text { Minimum }\end{array}$ & Maximum & Sources \\
\hline & & $\mathrm{g} \mathrm{kg}^{-1}$ & & & \\
\hline \multicolumn{6}{|l|}{ Leaves } \\
\hline $\mathrm{N}$ & 39.0 & 55.0 & 33.0 & 60.0 & \multirow{7}{*}{$\begin{array}{l}\text { (Howeler and Cadavid, 1983; } \\
\text { Howeler, 2012; Santos et al., } \\
\text { 2014) }\end{array}$} \\
\hline $\mathrm{P}$ & 1.8 & 4.4 & 2.4 & 3.8 & \\
\hline K & 6.0 & 21.0 & 11.0 & 22.0 & \\
\hline Stems & & & & & \\
\hline $\mathrm{N}$ & 6.0 & 12 & 7.8 & 17.0 & \\
\hline $\mathrm{P}$ & 0.6 & 2.6 & 1.8 & 2.4 & \\
\hline K & 2.3 & 12.5 & 8.0 & 15.0 & \\
\hline \multicolumn{6}{|l|}{$\begin{array}{l}\text { Storage } \\
\text { roots }\end{array}$} \\
\hline $\mathrm{N}$ & 3.2 & 16.0 & 2.7 & 11.0 & Howeler and Cadavid, 1983 \\
\hline $\mathrm{P}$ & 0.6 & 2.2 & 0.9 & 6.0 & Nijhof, 1987 \\
\hline $\mathrm{K}$ & 2.7 & 13.0 & 3.4 & 11.0 & \\
\hline
\end{tabular}

\subsubsection{Nutrient dilution at different nutrient application rates}

The whole plant concentrations of N, P and $\mathrm{K}$ varied between 5 and 33, 0.6 and 2.0 and 3.0 and $11.4 \mathrm{~g}$ $\mathrm{kg}^{-1}$, respectively. The nutrient dilution pattern for the different treatments (Control, N150P40K180, $\mathrm{NfPfK} 180$ and NfPfKf) with varied rates of applied $\mathrm{N}(0,150$ and 300$), \mathrm{P}(0,40$ and 100$)$ and $\mathrm{K}(0,180$ and 300) are shown in Table 4.4 and Fig. 4.4 a, b, c. The concentrations of N, P and $\mathrm{K}$ in the total biomass declined as DM increased during the growth period. The fertilized treatments had a larger $a$ parameter value than the unfertilized (Table 4.4). The dilution coefficient parameter $b$ for $\mathrm{N}$ and $\mathrm{P}$ was higher in the fertilized than unfertilized treatment, but parameter $b$ for $\mathrm{K}$ varied among the treatments (Table 4.4).

Table 4.4. Critical dilution coefficients of N, P and $\mathrm{K}$ for different N, P and K levels, obtained from nutrient limiting (Control) and non-nutrient limiting (NfPfKf) conditions

\begin{tabular}{|c|c|c|c|c|c|c|c|}
\hline Treatment & $\begin{array}{l}\text { N Dilution } \\
\text { curve } \\
\mathrm{C}_{\mathrm{N}}= \\
a(\mathrm{DM})^{-b}\end{array}$ & $\mathrm{R}^{2}$ & $\begin{array}{l}\text { P Dilution } \\
\text { curve } \\
\mathrm{C}_{\mathrm{P}}=a(\mathrm{DM})^{-} \\
b\end{array}$ & $\mathrm{R}^{2}$ & $\begin{array}{l}\text { K Dilution } \\
\text { curve } \\
\mathrm{C}_{\mathrm{K}}=a(\mathrm{DM})^{-b}\end{array}$ & $\mathrm{R}^{2}$ & Range DM \\
\hline Control & $32(\mathrm{DM})^{-0.55}$ & 0.53 & $3.1(\mathrm{DM})^{-0.48}$ & 0.45 & $19(\mathrm{DM})^{-0.6}$ & 0.57 & $\begin{array}{l}\text { t ha }^{-1} \\
5-57\end{array}$ \\
\hline N150P40K180 & $107(\mathrm{DM})^{-0.82}$ & 0.84 & $9(\mathrm{DM})^{-0.73}$ & 0.77 & $47(\mathrm{DM})^{-0.67}$ & 0.74 & $5-57$ \\
\hline NfPfK 180 & $90(\mathrm{DM})^{-0.67}$ & 0.67 & $8(\mathrm{DM})^{-0.6}$ & 0.72 & $40(\mathrm{DM})^{-0.58}$ & 0.80 & $5-57$ \\
\hline NfPfKf & $82(\mathrm{DM})^{-0.61}$ & 0.73 & $7.4(\mathrm{DM})^{-0.54}$ & 0.57 & $43(\mathrm{DM})^{-0.54}$ & 0.71 & $5-57$ \\
\hline
\end{tabular}




\subsubsection{Nutrient dilution curve for maximum growth rate}

The NfPfKf treatment was considered to be non-limiting, and the associated dilution curve for this treatment was used to determine the nutrient concentration of cassava required for maximum growth (Fig. 4.4). The equations indicate that $\mathrm{Nc}=82, \mathrm{Pc}=7.4$ and $\mathrm{Kc}=43 \mathrm{~g} \mathrm{~kg}^{-1} \mathrm{DM}$, when total biomass equals $1 \mathrm{t} \mathrm{ha}^{-1}$ for cassava in tropical conditions of West Africa (Table 4.4). About 73, 57 and $71 \%$ of the variation for total biomass was explained by the N, P and $\mathrm{K}$ concentration from $4 \mathrm{MAP}$ to FH. There was a declining trend of nutrient concentration with increasing DM and crop age (Fig. 4.4). The $a$ parameter in the dilution equation was derived for $\mathrm{N}$, when set at 55 and $106 \mathrm{~g} \mathrm{~kg}^{-1}, \mathrm{P}$ at 4.5 and $9.5 \mathrm{~g}$ $\mathrm{kg}^{-1}$ and $\mathrm{K}$ at 25 and $45 \mathrm{~g} \mathrm{~kg}^{-1}$ for the $\mathrm{C}_{\min }$ and $\mathrm{C}_{\max }$ curves.
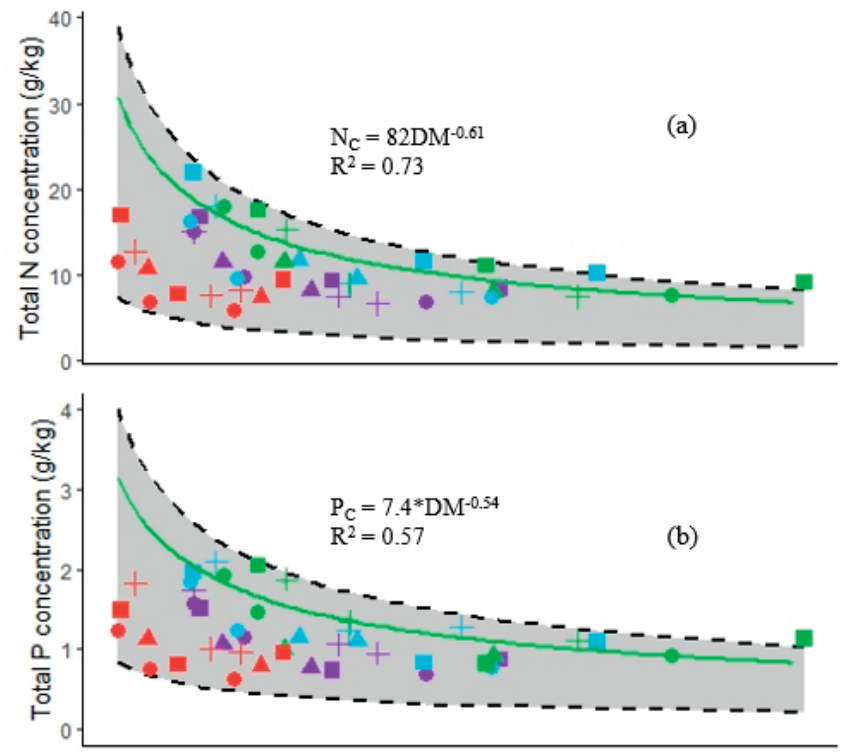

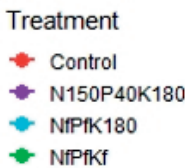

Field trial

- CRS, 2016

A CRS, 2017

- Edo, 2016

+ Edo, 2017

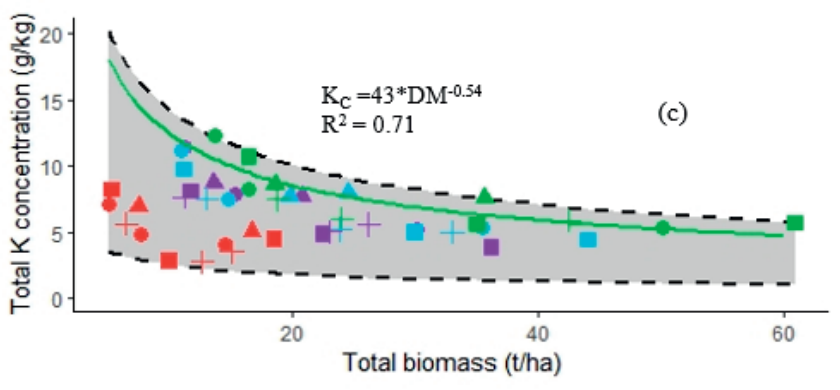

Fig. 4.4a, b and c. N, P and K dilution curves for plant nutrient concentrations as function of total plant biomass per treatment, location and year. Each observation represents an average of three replications for each treatment. The black broken lines are the upper and lower 'envelope curves' $-C_{\max }$ and $C_{\min }$; and the green line represents the $\mathrm{N}, \mathrm{P}$ and $\mathrm{K}$ dilution curves for treatments that are not nutrient limited. 


\subsubsection{Nutrition indices and relative biomass yield of $N, P$ and $K$}

With the established $C_{\max }$ and $C_{\min }$ dilution curves (Fig. $4.4 \mathrm{a}, \mathrm{b}, \mathrm{c}$ ), the nitrogen nutrition index (NNI), phosphorus nutrition index (PNI) and potassium nutrition index (KNI) were obtained. The largest nutrition indices were obtained from the full treatment (NfPfKf) at 4 MAP and FH (Fig. 4.5). Except the NfPfKf treatment, NI were generally small amongst treatments at 8 MAP (during the dry season). Values of NNI in the unfertilized treatment ranged between 0.1 to 0.3 at the 4 MAP and 0.1 to 0.43 at $\mathrm{FH}$, with total biomass between 5.0 to $18.5 \mathrm{t} \mathrm{DM} \mathrm{ha}^{-1}$. In the NfPfKf, NNI ranged between 0.9 to 1.0 at $4 \mathrm{MAP}$ and 0.8 to 1.13 at $\mathrm{FH}$, with total biomass between 14 and $57 \mathrm{t} \mathrm{ha}^{-1}$. PNI values from the unfertilized treatment ranged from 0.1 to 0.33 at $4 \mathrm{MAP}$ and 0.1 to 0.4 at $\mathrm{FH}$, while in the NfPfKf treatments, values ranged from 0.9 to 0.94 at 4 MAP and 0.8 to 1.13 at FH. Values of KNI from the unfertilized treatment varied between 0.1 and 0.3 at $4 \mathrm{MAP}$ and 0.2 and 0.33 at FH. The KNI values from NfPfKf treatment varied between 0.95 and 1.02 at 4 MAP and 0.8 and 1.0 at FH. There was a linear relationship between relative biomass yield and NI across the locations. In Edo, about 69, 46 and $62 \%$ of the variation for the relative biomass for all treatments was explained by NNI, PNI and KNI (Fig. 4.5). In Cross River, 73, 63 and $53 \%$ of the variation was explained (Fig. 4.5), while in Benue, only 33, 30 and $27 \%$ of the variation was obtained (Fig. 4.5). The NNI and PNI values for Edo fell on the 1:1 line, whereas KNI was shifted to the left. This indicates that $\mathrm{K}$ was lower than in Cross River at equivalent biomass amounts. For Cross River NNI and PNI were lower than for Edo, suggesting that $\mathrm{K}$ supply was most limiting in Edo, while in Cross River, $\mathrm{K}$ supply was sufficiently and $\mathrm{N}$ and $\mathrm{P}$ were less abundantly available. At Benue, the NNI, PNI and KNI were on the left side of the 1:1 line, indicating strong dilution of the three nutrients. The patterns strongly differed for 2016 and 2017, where 2017 was relatively close to the 1:1 line. Especially in 2016, the final harvest in Benue had relatively low nutrient uptake when compared to Edo and Cross River, resulting in small nutrient concentrations and low NNI, PNI and KNI values. The largest uptake rates after the dry period for Benue however were similar to the other sites (Table 4.2).The low NI value may result from a dry top-soil, with temporary unavailable nutrients and low plant nutrient reserves while high uptake rates after the drought were sufficient to sustain maximum growth rates leading to strong nutrient dilution. This indicates that under very dry conditions, plant nutrient concentrations poorly reflect nutrient availability. 


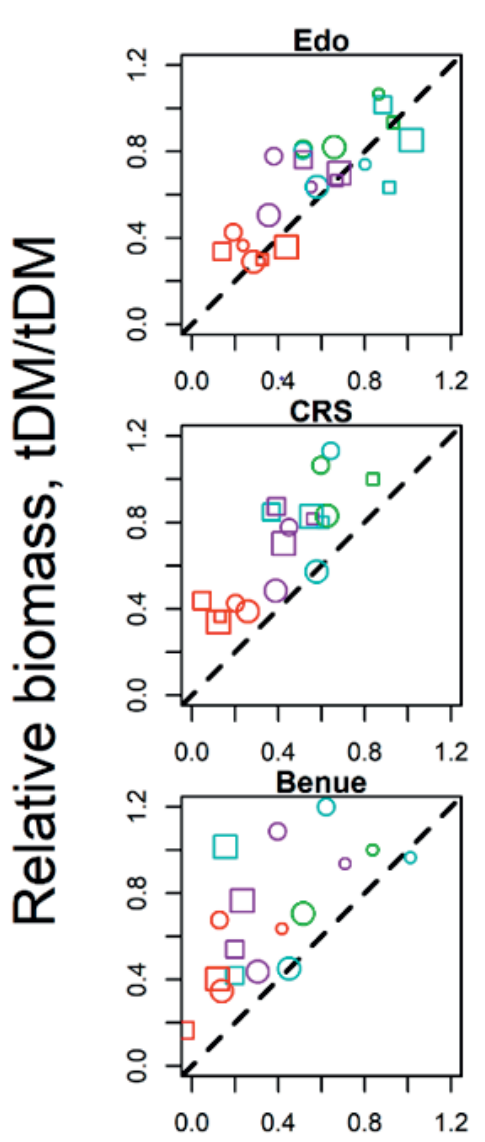

$\mathrm{NNI}$
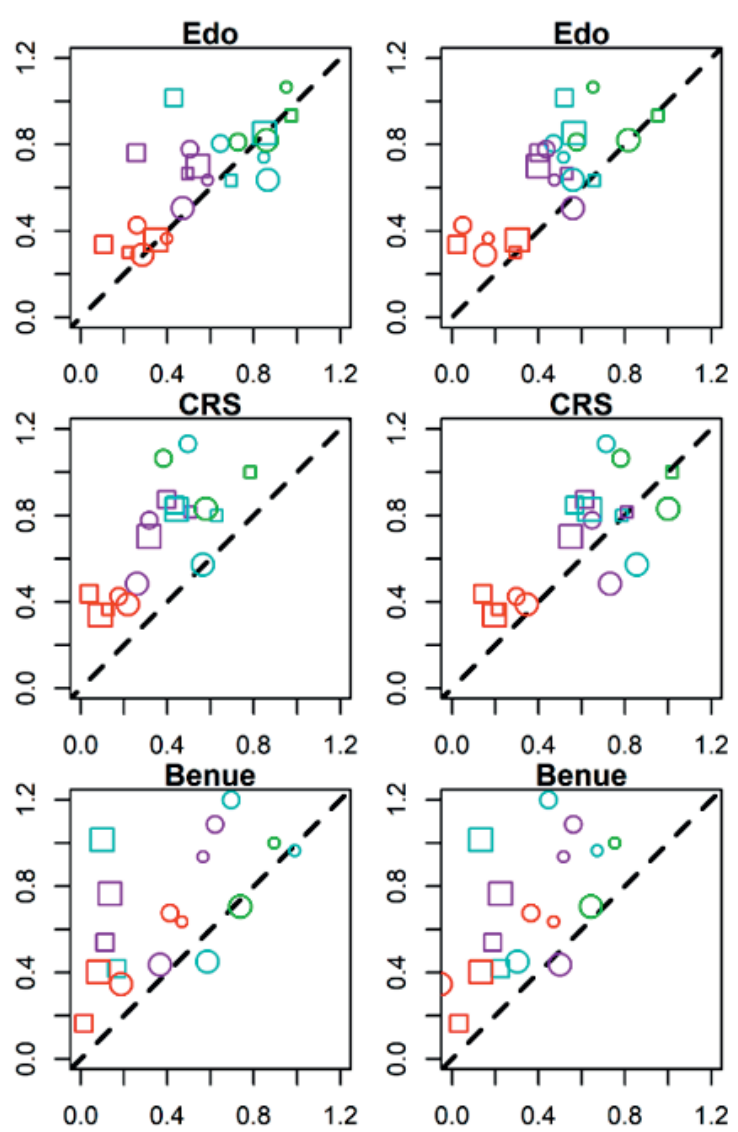

$\mathrm{PNI}$

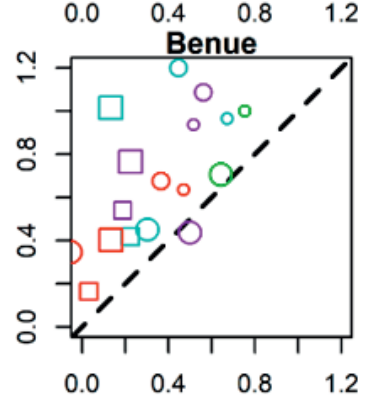

$\mathrm{KNI}$

Fig. 4.5. Relationships between the relative accumulated biomass and the $\mathrm{N}, \mathrm{P}$ and $\mathrm{K}$ nutrition indices for cassava at 4 and 8 months after planting and at final harvest with different $\mathrm{N}, \mathrm{P}$ and $\mathrm{K}$ application rates in three locations - Edo, Cross River and Benue. Relative biomass is defined here as the ratio of biomass in each plot and the mean of the biomass in the three NfPfKf plots per location for each harvest. Different symbols indicate values recorded in plots for the year with squares for 2016 and circles for 2017 and colors for treatments (red for control, purple for N150P40K180, cyan for NfPfK180 and green for NfPfKf). The small and intermediate symbol sizes were used for the 4 and 8 MAP sampling while the largest symbol was used for final harvest. The black dashed line is the 1:1 line. There were overlap or missing points due to either; relative biomass for Cross River at 4 and 8 MAP in 2016 did not differ much for treatments or no available data for Benue 2016 and Cross River 2017 at 4 MAP. Also, NfPfPf treatment at final harvest in Benue 2016 had low NI (0.3) with high relative biomass of 1.3.

\subsection{Discussion}

Nutrient uptake in cassava was mostly concentrated in the first 4 months but continued after return of the rains. In the dry period, small amounts of nutrients were taken up or even lost, depending on the location. At 4 MAP, plants already took up on average 67,61 and $52 \%$ of N, P and $\mathrm{K}$ that was present 
in the whole plant (leaves, stems and storage roots) at final harvest. In Edo, at $8 \mathrm{MAP}$, the uptake of N, $\mathrm{P}$ and $\mathrm{K}$ increased only by $4,1.1$ and $10 \%$ in the fertilized treatments from 4 MAP. In the unfertilized treatment, there was no difference in $\mathrm{N}$ and $\mathrm{K}$ uptake between 4 and $8 \mathrm{MAP}$, only $\mathrm{P}$ uptake increased by $3.5 \%$. The peak nutrient uptake rate occurred in the first 4 MAP. At this stage, approximately twothird of total whole plant $\mathrm{N}$ and $\mathrm{P}$ and half of $\mathrm{K}$ were taken up, while only one-third of whole season total biomass was produced (Fig. 4.1). In Edo, nutrient uptakes strongly reduced in the drier part of the season, while biomass growth continued. The soil type in Edo allowed for deep rooting, and plants likely had access to deeper soil water while nutrients were not available for uptake in the top soil because this soil layer was too dry. It is possible that excess nutrient uptake in the first part of the season is needed to support growth during this period, with dilution as a result. This means that split fertilizer application, such as top dressing with $\mathrm{N}, \mathrm{P}$ and $\mathrm{K}$ after the dry season could benefit cassava and may strongly reduce nutrient loss but may also reduce growth in the dry season for sites with deep soil water availability. From this, it is unclear what the best fertilizer strategy would be: split applications after drought or a large initial supply. Our results suggest that a substantial supply of nutrients is needed before the dry season for sites where the crop can access soil water at depth.

The fastest uptake rates of $\mathrm{N}$ and $\mathrm{P}$ were obtained in Edo, while the largest $\mathrm{K}$ uptake rate was obtained in Cross River with values of 2.1, 0.25 and $1.25 \mathrm{~kg} \mathrm{ha}^{-1} \mathrm{~d}^{-1}$ for $\mathrm{N}, \mathrm{P}$ and $\mathrm{K}$ respectively. The high nutrient uptake rate observed in Edo is related to availability of these nutrients and deep rooting ability of cassava (Mengel and Barber, 1974), as the soil type in Edo is porous and permits deep rooting, with large amount of soil water available to plants even during dry periods (van den Beuken, 2018). Potassium was the most limiting nutrient at Edo, while soils in Cross River had a higher K availability. The least nutrient uptake rate was recorded for Benue. This could be attributed to limitations in soil water availability resulting from shallow rooting due to a some periodic water stagnation at depth due to a clay-rich layer resulting in lower soil moisture availability in the dry season (van den Beuken, 2018) and a large impact of the seasonal dry conditions (Adiele et al. Chapter 3).

The relative nutrient uptake and allocation to plant parts varied over time but was similar for fertilized and unfertilized plants although the fertilized plants absorbed nutrients in much greater quantities, concurring with Howeler (2012). Results from our study show that varied fertilizer rates and locational differences did not result in any changes or modifications of cassava physiology. At the first harvest at $4 \mathrm{MAP}, \mathrm{N}$ was mostly partitioned to the leaves. The partitioning to leaves for $\mathrm{N}$ significantly reduced at $8 \mathrm{MAP}$, while at the same time, $\mathrm{N}$ partitioning to the stems increased. The regrowth of new leaves with onset of rains, resulted in a larger partitioning of $\mathrm{N}$ to leaves while partitioning to stems was smaller (Fig. 4.2) resulting in a strong dilution of $\mathrm{N}$ in the stems. The storage root was the primary sink for $\mathrm{P}$ and $\mathrm{K}$, demonstrated by high storage root/shoot ratios, while the shoot was the primary sink for N (Fig. 4.2), increasing as DM increased.

Concentrations of nutrients in the cassava leaves varied with the growth stage, but within a narrow range throughout the season, as previously observed by Howeler (2012). The leaf $\mathrm{N}$ concentrations we observed were within the sufficiency range of 45 to $60 \mathrm{~g} \mathrm{~kg}^{-1}$ suggested for cassava (Santos et al., 2014). Contrary to the finding of Howeler (2012), stem N concentration increased at 8 MAP (dry season) (Fig. 4.3), while $\mathrm{P}$ and $\mathrm{K}$ concentration decreased in stems and roots (Fig. 4.3). This could be due to resorption of $\mathrm{N}$ from senescing leaves and storage in the already $\mathrm{N}$-rich stems. At this stage, stem mass increased, thereby diluting the $\mathrm{P}$ and $\mathrm{K}$ concentration in the stem tissue. In addition, He and Dijkstra (2014) observed that plant $\mathrm{P}$ concentration decreased more than $\mathrm{N}$ during dry periods. This was because available soil $\mathrm{N}$ concentrations increased while those of $\mathrm{P}$ decreased. Potassium concentration varied least in the storage roots; consistent with reports from Howeler (2002). Also, Mallarino and Higashi (2009) observed in cereal crops that $\mathrm{K}$ concentrations vary less in grain than in vegetative tissues across 
a range of conditions. Understanding these trends in nutrient concentrations during cassava growth stages are important to determine times of sampling and interpretation of plant analysis results to identify nutrient deficiencies.

Our results suggest that nutrient dilution was stronger in cassava than in other crops (Greenwood et al., 1990; Justes et al., 1994; Ciampitti et al., 2013). The nutrient dilution may have been affected by the rapid storage root growth and translocation of assimilates to the roots, especially, under non-nutrient limiting conditions and water availability, as was the case in potato (Gomez et al., 2018). The NfPfKf treatment allowed a significant increase in growth rate and the data points were considered as corresponding to sufficiency level (Fig. $4.4 \mathrm{a}, \mathrm{b}$ and c). As expected, the whole plant nutrient concentration for maximum growth $\left(\mathrm{Nc}=82 \mathrm{DM}^{-0.61}, \mathrm{Pc}=7.4 \mathrm{DM}^{-0.54}\right.$ and $\left.\mathrm{Kc}=43 \mathrm{DM}^{-0.54}\right)$ decreased with increasing biomass resulting mainly from greater accumulation of assimilates in the storage roots and stems. Crop aging and plant physiology contribute also to the decrease in nutrient concentration. This is as a result of decrease in leaf area ratio (leaf area per unit of plant mass) as plants invest a greater proportion of biomass in structural (development of stems and storage roots) relatively to metabolic (e.g. leaf) tissues (Lemaire et al., 2008). The $\mathrm{P}$ and $\mathrm{K}$ requirements for optimal plant growth are $3-10$ and $20-50 \mathrm{~g} \mathrm{~kg}^{-1}$ whole plant material (Hawkesford and White, 2012). Generally, the nutrient dilution of cassava is somewhat similar to potato (Marouani et al., 2014; Gómez et al., 2018), with higher dilution coefficients (b) than cereals (Ciampitti et al., 2013; He et al., 2017). Cassava and potato accumulate mainly starch in roots or tubers, thus plant $\mathrm{N}, \mathrm{P}$ and $\mathrm{K}$ concentrations would decline more rapidly with increasing crop mass as storage organ filling occurs. Grain and legume crops accumulate large amounts of proteins in the grains, with smaller assimilate conversion efficiency hence less decline in plant $\mathrm{N}, \mathrm{P}$ and $\mathrm{K}$ concentration as the plants develop (Lemaire, 2012). Also, differences in environmental conditions could contribute to the larger $a$ and $b$ coefficients in cassava due to high temperature and radiation in the tropics. As more radiation is captured, energy is made available for the plants to produce more assimilates and increase biomass. He et al. (2017) reported differences in dilution coefficients of rice (Oryza sativa L.) cultivated in southern and eastern China, which was attributed to differences in temperature and solar radiation. As lower temperature and radiation resulted in slower dilution. In our study, the amount of dry matter explained about $65 \%$ of variation in nutrient concentrations for $\mathrm{N}, \mathrm{P}$ and $\mathrm{K}$. This indicates that other factors may have contributed to the nutrient dilution e.g., crop age, sampling/harvest time spacing, nutrient availability and self-shading of leaves.

Nutrition indices indicate nutrient deficiency, sufficiency, luxury consumption or excesses (He et al., 2017; Gómez et al., 2018). In our study, NI of the non-nutrient limiting treatments at 4 MAP and FH in Edo and Cross River were assumed to be in the sufficiency or luxury consumption zones. The obtained NNI ranged between $0.1-1.13$ (4 MAP - FH), while most studies reported NNI between $0.25-1.5$ for potato and $0.45-1.53$ for rice (Marouani et al., 2014; He et al., 2017; Gómez et al., 2018). Though these authors obtained NNI by dividing the $\mathrm{N}$ concentration in the DM by the critical $\mathrm{N}$ concentration. The only available work on PNI (Zamuner et al., 2016) recorded values $>1$ when potato was supplied with $100 \mathrm{~kg} \mathrm{ha}^{-1} \mathrm{P}$, in the Pampas region of Argentina. Though there is yet no known reported values of KNI either on cassava or other crops, the standard used to quantify the status of NNI and PNI were used to evaluate that of KNI values obtained from this study. The lowest nutrition indices of $\mathrm{N}, \mathrm{P}$ and $\mathrm{K}$ were obtained from the unfertilized treatments and during the dry season (Fig. 4.5). The NI can be used to assess the effect of nutrient on crop yield, as greater yields in this study were associated with high nutrient amounts in the crop (Fig. 4.5). We observed positive linear relationships between relative biomass yield and NI estimated at different growth stages which is consistent with findings of Marouani et al. (2014) and He et al. (2017) for potato and rice, respectively. Relative biomass yield increased with increasing NI, especially in Edo and Cross River. However, the relationship was weak in Benue in 2016 which may be due to the specific conditions for this year with late planting and limited nutrient 
availability in the first few months due to dry topsoil but large nutrient uptake and growth rates after the dry period.

\subsection{Conclusion}

Our study provides essential insight in the dynamics of nutrient uptake and uptake rates of cassava under West African conditions. Results indicated that one-third of the total biomass expected at 12-14MAP is achieved at 4MAP under non-water limiting conditions. This can be used as a proxy for estimating final harvest biomass at 4MAP. More than half of the total nutrient uptake was also required at that period, providing insights into optimizing timing of nutrient applications and management for maximum yield response. Also, our results enable an understanding of the dynamics of nutrient concentrations among cassava plant parts during growth. This is important in terms of time of sampling and interpretation of plant analysis results. Nutrient dilution curves for $\mathrm{N}, \mathrm{P}$ and $\mathrm{K}$ at different application rates were quantified for the first time in cassava. We observed stronger nutrient dilution coefficients than those reported for most crops. Under conditions without water deficiency, the defined nutrition indices were linearly related to relative crop growth rates. Nutrition index values remained more or less constant throughout the growing season. These insights are key to further develop water- and nutrient limited crop growth models that help to further optimize nutrition and to help us understand how water and nutrient limitations interact with crop growth rates and fertilizer response under a range of environments. Determining nutritional status of cassava at different growth stages from N, P and K dilution curves allows identification of specific deficiencies and will in future enable adjustments in supply of these elements to increase yields.

\section{Acknowledgements}

We thank the Netherlands Fellowship Program (NUFFIC) and the African Cassava Agronomy Initiative (ACAI) of IITA for funding. We are grateful to A. Olojede and C. Ifenkwe for their assistance in the field. 


\subsection{Appendices}

Table 4.A1. Uptake of N, P, and K in leaves, stem, and storage roots for cassava grown in three locations at 4 months after planting (MAP)

\begin{tabular}{|c|c|c|c|c|c|}
\hline \multirow[b]{3}{*}{ Treatment } & \multicolumn{2}{|l|}{2016} & \multicolumn{2}{|l|}{2017} & \\
\hline & Cross River & Edo & Benue & Edo & \\
\hline & Leaf/Stem/Roots & Leaf/Stem /Roots & Leaf/Stem /Roots & Leaf/ Stem /Roots & \\
\hline & & $\mathbf{N}\left(\mathrm{g} \mathrm{m}^{-2}\right)$ & & & \\
\hline Control & $3.29 / 1.0 / 1.49$ & $3.47 / 1.18 / 4.33$ & $2.64 / 0.59 / 1.13$ & $5.3 / 1.24 / 1.59$ & \\
\hline N150P40K180 & $9.18 / 2.83 / 4.87$ & $9.74 / 3.13 / 6.75$ & $4.68 / 1.31 / 2.23$ & $11.91 / 2.05 / 2.78$ & \\
\hline NfPfK180 & $9.63 / 3.35 / 4.78$ & $13.48 / 3.44 / 7.49$ & $6.08 / 1.70 / 2.89$ & $16.52 / 3.52 / 3.34$ & \\
\hline NfPfKf & $13.50 / 4.57 / 6.59$ & $11.72 / 5.0 / 12.04$ & $4.68 / 1.51 / 3.5$ & $18.41 / 3.71 / 6.36$ & \\
\hline $\begin{array}{l}\text { ANOVA } \\
\text { SE }(0.05)\end{array}$ & $\begin{array}{l}\text { Treatment*Year } \\
\mathrm{ns} / \mathrm{ns} / \mathrm{ns}\end{array}$ & $\begin{array}{l}\text { Treatment } \\
2 / 0.65 / 1.71\end{array}$ & $\begin{array}{l}\text { Year } \\
\text { ns/ns/1.14 }\end{array}$ & $\begin{array}{l}\text { Location } \\
2.01 / 0.59 / 1.15\end{array}$ & $\begin{array}{l}\text { Treatment*Location } \\
\text { ns/ns/ns }\end{array}$ \\
\hline & & $\mathbf{P}\left(\mathrm{g} \mathrm{m}^{-2}\right)$ & & & \\
\hline Control & $0.24 / 0.19 / 0.18$ & $0.17 / 0.23 / 0.39$ & $0.16 / 0.1 / 0.25$ & $0.38 / 0.4 / 0.4$ & \\
\hline N150P40K180 & $0.7 / 0.48 / 0.59$ & $0.44 / 0.48 / 0.85$ & $0.24 / 0.2 / 0.38$ & $0.76 / 0.54 / 0.65$ & \\
\hline NfPfK180 & $0.9 / 0.62 / 0.5$ & $0.6 / 0.66 / 0.94$ & $0.32 / 0.34 / 0.52$ & $1.05 / 0.91 / 0.76$ & \\
\hline NfPfKf & $1.06 / 0.84 / 0.72$ & $0.52 / 1.07 / 1.78$ & $0.27 / 0.26 / 0.61$ & $1.22 / 0.95 / 1.34$ & \\
\hline $\begin{array}{l}\text { ANOVA } \\
\text { SE (0.05) }\end{array}$ & $\begin{array}{l}\text { Treatment*Year } \\
\text { Ns/ns/ns }\end{array}$ & $\begin{array}{l}\text { Treatment } \\
\mathrm{ns} / 0.12 / 1.71\end{array}$ & $\begin{array}{l}\text { Year } \\
\mathrm{ns} / \mathrm{ns} / 1.14\end{array}$ & $\begin{array}{l}\text { Location } \\
0.13 / 0.12 / 1.15\end{array}$ & $\begin{array}{l}\text { Treatment*Location } \\
\mathrm{ns} / \mathrm{ns} / \mathrm{ns}\end{array}$ \\
\hline & & $\mathbf{K}\left(\mathrm{g} \mathrm{m}^{-2}\right)$ & & & \\
\hline Control & $0.9 / 0.81 / 1.83$ & $0.52 / 0.46 / 3.36$ & $0.69 / 0.81 / 2.17$ & $0.4 / 0.69 / 2.16$ & \\
\hline N150P40K180 & $3.75 / 3.69 / 5.23$ & $1.86 / 2.78 / 4.83$ & $1.03 / 1.42 / 3.15$ & $2.58 / 1.72 / 4.26$ & \\
\hline NfPfK180 & $4.09 / 3.81 / 4.35$ & $2.34 / 2.6 / 5.89$ & $1.38 / 1.65 / 3.19$ & $3.33 / 2.56 / 3.91$ & \\
\hline NfPfKf & $5.68 / 4.9 / 6.32$ & $2.23 / 5.25 / 10.1$ & $1.16 / 1.29 / 4.24$ & $3.42 / 3.17 / 7.34$ & \\
\hline ANOVA & Treatment*Year & Treatment & Year & Location & Treatment*Location \\
\hline SE $(0.05)$ & $\mathrm{ns} / \mathrm{ns} / \mathrm{ns}$ & $\mathrm{ns} / 0.78 / 0.9$ & $\mathrm{~ns} / \mathrm{ns} / \mathrm{ns}$ & $0.57 / 2.4 / 1.0$ & $0.40 / \mathrm{ns} / \mathrm{ns}$ \\
\hline
\end{tabular}


Table 4.A2. Uptake of N, P, and $\mathrm{K}$ in leaves, stem, and storage roots for cassava grown in three locations at 8 months after planting (MAP).

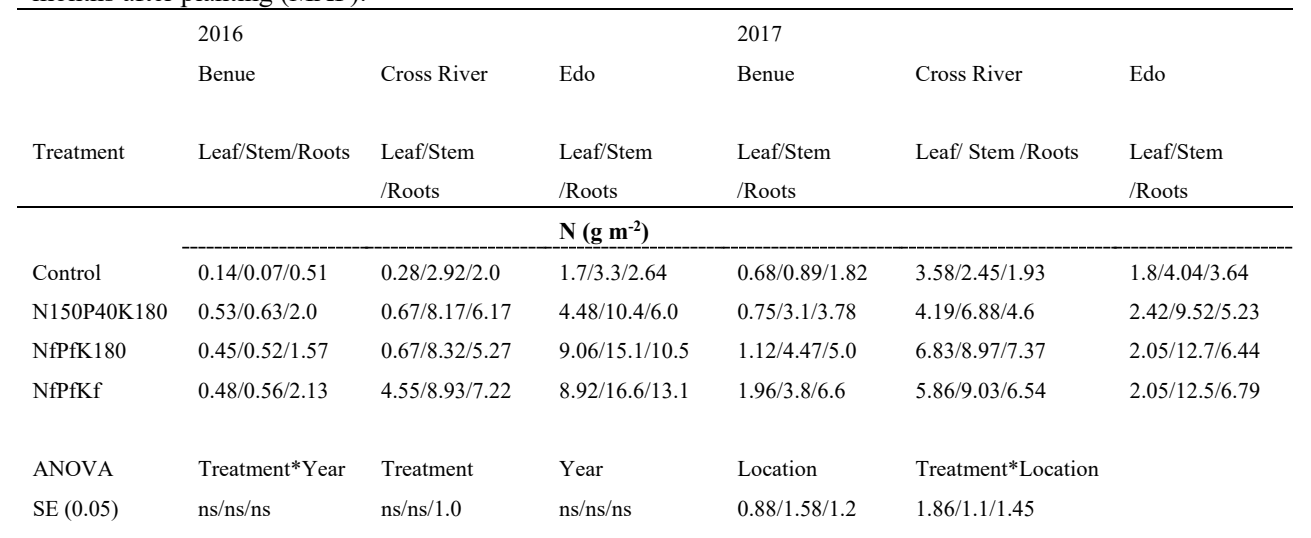

P $\left(\mathrm{g} \mathrm{m}^{-2}\right)$

$\begin{array}{lllllll}\text { Control } & -0.01 / 0.01 / 0.07 & 0.01 / 0.28 / 0.29 & 0.07 / 0.39 / 0.34 & 0.04 / 0.16 / 0.39 & 0.17 / 0.23 / 0.43 & 0.12 / 0.56 / 0.58 \\ \text { N150P40K180 } & 0.02 / 0.08 / 0.22 & 0.03 / 0.84 / 0.87 & 0.14 / 0.74 / 0.77 & 0.04 / 0.4 / 0.69 & 0.2 / 0.51 / 0.74 \\ \text { NfPfK180 } & 0.02 / 0.06 / 0.19 & 0.03 / 0.93 / 0.85 & 0.41 / 0.95 / 1.13 & 0.06 / 0.52 / 0.75 & 0.33 / 0.73 / 1.19 \\ \text { NfPfKf } & 0.02 / 0.06 / 0.25 & 0.24 / 1.14 / 1.0 & 0.41 / 1.07 / 1.38 & 0.1 / 0.53 / 1.0 & 0.27 / 0.6 / 1.0 \\ & & & & & 0.12 / 1.67 / 1.15 \\ \text { ANOVA } & \text { Treatment*Year } & \text { Treatment } & \text { Year } & \text { Location } & \text { Treatment*Location } \\ \text { SE (0.05) } & \text { ns/ns/ns } & \text { ns/ns/1.01 } & \text { ns/ns/ns } & 0.04 / 0.16 / 1.2 & \text { ns } / \mathrm{ns} / \mathrm{ns}\end{array}$

\begin{tabular}{|c|c|c|c|c|c|c|}
\hline \multirow[b]{2}{*}{ Control } & \multicolumn{5}{|c|}{$\mathbf{K}\left(\mathrm{g} \mathrm{m}^{-2}\right)$} & \multirow[b]{2}{*}{$0.21 / 0.93 / 2.35$} \\
\hline & $0.04 / 0.04 / 0.74$ & $0.05 / 1.04 / 2.58$ & $0.35 / 0.94 / 1.51$ & $0.14 / 0.86 / 3.26$ & $0.75 / 1.06 / 3.37$ & \\
\hline N150P40K180 & $0.12 / 0.34 / 2.6$ & $0.16 / 4.35 / 7.5$ & $0.65 / 4.6 / 5.6$ & $0.15 / 1.93 / 5.59$ & $1.18 / 3.48 / 7.12$ & $0.39 / 5.29 / 5.89$ \\
\hline NfPfK 180 & $0.12 / 0.3 / 1.98$ & $0.16 / 4.51 / 6.47$ & $1.33 / 6.0 / 7.6$ & $0.25 / 3.06 / 4.72$ & $1.65 / 4.81 / 8.84$ & $0.34 / 6.36 / 5.67$ \\
\hline NfPfKf & $0.13 / 0.35 / 2.75$ & $1.07 / 4.84 / 7.58$ & $1.73 / 7.13 / 10.4$ & $0.4 / 2.28 / 6.92$ & $1.45 / 5.41 / 9.02$ & $0.38 / 7.27 / 6.74$ \\
\hline ANOVA & Treatment*Year & Treatment & Year & Location & Treatment*Location & \\
\hline SE $(0.05)$ & $\mathrm{ns} / \mathrm{ns} / \mathrm{ns}$ & $\mathrm{ns} / 0.82 / 0.87$ & $\mathrm{~ns} / \mathrm{ns} / \mathrm{ns}$ & $0.19 / 0.9 / 1.14$ & $\mathrm{~ns} / 0.58 / \mathrm{ns}$ & \\
\hline
\end{tabular}


Table 4.A3. Uptake of N, P, and K in leaves, stem, and storage roots for cassava grown in three locations at final harvest $(\mathrm{FH})$

\begin{tabular}{|c|c|c|c|c|c|c|}
\hline \multirow{4}{*}{ Treatment } & \multicolumn{3}{|l|}{2016} & \multicolumn{3}{|l|}{2017} \\
\hline & Benue & Cross River & Edo & Benue & Cross River & Edo \\
\hline & Leaf/Stem/Roots & Leaf/Stem & Leaf/Stem & Leaf/Stem & Leaf/Stem /Roots & Leaf/Stem \\
\hline & & /Roots & /Roots & /Roots & & /Roots \\
\hline & & & $\mathbf{N}\left(\mathrm{g} \mathrm{m}^{-2}\right)$ & & & \\
\hline Control & $2.04 / 1.47 / 2.82$ & $3.05 / 2.52 / 2.85$ & $7.36 / 7.01 / 5.04$ & $2.64 / 1.26 / 1.75$ & $4.2 / 2.69 / 5.98$ & $5.15 / 3.66 / 4.54$ \\
\hline N150P40K180 & $4.93 / 2.84 / 5.62$ & $4.86 / 7.37 / 8.24$ & 7.91/11.6/11.0 & $2.92 / 1.92 / 4.27$ & $5.89 / 4.48 / 6.38$ & $3.4 / 7.88 / 6.09$ \\
\hline NfPfK 180 & $5.84 / 4.43 / 4.78$ & $8.77 / 9.08 / 8.15$ & $11.4 / 19.2 / 14.2$ & $2.48 / 2.86 / 5.87$ & $7.45 / 7.1 / 8.72$ & $3.86 / 13.1 / 9.15$ \\
\hline NfPfKf & $6.59 / 6.85 / 8.77$ & $12.1 / 14.2 / 12.2$ & $15.1 / 17.6 / 19.0$ & $3.74 / 4.02 / 9.99$ & $7.13 / 8.36 / 12.9$ & $6.93 / 10.9 / 13.7$ \\
\hline ANOVA & Treatment*Year & Treatment & Year & Location & Treatment*Location & \\
\hline \multirow[t]{2}{*}{ SE $(0.05)$} & $\mathrm{ns} / \mathrm{ns} / \mathrm{ns}$ & $1.87 / 2.19 / 1.25$ & $1.36 / \mathrm{ns} / \mathrm{ns}$ & $1.39 / 2.0 / 2.04$ & $\mathrm{~ns} / \mathrm{ns} / \mathrm{ns}$ & \\
\hline & & & $\mathbf{P}\left(\mathrm{g} \mathrm{m}^{-2}\right)$ & & & \\
\hline Control & $0.13 / 0.14 / 0.49$ & $0.23 / 0.26 / 0.42$ & $0.51 / 0.76 / 0.72$ & $0.18 / 0.17 / 0.41$ & $0.20 / 0.31 / 0.95$ & $0.37 / 0.42 / 0.77$ \\
\hline N150P40K180 & $0.31 / 0.27 / 0.96$ & $0.33 / 0.67 / 1.09$ & $0.64 / 1.27 / 1.24$ & $0.19 / 0.26 / 0.76$ & $0.28 / 0.36 / 0.96$ & $0.24 / 1.02 / 1.22$ \\
\hline NfPfK180 & $0.31 / 0.41 / 1.17$ & $0.57 / 1.03 / 1.15$ & $0.92 / 2.26 / 1.6$ & $0.18 / 0.44 / 0.95$ & $0.4 / 0.83 / 1.49$ & $0.31 / 2.08 / 1.84$ \\
\hline NfPfKf & $0.41 / 0.67 / 1.72$ & $0.99 / 1.86 / 1.71$ & $1.23 / 2.33 / 2.93$ & $0.29 / 0.56 / 1.87$ & $0.38 / 0.83 / 2.07$ & $0.6 / 1.65 / 2.48$ \\
\hline ANOVA & Treatment*Year & Treatment & Year & Location & Treatment*Location & \\
\hline \multirow[t]{2}{*}{ SE $(0.05)$} & $\mathrm{ns} / \mathrm{ns} / \mathrm{ns}$ & $0.16 / 0.26 / 1.23$ & $0.12 / \mathrm{ns} / \mathrm{ns}$ & $0.11 / 0.27 / 2.04$ & $\mathrm{~ns} / 0.22 / \mathrm{ns}$ & \\
\hline & & & $\mathbf{K}\left(\mathrm{g} \mathrm{m}^{-2}\right)$ & & & \\
\hline Control & $0.54 / 1.11 / 6.25$ & $0.54 / 1.13 / 4.17$ & $1.73 / 1.79 / 5.28$ & $0.89 / 1.50 / 3.81$ & $0.72 / 1.48 / 7.05$ & $0.60 / 1.80 / 3.51$ \\
\hline N150P40K180 & $1.56 / 2.29 / 12.3$ & $1.22 / 4.59 / 9.73$ & $1.31 / 3.61 / 8.78$ & $1.14 / 3.23 / 6.16$ & $1.27 / 4.53 / 10.2$ & $0.71 / 6.34 / 7.63$ \\
\hline NfPfK180 & $1.84 / 4.29 / 14.3$ & $2.42 / 6.17 / 10.2$ & $2.64 / 6.65 / 9.9$ & $0.92 / 3.25 / 5.64$ & $1.76 / 5.76 / 12.1$ & $0.78 / 7.53 / 8.19$ \\
\hline NfPfKf & $2.23 / 5.99 / 20.9$ & $3.35 / 9.33 / 14.3$ & $4.34 / 10.0 / 18.1$ & $1.51 / 4.0 / 12.9$ & $1.68 / 6.82 / 18.3$ & $2.1 / 10.4 / 12.4$ \\
\hline ANOVA & Treatment*Year & Treatment & Year & Location & Treatment*Location & \\
\hline SE $(0.05)$ & $\mathrm{ns} / \mathrm{ns} / \mathrm{ns}$ & $0.5 / 0.72 / 1.49$ & $0.28 / \mathrm{ns} / \mathrm{ns}$ & $\mathrm{ns} / 1.45 / \mathrm{ns}$ & $\mathrm{ns} / 0.67 / \mathrm{ns}$ & \\
\hline
\end{tabular}



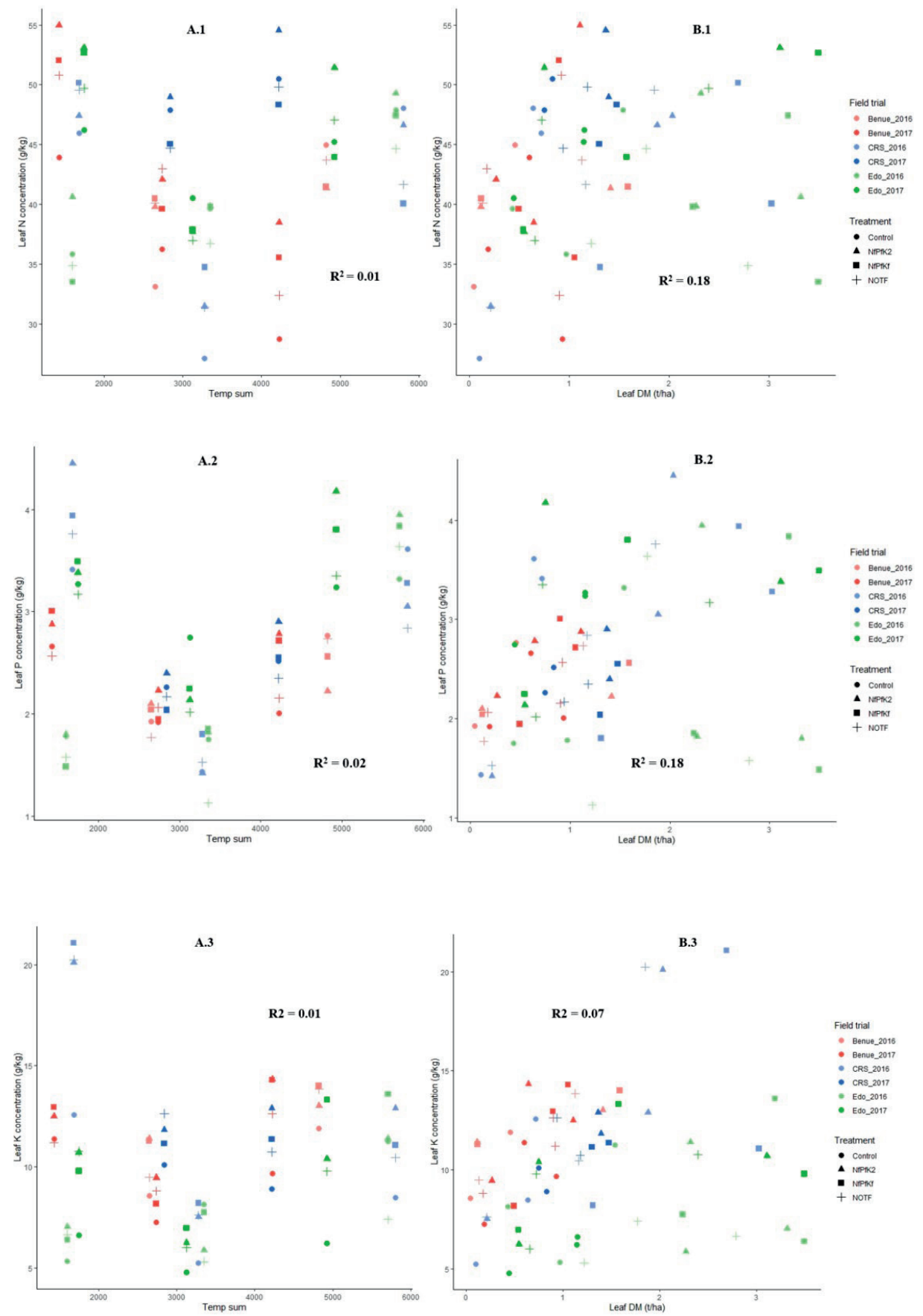

Fig. A1. N, P and K concentration dilution patterns in leaves as function of temperature sum (panels A, C, E) or leaf dry matter (panels B, D, F) across treatments, locations and years. NfPfK2 $=$ NfPfK180 and NOTF $=$ N150P40K180 

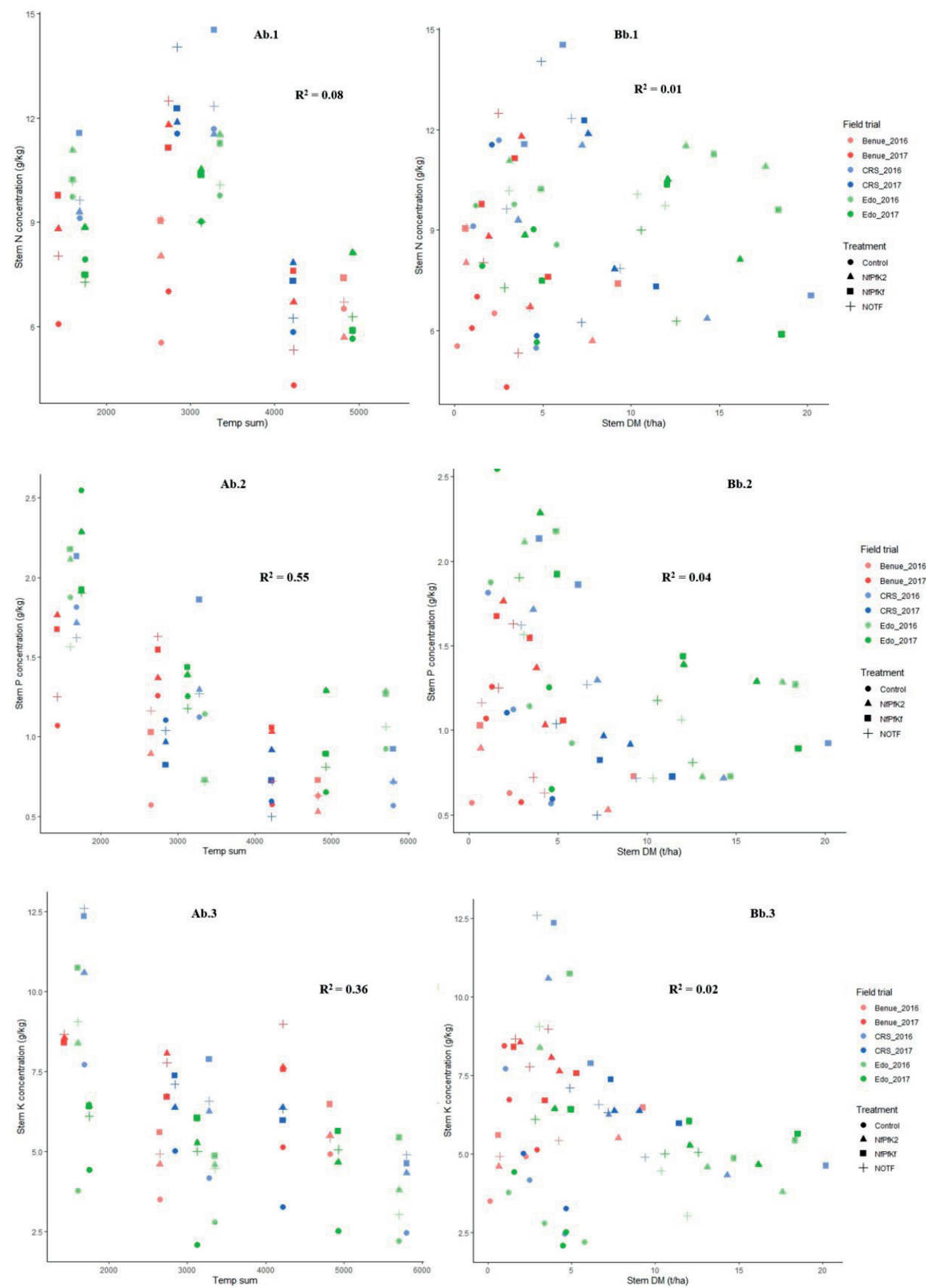

Fig. 4.A2. Stems DM N, P and K concentration dilution patterns during crop growth (4MAP to harvest), across all treatments, locations and years. NfPfK2 $=\mathrm{NfPfK} 180$ and NOTF $=\mathrm{N} 150 \mathrm{P} 40 \mathrm{~K} 180$. 

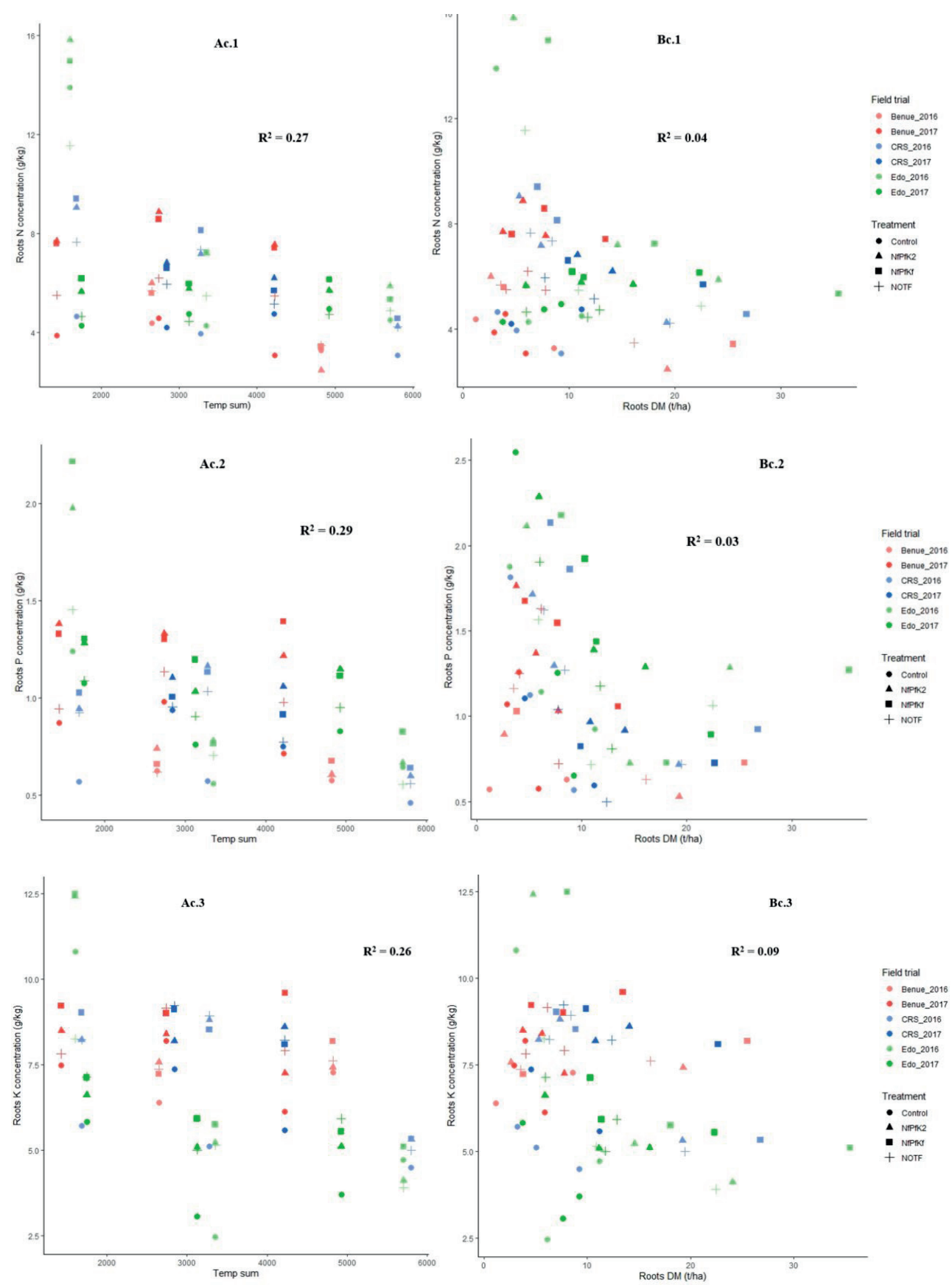

Fig. 4.A3. Storage roots DM N, P and K concentration dilution patterns during crop growth (4MAP to harvest), across all treatments, locations and years. NfPfK2 $=\mathrm{NfPfK} 180$ and NOTF $=\mathrm{N} 150 \mathrm{P} 40 \mathrm{~K} 180$ 



\section{Chapter 5. LINTUL-Cassava-NPK: a simulation model for nutrient-limited cassava growth}

This chapter is submitted as:

Adiele, J.G., Schut, A.G.T., Ezui, K.S., Giller, K.E. LINTUL-Cassava-NPK: a simulation model for nutrient-limited cassava growth. Submitted to Field Crops Research. 


\begin{abstract}
A solid understanding of the dynamics of plant nutrient requirements and uptake from the soil is needed to provide robust fertilizer recommendations, timing of applications and nutrient use efficiency. Our objective was to develop and test the crop model LINTUL-Cassava-NPK - to simulate biomass growth and yield of cassava under nutrient-limited conditions. We used experimental data in six fields from three different agro-ecologies in Nigeria: Tropical Rainforest - Ogoja and Ikom (Cross River), Rainforest Transition - Ekpoma (Edo) and Guinea Savanna - Otukpo (Benue) during two consecutive growing seasons from 2016 - 2018. Nutrient stress in the model was implemented by combining N, P and $\mathrm{K}$ nutrition indices (NI) to account for interaction of multi-nutrient limitations for crop growth. Nutrient uptake was determined by balancing demand and supply of nutrient equivalents. We parameterized and calibrated the model using observations from an experiment conducted under optimal growing conditions in Edo during the 2016 planting season. The model was then tested with data from experiments conducted in the 2017 season in Edo, Cross River and Benue. The model captured well the uptake patterns of $\mathrm{N}, \mathrm{P}$ and $\mathrm{K}$. Uptakes of $\mathrm{N}, \mathrm{P}$ and $\mathrm{K}$, and storage root yield were predicted with a small root mean squared error of $5.5 \mathrm{~g} \mathrm{~N} \mathrm{~m}^{-2}, 0.8 \mathrm{~g} \mathrm{P} \mathrm{m}^{-2}, 4.0 \mathrm{~g} \mathrm{~K} \mathrm{~m}^{-2}$ and $355 \mathrm{~g} \mathrm{DM}$ roots m$^{-2}$, with an $R^{2}$ of $0.7-0.8$ for linear relationships between simulated and observed values. The time course of development of nutrient-limited yield of green leaves, stems and storage root were simulated reasonably well. In general, the model responded well to both nutrient omissions and varying amounts of NPK. These findings increase our understanding of nutrient limitations and N, P and K interactions on cassava growth and yield. The model provided insight into surplus amounts of nutrients in the soil at the end of the season and specifically the need to balance supply of $\mathrm{N}$ and $\mathrm{K}$ for cassava. To our knowledge, this is the first tested crop model that includes the three macro-nutrients.
\end{abstract}

Keywords: nutrient uptake; balanced nutrition; root crops; simulation model; nutrient stress 


\subsection{Introduction}

Cassava (Manihot esculenta Crantz) is a major staple food crop in the tropics. Sustainable intensification of cassava has become necessary for food security in sub-Saharan Africa (SSA), especially with projected growth of the SSA population (UNDESA, 2017). Cassava also provides options for industrial starch processing and associated rural development (Rahman and Awerije, 2016; FAO, 2018). Insufficient supply of N, P and K restricts the productivity of crops. Understanding the dynamics of nutrient requirements and the impact of uptake limitations of cassava during the growth cycle enables prediction of cassava yields under nutrient limited conditions and may provide insight in best management practices to improve nutrient use efficiency. The nutrient contents of organs of the cassava plant vary during the growth cycle (Adiele et al. Chapter 4). Typically, plants dilute nutrients over time as carbon accumulates (Lemaire, 2012). Nutrients are translocated from one organ to another depending on the sink strength (Shibu et al., 2010), and whether they are mobile in the phloem (Eichert and Fernández, 2012). Although N, P and K have specific roles in plants (Hawkesford and White, 2012), their limitations impact average growth rates in a more or less linear fashion compared to when nutrient supply is balanced (Janssen et al., 1990). A crop's demand for nutrients at any given time is presumed to be determined by the difference between the current nutrient content in the tissue and a possible maximum content (Shibu et al., 2010).

Nutrient uptake rates decrease during drought for several reasons: the inability to transport nutrients, including reduction of nutrient supply through mineralization (Bista et al., 2018), partly compensated by higher concentrations in soil water and stronger diffusion. Severe drought strongly decreases nutrient demand and uptake rates from soil; the impact on plant growth is highly dependent on the intensity and duration of drought stress and the developmental stage of the plant (El-Sharkawy, 2007; Mithra et al., 2013). A decrease in nutrient uptake will result in lower growth rates when nutrients are deficient, which affects canopy cover and light interception.

Nitrogen availability affects photosynthesis through its impact on chlorophyll content, leaf area development and photosynthetic efficiency (El-Sharkawy and De Tafur, 2010; Ezui et al., 2017b). Phosphorus supply improves cassava growth through increased leaf area index (LAI) and photosynthesis of leaves (Pellet and El-Sharkawy, 1993; Howeler, 2017; Omondi et al., 2019). However, LAI increase in response to $\mathrm{P}$ supply did not directly increase root yield in all cassava varieties, suggesting that other aspects of canopy function such as, carbon fixation and assimilate use and partitioning interact in yield formation. Potassium has numerous functions in crop growth (Eichert and Fernández, 2012; Engels et al., 2012) and influences leaf appearance rates, especially at the early growth stages, and leaf size (Jordan-Meille and Pellerin, 2004; Engels et al., 2012). Ezui et al. (2017b) observed that K applications increased radiation use efficiency (RUE) in cassava, while $\mathrm{N}$ increased the amount of light intercepted. A decrease in cassava biomass production in response to $\mathrm{N}, \mathrm{P}$ and $\mathrm{K}$ deficiency is associated with reduced light interception by the canopy and a decrease in the use efficiency.

Knowledge of nutrient (N, P and $\mathrm{K}$ ) demand and uptake patterns under deficient conditions in cassava (Adiele et al. Chapter 4) can be used to develop a simulation model. After testing the model, it may be used for many purposes, including to generate crop responses for series of years in order to characterize cassava growth and nutrient uptake, provide location-specific fertilizer recommendation, and to extrapolate from the studied area to other areas where less detailed information is available. There are a few dynamic crop growth models for the simulation of nutrient-limited growth in crops. The Light INTerception and UTilization (LINTUL3) model for rice (Shibu et al., 2010) and Agricultural Production Systems Simulator (APSIM) for pearl millet (Akponikpè et al., 2010) models were developed primarily to simulate the crops responses to N supply. APSIM (P) was developed to simulate effects of P on common bean and maize (Delve et al., 2009). The simulation model of cassava 
(SIMCAS) simulates $\mathrm{N}$ and $\mathrm{K}$ uptake and effects on cassava (Mithra et al., 2013), assuming a proportional reduction in growth rate due to $\mathrm{N}$ or $\mathrm{K}$. The modelling approach of Shibu et al. (2010) in LINTUL3 incorporated the effects of nitrogen shortage on crop growth through growth reduction factors, similar to the approach used to simulate water stress in LINTUL2 for water-limited yield. A major breakthrough in crop growth modelling is needed to simulate NPK interactions and the relationships between soil available nutrients and crop demand over time. In this study, our objectives were to develop and test a dynamic model for cassava that simulates growth limited by $\mathrm{N}, \mathrm{P}$ and $\mathrm{K}$. The model, LINTUL-Cassava-NPK, is based upon the previously tested LINTUL-Cassava model (Ezui et al., 2018); Adiele et al. Chapter 3).

\subsection{Materials and methods}

\subsubsection{Model description}

LINTUL-Cassava model was developed to simulate potential and water-limited production. The crop's development as simulated by the model undertakes three development stages: (1) planting to sprouting, (2) sprouting to first branching and (3) first branching to harvest, as described in Ezui et al. (2018). In our study, the model was modified to LINTUL-Cassava-NPK in order to incorporate the development and growth of cassava under nutrient-limited conditions. The LINTUL-Cassava-NPK model describes $\mathrm{N}, \mathrm{P}$ and $\mathrm{K}$ demand and uptake by the crop in detail. The effect of the nutrients deficiency was expressed through a combined growth reduction factor, called nutrient nutrition index (NPKI). The following main processes in cassava growth and development are described in the LINTUL-Cassava-NPK model: 1) soil supply of NPK, 2) plant nutrient demand, 3) nutrient uptake and partitioning, 4) nutrient redistribution and 5) nutrient stress.

\subsubsection{Soil supply of $N, P$ and $K$}

In the model, available $\mathrm{N}, \mathrm{P}$ and $\mathrm{K}\left(\mathrm{g} \mathrm{m}^{-2}\right)$ for crop uptake is from two sources: nutrients present in the soil profile during the growing season and $\mathrm{N}, \mathrm{P}$ and $\mathrm{K}$ applied as fertilizers. Whilst $\mathrm{N}$ (and to a lesser extent $\mathrm{P}$ ) are mineralized from soil organic matter, $\mathrm{P}$ and $\mathrm{K}$ availability depends on the equilibrium between so-called plant available pools (the quantity or $\mathrm{Q}$ factor) and the concentration in the soil solution (the intensity or I factor) (Marschner and Rengel, 2012). Nutrients in the soil are modelled with three states per nutrient, including the amount of plant available nutrient in the soil $\left(A, \mathrm{~g} \mathrm{~m}^{-2}\right)$, and total nutrient from soil pools $\left(\mathrm{S}, \mathrm{g} \mathrm{m}^{-2}\right)$ and total available nutrients from fertilizer application $\left(F, \mathrm{~g} \mathrm{~m}^{-2}\right)$. It is assumed that $25 \%$ of total soil N, P and $\mathrm{K}$ supply was available at emergence, the remainder is assumed to become available at a constant rate, matching observed uptake patterns (Adiele et al. Chapter 4). The daily change in plant available nutrients $\left(R A, \mathrm{~g} \mathrm{~m}^{-2} \mathrm{~d}^{-1}\right)$ was determined as follows:

$$
R A_{N, P, K}=\frac{0.75 \times S_{N, P, K}}{0.9 \times S L}+\left(\operatorname{rec}_{N, P, K} \times r f_{N, P, K} \times F_{N, P, K}\right) \times W L I M I T-\operatorname{RUptake}_{N, P, K}
$$

It is assumed that nutrients from the $S$ pool ( $\mathrm{S}$ is a combination of measured nutrient uptake in plots without nutrient applications and an additional measured uptake when other macro nutrients are supplied), becomes available in 0.9 of total season length $(S L)$ in days. For fertilizers, the relative release rates $(r f)$ are assumed constant, with $r f_{N}=0.1, r f_{P}=0.01$ and $r f_{K}$ $=0.04$ and RUptake is the daily uptake of nutrients. Under drought, soil water limitation (WLIMIT) affect crop growth, reduces nutrient uptake, including fertilizer release rates. WLIMIT was calculated as follows:

$$
W L I M I T=T R A N R F /\left(K \_W A T E R+T R A N R F\right) \quad(\text { eq. } 2)
$$


Where TRANRF represents the transpiration reduction factor and $K \_W A T E R$ a parameter set to a value of 0.2. TRANRF reflects the drought stress of the crop, defined as the ratio between actual and potential transpiration where actual transpiration is limited by soil water content, a crop specific transpiration coefficient and potential transpiration.

\subsubsection{Nutrients in the crop}

For each plant organ, the model tracked changes in states for biomass and N, P and $\mathrm{K}$ uptakes. Minimum and maximum concentrations for each organ were provided as a function of temperature sum, and were linearly interpolated to arrive at daily values. All organs are assumed to be at equivalent nutrition index values, i.e. at the same relative distance to minimum and maximum concentrations. Nutrients are translocated between organs with a short delay and a time coefficient of 10 days was set. Although reallocation of nutrients was modelled, it does not have an effect on crop growth. Nutrient uptake depended on total nutrient demand and availability of nutrients in the soil.

\subsubsection{Crop nutrient translocation}

Nutrient uptake was allocated to organs depending on the weight of organs. Nutrients in dying leaves are reallocated to stem $(\mathrm{N})$ or storage organs $(\mathrm{P}$ and $\mathrm{K})$. As total nutrients lost with dying leaves were not known, it is assumed that these fallen leaves contain no nutrients. This was in our view reasonable, as measured recovery of nutrients from fertilizers and nutrient supply from the soil also did not include estimates of the amount of nutrients in dead leaves on the soil or from recycled nutrients from dead leaves that already decayed within the same season.

\subsubsection{Crop demand and uptake of $N, P$ and $K$}

The nutrient demand of the plant is calculated as the sum of the demand of each organ, computed as the difference between the actual and maximum amounts of nutrient in the plant organs. First, the actual and maximum amounts of nutrients were calculated from actual $(\mathrm{Ca})$ or maximum concentrations $(\mathrm{Cm})$ and weights $(W)$ of leaves $(L)$, stems $(S T)$, storage organs $(S O)$ and roots $(R T)$ :

$$
\begin{aligned}
& \operatorname{Act}_{N, P, K}=\operatorname{CaL}_{N, P, K} \times W L+\operatorname{CaST}_{N, P, K} \times W S T+\operatorname{CaSO}_{N, P, K} \times W S O+\operatorname{CaRT}_{N, P, K} \times W R T \text { (eq. 3) } \\
& \operatorname{Max}_{N, P, K}=C m L_{N, P, K} \times W L+C m S T_{N, P, K} \times W S T+C m S O_{N, P, K} \times W S O+C m R T_{N, P, K} \times W R T
\end{aligned}
$$

(eq.4)

Minimum and maximum concentrations of plant organs change as function of temperature sum. The measured values for minimum and maximum concentrations of $\mathrm{N}, \mathrm{P}$ and $\mathrm{K}$ in leaves, stems and storage organs were provided in look-up tables and linearly interpolated to obtain daily values. These values were multiplied with weights of plant organ to obtain the total minimum ( $\operatorname{Min}_{\mathrm{N}, \mathrm{P}, \mathrm{K}}$ ) (Table 5.SE) and maximum $\left(\operatorname{Max}_{\mathrm{N}, \mathrm{P}, \mathrm{K}}\right)$ amounts. The actual uptake of $\mathrm{N}, \mathrm{P}$ and $\mathrm{K}\left(\mathrm{g} \mathrm{m}^{-2}\right)$ is determined by crop demand and the plant available nutrients in the soil. To determine total nutrient demand and supply, both were converted to nutrient equivalents.

Nutrient equivalent demand $\left(N E D, \mathrm{~g} \mathrm{~m}^{-2}\right)$ was determined as:

$$
N E D=\left(\operatorname{Max}_{N}-A c t_{N}\right)+\left(\operatorname{Max}_{P}-A_{c} t_{P}\right) \times \frac{\operatorname{Max}_{N}}{\operatorname{Max}_{P}}+\left(\operatorname{Max}_{K}-A t_{K}\right) \times \frac{\operatorname{Max}_{N}}{\operatorname{Max}_{K}}
$$

Nutrient equivalents in the soil $\left(N E S, \mathrm{~g} \mathrm{~m}^{-2}\right)$ was computed as: 
$N E S=A_{N}+A_{P} \times \frac{\operatorname{Max}_{N}}{\operatorname{Max}_{P}}+A_{K} \times \frac{\operatorname{Max}_{N}}{\operatorname{Max}_{K}}$

The parameter $R N E$ represents the maximum daily nutrient equivalent uptake rate and its value was calibrated with a value of $0.012 \mathrm{~d}^{-1}$. However, its value could also be computed from the highest recorded measured uptake rates of $\mathrm{N}, \mathrm{P}$ and $\mathrm{K}$, as provided in Adiele et al. (Chapter 4).

Actual nutrient equivalent uptake is limited by either demand or supply:

$$
R N E_{U P}=\min \left(R N E \times N E S, \frac{N E D}{D E L T}\right)
$$

Actual uptake rate $(U P)$ of $\mathrm{N}, \mathrm{P}$ and $\mathrm{K}$ is limited by demand for these nutrients and should not exceed total demand for a specific nutrient or maximum soil supply per time-step (DELT):

$\frac{d U P_{N, P, K}}{d t}=\min \left(\frac{\operatorname{Max}_{N, P, K}-A c t_{N, P, K}}{D E L T}, \frac{A_{N, P, K}}{D E L T}, \frac{\operatorname{Max}_{N, P, K}}{\operatorname{Max}_{N}} \times \frac{R N E_{U P}}{N E S}\right)$

\subsubsection{Redistribution of $N, P$ and $K$}

In cassava, nutrients are redistributed to living plant organs from stem cuttings to form shoot at sprouting, from dying leaves to stem and storage roots at senescence, and from storage roots to form new leaves after dormancy. Biomass reallocation for cassava cuttings was described by Ezui et al. (2018), simply assuming that nutrients are transferred proportionally. Reallocation after drought from storage roots occurs in short periods when leaves were considered at maximum concentrations, where the required nutrients were reallocated from storage roots.

\subsubsection{Nutrient stress}

Crops undergo nutrient stress when nutrient concentrations are below critical values for maximum growth rates. Nutrition indices $(N I)$ were defined for $\mathrm{N}, \mathrm{P}$ and $\mathrm{K}$ and can range from 0 (acute shortage or deficiency of the nutrient) to 1 (nutrient sufficiency) status of the crop. Following Greenwood et al. (1986) and Angus and Moncur (1985), the nutrition indices (NI) were calculated as:

$N I_{N, P, K}=\frac{\operatorname{Act}_{N, P, K}-\operatorname{Min}_{N, P, K}}{O p t_{N, P, K}-\operatorname{Min}_{N, P, K}} \quad$ where $A c t \leq O p t$

where Act reflects the actual amount of nutrients in the plant, Min the minimum amount and Opt the optimum amount needed for maximum growth rates. The optimum amount was computed as follows:

$O p t_{N, P, K}=\operatorname{Min}_{N, P, K}+F R_{-} M A X \times\left(\operatorname{Max}_{N, P, K}-\operatorname{Min}_{N, P, K}\right)$

FR_MAX is a parameter which was set at a value of 0.8 .

The three nutrition indices were multiplied to account for interaction effects:

$\left\{\begin{array}{l}N P K I=\frac{c \times N I_{N} \times N I_{P} \times N I_{K}}{K_{N I}+N I_{N} \times N I_{P} \times N I_{K}} \quad \text { when } K_{N I} \leq K M A X \\ N P K I=1-\frac{c \times\left(1-N I_{N} \times N I_{P} \times N I_{K}\right)}{K_{N I}+\left(1-N I_{N} \times N I_{P} \times N I_{K}\right)} \text { when } K_{N I}>K M A X\end{array}\right.$

Where $c$ equals $K+1$ to ensure that when there is no stress, the $N P K I$ is also exactly 1, irrespective of the value of $K_{N I}$. The values for $K M A X$ (value of 4) and the $K_{N I}$ of 6.1 were calibrated (Table 5.1). These 
values mean that $N P K I$ was more strongly reduced when multiple nutrient stresses occurred, i.e. when $N I_{N} \times N I_{P} \times N I_{K}$ had a value of e.g. 0.8 , the $N P K I$ was slightly smaller with a value of 0.77 .

The effect of the nutrient reduction factor was included in the model to represent the effect of nutrient stress on crop performance, including effects on light interception and total crop growth rate:

$\left\{\begin{array}{l}\frac{d W}{d t}=R U E \times P A R_{\text {int }} \times T R A N R F \times(1-\text { Dormancy }, \text { when } T R A N R F \leq N P K I \\ \frac{d W}{d t}=R U E \times P A R_{\text {int }} \times N P K I \times(1-\text { Dormancy }), \text { when } T R A N R F>N P K I\end{array}\right.$

$P A R_{\text {int }}$ (MJ PAR $\mathrm{m}^{-2} \mathrm{~d}^{-1}$ ) is defined as the amount of light intercepted by the crop per day and per $\mathrm{m}^{2}$; where $R U E$ (g DM MJ ${ }^{-1}$ IPAR) refers to the radiation use efficiency. Growth rate is expressed as $\frac{d W}{d t}$. The transpiration reduction function TRANRF accounts for growth rate reduction due to water limitations. Dormancy is defined as a prolonged period without growth due to water deficiency (Dormancy $=0$ means no dormancy; Dormancy $=1$, when dormancy occurred).

\subsubsection{Model parameterization and calibration}

For the model parameterization, only observed data from the Edo experiment in 2016 were used (Adiele et al. Chapter 4). The experimental field in Edo experienced no drought as there was abundant and well distributed rainfall during the 2016 growing season (approx. $3000 \mathrm{~mm}$ ), with measured rooting depth of over $3.2 \mathrm{~m}$, ensuring sufficient soil moisture supply during the short dry season (Adiele et al. Chapter 3). The field was located at $7.05^{\circ} \mathrm{N}, 6.13^{\circ} \mathrm{E}$. The experiment contained three blocks, with 12 fertilizer treatments randomized within these blocks and plot size was $10 \mathrm{~m}$ by $8 \mathrm{~m}$ where fertilizer applications rates were 0,150 , and $300 \mathrm{~kg} \mathrm{~N} \mathrm{ha}^{-1}, 0,40$ and $100 \mathrm{~kg} \mathrm{P} \mathrm{ha}^{-1}$ and $0,60,120,180,240$ and $300 \mathrm{~kg} \mathrm{~K} \mathrm{ha}^{-1}$ in various combinations (Adiele et al. Chapter 2 ). The widely cultivated cassava variety TME 419 was planted on May 24, 2016 at the onset of rainfall. Cassava was harvested about 4, 8 and 14 months after planting (MAP) from a net plot of $6.4 \mathrm{~m}^{2}$ (eight plants) of each experimental plot. At each harvest, storage roots, leaves and stem weights were measured. Sub-samples of about $400 \mathrm{~g}$ fresh weight were collected in the field using a digital field scale, and oven dried at $60^{\circ} \mathrm{C}$ until constant weight and weighed to allow dry matter (DM) yield to be calculated. Dried subsamples from leaves with petioles, stems, and storage roots were analysed for total N, P and K concentration, using standard protocols of the laboratory of Leuven University, Belgium. Total $\mathrm{N}$ was analysed by Dumas combustion using a Carlo Erba EA1108 elemental analyser. Total $\mathrm{P}$ and $\mathrm{K}$ concentrations were measured with inductively coupled plasma (ICP) (iCAP 7400, Thermo Fisher Scientific, USA). Crop nutrient data for parameterization are as outlined in Table 5.1, with measured $\mathrm{N}, \mathrm{P}$ and $\mathrm{K}$ recovery efficiency (Table 5.2), uptake by plant parts obtained from Adiele et al. (Chapter 4), Table 5.3 and in supplementary information (Table 5.SA), dry matter yield of leaves, stems and storage roots at 4 and $8 \mathrm{MAP}$, including final harvest are outlined in Tables 5.SB, 5.SC and 5.SD). Other parameters such as specific leaf area (SLA), light extinction coefficient $(k)$, radiation use efficiency $\left(L U E_{-} O P T\right)$ and soil hydraulic properties at water content saturation $(S A T)$, air dry $(A D)$, field capacity $(F C)$ and wilting point $(W P)$ were derived and elaborately explained by Adiele et al. (Chapter 3). Other required model parameters and values are in Table 5.SE. Weather data were obtained from the nearest weather station located approximately $61 \mathrm{~km}$ from the field at $\left(6.33^{\circ} \mathrm{N}, 5.60^{\circ} \mathrm{E}\right)$.

After parameterization, model results were compared graphically to observed data to check similarity and there was a good match between simulated and observed yields (Fig. 5.SAa). After which calibration was performed by optimization on estimated parameters $\left(K_{N I}, K_{-} M A X\right.$, and $\left.R N E\right)$ that were not obtained directly from the experiment, to best match $\mathrm{N}, \mathrm{P}$ and $\mathrm{K}$ uptakes and dry matter accumulation in plant organs at 4,8 and 14 months. The optimization sought to minimize the root mean square error (RMSE) between the measured and simulated values of DM storage root yield, N, P and $\mathrm{K}$ uptakes. In order to 
obtain a model representation of cassava growth process as influenced by nutrient availability, the model was first calibrated for non-nutrient limiting situations and subsequently for the nutrient limiting conditions.

\subsubsection{Model testing}

For the model testing, data from three other field experiments from 2017 were used. The three experimental fields were located in three agro-ecological zones (Rainforest - Cross River, Transition Rainforest - Edo, and Guinea Savanna - Benue), where most of the cassava is grown in Nigeria. The fields were located at $\left(6.80^{\circ} \mathrm{N}, 6.23^{\circ} \mathrm{E}\right),\left(5.96^{\circ} \mathrm{N}, 8.77^{\circ} \mathrm{E}\right)$ and $\left(7.27^{\circ} \mathrm{N}, 8.19^{\circ} \mathrm{E}\right)$ respectively for Edo, Cross Rover and Benue. These experiments had the same design, planting density and data collection schemes as the experiment in Edo 2016 (used for model parameterisation and calibration). Weather data were obtained from the closest weather stations at each location in 2017 , at approximately $6.76^{\circ} \mathrm{N}$, $8.69^{\circ} \mathrm{E}$ in Benue and $5.97^{\circ} \mathrm{N}, 8.72^{\circ} \mathrm{E}$ in Cross River, while for the field in Edo weather data where derived from $\left(6.33^{\circ} \mathrm{N}, 5.60^{\circ} \mathrm{E}\right)$. In order to assess the reliability of the model in diverse environmental conditions and soil $\mathrm{N}, \mathrm{P}$ and $\mathrm{K}$ supply, measured and simulated results were compared using the root mean square error of prediction (RMSEP) to assess model error, the coefficient of determination $\left(R^{2}\right)$ and slope of a linear relationship between measured and simulated values to assess repeatability and bias.

Table 5.1. Parameters of LINTUL CASSAVA NPK

\begin{tabular}{|c|c|c|c|c|c|c|}
\hline Parameter & Parameter description & $\begin{array}{l}\text { Defau } \\
\text { lt }\end{array}$ & Calibr. & RMSRE & Unit & $\begin{array}{l}\text { Source of default } \\
\text { values }\end{array}$ \\
\hline$R D R N S$ & $\begin{array}{l}\text { Maximum relative death rate of the leaves } \\
\text { due to nutrient stress }\end{array}$ & 0.05 & - & - & $\mathrm{d}^{-1}$ & Estimated \\
\hline TSUM_NPKI & $\begin{array}{l}\text { Minimal TSUM before which nutrient } \\
\text { limitations do not reduce growth rates }\end{array}$ & 272 & - & - & ${ }^{0} \mathrm{C}$ & Estimated \\
\hline$F R \_M A X$ & $\begin{array}{l}\text { Optimal NPK concentration as fraction of } \\
\text { maximum NPK concentration }\end{array}$ & 0.8 & - & - & - & Measured \\
\hline $\operatorname{Rec}_{N}$ & Nitrogen recovery & 0.75 & - & - & - & Measured \\
\hline $\operatorname{Rec} P$ & Phosphorus recovery & 0.28 & - & - & - & Measured \\
\hline $\operatorname{RecK}$ & Potassium recovery & 0.7 & - & - & - & Measured \\
\hline$T C_{N P K} T$ & Time coefficient for NPK translocation & 10 & - & - & d & Estimated \\
\hline$K_{N I}$ & $\mathrm{~K}$ value in Monod relationship for $N P K I$ & 6.1 & 6.6 & 1.03 & - & Calibrated \\
\hline$K \_M A X$ & Maximum value of $\mathrm{K}$ & 4 & 3.9 & 1.05 & - & Calibrated \\
\hline K_WATER & $\begin{array}{l}\mathrm{K} \text { value in Monod relationship with } \\
T R A N R F\end{array}$ & 0.20 & - & - & - & Estimated \\
\hline$R N E$ & Maximum nutrient equivalent uptake rate & 0.012 & 0.01 & 1.05 & $\mathrm{~d}^{-1}$ & Calibrated \\
\hline
\end{tabular}


Table 5.2. Average soil $\mathrm{N}, \mathrm{P}$ and $\mathrm{K}\left(\mathrm{kg} \mathrm{ha}^{-1}\right)$ derived from control plots and where each nutrient was omitted and recovery efficiency $(R E)$ of N, P and K (NfPfKf treatment) with standard errors, from Benue, Cross River and Edo in 2016 and 2017 growing periods.

\begin{tabular}{lllllllllll}
\hline Year & Location & N-soil & P-soil & K-soil & NOPK & NP0K & NPK0 & $R E_{N}$ & $R E_{P}$ & $R E_{K}$ \\
\hline 2016 & Benue & $63 \pm 12$ & $7.6 \pm 1.7$ & $79 \pm 20$ & $17 \pm 17$ & $2 \pm 3.6$ & $87 \pm 8$ & $0.47 \pm 0.1$ & $0.18 \pm 0.1$ & $0.42 \pm 0.1$ \\
2016 & Cross & $84 \pm 14$ & $9.2 \pm 1.1$ & $58 \pm 2$ & $6 \pm 26$ & $6 \pm 4.8$ & $18 \pm 18$ & $0.92 \pm 0.3$ & $0.28 \pm 0.1$ & $0.62 \pm 0.2$ \\
& River & & & & & & & & & \\
2016 & Edo & $194 \pm 82$ & $19.9 \pm 6.7$ & $88 \pm 26$ & $63 \pm 105$ & $11 \pm 12$ & $-28 \pm 26$ & $0.79 \pm 0.2$ & $0.32 \pm 0.1$ & $0.88 \pm 0.1$ \\
2017 & Benue & $57 \pm 13$ & $7.6 \pm 2.6$ & $62 \pm 31$ & $23 \pm 24$ & $4 \pm 4.5$ & $38 \pm 97$ & $0.20 \pm 0.3$ & $0.08 \pm 0.2$ & $0.24 \pm 0.4$ \\
2017 & Cross & $108 \pm 47$ & $11.1 \pm 7.0$ & $69 \pm 48$ & $36 \pm 40$ & $7 \pm 12$ & $54 \pm 75$ & $0.47 \pm 0.16$ & $0.15 \pm 0.1$ & $0.47 \pm 0.2$ \\
& River & & & & & & & & & $0.61 \pm 0.2$ \\
\hline
\end{tabular}

NPK - soil; N, P or K from control plots

NOPK, NOPK and NOPK; N, P and K from each nutrient omitted plots

\subsubsection{Statistical analysis}

Treatment effects on biomass components (leaves, stem and storage roots) were analysed separately for each growth stage, using a linear mixed model with biomass components as response variable and fertilizer treatment as explanatory factor, while either year or location were considered random effects. The interaction of nutrient uptake response with location and year or treatment were analysed with a mixed linear regression model. Effects were analysed with a type-III ANOVA using Satterthwaite's approximation method. Differences between treatment means were considered significant when probability $\leq 0.05$. R software (R Core, 2019), version 3.5 with the lme4, lmerTest, and Predictmeans packages was used for statistical analysis.

\subsection{Results}

\subsubsection{Observed nutrient uptake}

Nutrient uptake by the plant components increased with nutrient availability. Leaf $\mathrm{N}$ uptake differed by treatment, location and year (Table 5.3). There was no interaction between treatment, year or location. Leaf $\mathrm{N}$ uptake was largest in the NfPfKf treatment with an average of $11.02 \mathrm{~g} \mathrm{~m}^{-2}$, between Edo and Cross River where locations did not differ significantly. Leaf $\mathrm{P}$ and $\mathrm{K}$ uptake differed by year and location $(\mathrm{p}>0.01)$, the largest leaf $\mathrm{P}$ uptake in 2016 was recorded in Edo, the largest leaf $\mathrm{K}$ uptake in Cross River. Stem N and P uptake was largest in the NfPfKf treatment, with year average of 14.25 and $1.94 \mathrm{~g} \mathrm{~m}^{-2}$, respectively. Stem $\mathrm{K}$ uptake differed between location and treatment $(\mathrm{p}>0.001)$ (Table 5.3), with uptake increasing with application rates as expected. Uptake of $\mathrm{N}$ and $\mathrm{P}$ by the storage roots was significantly different between treatments and locations $(p>0.001)$. Storage root $K$ uptake was only significantly different for treatments $(\mathrm{p}>0.001)$, with the greatest uptake in the NfPfKf treatment (Table 5.3). 
Table 5.3. Uptake of N, P, and K in leaves, stem, and storage roots for cassava grown in three locations at final harvest (FH)

\begin{tabular}{|c|c|c|c|c|c|c|}
\hline \multirow[b]{3}{*}{ Treatment } & \multicolumn{3}{|l|}{2016} & \multicolumn{3}{|l|}{2017} \\
\hline & Benue & Cross River & Edo & Benue & Cross River & Edo \\
\hline & Leaf/Stem/Roots & $\begin{array}{l}\text { Leaf/Stem } \\
\text { /Roots }\end{array}$ & $\begin{array}{l}\text { Leaf/Stem } \\
\text { /Roots }\end{array}$ & $\begin{array}{l}\text { Leaf/Stem } \\
\text { /Roots }\end{array}$ & Leaf/ Stem /Roots & Leaf/Stem /Roots \\
\hline & & & $\mathrm{N}\left(\mathrm{g} \mathrm{m}^{-2}\right)$ & & & \\
\hline Control & $2.04 / 1.47 / 2.82$ & $3.05 / 2.52 / 2.85$ & $7.36 / 7.01 / 5.04$ & $2.64 / 1.26 / 1.75$ & $4.2 / 2.69 / 5.98$ & $5.15 / 3.66 / 4.54$ \\
\hline N150P40K180 & $4.93 / 2.84 / 5.62$ & $4.86 / 7.37 / 8.24$ & $7.91 / 11.6 / 11.0$ & $2.92 / 1.92 / 4.27$ & $5.89 / 4.48 / 6.38$ & $3.4 / 7.88 / 6.09$ \\
\hline NfPfK 180 & $5.84 / 4.43 / 4.78$ & $8.77 / 9.08 / 8.15$ & $11.4 / 19.2 / 14.2$ & $2.48 / 2.86 / 5.87$ & $7.45 / 7.1 / 8.72$ & $3.86 / 13.1 / 9.15$ \\
\hline NfPfKf & $6.59 / 6.85 / 8.77$ & $12.1 / 14.2 / 12.2$ & $15.1 / 17.6 / 19.0$ & $3.74 / 4.02 / 9.99$ & $7.13 / 8.36 / 12.9$ & $6.93 / 10.9 / 13.7$ \\
\hline ANOVA & Treatment*Year & Treatment & Year & Location & Treatment*Location & \\
\hline \multirow[t]{2}{*}{ SE $(0.05)$} & $\mathrm{Ns} / \mathrm{ns} / \mathrm{ns}$ & $1.87 / 2.19 / 1.25$ & $1.36 / \mathrm{ns} / \mathrm{ns}$ & $1.39 / 2.0 / 2.04$ & $\mathrm{Ns} / \mathrm{ns} / \mathrm{ns}$ & \\
\hline & & & $\mathrm{P}\left(\mathrm{g} \mathrm{m}^{-2}\right)$ & & & \\
\hline Control & $0.13 / 0.14 / 0.49$ & $0.23 / 0.26 / 0.42$ & $0.51 / 0.76 / 0.72$ & $0.18 / 0.17 / 0.41$ & $0.20 / 0.31 / 0.95$ & $0.37 / 0.42 / 0.77$ \\
\hline $\mathrm{N} 150 \mathrm{P} 40 \mathrm{~K} 180$ & $0.31 / 0.27 / 0.96$ & $0.33 / 0.67 / 1.09$ & $0.64 / 1.27 / 1.24$ & $0.19 / 0.26 / 0.76$ & $0.28 / 0.36 / 0.96$ & $0.24 / 1.02 / 1.22$ \\
\hline NfPfK180 & $0.31 / 0.41 / 1.17$ & $0.57 / 1.03 / 1.15$ & $0.92 / 2.26 / 1.6$ & $0.18 / 0.44 / 0.95$ & $0.4 / 0.83 / 1.49$ & $0.31 / 2.08 / 1.84$ \\
\hline NfPfKf & $0.41 / 0.67 / 1.72$ & $0.99 / 1.86 / 1.71$ & $1.23 / 2.33 / 2.93$ & $0.29 / 0.56 / 1.87$ & $0.38 / 0.83 / 2.07$ & $0.6 / 1.65 / 2.48$ \\
\hline ANOVA & Treatment*Year & Treatment & Year & Location & Treatment*Location & \\
\hline \multirow[t]{2}{*}{ SE $(0.05)$} & $\mathrm{Ns} / \mathrm{ns} / \mathrm{ns}$ & $0.16 / 0.26 / 1.23$ & $0.12 / \mathrm{ns} / \mathrm{ns}$ & $0.11 / 0.27 / 2.04$ & $\mathrm{Ns} / 0.22 / \mathrm{ns}$ & \\
\hline & & & $\mathrm{K}\left(\mathrm{g} \mathrm{m}^{-2}\right)$ & & & \\
\hline Control & $0.54 / 1.11 / 6.25$ & $0.54 / 1.13 / 4.17$ & $1.73 / 1.79 / 5.28$ & $0.89 / 1.50 / 3.81$ & $0.72 / 1.48 / 7.05$ & $0.60 / 1.80 / 3.51$ \\
\hline N150P40K180 & $1.56 / 2.29 / 12.3$ & $1.22 / 4.59 / 9.73$ & $1.31 / 3.61 / 8.78$ & $1.14 / 3.23 / 6.16$ & $1.27 / 4.53 / 10.2$ & $0.71 / 6.34 / 7.63$ \\
\hline NfPfK180 & $1.84 / 4.29 / 14.3$ & $2.42 / 6.17 / 10.2$ & $2.64 / 6.65 / 9.9$ & $0.92 / 3.25 / 5.64$ & $1.76 / 5.76 / 12.1$ & $0.78 / 7.53 / 8.19$ \\
\hline NfPfKf & $2.23 / 5.99 / 20.9$ & $3.35 / 9.33 / 14.3$ & $4.34 / 10.0 / 18.1$ & $1.51 / 4.0 / 12.9$ & $1.68 / 6.82 / 18.3$ & $2.1 / 10.4 / 12.4$ \\
\hline ANOVA & Treatment*Year & Treatment & Year & Location & Treatment*Location & \\
\hline $\mathrm{SE}(0.05)$ & $\mathrm{Ns} / \mathrm{ns} / \mathrm{ns}$ & $0.5 / 0.72 / 1.49$ & $0.28 / \mathrm{ns} / \mathrm{ns}$ & $\mathrm{Ns} / 1.45 / \mathrm{ns}$ & $\mathrm{Ns} / 0.67 / \mathrm{ns}$ & \\
\hline
\end{tabular}




\subsubsection{Dry matter yield of measured plant components (leaves, stems and storage roots)}

Leaf DM at about 4 and 8 MAP differed only among locations in both years ( $p>0.001)$. At 4 MAP, year average leaf DM ranged from $36.92 \mathrm{~g} \mathrm{~m}^{-2}$ in the control treatment at Benue to $349.68 \mathrm{~g} \mathrm{~m}^{-2}$ in the NfPfKf treatment at Edo. Leaf DM decreased across all treatments, years and locations at 8 MAP (seasonal dry period). At final harvest, leaf DM differed by treatment, year and location $(p<0.05)$ (Table 5.SD) and was highest in the NfPfKf treatment $\left(319 \mathrm{~g} \mathrm{~m}^{-2}\right)$ from Edo. Interaction between treatment and location was significant $(\mathrm{p}<0.01)$ for stems DM at 4 MAP (Table 5.SB) and final harvest $(p<0.001)$ (Table 5.SD). At 4 MAP, year average stem DM ranged between $55 \mathrm{~g} \mathrm{~m}^{-2}$ in the control treatment at Benue and $492 \mathrm{~g} \mathrm{~m}^{-2}$ in the NfPfKf treatment at Edo. Interaction between treatment and location for storage roots DM was significant $(\mathrm{p}<0.01)$ at 4 MAP (Table 5.SB). Storage roots DM was lowest at Benue during this stage. Storage root DM at final harvest differed by treatment, year and location $(\mathrm{p}<$ 0.001 ) (Table 5.SD). It ranged from $588 \mathrm{~g} \mathrm{~m}^{-2}$ in the control treatment at Benue to $3547 \mathrm{~g} \mathrm{~m}^{-2}$ in the NfPfKf treatment at Edo. Overall DM of plant biomass decreased with decreasing fertilizer rates.

\subsubsection{Model calibration results}

After calibration, the N, P, K uptakes and yields simulated by the model were close to the measurements with a difference between the observed and simulated stems and storage root yields at final harvest of 15 and $23 \%$, respectively (Fig. 5.SAa). However, green leaf DM was underestimated by the model. Nevertheless, LINTUL-Cassava simulated whole leaves (sum of green and dead leaves) reasonably well, when $20 \%$ was subtracted from the total weight of leaves to account for petioles (Adiele et al. Chapter 3). Simulated N, P and K nutrition indices showed a strong response to the various treatments (Fig. 5.1). All treatments showed an initial $N I_{N}$ value below optimum, most strongly for the $150 \mathrm{~kg} \mathrm{~N}$ $\mathrm{ha}^{-1}$ treatment. The treatments with $180 \mathrm{~kg} \mathrm{~K} \mathrm{ha}^{-1}$ showed a deficiency towards the end of the growing season. In the NfPfK60 treatment, P supply was sufficient throughout the season, while K supply restricted growth. The calibrated model simulated a storage root yield of $1332 \mathrm{~g} \mathrm{~m}^{-2}$, below the observed yield of $1969 \mathrm{~g} \mathrm{~m}^{-2}$. In the NfPfKf treatment, $\mathrm{N}$ and $\mathrm{P}$ supply were adequate to support growth, but $\mathrm{K}$ supply was suboptimal $\left(\mathrm{NI}_{\mathrm{K}}=0.74\right)$ from about 70 days to the end of the growth season. The simulated soil nutrient availability during the growing season showed that the NfPfK60 treatment had a surplus of $\mathrm{N}$ in the soil at the end of the growing season (Fig. 5.1). The calibrated model simulated well the N, P and $\mathrm{K}$ nutrition indices and soil nutrient in Cross River 2016 (Fig. 5.2). Similarly, N supply was limited at the beginning of the season. K supply was adequate for crop growth in the NfPfKf and N150P40K180 treatments. Shortage of $\mathrm{N}\left(\mathrm{NI}_{\mathrm{N}}=0.74\right)$ affected growth in the NfPfKf treatment from about 69 days to the final harvest, while in the N150P40K180 treatment, $\mathrm{N}$ and $\mathrm{P}$ were insufficient from 82 and 28 days to the final harvest, respectively (Fig. 5.2). 


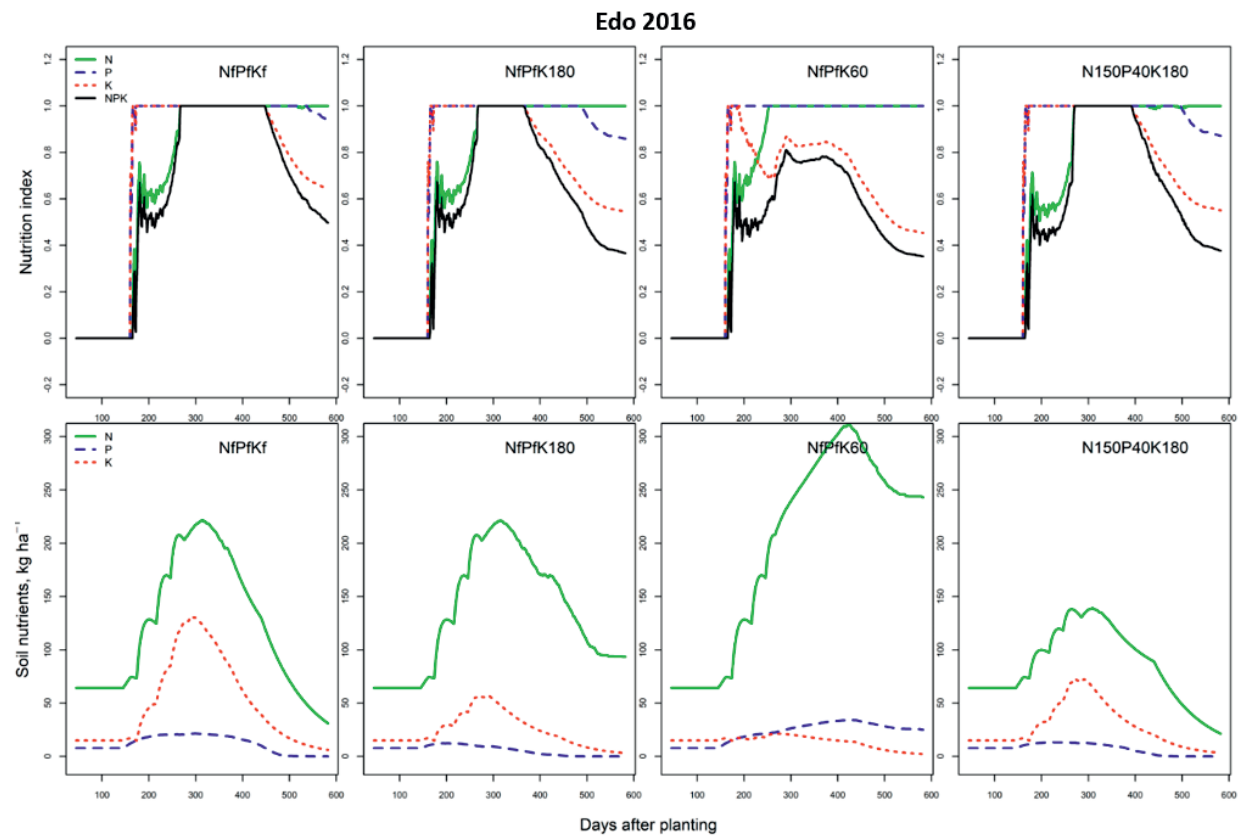

Fig. 5.1. Results of simulated $\mathrm{N}, \mathrm{P}$ and $\mathrm{K}$ nutrition indices, and relative interaction among $\mathrm{N}, \mathrm{P}$ and $\mathrm{K}$ nutrition indices (NPKI) and soil nutrients available $\left(\mathrm{kg} \mathrm{ha}^{-1}\right)$ of treatments used for calibration from Edo in 2016. 


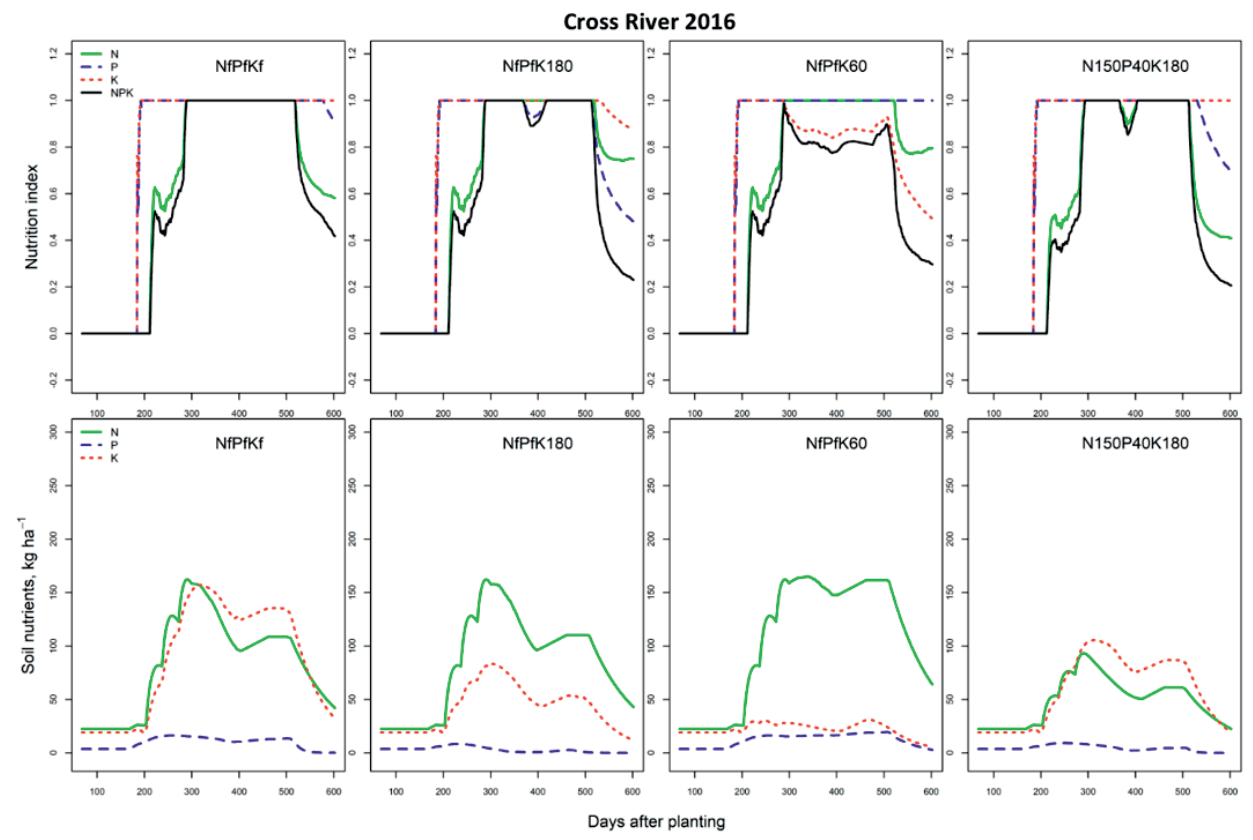

Fig. 5.2. Results of simulated N, P and $\mathrm{K}$ nutrition indices, and relative interaction among $\mathrm{N}, \mathrm{P}$ and $\mathrm{K}$ nutrition indices (NPKI) and soil nutrients $\left(\mathrm{kg} \mathrm{ha}^{-1}\right)$ of treatments used for model testing from Cross River in 2016.

Simulated time course of nutrient limited yield of green leaves, stem and storage root DM for the optimized (NfPfKf ) treatment showed a good match with observed values, in the test with other locations in different agro-ecologies for 2017 (Fig. 5.3). Most especially, the interaction between soil moisture and nutrient availability for crop use and its effect on yield was well captured at Benue 2017, where shortage of soil moisture hampered nutrient uptake, and subsequently cassava growth (Fig. 5.3). The simulated green leaves, stem and storage root DM for the N150P40K180 treatment showed that the observed yield was below the simulated nutrient-limited storage root yield for Edo and Cross River (CRS) (Fig. 5.3). 

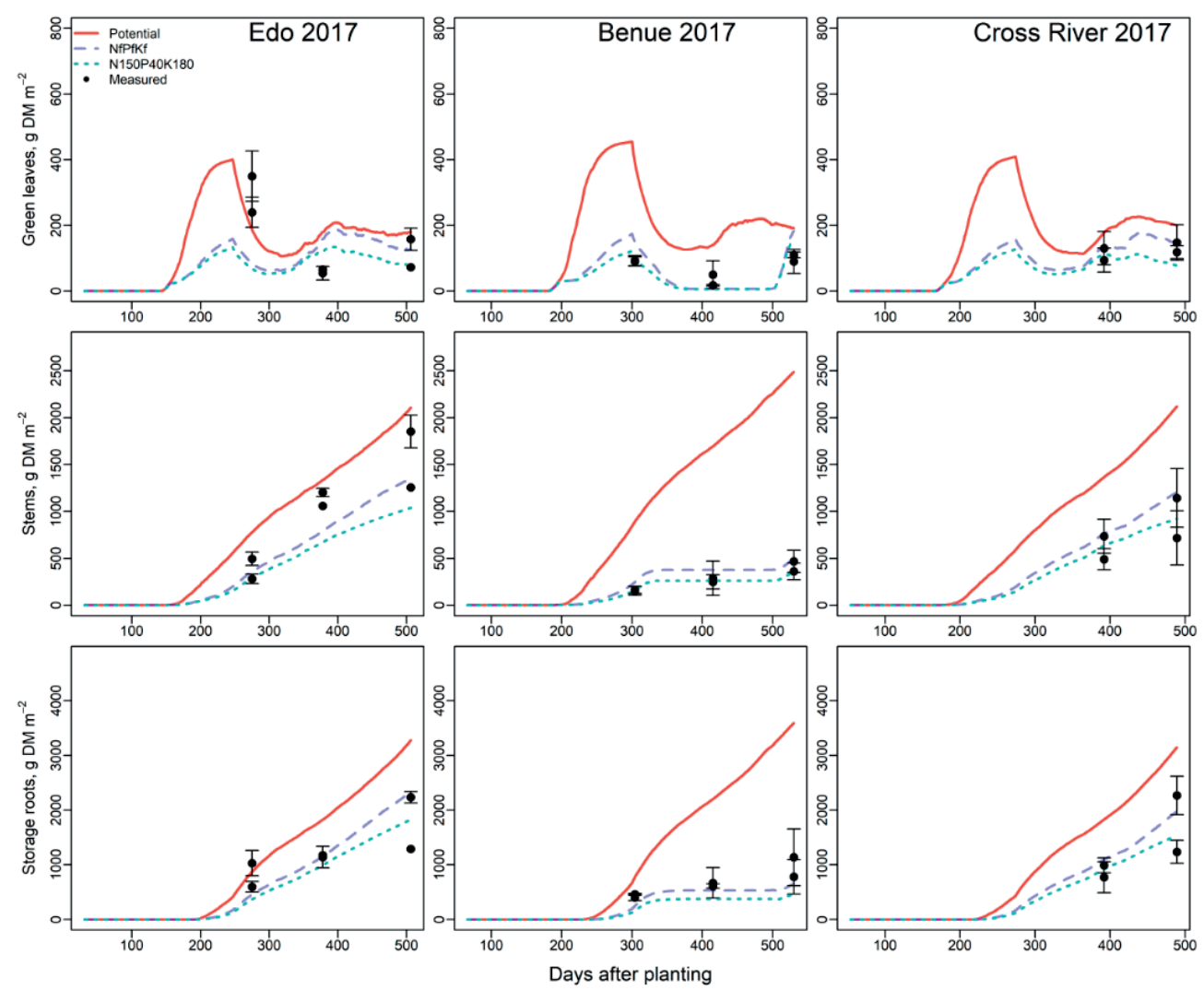

Fig. 5.3. Observed and simulated green leaves, stems and storage root yield $\mathrm{DM}\left(\mathrm{g} \mathrm{m}^{-2}\right)$ under water- and nutrient limited conditions from Edo, Benue and Cross River in 2017. For NfPfKf and N150P40K180 treatments. Error bars of the observed means are one standard deviation of the mean.

\subsubsection{Model testing results}

The simulated values of storage root yield, N, P and K uptakes were in good agreement with the observed uptakes for all treatments (Fig. 5.4). The RMSEP obtained, indicating the mean of the absolute difference of observed and simulated values, was about $355.2 \mathrm{~g}$ storage root $\mathrm{DM} \mathrm{m} \mathrm{m}^{-2}$ with a $R^{2}$ of 0.7 for the linear relationship between measured (observed) vs. modelled (simulated) yields. The simulation of total N, P and K uptake resulted in a RMSEP and a $\mathrm{R}^{2}$ value of $5.5 \mathrm{~g} \mathrm{~m}^{-2}$ and 0.8 for N, $0.8 \mathrm{~g} \mathrm{~m}^{-2}$ and 0.7 for $\mathrm{P}$ and $4 \mathrm{~g} \mathrm{~m}^{-2}$ with $\mathrm{R}^{2}$ of 0.7 for $\mathrm{K}$. The observed data are also shown in Tables 5.3 and 5.SA for uptakes and Table 5.SD for storage root dry matter yield. 

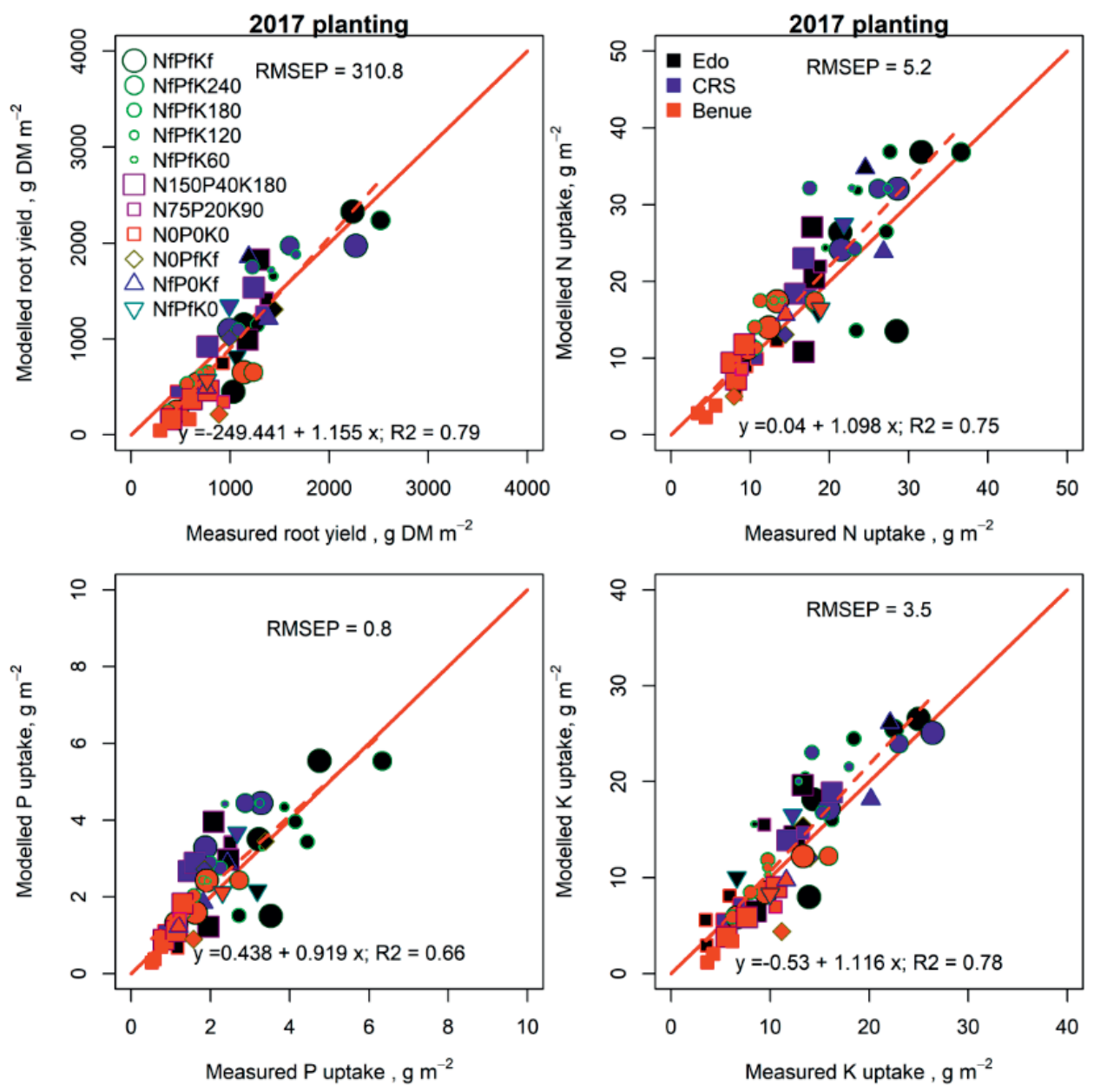

Fig. 5.4. Observed and simulated storage roots, N, P and $\mathrm{K}$ uptakes of both non-nutrient and nutrient limiting conditions from Edo, Cross River (CRS) and Benue in 2017 at final harvest. The solid line is the 1:1 line, while the dashed line is the best fit regression.

\subsection{Discussion}

\subsubsection{Nutrient uptake and yield}

Cassava accumulated more nutrients when more were supplied, as expected. The largest sinks for the nutrients were storage roots, followed by stems and leaves (Tables 5.3 and 5.SA). Such a nutrient uptake pattern was expected since there was more DM in storage roots (Ichinose et al., 2018). The differences in nutrient uptake among the treatments clearly show that crop growth is limited by the inadequate nutrient supply due to poor soil fertility. Besides limiting yields, inadequate nutrient supply further restricts the nutritional composition of crops, thereby altering their nutritional quality (Imakumbili et al., 2019). Also, soil water availability influences nutrient uptake as observed through differences among locations, with cassava accumulating more nutrients throughout the season at Edo where less effect of 
drought was observed. Leaf growth did not differ among treatments at 4 and 8 MAP. Rather, it generally decreased across locations and treatments in the middle of the cropping season (8 MAP) due to assimilate partitioning in synchrony with the mid-season drought. Stem and storage root yield increased with fertilizer application. Also leaf biomass increased early in the season with fertilizer application, resulting in sufficient LAI in the dry season with crops that were less affected by drought effects at 8 MAP, especially at Edo where the deep-rooted crop had access to deeper soil water reserves (Adiele et al. Chapter 3). Nutrient demand was however strongly reduced as dying leaves provided sufficient nutrients. Further, with partial stomatal closure, cassava maintains reasonable $\mathrm{CO}_{2}$ uptake rates, and continues to accumulate dry matter in its storage roots (El-Sharkawy et al., 1992; Rosenthal and Ort, 2012; De Souza and Long, 2018). After the dry period, nutrient uptake and yield increased in all locations, and was larger in optimized fertilizer treatments than in the control and treatments with smaller fertilizer rates, suggesting that soil available pools were larger as well.

\subsubsection{Model performance}

LINTUL-Cassava-NPK combines the essential crop growth processes described in LINTULCassava (Ezui et al., 2018) with the major plant and soil N, P and $\mathrm{K}$ processes. The low $N I_{N}$ indicates insufficient $\mathrm{N}$ supply in the first part of the season before fertilizer application in all experiments. Thereafter, $\mathrm{N}$ supply was adequate in Edo throughout the growth period, including the treatment with $150 \mathrm{~kg} \mathrm{~N} \mathrm{ha}^{-1}$. This could be related to the relatively fertile soils compared with the other locations and the absence of leaching due to deep rooting of cassava at Edo (Adiele et al. Chapters 2 and 3). In the NfPfK60 treatment P supply was sufficient to support crop growth without stress throughout the growing season, as was $\mathrm{N}$ supply after fertilizer application (Fig. 5.1). However, modelled K supply was sub-optimal from 34 days after the initial split fertilizer application of $20 \mathrm{~kg} \mathrm{~K} \mathrm{ha}^{-1}$ onwards, resulting in a moderate but consistent reduction of water limited potential growth. In this study, a large $\mathrm{N}$ rate ( $300 \mathrm{~kg} \mathrm{~N} \mathrm{ha}^{-1}$ ) with increasing rates of $\mathrm{K}$ fertilizer were studied. At low $\mathrm{K}$ supply, yield response to the large $\mathrm{N}$ rate was strongly depressed. Seasonal trends of the nutrition indices and soil nutrient availability during the growing season in Cross River 2016 were simulated reasonably well by the model (Fig. 5.2), also indicating insufficient $\mathrm{N}$ supply at the beginning of the season. $\mathrm{K}$ supply was sufficient for crop growth in the NfPfKf and N150P40K180 treatments, but growth was later suppressed by insufficient $\mathrm{N}$ supply in the NfPfKf, while shortages of $\mathrm{N}$ and $\mathrm{P}$ supply contributed more to growth reduction in the N150P40K180 treatment (Fig. 5.2). Imbalanced nutrient combinations, for instance in the NfPfK60 resulted in an excess of $\mathrm{N}$ in the soil, although not to the same extent as in Edo. This could be related to the relatively strong indigenous soil K supply in the Cross River sites when compared to the sites in Edo.

The model simulated reasonably well the dynamics of cassava organ growth and dry matter production under nutrient-limited conditions (Fig. 5.3). The observed storage root yield at final harvest in the NfPfKf treatment was in good agreement with the simulated nutrient-limited yield across the locations and was larger than the yield from the nutrient-limited treatment N150P40K180. Observed storage root yield in the N150P40K180 treatment at final harvest was far less than that simulated in Edo and Cross River, where growing conditions were normal resulting in large and significant increases in storage root yield at higher fertilizer application rates. Moreover, the test results show that the effect of nutrient stress on dry matter production is well simulated. The prediction accuracy of storage root yield, $\mathrm{N}, \mathrm{P}$ and $\mathrm{K}$ uptakes was satisfactory (Fig. 5.4) with linear relationships between simulated and observed values, a slope close to 1 , good repeatability $\left(R^{2}\right.$ of $\left.0.7-0.8\right)$ and only a minor bias.

\subsubsection{The nutrient equivalents modelling approach}

Measured crop N, P and K uptakes were more or less proportional to soil available nutrients, as if the crop was aware of total amounts present in the soil, with e.g. lower $\mathrm{N}$ uptake if $\mathrm{K}$ is limiting or vice 
versa. To balance the nutrient uptake with soil supply, both demand and supply were expressed as nutrient equivalents. Both total nutrient equivalent uptake and actual uptake of an individual nutrients were limited by soil supply, ensuring that proportionally more $\mathrm{N}$ and $\mathrm{P}$ were taken up when $\mathrm{K}$ was limited while $\mathrm{N}$ and $\mathrm{P}$ uptake were still much lower than possible with a perfectly balanced $\mathrm{N}, \mathrm{P}$ and $\mathrm{K}$ supply in the soil. The idea of nutrient equivalents (Janssen, 2011) was developed with the model QUEFTS in mind. When the three major nutrients, N, P and K, are expressed in terms of nutrient equivalents, it becomes possible and reasonable to calculate the fraction of each nutrient taken up in the sum of the three (Janssen, 2011). Results in our experiments show that nutrients were taken up in proportion to their supplies (Adiele et al. Chapter 4). The nutrient equivalent approach to determine N, $\mathrm{P}$ and $\mathrm{K}$ uptake, differs from the approach used in the SIMCAS model, as SIMCAS does not consider the interaction between $\mathrm{N}$ and $\mathrm{K}$ uptakes (Mithra et al., 2013). In our approach, the actual uptake determined the nutrition indices for $\mathrm{N}, \mathrm{P}$ and $\mathrm{K}$, comparing actual uptake with minimum and optimum uptake following the nitrogen nutrition index approach (Greenwood et al., 1986; Shibu et al., 2010).

Furthermore, plants do not only strive for an optimal ratio of nutrients in their tissues but also need to remain neutral with a balance between cations and anions (de Wit et al., 1963; Hawkesford et al., 2012). The nutrient equivalents approach adopted here ensures a balance between nitrate and $\mathrm{K}$, as $\mathrm{P}$ has a much smaller influence on the total demand and supply of nutrient equivalents when compared to $\mathrm{N}$ and $\mathrm{K}$. The strong and linear response to $\mathrm{K}$ observed can be understood when considering the large $\mathrm{N}$ supply and uptake of cassava, where $\mathrm{K}$ is the dominant cation to counterbalance anions in the cytoplasm (Hawkesford et al., 2012) and is needed to extrude excess anions (de Wit et al., 1963) enabling uptake of the nitrate anion.

Under imbalanced supply of nutrients, plants take up more of the omitted nutrients (Pasley et al., 2019) due to improved soil exploration by more developed root systems and/or root functioning. This plantsoil interaction is not modelled, we used input values for indigenous nutrient supply and fertilizer recovery derived from experimental measurements (Table 5.2) as parameter in the LINTUL-CassavaNPK model. However, we hypothesise that the proportional increase in soil supply of an omitted nutrient depends on the amounts of the other nutrients applied. Also, partitioning of the total N, P and K uptake over the leaves, stem and storage roots was based solely on the proportional weight of each organ. Though partitioning is not explicitly modelled, it does not affect overall nutrient uptakes and yield responses. Moreover, we do not consider it realistic to attempt to simulate a complete description of plant-soil nutrient interactions influencing cassava growth and yield under nutrient-limited conditions given the lack of detailed information on nutrient availability. Our research illustrates, for the first time, how the interactions of $\mathrm{N}, \mathrm{P}$ and $\mathrm{K}$ limitations impact cassava growth rates and storage root yield under rainfed conditions, using a dynamic simulation model.

\subsection{Conclusion}

The LINTUL-Cassava-NPK model simulates the effects of stress due to inadequate N, P and K supply on nutrient uptake, crop growth rates and yield of cassava. The model was built based on observed data from field experiments, with simulated nutrient uptakes and root yields in good agreement with observed nutrient uptakes and root yields. Our modelled results suggest that more $\mathrm{N}$ is needed at the onset of the season, whereas $\mathrm{K}$ needs to be applied at larger amounts and at a later growth stage. This model can help to better understand spatial and seasonal variations in nutrient recovery and use efficiency enabling the development of improved nutrient management recommendations, with respect to both space, timing and quantity, to improve efficiency of applied nutrients with reduced losses and maximum storage root yields. 


\section{Acknowledgements}

We thank the Netherlands Fellowship Program (NUFFIC) and the African Cassava Agronomy Initiative (ACAI) of IITA for funding. We are grateful to A. Olojede and C. Ifenkwe for their assistance with the fieldwork. 


\subsection{Supplementary materials}

Table 5.SA. Uptake of N, P, and $\mathrm{K}$ in leaves, stem, and storage roots at final harvest, for cassava grown in three locations (Benue, Cross River and Edo) in 2016 and 2017.

\begin{tabular}{|c|c|c|c|c|c|c|}
\hline & 2016 & & & 2017 & & \\
\hline & Benue & Cross River & Edo & Benue & Cross River & Edo \\
\hline \multirow[t]{2}{*}{ Treatment } & Leaf/Stem/Roots & $\begin{array}{l}\text { Leaf/Stem } \\
\text { /Roots }\end{array}$ & Leaf/Stem/Roots & $\begin{array}{l}\text { Leaf/Stem } \\
\text { /Roots }\end{array}$ & Leaf/Stem /Roots & $\begin{array}{l}\text { Leaf/Stem } \\
\text { /Roots }\end{array}$ \\
\hline & & & $\mathrm{N}\left(\mathrm{g} \mathrm{m}^{-2}\right)$ & & & \\
\hline NOPfKf & $3.18 / 1.58 / 3.23$ & $3.53 / 3.26 / 2.21$ & $9.50 / 10.59 / 5.60$ & $3.29 / 1.87 / 2.81$ & $4.27 / 4.57 / 5.59$ & $4.26 / 6.69 / 7.12$ \\
\hline NfP0Kf & $5.61 / 4.55 / 4.09$ & $11.01 / 8.83 / 6.22$ & $15.07 / 15.54 / 7.99$ & $4.00 / 4.73 / 5.70$ & $11.33 / 7.53 / 7.96$ & $5.37 / 12.79 / 6.35$ \\
\hline NfPfK0 & $5.46 / 4.51 / 5.89$ & $4.74 / 7.68 / 6.32$ & $3.44 / 11.71 / 11.61$ & $2.55 / 11.41 / 4.93$ & $4.95 / 10.12 / 6.75$ & $3.50 / 7.25 / 7.82$ \\
\hline NfPfK240 & $5.63 / 4.34 / 4.84$ & $8.47 / 10.13 / 9.52$ & $13.54 / 21.32 / 10.76$ & $4.15 / 4.70 / 9.29$ & $7.08 / 8.24 / 10.83$ & $8.87 / 14.00 / 13.12$ \\
\hline NfPfK120 & $6.70 / 4.52 / 5.93$ & $6.95 / 10.61 / 6.76$ & $8.44 / 17.83 / 11.93$ & $2.92 / 5.15 / 4.88$ & $7.82 / 9.03 / 10.52$ & $4.44 / 10.88 / 8.22$ \\
\hline NfPfK60 & $5.38 / 3.13 / 5.28$ & $3.77 / 6.76 / 4.56$ & $8.49 / 22.43 / 11.30$ & $4.57 / 3.33 / 5.06$ & $7.15 / 6.78 / 8.89$ & $3.25 / 9.28 / 6.96$ \\
\hline N75P20K90 & $4.06 / 2.13 / 3.20$ & $2.84 / 3.51 / 3.70$ & $6.50 / 11.31 / 7.49$ & $3.30 / 2.49 / 3.16$ & $5.35 / 5.11 / 7.01$ & $4.22 / 8.22 / 6.35$ \\
\hline ANOVA & Treatment*Year & Treatment & Year & Location & Treatment*Location & \\
\hline \multirow[t]{2}{*}{ SE (0.05) } & $\mathrm{Ns} / \mathrm{ns} / \mathrm{ns}$ & $1.52 / 2.85 / 1.48$ & $0.75 / \mathrm{ns} / \mathrm{ns}$ & $0.8 / 0.97 / 0.57$ & $\mathrm{Ns} / \mathrm{ns} / \mathrm{ns}$ & \\
\hline & & & $\mathrm{P}\left(\mathrm{g} \mathrm{m}^{-2}\right)$ & & & \\
\hline NOPfKf & $0.21 / 0.22 / 0.61$ & $0.23 / 0.55 / 0.69$ & $0.77 / 1.56 / 1.06$ & $0.25 / 0.46 / 0.86$ & $0.23 / 0.50 / 1.13$ & $0.35 / 1.46 / 1.58$ \\
\hline NfP0Kf & $0.28 / 0.20 / 0.48$ & $0.47 / 0.42 / 0.63$ & $0.97 / 1.20 / 0.97$ & $0.21 / 0.28 / 0.71$ & $0.51 / 0.48 / 0.83$ & $0.35 / 1.08 / 1.00$ \\
\hline NfPfK0 & $0.26 / 0.48 / 1.07$ & $0.38 / 1.06 / 0.86$ & $0.33 / 1.63 / 0.97$ & $0.19 / 1.24 / 0.87$ & $0.30 / 1.21 / 1.16$ & $0.30 / 1.56 / 1.32$ \\
\hline NfPfK240 & $0.34 / 0.43 / 0.88$ & $0.55 / 1.14 / 1.53$ & $0.79 / 2.75 / 1.47$ & $0.30 / 0.73 / 1.69$ & $0.37 / 0.80 / 1.70$ & $0.69 / 2.40 / 3.10$ \\
\hline NfPfK120 & $0.39 / 0.42 / 1.08$ & $0.48 / 1.19 / 0.96$ & $0.68 / 1.87 / 1.45$ & $0.23 / 0.72 / 0.86$ & $0.47 / 1.05 / 1.73$ & $0.36 / 1.77 / 1.74$ \\
\hline NfPfK60 & $0.32 / 0.41 / 0.98$ & $0.27 / 0.83 / 0.78$ & $0.74 / 3.47 / 1.54$ & $0.33 / 0.50 / 0.91$ & $0.38 / 0.71 / 1.28$ & $0.25 / 1.62 / 1.45$ \\
\hline N75P20K90 & $0.26 / 0.22 / 0.62$ & $0.16 / 0.35 / 0.66$ & $0.54 / 1.19 / 0.90$ & $0.22 / 0.31 / 0.69$ & $0.27 / 0.46 / 1.09$ & $0.30 / 1.02 / 1.17$ \\
\hline ANOVA & Treatment*Year & Treatment & Year & Location & Treatment*Location & \\
\hline \multirow[t]{2}{*}{ SE (0.05) } & $\mathrm{Ns} / \mathrm{ns} / \mathrm{ns}$ & $\mathrm{Ns} / \mathrm{ns} / 0.22$ & $0.04 / \mathrm{ns} / 0.14$ & $0.05 / 1.13 / 0.11$ & $\mathrm{Ns} / 0.32 / \mathrm{ns}$ & \\
\hline & & & $\mathrm{K}\left(\mathrm{g} \mathrm{m}^{-2}\right)$ & & & \\
\hline NOPfKf & $1.10 / 1.62 / 8.34$ & $0.97 / 3.08 / 6.92$ & $2.39 / 4.95 / 7.30$ & $1.32 / 2.55 / 7.31$ & $0.94 / 4.07 / 9.04$ & $0.85 / 4.22 / 8.27$ \\
\hline NfP0Kf & $2.08 / 2.29 / 7.90$ & $3.45 / 6.09 / 9.71$ & $4.32 / 9.85 / 10.84$ & $1.63 / 3.65 / 6.33$ & $2.72 / 6.28 / 11.17$ & $1.50 / 11.63 / 8.97$ \\
\hline NfPfK0 & $1.55 / 3.11 / 11.98$ & $0.73 / 1.91 / 5.03$ & $0.53 / 2.19 / 3.30$ & $0.57 / 4.88 / 4.54$ & $1.02 / 4.89 / 6.37$ & $0.44 / 2.53 / 3.67$ \\
\hline NfPfK240 & $1.76 / 3.79 / 11.43$ & $2.06 / 6.60 / 12.63$ & $2.32 / 9.92 / 10.73$ & $1.58 / 4.58 / 9.75$ & $1.63 / 6.44 / 14.94$ & $1.89 / 6.00 / 13.99$ \\
\hline NfPfK120 & $1.70 / 2.85 / 12.66$ & $1.56 / 4.16 / 6.44$ & $1.66 / 5.11 / 8.75$ & $1.03 / 3.42 / 5.27$ & $1.64 / 5.00 / 11.33$ & $0.90 / 5.52 / 7.13$ \\
\hline NfPfK60 & $1.59 / 2.32 / 10.61$ & $0.74 / 3.35 / 5.79$ & $1.51 / 4.78 / 6.54$ & $1.45 / 2.62 / 4.79$ & $1.30 / 4.00 / 7.60$ & $0.50 / 3.25 / 4.67$ \\
\hline N75P20K90 & $1.38 / 1.68 / 8.47$ & $0.59 / 2.37 / 6.82$ & $1.34 / 3.04 / 5.28$ & $1.24 / 3.11 / 6.20$ & $1.09 / 3.14 / 9.10$ & $0.66 / 3.10 / 5.65$ \\
\hline ANOVA & Treatment*Year & Treatment & Year & Location & Treatment*Location & \\
\hline SE $(0.05)$ & $\mathrm{Ns} / \mathrm{ns} / \mathrm{ns}$ & $0.33 / 1.03 / 1.40$ & $0.22 / \mathrm{ns} / \mathrm{ns}$ & $\mathrm{Ns} / 0.47 / \mathrm{ns}$ & $\mathrm{Ns} / \mathrm{ns} / \mathrm{ns}$ & \\
\hline
\end{tabular}



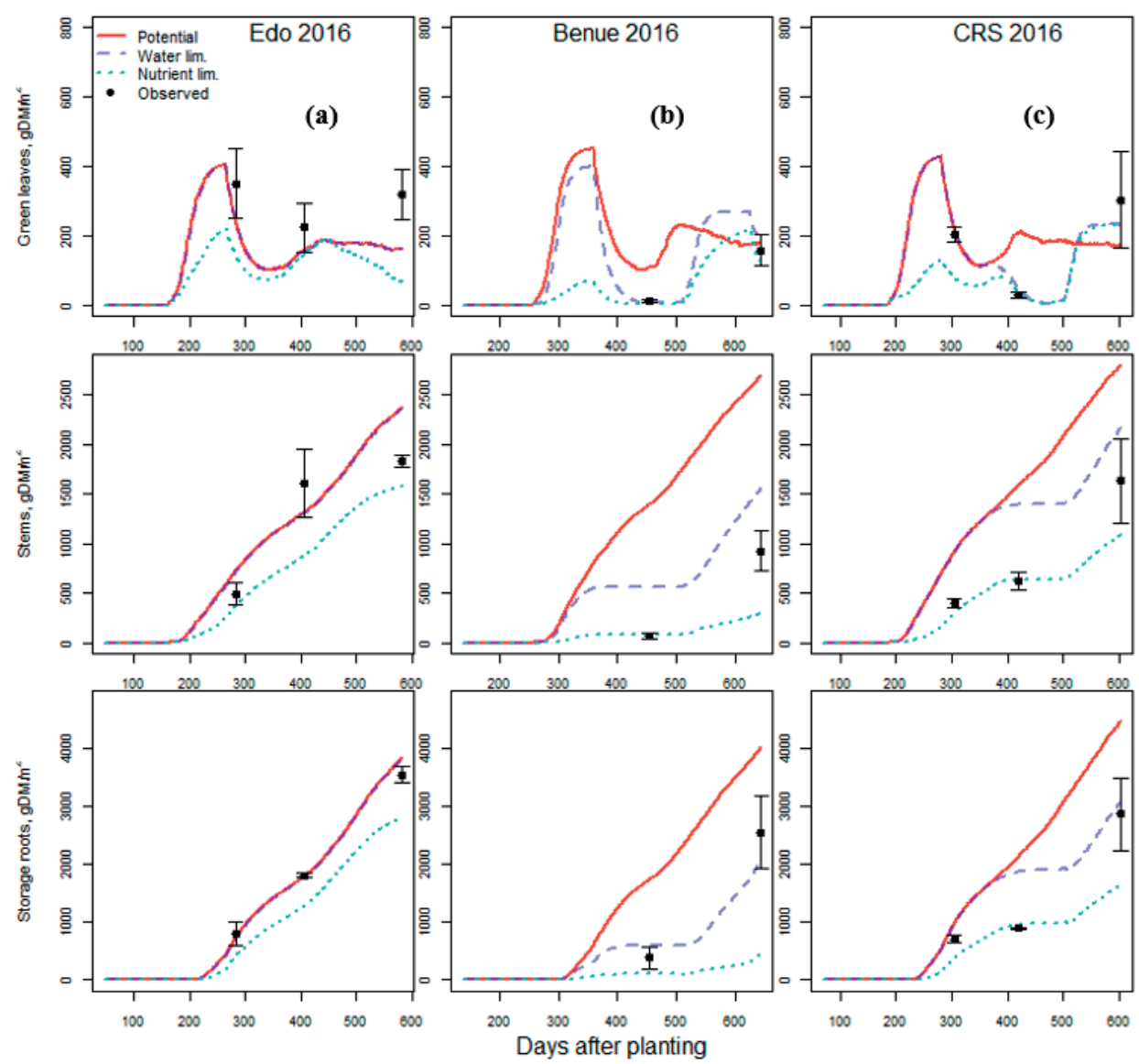

Fig. 5.SA. Observed and simulated green leaves, stems, and storage root yield DM $\left(\mathrm{g} \mathrm{m}^{-2}\right)$ under water- and nutrient limited conditions from Edo, Cross River and Benue in 2016. Error bars of the observed means are one standard deviation of the mean. 


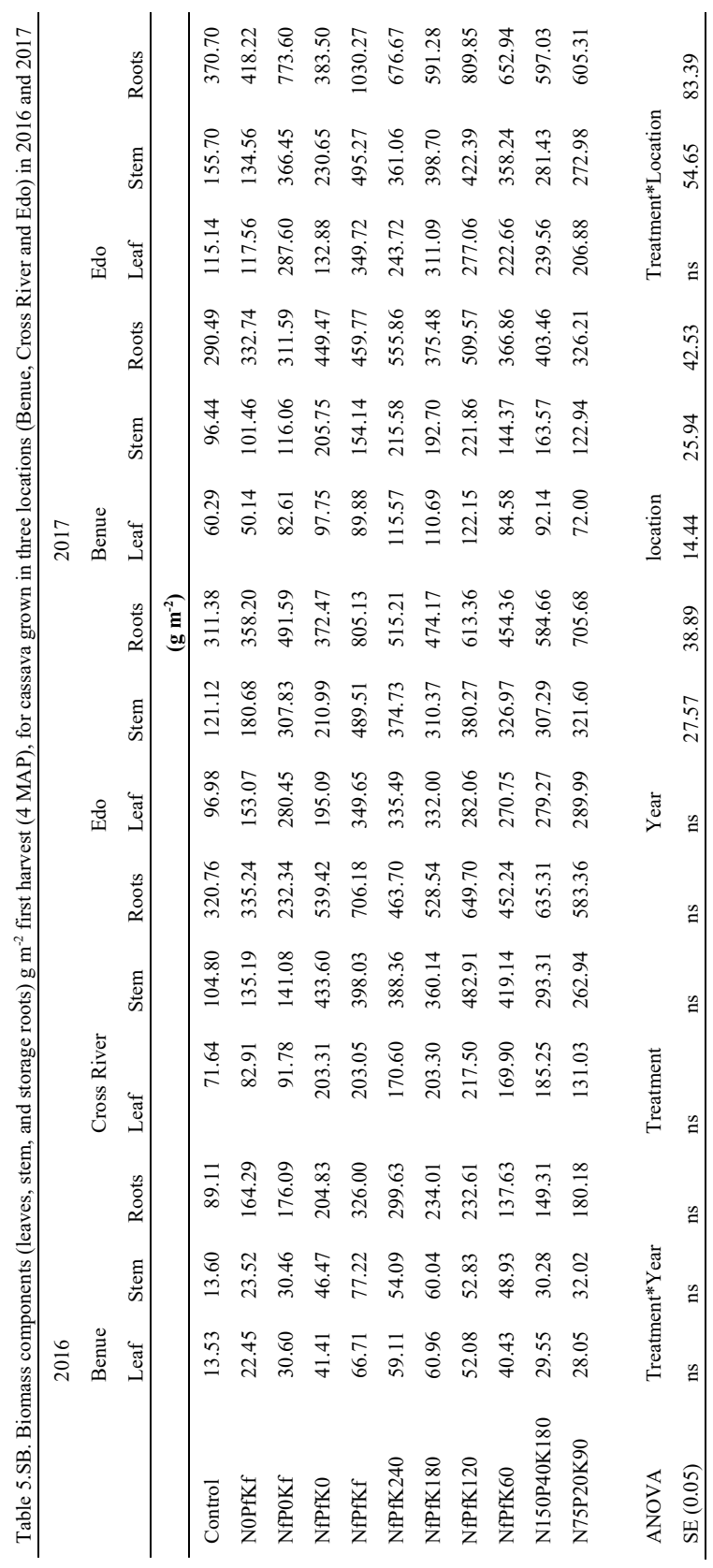




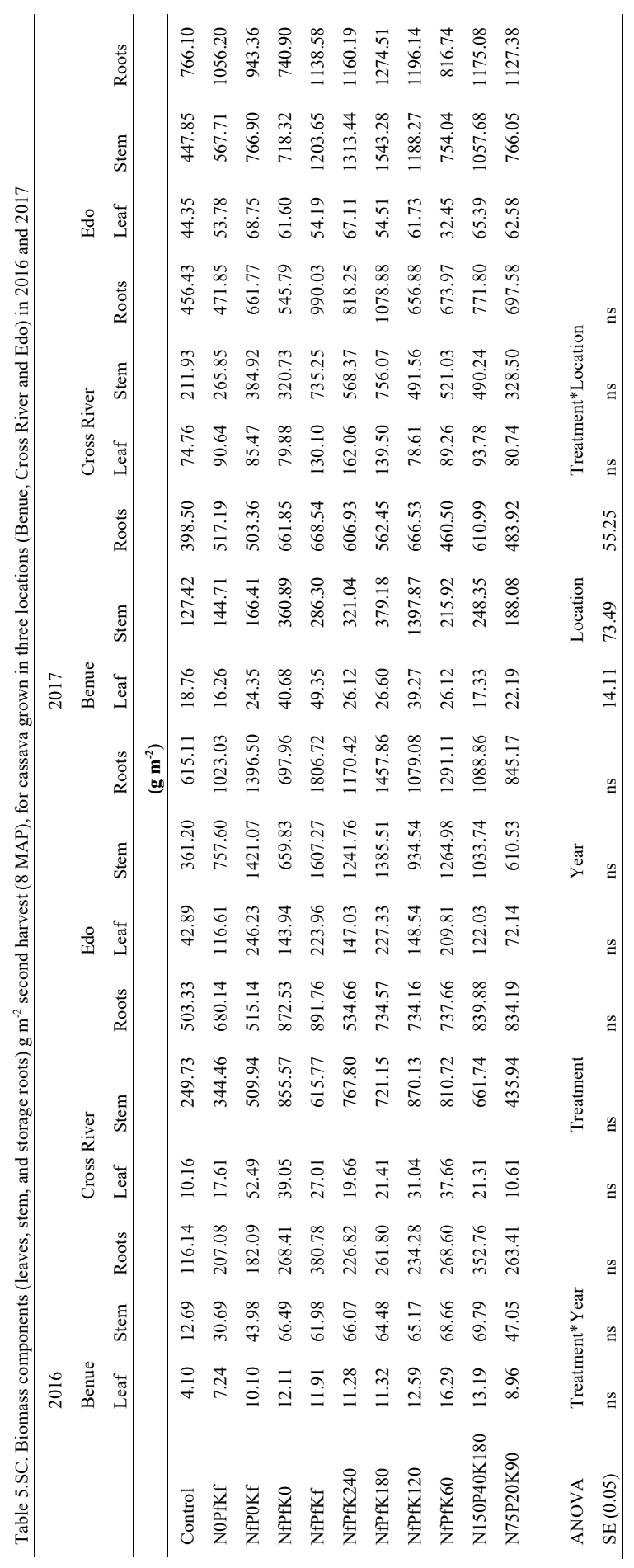



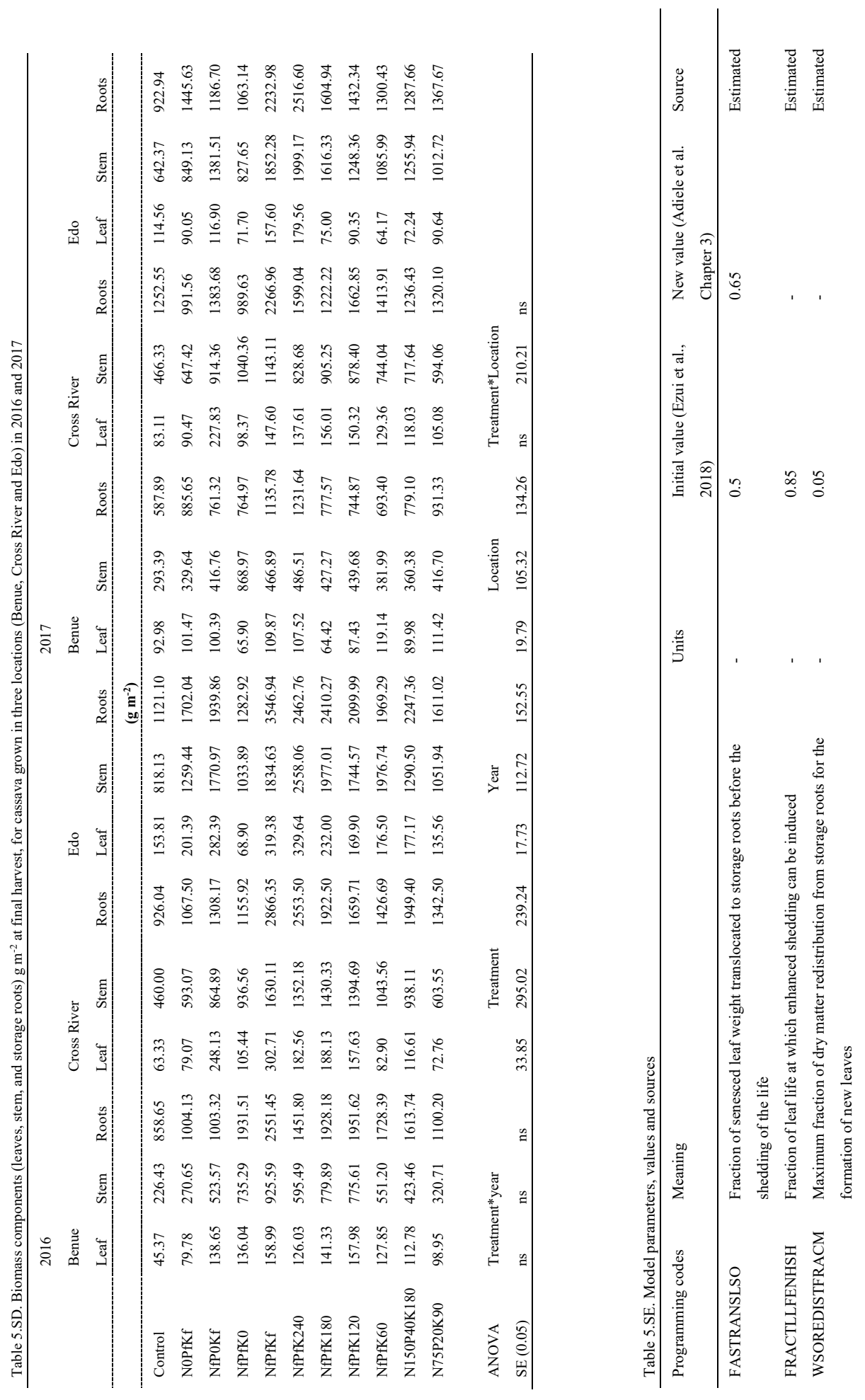
MHMMnMUn!

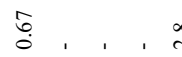

$$
\begin{aligned}
& \stackrel{8}{8}
\end{aligned}
$$

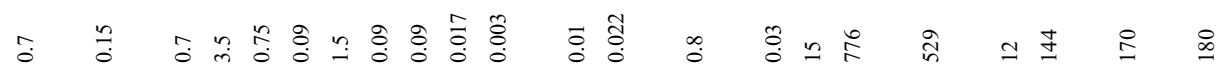

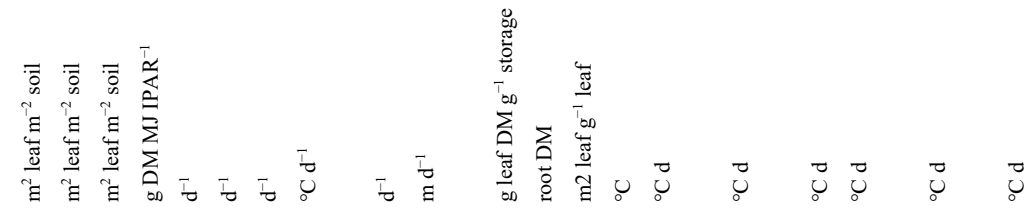

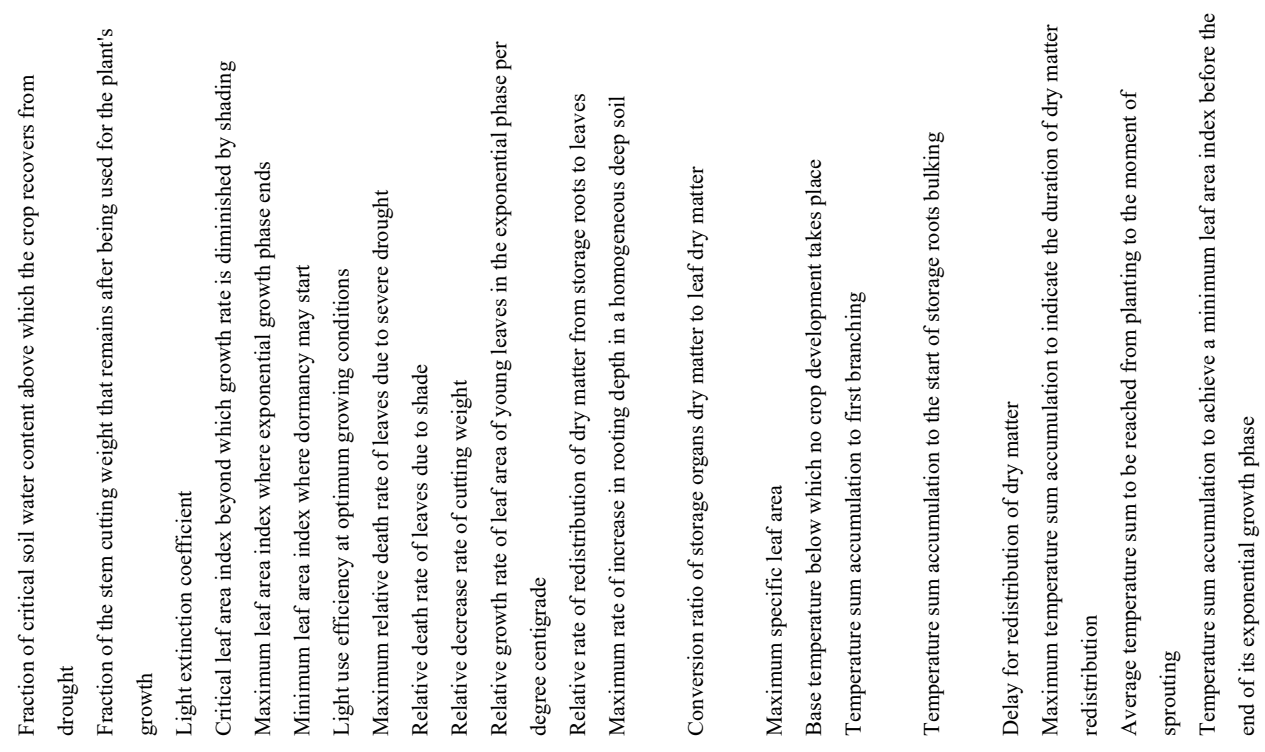

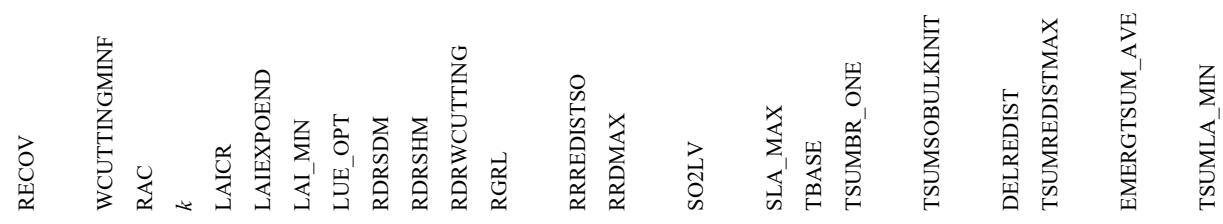




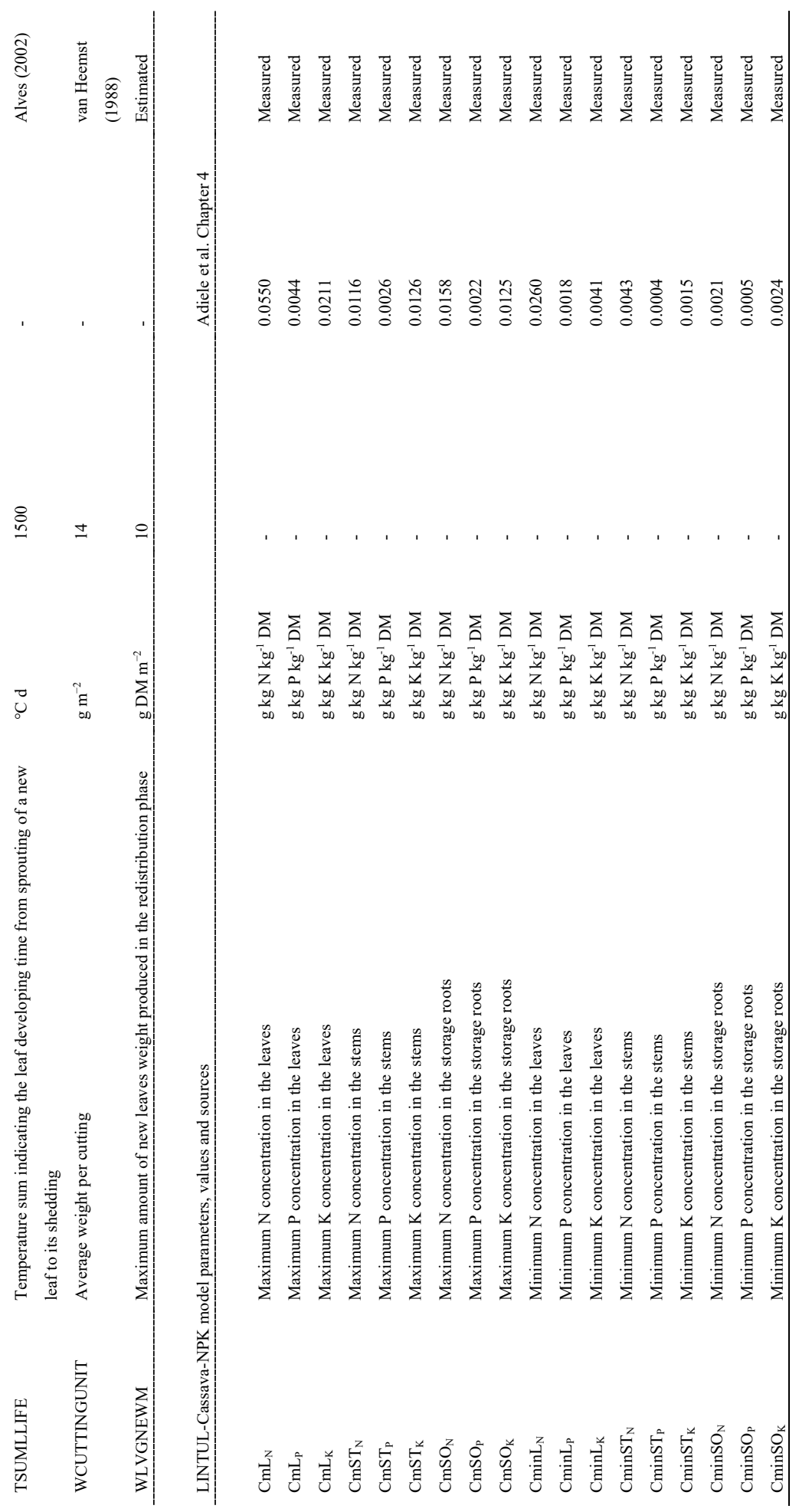



Chapter 6. General discussion 


\subsection{Overview}

As explained in the first chapter, an increase in the productivity of cassava is essential and crop yields are expected to increase per unit land area, in order to support the rapidly growing population (Oliveira et al., 2017). However, the intensification and expansion of cassava production in the area will require informed management strategies in order to minimize its environmental impacts. Also, quantifying the key parameters that describe cassava growth processes at optimal growing condition and the dynamics of nutrient uptake and distribution is important so as to benchmark and understand the yield potential of cassava in SSA. Our results show that cassava can produce up to $35 \mathrm{t} \mathrm{DM} \mathrm{ha}^{-1}$ of storage root yield at 14 MAP, which is equivalent to about $97 \mathrm{t} \mathrm{ha}^{-1}$ of fresh storage roots (Chapter 2). This is the largest cassava yield recorded in West Africa (WA) and was achieved with high agronomic and recovery efficiency of nutrients. In addition, we found that at high $\mathrm{N}$ and $\mathrm{K}$ supply, increasing $\mathrm{K}$ availability strongly increased cassava yield and recovery of applied nutrients. This highlights the need for enhanced $\mathrm{K}$ management to achieve high yields in cassava. Despite the enormous yields observed, there were no apparent gains from the application of other essential nutrients such as $\mathrm{S}, \mathrm{Ca}, \mathrm{Mg}, \mathrm{Zn}$ and boron. Storage root yield at Edo and Cross River (CRS) were larger than simulated potential yields (Chapter 2). This indicates that some crop parameters used in existing cassava growth simulation models require modification. In Chapter 3, we demonstrated that under optimum management, cassava can grow vigorously and provide early canopy cover, hence, intercepting more light needed for optimum growth. Seasonal average of $L A I$ and fraction of light intercepted $(f L I)$ at 3 and $80 \%$, respectively and seasonal $R U E$ of $2.8 \mathrm{~g} \mathrm{DM} \mathrm{MJ}^{-1}$ IPAR were obtained. This was achieved at near-optimal conditions throughout the growing season. Furthermore, the LINTUL-Cassava model was able to describe the observed patterns of LAI and growth of leaves, stems and storage roots, after parameterization and calibration of DM partitioning with the new observed values.

Chapter 4 of this work provided detailed insights in the dynamics of nutrient uptake and uptake rates, $\mathrm{N}, \mathrm{P}$ and $\mathrm{K}$ dilution curves and nutrition indices for cassava under varying environmental and soil conditions over time. We observed that though nutrient uptake and rate peaked at about four months after planting, when about 67,61 and $52 \%$ of $\mathrm{N}, \mathrm{P}$ and $\mathrm{K}$ present in the plant at final harvest were taken up, the nutrient uptake and rate increased again after the seasonal dry period. This is similar to the findings of (Howeler, 2012). This means that split fertilizers application, where one-third portion is applied at later growth stages, may contribute to improved uptake, yield and environmental safety. However, this needs further investigation as cassava is deep rooting and can access nutrients even at deeper levels. For shallow soils such as in Benue (Chapter 3), fertilizer application for target yield should consider site-specific conditions that affect applied nutrient availability to the crop. From our findings, nutrient uptake rates were similar among locations during the second regrowth, with the return of the rains.

The knowledge developed about nutrient (N, P and K) uptake and distribution patterns under both ample and deficient conditions in cassava was used to develop a dynamic simulation model (LINTUL-CassavaNPK) in Chapter 5. After parameterization and calibration, values of simulated N, P and K nutrition indices for different treatments showed strong responses to fertilizer application. The simulated $\mathrm{N}, \mathrm{P}$ and $\mathrm{K}$ uptakes showed a familiar trend with cassava nutrient dynamics, uptake of $\mathrm{K}$ was highest in the storage roots across all treatments, with simulated values close to those observed at final harvest. The model was validated using data from three other field experiments from 2017 and it simulated cassava storage root yield and nutrient uptake with reasonable accuracy, explaining about $70,80,70$ and $70 \%$ of the variation between observed and simulated storage roots yield, $\mathrm{N}, \mathrm{P}$ and $\mathrm{K}$ uptakes, respectively across locations. Therefore, LINTUL-Cassava-NPK model can help build a decision support system that will increased cassava production. However, the model requires further validation beyond the study areas and adapted to other cassava cultivars for wider applicability. 


\subsection{Towards improving cassava yield: Good crop management}

Despite the vast importance of cassava to smallholder farmers in SSA and growing demands for animal feed and raw materials for related industries, cassava has received relatively little attention or investment. This is vividly demonstrated by the fact that average cassava yield has not increased remarkably in Nigeria over the past five decades (FAOSTAT, 2020a), while over the same period, maize yields in Nigeria increased by 129 \% (De Souza et al., 2017). Most breeding programs and efforts to improve cassava yields have prioritized drought tolerance, reducing cyanogenic content, and resistance to pest and diseases (Egesi et al., 2007; De Souza and Long, 2018). Recently, efforts have focused on improving cassava nutritional quality (Montagnac et al., 2009; Adenle et al., 2012). Increasing cassava yield requires an in-depth understanding of limitations in growth. Optimum plant population densities are required for good yield, though they vary widely in farmers' fields (Hauser et al., 2014). Although cultivar dependent, the current recommended planting density of 12,500 plants ha ${ }^{-1}$ supports uniform growth and high storage root yield. Also, good land preparation such as 'the ridge land management system' enhances cassava growth (Mmom et al., 2017). Canopy development of cassava at the initial growth stage is slow, it takes about 80 days after planting to attain a leaf area index (LAI) of one (Veltkamp, 1985; Alves, 2002). This makes cassava a poor competitor with weeds, for light, water and nutrients, resulting in reduced cassava growth. Hence, the need to weed cassava fields two to three times before the canopy closes at about 4 MAP (Howeler, 2014; Ekeleme et al., 2016). Enhancing radiation use efficiency, that is the efficiency at which available sunlight is utilized to produce biomass is required to increase cassava yield. In our study, $L A I$ and intercepted light were maintained at sufficient high levels for good crop growth. Overall, good land preparation, selection of high-quality planting material from improved cultivars, optimum planting density and appropriate and balanced fertilizer rates, can stimulate early cassava growth and rapid canopy closure. Thereby, reducing labour demands for weeding.

\subsection{The cassava crop: demystifying the myth about its response to fertilizers}

Cassava is often grown by resource-poor farmers who operate under limited resources. Its ability to produce where other crops fail has led many to believe that cassava does not require fertilizers, but if at all, it must be in small rates. Fermont et al. (2010) showed that inorganic fertilizers were never applied to cassava in Central/Eastern Uganda and Western Kenya. In Cambodia farmers applied on average only $0-7 \mathrm{~kg} \mathrm{~N}, 0-11 \mathrm{~kg}$ P and no K fertilizer (Pampolino, 2018). Similar study in Philippines recorded application rates of $0-109 \mathrm{~N}, 0-26 \mathrm{P}$ and $0-29 \mathrm{~kg} \mathrm{~K}$ ha $^{-1}$ (Pampolino, 2018). It appears to be a common belief among farmers in countries where cassava is grown that cassava does not need to be fertilized (Howeler et al., 2013; Biratu et al., 2018; Pampolino, 2018). Further, fertilizer response trials on cassava show poor yield responses at low nutrient rates (Agbaje and Akinlosotu, 2004). In Nigeria, for instance, the recommended NPK application rates for cassava production is $600 \mathrm{~kg}$ of compound NPK 15:15:15, which is equivalent to 90,39 and $75 \mathrm{~kg} \mathrm{~N}, \mathrm{P}$ and $\mathrm{K} \mathrm{ha}^{-1}$. Another study by Biratu et al. (2018) investigating the effect of fertilizers on yield in two different agro-ecologies in Zambia with four NPK rates (0-0-0, 50-11-41.5, 100-22-83, and 150-33-124.5 kg N, $\mathrm{P}$ and $\left.\mathrm{K} \mathrm{ha}^{-1}\right)$, reported no significant difference between the two lower and the two higher rates of applied fertilizer across the sites. The obtained largest yield was $27.8 \mathrm{tha}^{-1}$ fresh storage root yield and $24.8 \mathrm{t} \mathrm{ha}^{-1}$ fresh stem at $12 \mathrm{MAP}$. These and similar observations such as recorded by (Lebot, 2019) contribute to the myth that cassava does not respond to fertilizer.

In addition, unbalanced $\mathrm{N}, \mathrm{P}$ and $\mathrm{K}$ rates, where in most cases too much $\mathrm{N}$ is applied, contribute to the limited response of cassava to applied fertilizers. For example, in Chapter 2, there was no significant yield difference between two treatments where NPK was applied at the rates of 300-100-180 and 150$40-180 \mathrm{~kg} \mathrm{ha}^{-1}$. Our results show that without adequate $\mathrm{K}$ supply, cassava responds poorly to $\mathrm{N}$ 
fertilizers. These two major mineral nutrients interact with each other in cassava production, with $\mathrm{N}$ playing a dominant role in vegetative growth, including leaf development, and $\mathrm{K}$ in storage root initiation and bulking. A cassava study in Colombia attained maximum yield when $130 \mathrm{~kg} \mathrm{~N} \mathrm{ha}^{-1}$ and $160 \mathrm{~kg} \mathrm{~K} \mathrm{ha}^{-1}$ were applied (Imas and John, 2013), indicating that relatively higher rates of $\mathrm{K}$ are essential to achieve high root yield for cassava. At balanced rates, there is a positive synergistic interaction between $\mathrm{N}$ and $\mathrm{K}$ on assimilate production, nutrient uptake, yield formation and stress tolerance (Guo et al., 2019). Based on our findings, balanced NPK applications were required to substantially increase yields in strongly depleted soils as in our case. The largest yield of about $35 \mathrm{t} \mathrm{ha}$ ${ }^{1} \mathrm{DM}$ was achieved when $\mathrm{N}, \mathrm{P}$ and $\mathrm{K}$ were applied at the rates of 300,100 and $300 \mathrm{~kg} \mathrm{ha}^{-1}$, respectively. Similar high yields have been obtained by other workers in Colombia (El-Sharkawy et al., 1990; ElSharkawy, 2007), Australia (Fukai et al., 1984) and most recently in India (Byju and Suja, 2020). Therefore, poor cassava yield responses to fertilizer applications in SSA are related to imbalanced nutrient supply, low application rates, wrong timing of application, poor weed management etc.

Average total uptake of $\mathrm{N}, \mathrm{P}$ and $\mathrm{K}$ was $13.5,1.7$ and $9.7 \mathrm{~kg}$ per ton of DM storage root harvested (Chapter 2). Therefore, fertilizer rates can be adjusted based on farmer's budget for economic yield. Farmers with budget constraints can apply small but balanced rate. If cassava is being grown commercially for food or industrial use, balanced fertilizer rates targeting high storage root yield would be preferred. It is expected that the agricultural sector will provide the much needed food security and other by-products, as well as employment to a growing labour force in SSA. This underscores the need for yield increasing technologies. Increasing yield through breeding for higher yielding varieties at low fertilizer input levels will be unsustainable if soil fertility is not improved (Fresco, 1986). Therefore, research that is aimed at food security, economic growth and continuity of crop production should focus on maximum (where possible) and sustainable productivity (de Wit, 1994). If not, crop productivity will decrease over time.

\subsection{Nutrient use efficiency at high yielding conditions}

The efficient use of nutrients has two significant dimensions, one to enable more food to be produced with the same or lower nutrient input and the other to reduce nutrient losses to the environment. Hence, management practices that improve NUE without reducing productivity or the potential for future productivity increases are likely to be most valuable (Fixen et al., 2015). Increasing yield is the key strategy to preserve food security. Growing cassava in Nigeria with current fertilizer rate of $600-800$ $\mathrm{kg}$ of compound NPK 15:15:15 or no fertilizer at all will keep the yield low. In this and similar scenarios, a very high NUE can be obtained but with production well below the maximum (Norton, 2014). With improved management, high yield cereal systems are maintained with higher NUE than systems with lower productivity (Bruulsema et al., 2004; Fixen et al., 2015). Our results show that it is possible to achieve high NUE with cassava at relatively large fertilizer rates, but only when crop nutrient demand is much larger than the indigenous supply and growing conditions are favourable (Chapter 2). These AE values (Table 6.1) are above the benchmark for AE of high-yielding cereal crops (maize, rice, and wheat) in well managed production systems, which ranges from $15-30,15-40$ and $8-20 \mathrm{~kg} \mathrm{~kg}^{-1}$ for $\mathrm{N}, \mathrm{P}$ and K, respectively (Norton, 2014; Fixen et al., 2015). Yet, the wide ranges in the AE and RE of applied $\mathrm{N}, \mathrm{P}$ and $\mathrm{K}$ observed across the agro-ecologies (Chapter 2) highlight the opportunity and need for optimizing NUE for different growing conditions. 
Table 6.1. Agronomic and recovery efficiency of fertilizers for the highest yielding treatment (NfPfKf) from Edo, Cross River (CRS) and Benue.

\begin{tabular}{lllll}
\hline & $\mathrm{AE}\left(\mathrm{kg} \mathrm{kg}^{-1}\right)$ & & $\mathrm{RE}$ & \\
& 2016 & 2017 & 2016 & 2017 \\
& & & & \\
$\mathrm{~N}$ & $52-68$ & $16-43$ & $0.47-0.92$ & $0.20-0.50$ \\
$\mathrm{P}$ & $155-172$ & $59-94$ & $0.18-0.32$ & $0.08-0.24$ \\
$\mathrm{~K}$ & $21-73$ & $25-43$ & $0.42-0.88$ & $0.24-0.61$ \\
\hline
\end{tabular}

With good management and no fertilizer applied, we obtained on average a yield of $9 \mathrm{t} \mathrm{ha}^{-1} \mathrm{DM}$ storage root, equivalent to $27 \mathrm{tha}^{-1}$ fresh weight (Chapter 2). Such yield were similar in the control plots across the study locations. This implies that the lowest AE and RE obtained from Benue (Guinea Savanna) reflects the need for adjustment of fertilizer applications to the production potential of the different locations (agro-ecologies) as well as to improve management of other factors (e.g., planting date and crop rotation) in order to make the investment in fertilizer more profitable.

\subsection{Adapting crop management to local conditions - Planting and harvest time}

Current management practices for growing cassava in WA, for instance Nigeria may be contributing to the low yields. In practice, the most suitable planting time of cassava in a particular locality is usually determined by weather pattern (Ezui et al., 2018). However, insights from our study show that cassava planted with the first rains with the intention to harvest at 12 MAP, undergoes enormous yield losses due to the regrowth that occurs with the return of rains from April of the following year. This is because, cassava endures a seasonal dry period at the mid growth stage (7 to 11 MAP) (Fig. 6.3a) which results in reduced crop growth or dormancy due to severe climatic conditions and prolonged water deficit. With return of the rains and the regrowth of new leaves, storage root yield is decreased, even under best crop management. In practice, most farmers harvest before the start of the next rainy season, while others harvest with the rains as long as the crop is 11 to 12 months old or due to their immediate needs. Longer growing periods are seldom feasible, because of the high demand for crop land. Results from our study show that harvesting before or during the first 2 months of rainfall decreases cassava storage root yield by 17 to $50 \%$, compared with harvesting after full recovery from drought. However, the yield penalty was less when fertilizer was not applied. Under rainfed conditions, planting cassava in the middle of the rainy season (August - September) would allow for adequate crop establishment before the onset of the seasonal dry period (Fig. 6.3b). Crop growth continues with rapid regeneration and higher photosynthetic capacity with the return of rains (El-Sharkawy, 2007; Rosenthal and Ort, 2012; Byju and Suja, 2020) when the crop is still about 7 or 8 months old. This allows an adequate time for recovery from drought and consequently a large yield at harvest, as was the case in Benue during the 2016 growing season (Chapter 2 and 3). Also, based on cassava nutrient uptake patterns (Chapter 4), top dressing during this second growth cycle will improve the synchrony between soil available nutrients and crop demand, resulting in high nutrient use efficiency and storage root yield. Also, K applied in the second cycle has a greater effect on the synthesis and allocation of starch in the storage roots (Fernandes et al., 2017). 


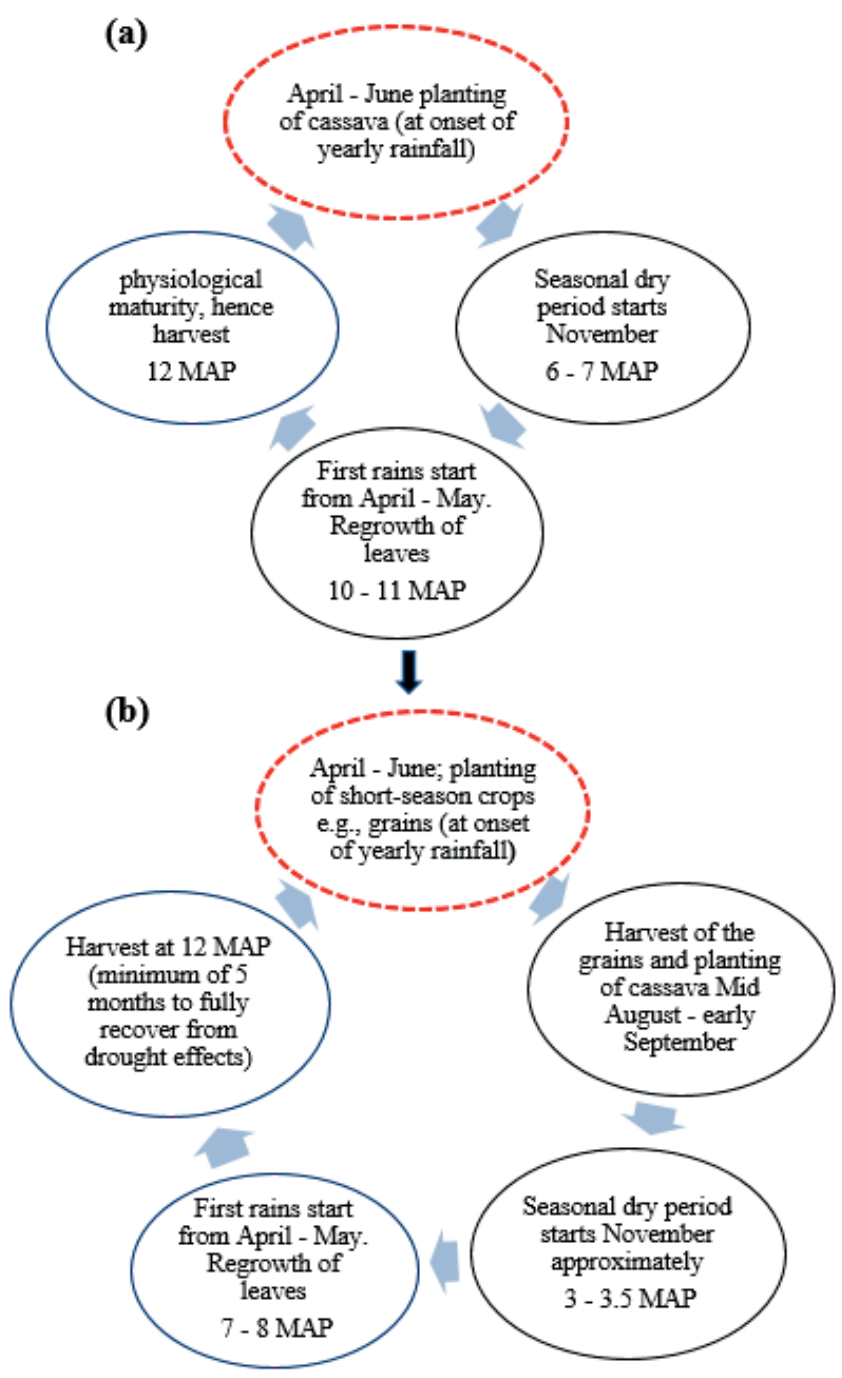

Fig. 6.3. (a) The usual cassava growth cycle under WA climatic condition when planted with early first rainfall and (b) when planted mid-cropping season.

The Guinea Savannah (one of the study locations) has unexploited opportunity for the expansion of commercial cassava production (Morris et al., 2009; Shackelford et al., 2018). As confirmed from this study, planting mid-cropping season (August) produced higher storage root yield than early planting with first rains in June (Chapter 2). This knowledge can help develop appropriate crop rotational systems (cereals - cassava - legume) or intercropping of cassava with short duration crops (Pypers et al., 2011), to improve nutrient management and limit losses.

6.6. Sustainable cassava production - the role of genetic improvement.

For ecologically sustainable production of food and biomass, the use of more nutrient-efficient crops is likely to play an essential role in increasing or maintaining crop yields in the future (Weih et al., 2018). 
An overriding factor in genetic improvement of cassava has been disease resistance and drought tolerance. For example, TMS 98/0581 was bred for its resistance to cassava mosaic virus disease (CMD) (Egesi et al., 2007). The other improved cultivar TMS 30572 was bred for resistance to cassava anthracnose disease, cassava bacterial blight (CBB), cassava mealybug, and cassava green mite (EkeOkoro and Njoku, 2012). Through bioengineering, it may be possible to substantially increase the photosynthetic capacity of cassava for higher yields (De Souza and Long, 2018). A study by De Souza and Long (2018) on yield assessment and disease resistance of different cassava varieties showed that while TME 419 was only moderately resistant to diseases and pest, the cultivar showed a greater water use efficiency through its slower stomatal conductance, with higher photosynthetic rates than others studied. TME 419 accumulated the largest total biomass and dry matter partitioning to its storage roots, after 45 days of growth, producing about $435 \%$ more storage roots DM than other cultivars that were evaluated (De Souza and Long, 2018). Our results (Chapter 2 to 5) with the cultivar TME 419, on the basis of its response to fertilizers, enhanced growth, uptake and NUE confirm the specified traits. Hence, this information can be used in selecting more efficient genotypes.

\subsection{Importance of study for decision support tools}

Simulation models for cassava have been developed and have helped in defining and understanding key physiological determinants of the crop's growth (Matthews and Hunt, 1994; Mithra et al., 2013; De Souza et al., 2017; Ezui et al., 2018). My aim is to contribute to improving cassava production using the LINTUL-Cassava model as a tool. Results from our study improved the model's performance under rain-fed systems (Chapter 3) and formed the empirical and theoretical foundations of nutrient-limited cassava growth modelling (Chapter 5). Dynamic partitioning of assimilates into leaves, stem, storage root and fibrous roots to reflect the pattern at field conditions is important (De Souza et al., 2017). Our work improved this aspect through dry matter partitioning of cassava under non-water limited conditions, in synchrony with the changes in $L A I$ during the growth period. This helped to describe cassava growth and yield reasonably well. The LINTUL-Cassava-NPK model provides insight in best times of nutrient application in the season. This will help to reduce nutrient losses and maximize yield by applying the required amounts at the proper time, contributing to the $4 \mathrm{R}$ nutrient stewardship concept of the International Plant Nutrition Institute (IPNI). The knowledge provided will be useful and can improve agricultural decision support tools, also building on the ongoing work of the African Cassava Agronomy Initiative (ACAI) project. Through providing benchmarks for nutrient limited production and enabling comparisons of management independent of nutrient application levels.

\subsection{Cassava: contributing to local and economic development of Nigeria}

In Nigeria, about 6.9 million hectares of land were cultivated in 2018 for average fresh storage root yield of $8.8 \mathrm{t} \mathrm{ha}^{-1}$ (FAOSTAT, 2020a). Cassava yields could be increased in a sustainable manner through improved crop management and fertilizer application, thereby reducing the need for further expansion of crop land, similar to Thailand and other cassava growing countries (Table 6.2).

Table 6.2. Top five cassava producing countries with area of land harvested, total amount produced and fresh yield in $\mathrm{t} \mathrm{ha}^{-1}$ in 2018 (FAOSTAT, 2020a).

\begin{tabular}{llll}
\hline Countries & Area harvested (million ha) & Yield $\left(\mathrm{t} \mathrm{ha}^{-1}\right)$ & Amount produced $(\mathrm{Mt})$ \\
\hline Nigeria & 6.9 & 8.7 & 60.0 \\
Thailand & 1.4 & 23.0 & 31.7 \\
Ghana & 1.0 & 20.2 & 20.8 \\
Indonesia & 0.7 & 23.0 & 16.1 \\
Brazil & 1.2 & 14.0 & 17.6 \\
\hline
\end{tabular}


The main factors limiting cassava productivity in Nigeria include reliance on rain-fed agriculture and poor soil fertility. In addition to resilience to adverse growing conditions, cassava seems a better option for various reasons. With cereals, it is more difficult to take advantage of the full season as double cropping or cropping long-season cultivars may be too risky for farmers. Therefore, high-yielding cassava can play a key role towards meeting the increasing demand for food and agro-based products, because of its high energy content and efficiency. Under limited $\mathrm{N}$ availability, applying fertilizer to cassava results in more energy per $\mathrm{kg} \mathrm{N}$ applied with lower environmental risks, evidenced by higher recovery and nutrient use efficiency than for maize (chapter 2). Crop calorie allocation fractions in Nigeria to food, feed, and others are $0.61,0.20$, and 0.19 respectively (Cassidy et al., 2013). If the calorie allocation to feed and others (e.g. raw materials) could be offset to a greater extent by cassava, more food will be available while satisfying dietary preferences of the growing and enlightened population, while saving cost from food importation. Furthermore, cassava is produced mainly for the domestic market in Nigeria, urban markets account for about $60 \%$ of total demand for cassava, with $20 \%$ going to rural markets and $10 \%$ for export, with the remaining $10 \%$ used for flour (CABRI, 2019). Little is processed as done in Thailand, Indonesia and Brazil for many and varied uses. This suggests that the outlook for increased cassava production is promising as it can spur rural and economic development through production, marketing and export of high quality cassava starch and chips to earn foreign exchange. Countries like Ghana, Mozambique, South Africa and Zambia have developed innovative uses of cassava for industrial raw materials such as starch, sweeteners, beer and in recent times, industrial bioethanol from cassava (replacing paraffin in cooking stoves in South Africa) (Adeyemo et al., 2019).

\subsection{Revisiting the presidential cassava initiative}

In July 2002, the Federal Government of Nigeria inaugurated the 'Presidential Initiative on Cassava', stating that, bread flour should contain at least $10 \%$ cassava flour. The objective of the initiative was to increase cassava production and demand for cassava, in order to achieve self-food sufficiency and promote export of cassava for foreign exchange. The target was to increase the area cultivated to 5 million ha, with the intention to harvest $150 \mathrm{Mt}$ of fresh cassava roots annually, to produce $37.5 \mathrm{Mt}$ of processed cassava products for domestic use and foreign exchange, potentially generating about 5 billion dollars annually from export (Donkor et al., 2017). The large yield response obtained in this study indicates that Nigeria economy could still be improved through cassava production. Policies aimed at boosting cassava production are expedient.

Nigeria spends on average \$22 billion yearly on food imports (Alo, 2018; Falayi, 2019), a very unsustainable situation. On the other hand, it could save from $127-225$ billion Naira (344 - 609 million dollars) yearly by $10-20 \%$ cassava flour addition to wheat flour for bread production (Vanguard, 2017; Nation, 2019). Cassava flour is the best component of composite flour to produce very high quality bread, when compared with composite flour from other crops such as corn, millet, and sorghum (Nation, 2019). A strategic policy, introducing a mandatory 10 - $20 \%$ cassava-wheat flour blending ratio, as was done in Brazil (FAO, 2018) could drive the implementation of this policy. Recently, the importation of rice, used clothing, poultry products and vegetable oil were banned in Nigeria (SaharaReporters, 2019). Since then, domestic rice production has increased, and consumers (irrespective of preferences) are already accustomed to local rice. Similar drastic measures should include wheat flour importation, while supporting cassava farmers through subsidies, loans and extension services. In addition to the foreseen savings, there will be job creation along the value chain.

Though cassava is more important for food security than for industry in Nigeria, other uses of cassava as feed and industrial raw material give a comparative advantage over cereals. Chips and pellets from cassava are good energy substitutes for cereals in pig and poultry diets, also, cassava starch is preferred 
by industries to modified starch (FAO, 2018). Cassava could become the raw material base for an array of processed products that would increase the demand and contribute to the long sought agricultural transformation and economic growth in Nigeria. The market for cassava in Nigeria is enormous and could still be further explored. For instance, there are already existing companies in Nigeria (e.g. Psaltry International Limited) that are processing cassava into standard pharmaceutical and food grade industrial starch and feedstock. Cassava, with its adaptability to drought, high energy content and variety of sub-products, could become the crop of choice for a much-needed agricultural revolution in Nigeria. To reach this goal, findings from our work will be useful in developing technologies for good agronomic practices that will support sustainable cassava production.

\section{An Endnote}

A maxim of Professor C.T. de Wit that is often repeated at the Plant Production Systems group is "No modelling without experimentation" or the opposite "No experimentation without modelling". Essentially my thesis followed this approach. Together with my daily supervisor, Tom Schut, we used the QUEFTS model (Ezui, 2017) to calculate how much and what balance of nutrients would be needed to attain the maximum recorded storage root yield of cassava of $90 \mathrm{t} \mathrm{ha}^{-1}$ of fresh root of cassava (Cock et al., 1979; El-Sharkawy et al., 1990; El-Sharkawy, 2007). We used the outcomes of this simple modelling exercise to design the field experiments that were then conducted at six experimental sites representative of the typical major agro-ecologies in which cassava is grown in Nigeria. Given that we did not have the opportunity to irrigate the experiments, I was very fortunate that one of the locations chosen for the experiments, Edo in the Transition Rain Forest agro-ecological zone, had a very deep and well-structured soil. The excellent physical properties of the soil at this site meant that cassava rooted to more than $3 \mathrm{~m}$ depth, which coupled with the well-distributed rainfall in the 2016 season allowed expression of the genetic potential of the cassava variety TME 419, achieving storage root yield of up to $35 \mathrm{t} \mathrm{DM} \mathrm{ha}^{-1}$ (equivalent to about $97 \mathrm{t} \mathrm{ha}^{-1}$ of fresh storage roots). In fact, the response to potassium was linear up to the highest rate used $\left(300 \mathrm{~kg} \mathrm{~K} \mathrm{ha}^{-1}\right)$, suggesting that the true potential yield of cassava is above $100 \mathrm{tha}^{-1}$ of fresh root on the best locations. The results of the balanced nutrition experiments were then used to develop a novel approach to simulating the response to N, P and K simultaneously in the LINTUL-Cassava-NPK model. In turn the model was then used to explore the experimental results of the different nutrient supply rates in the other sites and seasons of experimentation. This also led to new hypothesis. So effectively I modelled, experimented and then modelled again using theory derived from earlier work in production ecology at Wageningen.

My work was also inspired by earlier research on cassava at Wageningen University, from the early work of (Veltkamp, 1985), Professor Louise Fresco (Fresco, 1986) to more recent PhD studies of Dr Anneke Fermont in Kenya and Uganda (Fermont et al., 2009) and Dr Guillaume Ezui in Togo and Ghana (Ezui, 2017). It was a privilege to follow in the footsteps of these scientists and I trust that both I and others will continue this research in the future which is critical for the future of food security and economic development of Nigeria and other countries of sub-Saharan Africa.

\footnotetext{
${ }^{1}$ Note from my promotor "Despite an active search and consultation with Peter Leffelaar and Rudy Rabbinge we can find no publication of C.T. de Wit or anyone else which actually cites this phrase. As such it is simply part of the oral history of the Theoretical Production Ecology group and its descendants".
} 


\section{References}

Adejuwon, J.O., 2006. Food crop production in Nigeria. II. Potential effects of climate change. J. Clim. Res. 32, 229-245.

Adenle, A.A., Aworh, O.C., Akromah, R., Parayil, G., 2012. Developing GM super cassava for improved health and food security: future challenges in Africa. Agric. Food Secur. 1, 11.

Adeyemo, T., Amaza, P., Okoruwa, V., Akinyosoye, V., Salman, K., Abass, A., 2019. Determinants of intensity of biomass utilization: evidence from cassava smallholders in Nigeria. Sustainability 11, 2516.

Adiele, J.G., Schut, A.G.T., van den Beuken, R.P.M., Ezui, K.S., Pypers, P., Ano, A.O., Egesi, C.E., Giller, K.E., 2020. Towards closing cassava yield gap in West Africa: Agronomic efficiency and storage root yield responses to NPK fertilizers. Field Crops Res. Published online https://doi.org/10.1016/j.fcr.2020.107820. . Chapter 2.

Adiele, J.G., Schut, A.G.T., van den Beuken, R.P.M., Ezui, K.S., Pypers, P., Ano, A.O., Egesi, C.E., Giller, K.E., 2020. Evaluating cassava yield potential using the LINTUL-Cassava model. Submitted to Eur. J. Agron. Under review. Chapter 3.

Adiele, J.G., Schut, A.G.T., Ezui, K.S., Pypers, P., Ano, A.O., Egesi, C.E., Giller, K.E., Chapter 4. Dynamics of nutrient uptake, dilution and nutrition indices for cassava. Submitted to Agron. Sustain. Dev. Chapter 4.

Agbaje, G., Akinlosotu, T., 2004. Influence of NPK fertilizer on tuber yield of early and late-planted cassava in a forest alfisol of south-western Nigeria. Afr. J. of Biotechnol. 3, 547-551.

Akponikpè, P.I., Gérard, B., Michels, K., Bielders, C., 2010. Use of the APSIM model in long term simulation to support decision making regarding nitrogen management for pearl millet in the Sahel. Eur. J. Agron. 32, 144-154.

Alo, C., 2018. Nigeria spends \$22bn annually on food importation - Audu Ogbe. Vanguard. Available at https://www.vanguardngr.com/2018/08/nigeria-spends-22bn-annually-on-foodimportation-audu-ogbe/. Accessed on February 9, 2020.

Alva, A., Hodges, T., Boydston, R., Collins, H., 2002. Dry matter and nitrogen accumulations and partitioning in two potato cultivars. J. Plant Nutr. 25, 1621.

Alves, A.A.C., 2002. Cassava botany and physiology, In: Hillocks, R. J., Thresh, J. M., Bellotti, A. C., (Eds.), Cassava: biology, production and utilization, CAB International, Brazil, pp. 67-89.

Angelov, M.N., Sun, J., Byrd, G.T., Brown, R.H., Black, C.C., 1993. Novel characteristics of cassava, Manihot esculenta Crantz, a reputed C 3-C 4 intermediate photosynthesis species. Photosynth. Res. 38, 61-72.

Angus, J., Moncur, M., 1985. Models of growth and development of wheat in relation to plant nitrogen. Aust. J. Agric. Res. 36, 537-544.

Bamiro, O., 1983. Empirical relations for the determination of solar radiation in Ibadan, Nigeria. Sol. Energy 31, 85-94.

Barbieri, P.A., Echeverría, H.E., Saínz Rozas, H.R., Andrade, F.H., 2008. Nitrogen use efficiency in maize as affected by nitrogen availability and row spacing. Agron. J. 100, 1094-1100.

Barnosky, A.D., Ehrlich, P.R., Hadly, E.A., 2016. Avoiding collapse: Grand challenges for science 
and society to solve by 2050. Elementa-Sci. Anthrop. DOI: 0.12952/journal.elementa.000094.

BBC-News, 2008. The cost of food. Available at http://news.bbc.co.uk/2/hi/in depth/world/2008/costoffood/default.stm. Accessed on June 21, 2015.

Biratu, G.K., Elias, E., Ntawuruhunga, P., Sileshi, G.W., 2018. Cassava response to the integrated use of manure and NPK fertilizer in Zambia. Heliyon 4, e00759.

Bista, D., Heckathorn, S., Jayawardena, D., Mishra, S., Boldt, J., 2018. Effects of drought on nutrient uptake and the levels of nutrient-uptake proteins in roots of drought-sensitive and-tolerant grasses. Plants 7, 28.

Bruulsema, T., Fixen, P., Snyder, C., 2004. Fertilizer nutrient recovery in sustainable cropping systems. Better Crops 88, 15-17.

Byju, G., Suja, G., 2020. Mineral nutrition of cassava. Adv. Agron. 159, 169 - 235.

CABRI, 2019. The role of governments in developing agriculture value chains. Available online at https://www.cabri-sbo.org/uploads/files/Documents/Case-Study-2_Rice-and-CassavaENG.pdf. Accessed on February 4, 2020.

Campbell, G.S., 1986. Extinction coefficients for radiation in plant canopies calculated using an ellipsoidal inclination angle distribution. Agr. Forest Meteorol. 36, 317-321.

Cassidy, E.S., West, P.C., Gerber, J.S., Foley, J.A., 2013. Redefining agricultural yields: from tonnes to people nourished per hectare. Environ. Res. Lett. 8, 034015. Available at https://iopscience.iop.org/article/10.1088/1748-9326/8/3/034015.

Chuan, L., He, P., Zhao, T., Zheng, H., Xu, X., 2016. Agronomic characteristics related to grain yield and nutrient use efficiency for wheat production in China. Plos One, DOI:10.1371/journal.pone.0162802

Ciampitti, I.A., Camberato, J.J., Murrell, S.T., Vyn, T.J., 2013. Maize nutrient accumulation and partitioning in response to plant density and nitrogen rate: I. Macronutrients. Agron. J. 105, 783-795.

Ciampitti, I.A., Vyn, T.J., 2013. Grain nitrogen source changes over time in maize: a review. Crop Sci. $53,366-377$.

Cock, J.H., Franklin, D., Sandoval, G., Juri, P., 1979. The ideal cassava plant for maximum yield. Crop Sci. 19, 271-279.

Costa, A.d., Albuquerque, J.A., Costa, A.d., Pértile, P., Silva, F.R.d., 2013. Water retention and availability in soils of the State of Santa Catarina-Brazil: effect of textural classes, soil classes and lithology. Rev. Bras. Ciênc Solo. 37, 1535-1548.

Dai, D., Hu, Z., Pu, G., Li, H., Wang, C., 2006. Energy efficiency and potentials of cassava fuel ethanol in Guangxi region of China. Energy Convers. Manag. 47, 1686-1699.

De Souza, A.P., Long, S.P., 2018. Toward improving photosynthesis in cassava: Characterizing photosynthetic limitations in four current African cultivars. Food Energy Secur. DOI: $10.1002 /$ fes 3.130

De Souza, A.P., Massenburg, L.N., Jaiswal, D., Cheng, S., Shekar, R., Long, S.P., 2017. Rooting for cassava: insights into photosynthesis and associated physiology as a route to improve yield potential. New Phytol. 213, 50-65. 
de Wit, C., 1968. Plant production. Instituut voor Biologisch en Scheikundig Onderzoek van Landbouwgewassen. Wageningen Medeleling 3, 25-50.

de Wit, C., 1992. Resource use efficiency in agriculture. Agric. sys. 40, 125-151.

de Wit, C., 1994. Resource use analysis in agriculture: a struggle for interdisciplinarity, in: Fresco, L.O., Stroosnijder, L., Bouma, J., van Keulen, H., (Eds.), The Future of the Land: Mobilising and Integrating Knowledge for Land Use Options, John Wiley and Sons, New York, pp. 4155 .

de Wit, C.T., Dijkshoorn, W., and Noggle, J.C. (1963). Ionic balance and growth of plants. (Mededeling / Instituut voor biologisch en scheikundig onderzoek van landbouwgewassen; No. 220). Wageningen: Unknown Publisher.

Dekker, M., 2003. Plant available soil water. Encyclopedia of Water Science. DOI: 10.1081/E-EWS 120010265

Devices, D., 2014. AccuPAR PAR/LAI ceptometer model LP- 80: Operator's manual, version 1.2. Decagon Devices: Pullman, WA, USA. Available at https://www.metergroup.com/environment/products/accupar-lp-80-leaf-area-index/ Accessed on September 5, 2019.

Delve, R.J., Probert, M.E., Cobo, J., Ricaurte, J., Rivera, M., Barrios, E., Rao, I.M., 2009. Simulating phosphorus responses in annual crops using APSIM: model evaluation on contrasting soil types. Nutr. Cycl. Agroecosys. 84, 293-306.

Donatelli, M., Van Ittersum, M., Bindi, M., Porter, J., 2003. Modelling cropping systems—-highlights of the symposium and preface to the special issues. Eur. J. Agron. 18, 187-197.

Donkor, E., Onakuse, S., Bogue, J., de Los Rios Carmenado, I., 2017. The impact of the presidential cassava initiative on cassava productivity in Nigeria: Implication for sustainable food supply and food security. Cog. Food. Agric. 3, 1368857, https://doi.org/10.1080/23311932.2017.1368857.

Du Preez, C., Bennie, A., 1991. Concentration, accumulation and uptake rate of macro-nutrients by winter wheat under irrigation. S. Afr. J. Plant \& Soil 8, 31-37.

Dzotsi, K., Basso, B., Jones, J., 2013. Development, uncertainty and sensitivity analysis of the simple SALUS crop model in DSSAT. Ecol. Model. 260, 62-76.

Egesi, C.N., Ogbe, F., Akoroda, M., Ilona, P., Dixon, A., 2007. Resistance profile of improved cassava germplasm to cassava mosaic disease in Nigeria. Euphytica 155, 215-224.

Eke-Okoro, O., Njoku, D., 2012. A review of cassava development in Nigeria from 1940-2010. J. Agric. Biol. Sci. 7, 59-65.

Ekeleme, F., Hauser, S., Atser, G., Dixon, A., Weller, S., Olorunmaiye, P., Usman, H., Olojede, A., Chikoye, D., 2016. Weed management in cassava in Africa: Challenges and opportunities. Pest Manag. Sci. 27, 208-212.

El-Sharkawy, M.A., De Tafur, S.M., 2010. Comparative photosynthesis, growth, productivity, and nutrient use efficiency among tall-and short-stemmed rain-fed cassava cultivars. Photosynthetica 48, 173-188. 
El-Sharkawy, M.A., 2009. Pioneering research on C 4 leaf anatomical, physiological, and agronomic characteristics of tropical monocot and dicot plant species: Implications for crop water relations and productivity in comparison to C 3 cropping systems. Photosynthetica 47, 163-183.

El-Sharkawy, M.A., 2007. Physiological characteristics of cassava tolerance to prolonged drought in the tropics: implications for breeding cultivars adapted to seasonally dry and semiarid environments. Braz. J. Plant Physiol. 19 (4): 257-286.

El-Sharkawy, M.A., 2003. Cassava biology and physiology. Plant Mol. Biol. 53, 621-641.

El-Sharkawy, M.A., Hernández, A.D.P., Hershey, C., 1992. Yield stability of cassava during prolonged mid-season water stress. Exp. Agric. 28, 165-174.

El-Sharkawy, M.A., Cock, J.H., Lynam, J.K., del Pilar Hernàndez, A., Cadavid, L.F.L., 1990. Relationships between biomass, root-yield and single-leaf photosynthesis in field-grown cassava. Field Crops Res. 25, 183-201.

Eichert, T., Fernández, V., 2012. Uptake and release of elements by leaves and other aerial plant parts. Marschner's Mineral Nutrition of Higher Plants. Elsevier, pp. 71-84.

Engels, C., Kirkby, E., White, P., 2012. Mineral nutrition, yield and source-sink relationships. In: In Marschner, P. (Eds). Marschner's mineral nutrition of higher plants (Third Edition). San Diego: Academic Press, pp. 85-133.

Ezui, K., Leffelaar, P., Franke, A., Mando, A., Giller, K., 2018. Simulating drought impact and mitigation in cassava using the LINTUL model. Field Crops Res 219, 256-272.

Ezui, K., Franke, A., Ahiabor, B., Tetteh, F., Sogbedji, J., Janssen, B., Mando, A., Giller, K., 2017a. Understanding cassava yield response to soil and fertilizer nutrient supply in West Africa. Plant Soil 420, 331-347.

Ezui, K., Franke, A., Leffelaar, P., Mando, A., van Heerwaarden, J., Sanabria, J., Sogbedji, J., Giller, K., 2017b. Water and radiation use efficiencies explain the effect of potassium on the productivity of cassava. Eur. J. Agron. 83, 28-39.

Ezui, K.S., 2017. Understanding the productivity of cassava in West Africa. Wageningen University. $\mathrm{PhD}$. Thesis Wageningen University, Wageningen, NL, pp. 180.

Ezui, K., Franke, A., Mando, A., Ahiabor, B., Tetteh, F., Sogbedji, J., Janssen, B., Giller, K., 2016. Fertiliser requirements for balanced nutrition of cassava across eight locations in West Africa. Field Crops Res. 185, 69-78.

Falayi, K., 2019. Why Nigeria has restricted food imports. Available online at https://www.bbc.com/news/world-africa-49367968. Accessed on February 9, 2020.

Fageria, N., 2014. Nitrogen harvest index and its association with crop yields. J. Plant Nutr. 37, 795810.

FAO, 2018. Food Outlook - Biannual Report on Global Food Markets - November 2018. Rome, pp.104. Available at http://www.fao.org/3/CA2320EN/ca2320en.pdf. Accessed on September 30, 2019.

FAO, 2017. Global database of GHG emissions related to feed crops: Methodology. Version 1. Livestock Environmental Assessment and Performance Partnership. FAO, Rome, Italy. Available at http://www.fao.org/3/a-i8276e.pdf. Accessed on May 14, 2019.

FAO-DG, 2018. Africa's prosperity also lies in creating decent and attractive jobs for rural youth. 
Available at http://www.fao.org/news/story/en/item/1103385/icode/. Accessed on February $25,2020$.

FAOSTAT, 2020a. Global cassava yield. Available at http://www.fao.org/faostat/en/\#data/QC. Accesed on January 17, 2020.

FAOSTAT, 2020b. Data on yield of crops and area harvested. Available at http://www.fao.org/faostat/en/\#data/QC. Accessed on March 13, 2020.

FAOSTAT, 2019. FAOSTAT. In: FAOSTAT (Ed.). Food and Agriculture Organization of the United Nations. Available at http://www.fao.org/faostat/en/\#data/QA. Accessed on April 15, 2019.

FAOSTAT, 2017. Total crop area harvested. Available at http://www.fao.org/faostat/en/\#data/QC. Accessed on October 1, 2019.

Fermont, A.M., Babirye, A., Obiero, H.M., Abele, S., Giller, K.E., 2010. False beliefs on the socioeconomic drivers of cassava cropping. Agron. Sustain. Dev. 30, 433-444.

Fermont, A.M., Van Asten, P.J., Tittonell, P., Van Wijk, M.T., Giller, K.E., 2009. Closing the cassava yield gap: an analysis from smallholder farms in East Africa. Field Crops Res. 112, 24- 36.

Fermont, A., Obiero, H., van Asten, P.J., Baguma, Y., Okwuosa, E., 2007. Improved cassava varieties increase the risk of soil nutrient mining: An ex-ante analysis for western Kenya and Uganda, in: Bationo (Eds.) Advances in Integrated Soil Fertility Management in sub-Saharan Africa: Challenges and Opportunities. Springer, pp. 511-520.

Fernandes, A.M., Gazola, B., Nunes, J.G.d.S., Garcia, E.L., Leonel, M., 2017. Yield and nutritional requirements of cassava in response to potassium fertilizer in the second cycle. J. Plant Nutr. 40, 2785-2796.

Fixen, P., Brentrup, F., Bruulsema, T., Garcia, F., Norton, R., Zingore, S., 2015. Nutrient/fertilizer use efficiency: measurement, current situation and trends. Managing water and fertilizer for sustainable agricultural intensification 8. ISBN 979-10-92366-02-0. Available at https://www.researchgate.net/publication/269709648 Nutrientfertilizer use efficiency measu rement_current_situation_and_trends. Accessed on April 8, 2019.

Fresco, L.O., 1986. Cassava in shifting cultivation: a systems approach to agricultural technology development in Africa. Wageningen University. PhD. Thesis Wageningen University, Wageningen, NL, pp. 245.

Fukai, S., Alcoy, A., Llamelo, A., Patterson, R., 1984. Effects of solar radiation on growth of cassava (Manihot esculenta Crantz.). I. Canopy development and dry matter growth. Field Crop Res. 9, 347-360.

Fukai, S., Hammer, G., 1987. A simulation model of the growth of the cassava crop and its use to estimate cassava productivity in Northern Australia. Agric. Syst. 23, 237-257.

Gabriel, L.F., Streck, N.A., Roberti, D.R., Chielle, Z.G., Uhlmann, L.O., da Silva, M.R., da Silva, S.D., 2014. Simulating cassava growth and yield under potential conditions in Southern Brazil. Agron. J. 106, 1119-1137.

Godfray, H.C.J., Beddington, J.R., Crute, I.R., Haddad, L., Lawrence, D., Muir, J.F., Pretty, J., Robinson, S., Thomas, S.M., Toulmin, C., 2010. Food security: the challenge of feeding 9 billion people. Science 327, 812-818.

Gómez, M.I., Magnitskiy, S., Rodríguez, L.E., 2018. Critical Dilution Curves for Nitrogen, Phosphorus, and Potassium in Potato Group Andigenum. Agron. J. 111, 419-427. 
Greenwood, D., Gastal, F., Lemaire, G., Draycott, A., Millard, P., Neeteson, J., 1991. Growth rate and $\% \mathrm{~N}$ of field grown crops: theory and experiments. Ann. Bot. 67, 181-190.

Greenwood, D., Lemaire, G., Gosse, G., Cruz, P., Draycott, A., Neeteson, J., 1990. Decline in percentage $\mathrm{N}$ of $\mathrm{C} 3$ and $\mathrm{C} 4$ crops with increasing plant mass. Ann. Bot. 66, 425-436.

Greenwood, D., Neeteson, J., Draycott, A., 1986. Quantitative relationships for the dependence of growth rate of arable crops on their nitrogen content, dry weight and aerial environment. Plant Soil 91, 281-301.

Guo, J., Jia, Y., Chen, H., Zhang, L., Yang, J., Zhang, J., Hu, X., Ye, X., Li, Y., Zhou, Y., 2019. Growth, photosynthesis, and nutrient uptake in wheat are affected by differences in nitrogen levels and forms and potassium supply. Sci. Rep. 9, 1248.

Haberl, H., 2015. Competition for land: A sociometabolic perspective. Ecol. Econ. 119, 424-431.

Hall, A.J., Richards, R.A., 2013. Prognosis for genetic improvement of yield potential and waterlimited yield of major grain crops. Field Crops Res. 143, 18-33.

Hauser, S., Wairegi, L., Asadu, C.L., Asawalam, D.O., Jokthan, G., Ugbe, U., 2014. Cassava system cropping guide. Available at https://www.iita.org/wpcontent/uploads/2016/06/Cassava_system_cropping_guide.pdf. Accessed on March 10, 2020.

Hawkesford, M., W.H., Thomas Kichey, Hans Lambers, Jan Schjoerring Inge Skrumsager, White, M.a.P., 2012. Functions of Macronutrients. In Marschner, P. (Eds). Marschner's mineral nutrition of higher plants (Third Edition). San Diego Academic press, pp. 135-189.

He, M., Dijkstra, F.A., 2014. Drought effect on plant nitrogen and phosphorus: a meta-analysis. New Phytol. 204, 924-931.

He, Z., Qiu, X., Ata-Ul-Karim, S.T., Li, Y., Liu, X., Cao, Q., Zhu, Y., Cao, W., Tang, L., 2017. Development of a critical nitrogen dilution curve of double cropping rice in south China. Front. Plant sci. 8, 638. doi: 10.3389/fpls.2017.00638.

Howeler, R.H., 2017. Fertilizer requirements for balanced nutrition. In Howeler, R. (Eds). Nutrient sources and their application in cassava cultivation. Centro Internacional de Agricultura Tropical (CIAT), pp. 12-17. DOI: 10.19103/AS.2016.0014.35.

Howeler, R., 2014. Can chemical fertilizer and manure maintain high yield and long-term productivity of the soil? in: Howeler, R. (Eds.), Sustainable Soil and Crop Management of Cassava in Asia: A Reference Manual. CIAT Publication, Vietnam, pp. 56-75.

Howeler, R., Lutaladio, N., Thomas, G., 2013. Cassava, a $21^{\text {st }}$ century crop, in: Save and grow: cassava. A guide to sustainable production intensification. Available at http://www.fao.org/3/ai3278e.pdf pp. 1-18. Accessed on October 8, 2019

Howeler, R., 2012. Dry matter accumulation and nutrient absorption and distribution during the growth cycle of cassava. In Howeler (Eds). The cassava handbook: a reference manual based on the Asian regional cassava training course, held in Thailand. Centro Internacional de Agricultura Tropical (CIAT), pp. 351-410.

Howeler, R.H., 2002. Cassava mineral nutrition and fertilization. In: Hillocks, R.J., Thresh, J.M., Bellotti, A.C. (Eds.), Cassava, Biology, Production and Utilization. CABI Publishing, Wallingford, pp. 115-147.

Howeler, R., Cadavid, L., 1983. Accumulation and distribution of dry matter and nutrients during a 12-month growth cycle of cassava. Field Crops Res. 7, 123-139. 
Ichami, S.M., Shepherd, K.D., Sila, A.M., Stoorvogel, J.J., Hoffland, E., 2019. Fertilizer response and nitrogen use efficiency in African smallholder maize farms. Nutr. Cycl. Agroecosys. 113, 119.

Ichinose, J.G.d.S., Mantovani, C., Mazzini-Guedes, R.B., Pivetta, K.F.L., de Faria, R.T., Bôas, R.L.V., Hoshino, R.T., 2018. Plant development and nutrient uptake rate in Dendrobium nobile Lindl. J. Plant nutr. 41, 1937-1945.

Imakumbili, M.L., Semu, E., Semoka, J.M., Abass, A., Mkamilo, G., 2019. Soil nutrient adequacy for optimal cassava growth, implications on cyanogenic glucoside production: A case of konzoaffected Mtwara region, Tanzania. PloS one 14, e0216708.

Imas, P., John, K., 2013. Potassium nutrition of cassava. Division of Crop Production, Central Tuber Crops Research Institute, Kerala, India. Available at https://www.ipipotash.org/uploads/udocs/e-ifc-34-rf3.pdf. Accessed on September 22, 2019.

Janssen, B.H., 2011. Simple models and concepts as tools for the study of sustained soil productivity in long-term experiments. II. Crop nutrient equivalents, balanced supplies of available nutrients, and NPK triangles. Plant Soil 339, 17-33.

Janssen, B.H., Guiking, F., Van der Eijk, D., Smaling, E., Wolf, J., Van Reuler, H., 1990. A system for quantitative evaluation of the fertility of tropical soils (QUEFTS). Geoderma 46, 299-318.

Jordan-Meille, L., Pellerin, S., 2004. Leaf area establishment of a maize (Zea mays L.) field crop under potassium deficiency. Plant Soil 265, 75-92.

Justes, E., Mary, B., Meynard, J.-M., Machet, J.-M., Thelier-Huché, L., 1994. Determination of a critical nitrogen dilution curve for winter wheat crops. Ann. Bot. 74, 397-407.

Karuku, G.N., Gachene, C., Karanja, N., Cornelis, W., Verplancke, H., Kironchi, G., 2012. Soil hydraulic properties of a nitisol in kabete, Kenya. Trop. and Subtrop. Agroecosys. 15, 595-609.

Kiniry, J., Simpson, C., Schubert, A., Reed, J., 2005. Peanut leaf area index, light interception, radiation use efficiency, and harvest index at three sites in Texas. Field Crop Res. 91, 297-306.

Koning, N., Van Ittersum, M., Becx, G., Van Boekel, M., Brandenburg, W., Van Den Broek, J., Goudriaan, J., Van Hofwegen, G., Jongeneel, R., Schiere, J., 2008. Long-term global availability of food: continued abundance or new scarcity? NJAS-Wageningen J. Life Sci. 55, 229-292.

Kumar, U., Singh, P., Boote, K., 2012. Effect of climate change factors on processes of crop growth and development and yield of groundnut (Arachis hypogaea L.). Adv. Agron. 116, 41-69.

Lal, R., Maurya, P., 1982. Root growth of some tropical crops in uniform columns. Plant Soil 68, 193206.

Lebot, V., 2019. Tropical root and tuber crops. Available online at https://www.cabi.org/ISC/ebook/20093020206. Accessed on March 12, 2020

Lemaire, G., 2012. N Uptake and Distribution in Plant Canopies. In Lemaire, G. (Eds). Diagnosis of the nitrogen status in crops. Springer, pp. 3-41.

Lemaire, G., Jeuffroy, M.-H., Gastal, F., 2008. Diagnosis tool for plant and crop N status in vegetative stage: Theory and practices for crop N management. Eur. J. Agron. 28, 614-624. 
Lemaire, G., van Oosterom, E., Sheehy, J., Jeuffroy, M.H., Massignam, A., Rossato, L., 2007. Is crop $\mathrm{N}$ demand more closely related to dry matter accumulation or leaf area expansion during vegetative growth? Field Crops Res. 100, 91-106.

Mallarino, A.P., Higashi, S., 2009. Assessment of potassium supply for corn by analysis of plant parts. Soil Sci. Soc. Am. J. 73, 2177-2183.

Matthews, R., Hunt, L., 1994. GUMCAS: a model describing the growth of cassava (Manihot esculenta L. Crantz). Field Crop Res. 36, 69-84.

Marouani, A., Behi, O., Sahli, A., Ben, J., 2014. Critical nitrogen curve for two potato cultivars under semi-arid conditions. Fifth International Scientific Agricultural Symposium Agrosym 2014. 23-26 Oct. 2014, pp. 332-339.

Marschner, P., Rengel, Z., 2012. Nutrient availability in soils.In Marschner, P. (Eds). Marschner's mineral nutrition of higher plants (Third Edition). San Diego Academic press, pp. 315-330.

Mengel, D., Barber, S., 1974. Rate of Nutrient Uptake per Unit of Corn Root Under Field Conditions 1. Agron. J. 66, 399-402.

Mithra, V.S., Sreekumar, J., Ravindran, C., 2013. Computer simulation of cassava growth: a tool for realizing the potential yield. Arch. Agron. Soil Sci. 59, 603-623.

Mittal, A., 2009. The 2008 food price crisis: rethinking food security policies. Available at https://unctad.org/en/Docs/gdsmdpg2420093 en.pdf. Accessed on February 24, 2020.

Mmom, P., Ezekwe, I., Chukwu-Okeah, G., 2017. Land Management Practices and the Yield of Cassava (Manihot esculenta Crantz) in the Humid Deltaic Tropical Environment of Nigeria. Agri Res \& Tech. 8(4): 555742. DOI: 10.19080/ARTOAJ.2017.08.555742.

Montagnac, J.A., Davis, C.R., Tanumihardjo, S.A., 2009. Nutritional value of cassava for use as a staple food and recent advances for improvement. Compr. Rev. Food Sci F. 8, 181-194.

Monteith, J.L., 1977. Climate and the efficiency of crop production in Britain. Phil. Trans. R. Soc. Lond. B. $281,277-294$.

Morris, M., Binswanger-Mkhize, H.P., Byerlee, D., 2009. Awakening Africa's sleeping giant: prospects for commercial agriculture in the Guinea Savannah Zone and beyond. The World Bank. Available at https://www.semanticscholar.org/paper/Awakening-Africa's-SleepingGiant\%3A-Prospects-for-in-Morris-Larson/ae8f27c6882287ad656eff54a517a01fd2d07a1c. Accessed on February 26, 2020.

Nation, 2019. Nigeria to save N127b yearly from cassava flour in bread. Available at https://thenationonlineng.net/nigeria-save-n127b-yearly-cassava-flour-bread/. Accessed on January 22. 2020.

Nijland, G.O., Schouls, J., 1997. The relation between crop yield, nutrient uptake, nutrient surplus and nutrient application. Wageningen Agricultural University, Wageningen.

Nijhof, K., 1987. The concentration of macro-elements in economic products and residues of (sub) tropical field crops. Centr. World Food Stu. 1-53.

NIMET, 2012. Annual climate review. Nigeria meteorological agency. Avaible at https://nimet.gov.ng/publication/annual-climate-review-bulletin-2012. Accessed on July 17, 2019. 
Norton, R., 2014. Combating climate change through improved agronomic practices and input-use efficiency. J. Crop Improv. 28, 575-618.

Nyi, T., 2014. Improving agronomic efficiency in cassava- based farming systems in the Democratic Republic of Congo using organic and inorganic inputs. PhD Thesis. School of Environmental Studies, Kenyatta University. Kenya.

Oliveira, N.T.d., Uchôa, S.C.P., Alves, J.M.A., Albuquerque, J.d.A.A.d., Rodrigues, G.S., 2017. Effect of Harvest Time and Nitrogen Doses on Cassava Root Yield and Quality. Rev. Bras. Ciênc. Solo. 41:e0150204.

Omondi, J.O., Lazarovitch, N., Rachmilevitch, S., Yermiyahu, U., 2019. Phosphorus affects storage root yield of cassava through root numbers. J. Plant Nutr. 42, 2070-2079.

Orioli, G., Mogilner, I., Bartra, W., Semienchuk, P., 1967. Acumulacion de materia seca, N, P, K y Ca en Manihot esculenta. Bonplandia, 175-182.

Pasley, H.R., Cairns, J.E., Camberato, J.J., Vyn, T.J., 2019. Nitrogen fertilizer rate increases plant uptake and soil availability of essential nutrients in continuous maize production in Kenya and Zimbabwe. Nutr. Cycl. Agroecosys. 1-17.

Pampolino, M., F and Oberthur, T, 2018. Cassava Response to Fertilizer Application. Better Crops. $102,11-13$.

Pellet, D., El-Sharkawy, M.A., 1997. Cassava varietal response to fertilization: growth dynamics and implications for cropping sustainability. Exp. Agric. 33, 353-365.

Pellet, D., El-Sharkawy, M.A., 1993. Cassava varietal response to phosphorus fertilization. II. Phosphorus uptake and use efficiency. Field Crops Res. 35, 13-20.

Penning de Vries, F., 1989. Simulation of ecophysiological processes of growth in several annual crops. Simulation monographs. Pudoc, Den Hague. Available at https://edepot.wur.nl/108856. Accessed on September 11, 2019.

Plénet, D., Lemaire, G., 1999. Relationships between dynamics of nitrogen uptake and dry matter accumulation in maize crops. Determination of critical N concentration. Plant Soil 216, 65-82.

Pinheiro, C., Chaves, M., 2010. Photosynthesis and drought: can we make metabolic connections from available data? J. Exp. Bot. 62, 869-882.

Pypers, P., Sanginga, J.M., Kasereka, B., Walangululu, M., Vanlauwe, B., 2011. Increased productivity through integrated soil fertility management in cassava-legume intercropping systems in the highlands of Sud-Kivu, DR Congo. Field Crops Res. 120, 76-85.

Rahman, S., Awerije, B.O., 2016. Exploring the potential of cassava in promoting agricultural growth in Nigeria. J. Agr. Rural Dev. Trop. 117, 149-163.

Ray, D.K., Mueller, N.D., West, P.C., Foley, J.A., 2013. Yield trends are insufficient to double global crop production by 2050. PloS one 8(6): e66428. doi:10.1371/journal.pone.0066428

R Core Team (2019) R: A Language and Environment for Statistical Computing. R Foundation for Statistical Computing, Vienna. Available at https://www.R-project.org. Accessed on November 4, 2019.

Rezig, M., Sahli, A., Hachicha, M., Jeddi, F.B., Harbaoui, Y., 2013. Light Interception and Radiation Use Efficiency from a Field of Potato (Solanum tuberosum L.) and Sulla (Hedysarum coronarium L.) Intercropping in Tunisia. Asian J. Crop Sci. 5, 378-392. 
Rosenthal, D.M., Ort, D.R., 2012. Examining cassava's potential to enhance food security under climate change. Trop. Plant Biol. 5, 30-38.

Sadras, V.O., 2007. Evolutionary aspects of the trade-off between seed size and number in crops. Field Crops Res. 100, 125-138.

SaharaReporters, 2019. Nigeria Places Full Ban On Importation Of Goods Through Land Borders. Available at http://saharareporters.com/2019/10/14/nigeria-places-full-ban-importation-goodsthrough-land-borders. Accessed on February 9, 2020.

Santos, N.S.d., Alves, J.M.A., Uchôa, S.C.P., Oliveira, N.T.d., Albuquerque, J.d.A.A.d., 2014. Absorption of macronutrients by cassava in different harvest dates and dosages of nitrogen. Rev. Ciênc. Agron. 45, 633-640.

Senkoro, C.J., Tetteh, F.M., Kibunja, C.N., Ndungu-Magiroi, K.W., Quansah, G.W., Marandu, A.E., Ley, G.J., Mwangi, T.J., Wortmann, C.S., 2018. Cassava yield and economic response to fertilizer in Tanzania, Kenya and Ghana. Agron. J. 110, 1600-1606.

Shackelford, G.E., Haddaway, N.R., Usieta, H.O., Pypers, P., Petrovan, S.O., Sutherland, W.J., 2018. Cassava farming practices and their agricultural and environmental impacts: a systematic map protocol. Environ. Evid 7, 30.

Shah, S., McKenzie, B., Gaunt, R., Marshall, J.W., Frampton, C., 2004. Effect of production environments on radiation interception and radiation use efficiency of potato (Solanum tuberosum) grown in Canterbury, New Zealand. New Zeal. J. Crop and Hort. 32, 113-119.

Sheehy, J., Dionora, M., Mitchell, P., Peng, S., Cassman, K., Lemaire, G., Williams, R., 1998. Critical nitrogen concentrations: implications for high-yielding rice (Oryza sativa L.) cultivars in the tropics. Field Crops Res. 59, 31-41.

Shibu, M., Leffelaar, P., Van Keulen, H., Aggarwal, P., 2010. LINTUL3, a simulation model for nitrogen-limited situations: Application to rice. Eur. J. Agron. 32, 255-271.

Sinclair, T.R., Muchow, R.C., 1999. Radiation use efficiency. Adv. Agron. 65, 215-265.

Spitters, C., 1989. Crop growth models: their usefulness and limitations. VI Symposium on the Timing of Field Production of Vegetables. Acta. Hort. 267, 349-368.

Spitters, C., Schapendonk, A., 1990. Evaluation of breeding strategies for drought tolerance in potato by means of crop growth simulation. Plant Soil 123, 193-203.

Strzepek, K., Boehlert, B., 2010. Competition for water for the food system. Philosophical Transactions of the Royal Society B: Biol. Sci. 365, 2927-2940.

Syers, J., Johnston, A., Curtin, D., 2008. Efficiency of soil and fertilizer phosphorus use. FAO Fertilizer and plant nutrition bulletin 18 . Available at http://www.fao.org/3/a1595e/a1595e00.pdf.

Tripathi, A.M., Pohanková, E., Fischer, M., Orság, M., Trnka, M., Klem, K., Marek, M.V., 2018. The evaluation of radiation use efficiency and leaf area index development for the estimation of biomass accumulation in short rotation poplar and annual field crops. Forests 9, 168.

Tscharntke, T., Clough, Y., Wanger, T.C., Jackson, L., Motzke, I., Perfecto, I., Vandermeer, J., Whitbread, A., 2012. Global food security, biodiversity conservation and the future of agricultural intensification. Biol. Conserv. 151, 53-59. 
Ukhurebor, K., Abiodun, I., 2018. Variation in annual rainfall data of forty years (1978-2017) for South-South, Nigeria. J. Appl. Sci. Environ. Manage. 22, 511-518.

UNDESA, 2017. World population projected to reach 9.7 billion by 2050. Available at https://population.un.org/wpp/. Accessed on May 28, 2019.

Van der Eijk, D., Janssen, B.H., Oenema, O., 2006. Initial and residual effects of fertilizer phosphorus on soil phosphorus and maize yields on phosphorus fixing soils: a case study in south-west Kenya. Agric., Ecosys. and Environ. 116, 104-120.

van den Beuken, R., 2018. Water Availability and potassium uptake of cassava in Nigeria. MSc Thesis Wageningen University, Wageningen, NL, pp. 69.

Vanguard, 2017. Cassava bread initiative can generate N255bn annually. Available at https://www.vanguardngr.com/2017/06/cassava-bread-initiative-can-generate-n255bnannually-association/. Accessed on January 22, 2020.

Van Ittersum, M.K., Van Bussel, L.G., Wolf, J., Grassini, P., Van Wart, J., Guilpart, N., Claessens, L., de Groot, H., Wiebe, K., Mason-D’Croz, D., 2016. Can sub-Saharan Africa feed itself? Proc. Nat. Acad. Sci. 113, 14964-14969, www.pnas.org/cgi/doi/10.1073/pnas.1610359113.

Van Ittersum, M.K., Cassman, K.G., Grassini, P., Wolf, J., Tittonell, P., Hochman, Z., 2013. Yield gap analysis with local to global relevance-a review. Field Crop Res. 143, 4-17.

van Ittersum, M.K., Leffelaar, P.A., Van Keulen, H., Kropff, M.J., Bastiaans, L., Goudriaan, J., 2003. On approaches and applications of the Wageningen crop models. Eur. J. Agron. 18, 201-234.

Vanlauwe, B., Kihara, J., Chivenge, P., Pypers, P., Coe, R., Six, J., 2011. Agronomic use efficiency of $\mathrm{N}$ fertilizer in maize-based systems in sub-Saharan Africa within the context of integrated soil fertility management. Plant Soil 339, 35-50.

Veltkamp, H., 1985. Physiological causes of yield variation in cassava (Manihot esculenta Crantz). PhD Thesis. University of Wageningen, Wageningen, NL, pp. 132.

Viala, E., 2008. Water for food, water for life a comprehensive assessment of water management in agriculture. Irrig. Drainage Syst. 22:127-129

Weih, M., Hamnér, K., Pourazari, F., 2018. Analyzing plant nutrient uptake and utilization efficiencies: comparison between crops and approaches. Plant Soil 430:7-21

Wolf, J., Van Keulen, H., 1989. Modeling long-term crop response to fertilizer and soil nitrogen. Plant Soil 120, 23-38.

Worldometers, 2020. Current world population. Available at https://www.worldometers.info/world-population/. Accessed on January 8, 2020.

Yue, S., Meng, Q., Zhao, R., Li, F., Chen, X., Zhang, F., Cui, Z., 2012. Critical nitrogen dilution curve for optimizing nitrogen management of winter wheat production in the North China Plain. Agron. J. 104, 523-529.

Zamuner, E.C., Lloveras, J., Echeverría, H.E., 2016. Use of a critical phosphorus dilution curve to improve potato crop nutritional management. A. J. Potato Res. 93, 392-403.

Zhang, C., Dong, Y., Tang, L., Zheng, Y., Makowski, D., Yu, Y., Zhang, F., van der Werf, W., 2019. Intercropping cereals with faba bean reduces plant disease incidence regardless of fertilizer input; a meta-analysis. Eur. J. Plant Pathol. 154 (4) 931 - 942. 
Zhou, Z., Andersen, M.N., Plauborg, F., 2016. Radiation interception and radiation use efficiency of potato affected by different $\mathrm{N}$ fertigation and irrigation regimes. Eur. J. Agron. 81, 129-137.

Zhou, Z., Plauborg, F., Kristensen, K., Andersen, M.N., 2017. Dry matter production, radiation interception and radiation use efficiency of potato in response to temperature and nitrogen application regimes. Agri. Forest Meteorol. 232, 595-605. 


\section{Summary}

Many studies have been done to elucidate the relevance of cassava for food security and economic growth. Yet, its potential yield in SSA is unknown and the productivity on a land area basis has remained low. Fertilizers can enhance cassava yield tremendously, this is confirmed by large yields reported by scientists from South America, Asia and Australia. To test this knowledge in West African (WA) environment, a two-year on-farm study was done from 2016 to 2018. The experiment fields were located in three agro-ecological zones (AEZs) (Rain Forest - Cross River, Transition Rain Forest - Edo, and Guinea Savanna - Benue). Treatments were N, P, K, secondary and micronutrients applied in different amounts and combinations to cassava cultivar TME 419. Strong responses of cassava to applied N, P and $\mathrm{K}$ fertilizers were obtained across the different agro-ecologies, with the largest storage root yield recorded of about $35 \mathrm{t} \mathrm{ha}^{-1}$. The recovery of nutrients and the yield response to $\mathrm{K}$ increased with increasing rates of $\mathrm{K}$ applied when both $\mathrm{N}$ and $\mathrm{P}$ were also applied in large amounts. The results show that agronomic and internal utilization efficiency of nutrients by cassava are larger than for cereals. This indicates that environmental risks are less, but at the same time risks of mining soil nutrient reserves are larger with cassava, especially if also stems and leaves are removed from the field.

The observed storage root yields obtained were larger than those previously recorded in experiments and simulated by crop growth models. This indicates that crop parameters used in the simulation models needed to be re-calibrated. So we sought to understand the temporal dynamics of light interception in cassava, determine radiation use efficiency and photo-assimilate partitioning of cassava under optimal conditions. Then calibrate the LINTUL-Cassava model with data from the 2016 experiment in Edo and test the yield prediction accuracy with observations from other field experiments. Measured seasonal average $R U E$ values of $2.8 \mathrm{~g} \mathrm{DM} \mathrm{MJ}^{-1}$ IPAR, light extinction coefficient $(k)$ of 0.67 and $80 \%$ light intercepted were much larger than reported earlier for cassava. Overall, with re-calibrated parameters the LINTUL-Cassava model accurately estimated the storage root yield at the end of the growing season under rainfed conditions.

Information about nutrient uptake and dilution patterns of cassava during the growth cycle is limited, especially for WA growing conditions. This knowledge is necessary to understand the temporal nutrient demands of cassava and to identify best management practices that prevent nutrient deficiency or excess use. Hence we studied the nutrient uptake of cassava as affected by fertilizer application, quantified the proportions of $\mathrm{N}, \mathrm{P}$ and $\mathrm{K}$ in plant-parts and established nutrient dilution curves and nutrition indices for cassava. Nutrient demand differed across the phenological stages of cassava, providing means to optimize nutritional management and timing of applications for maximum yield response. Nutrient uptake rates peaked at about four months after planting. Also, nutrient dilution curves for $\mathrm{N}, \mathrm{P}$ and $\mathrm{K}$ were quantified for the first time in cassava. We observed stronger nutrient dilution coefficients than those reported for most crops. These insights underpin nutrient-limited crop growth models that are needed to further optimize nutrition and to understand how water and nutrient limitations interact with crop growth rates under a range of environments and nutrient availabilities.

Crop growth modelling has yet to include the simulation of NPK interactions and relation between soil available nutrients and crop demand over time. The knowledge about nutrient (N, P and $\mathrm{K}$ ) demand and uptake patterns under both ample and deficient conditions in cassava as obtained from this study were used to develop a simulation model. LINTUL-Cassava-NPK, a dynamic crop growth model for cassava that simulates potential, water limited and $\mathrm{N}, \mathrm{P}$ and $\mathrm{K}$ limited growth was developed and tested. The model calculates the stress effects due to inadequate water availability or N, P and K supply on crop growth rates and yield of cassava, and provides estimates of total uptakes of $\mathrm{N}, \mathrm{P}$ and $\mathrm{K}$. The predicted uptakes of $\mathrm{N}, \mathrm{P}$ and $\mathrm{K}$ and dry matter yields of storage roots were in good agreement with observed values. The modelling results suggest that more $\mathrm{N}$ is needed at the onset of the season, while more $\mathrm{K}$ needs to be applied at a later stage for maximum growth with minimum losses. Overall, the LINTULCassava-NPK model can help to better understand variations in nutrient recovery and nutrient use efficiency of cassava across sites and seasons. However, it requires further testing, especially under a range of water limited conditions. 
Increasing cassava yield requires an in-depth understanding of limitations in growth. Optimum plant population densities are required for good yield. Also, good land preparation such as 'the ridge land management system' enhances cassava growth. Canopy development of cassava at the initial growth stage is slow, it takes about 80 days after planting to attain an $L A I$ of one. This makes cassava a poor competitor with weeds, for light, water and nutrients. Hence, enhancing radiation use efficiency is required to increase cassava yield. In our study, $L A I$ and intercepted light were maintained at sufficient high levels for good crop growth. Overall, good land preparation, selection of high-quality planting material from improved cultivars, optimum planting density and appropriate and balanced fertilizer rates, can stimulate early cassava growth and rapid canopy closure. Cassava is often grown by resourcepoor farmers who operate under limited resources. Its ability to produce where other crops fail has led many to believe that cassava does not require fertilizers. Fertilizer response trials on cassava show poor yield responses at low nutrient rates. Furthermore, unbalanced N, P and K rates, where in most cases too much $\mathrm{N}$ is applied, contribute to the limited response of cassava to applied fertilizers. Our results show that without adequate $\mathrm{K}$ supply, cassava responds poorly to $\mathrm{N}$ fertilizers. At balanced rates, there is a positive synergistic interaction between $\mathrm{N}$ and $\mathrm{K}$ on assimilate production, nutrient uptake, yield formation and stress tolerance. Therefore, poor cassava yield responses to fertilizer applications in SSA are related to imbalanced nutrient supply, low application rates, wrong timing of application, poor weed management etc.

Improved crop management practises that improve both NUE and productivity without negative consequences for the long term are essential: increasing yields is the key strategy for food security. Our results show that it is possible to achieve high NUE with cassava at relatively large fertilizer rates, but only when crop nutrient demand is much larger than the indigenous supply and growing conditions are favourable. The lowest agronomic efficiency (AE) and recovery efficiency (RE) obtained from Benue (Guinea Savanna) reflects the need for adjustment of fertilizer applications to the production potential of the different locations (agro-ecologies) as well as to improve management of other factors. Current management practices for growing cassava in WA, for instance Nigeria may be contributing to the low yields. In practice, the most suitable planting time of cassava in a particular locality is usually determined by onset of rains. Insights from our study show that cassava planted with the first rains (April - June) with the intention to harvest at $12 \mathrm{MAP}$, undergoes enormous yield losses due to the regrowth that occurs with the return of rains from April of the following year. Under rainfed conditions, planting cassava in the middle of the rainy season (August - September) would allow for adequate crop establishment before the onset of the seasonal dry period. Crop growth continues with rapid regeneration and higher photosynthetic capacity with the return of rains, when the crop is still about 7 or 8 months old. This allows an adequate time for recovery from drought and consequently a large yield at harvest, as was the case in Benue during the 2016 growing season.

Results from our study improved the performance of LINTUL-Cassava model under rain-fed systems and formed the empirical and theoretical foundations of nutrient-limited cassava growth modelling. The LINTUL-Cassava-NPK model Provides insight in best times of nutrient application in the season. This will help to reduce nutrient losses and maximize yield by applying the required amounts at the proper time. The knowledge provided will be useful and can improve agricultural decision support tools. Highyielding cassava can play a key role towards meeting the increasing demand for food and agro-based products, because of its high energy content and efficiency. Under limited $\mathrm{N}$ availability, applying fertilizer to cassava results in more energy per $\mathrm{kg} \mathrm{N}$ applied with lower environmental risks than for maize. Cassava is produced mainly for the domestic market in Nigeria. Outlook for increased cassava production is promising as it can spur rural and economic development through production, marketing and export of high quality cassava starch and chips to earn foreign exchange. The large yield response obtained in this study indicates that Nigeria economy could still be improved through cassava production. Cassava could become the raw material base for an array of processed products that would increase the demand and contribute to the long sought agricultural transformation and economic growth in Nigeria. Most especially, findings from our work will be useful in developing technologies for good agronomic practices that will support sustainable cassava production. 


\section{Samenvatting}

Er bestaan veel studies die het belang van cassave voor voedselzekerheid en economische groei onderstrepen. Desondanks is onbekend hoeveel cassave in potentie kan opbrengen, de huidige gemiddelde opbrengsten per hectare zijn al gedurende vele jaren laag. Bemesting zou de productiviteit van cassave enorm kunnen verhogen, zoals aangetoond door de grote opbrengsten die met bemestingen zijn behaald in Zuid Amerika, Azië en Australië. Om dit te testen in de context van West-Afrika (WA) is er een tweejarige studie gedaan op velden van boeren tussen 2016 en 2018. De onderzoeksvelden bevonden zich in drie agro-ecologische zones (AEZs) in Nigeria (regenwoud - Cross River State, overgangsregenwoud - Edo State, en Guinea savanne - Benue State). Als behandelingen zijn de meststoffen $\mathrm{N}, \mathrm{P}, \mathrm{K}$, secundaire en micronutriënten in verschillende hoeveelheden en combinaties gegeven aan cassave cultivar TME 419. De respons van cassave op de N, P en K gift was groot in elk van de AEZs, en de hoogste gemeten wortelopbrengst was $35 \mathrm{t}$ droge stof ha $^{-1}$. De nutriëntenterugwinning en de productie namen toe wanneer er meer $\mathrm{K}$ werd gegeven, in combinatie met grote hoeveelheden $\mathrm{N}$ en $\mathrm{P}$. Deze resultaten tonen aan dat de agronomische en de fysiologische gebruiksefficiëntie van nutriënten hoger is voor cassave dan voor granen. Dat betekent dat het risico op nutriëntenverliezen naar het milieu lager is voor cassave dan voor granen, maar dat er wel een risico is op bodemverarming door de relatief grote nutriëntenopname, met name als stengels en bladeren van het veld gehaald worden.

De gerealiseerde opbrengsten van cassave waren hoger dan die gemeten in eerdere experimenten en simulaties in gewasmodellen. Dit betekende dat de gewasparameters in simulatiemodellen opnieuw gekalibreerd moesten worden. Dit is gedaan voor het LINTUL-Cassava model aan de hand van de data uit 2016 van het experiment in Edo, waar wij ook gegevens hebben verzameld over de lichtonderschepping, de lichtbenuttingsefficiëntie en de verdeling van assimilaten over de plantorganen van cassave onder optimale omstandigheden. De voorspellingkracht van het model is vervolgens getest met de data van de andere experimenten. Gedurende het groeiseizoen was de gemiddelde gemeten benuttingsefficiëntie van onderschept licht in fotosynthetisch actieve golflengten $2.8 \mathrm{~g} \mathrm{DM} \mathrm{MJ}^{-1}$, de licht extinctiecoëfficiënt $(k) 0.67$, en de gemiddelde lichtonderschepping $80 \%$. Deze waarden waren groter dan eerder gerapporteerd voor cassave. Met gekalibreerde parameters kon het LINTUL-Cassave model de cassave-opbrengsten aan het eind van het groeiseizoen onder water-gelimiteerde condities nauwkeurig berekenen.

Er is slechts beperkt informatie beschikbaar over de nutriëntenopname en -verdeling door cassave gedurende de groeicyclus, met name onder West-Afrikaanse condities. Deze kennis is echter noodzakelijk om de nutriëntengift aan te kunnen passen aan de variërende vraag van cassave, om daarmee nutriëntentekorten en -overschotten te voorkomen. We onderzochten daarom hoe nutriëntenopname van cassave afhing van de nutriëntengift en kwantificeerden de verdeling van $\mathrm{N}, \mathrm{P}$ en $\mathrm{K}$ over de plantorganen en bepaalden daarmee verdunningscurves en indicatoren voor de nutriëntenstatus in cassave. De verdunning van nutriënten was groter voor cassave dan voor de meeste andere gewassen. Met deze gegevens kunnen gewasmodellen verbeterd worden om beter te begrijpen hoe gewasgroei afhangt van de beperkte beschikbaarheid van nutriënten en water, onder diverse omstandigheden, om daarmee onder andere de bemesting van cassave verder te optimaliseren.

De huidige dynamische gewasgroeimodellen voor veldgewassen zijn nog niet in staat om de interacties tussen de beschikbare nutriënten in de bodem en de nutriëntenvraag van een gewas gedurende een groeiseizoen mee te nemen. Met de kennis opgedaan in deze studie, betreffende de gewasvraag naar $\mathrm{N}$, $\mathrm{P}$ en $\mathrm{K}$ en de opnamepatronen onder een verschillende omstandigheden en bemestingsregimes, is een simulatiemodel ontwikkeld: LINTUL-Cassava-NPK. Dit is een dynamisch gewasmodel dat de potentiële en de door water en nutriënt gelimiteerde groei en opbrengst van cassave simuleert. Daarnaast schat het model de gewasopname van N, P en K. Deze schattingen van nutriëntenopname en wortelopbrengsten kwamen goed overeen met de gemeten waarden in de proeven. De resultaten van het model geven aan dat er meer $\mathrm{N}$ nodig is aan het begin van het groeiseizoen, en dat er meer $\mathrm{K}$ nodig is in een later stadium voor maximale groei en minimaal nutriëntenverlies. Het LINTUL-Cassava-NPK model draagt bij tot een beter begrip van de variaties in zowel de opname en de benuttingsefficiëntie 
van de gegeven N, P en K door cassave in verschillende gebieden en seizoenen. Het model dient nog verder getest te worden, met name onder diverse condities van waterlimitatie.

Om de cassave-opbrengsten te verhogen is grondig inzicht nodig in de factoren die de gewasgroei beperken. Voor een goede opbrengst is een optimale plantdichtheid en een goede grondbewerking nodig, bijvoorbeeld door het telen van cassave op ruggen. De initiële loofontwikkeling van cassave gaat normaal gesproken traag, het duurt ongeveer 80 dagen om een bladindex van één te bereiken. Dit maakt dat cassave in het nadeel is in de competitie met onkruiden om licht, water en nutriënten. In onze studie werd een veel hogere bladindex bereikt die gedurende het seizoen op een voldoende niveau werd gehandhaafd voor goede gewasgroei in Edo en Cross River. Een goede landbewerking, gebruik van hoogwaardig plantmateriaal van verbeterde cultivars met een optimale plantdichtheid en gebalanceerde bemestingsgiften kan vroege groei stimuleren, waardoor het gewas het veld snel bedekt. Cassave wordt vaak geteeld door boeren met beperkte middelen op arme gronden. Veel boeren zijn ervan overtuigt geraakt dat het niet nodig is om cassave te bemesten omdat cassave groeit op arme gronden waar andere gewassen falen. Bemestingsproeven met kleine bemestingsgiften resulteerden in een slechte respons, doordat er vaak een ongebalanceerde $\mathrm{N}$, $\mathrm{P}$ en $\mathrm{K}$ bemesting werd gegeven met een relatieve overmaat aan N. Onze resultaten laten zien dat een te kleine gift van K leidt tot een slechte opbrengstrespons van cassave op N. Een gebalanceerde nutriëntengift met voldoende N, P en K gaf een positieve synergistische interactie met extra opbrengst, door een continuerende groei in de periode met weinig regen terwijl de nutriëntopname in de drogere periode beperkt was.

Verbeterde teeltmethoden die zowel de nutriëntenbenutting als de gewasproductie verbeteren zonder nadelige effecten op de langere termijn zijn essentieel: opbrengstverhoging is de sleutelstrategie voor voedselzekerheid. Onze resultaten laten zien dat het mogelijk is om met cassave een hoge benuttingsefficiëntie van de gegeven bemesting te halen bij grote giften, mits de gewasvraag veel groter is dan het aanbod van beschikbare nutriënten in de bodem en de groeiomstandigheden gunstig zijn. De agronomische efficiëntie en terugwinningsefficiëntie van de gegeven meststoffen was in de proeven in Benue laag ten opzichte van de proeven in Cross River en Edo. Dit geeft aan dat de bemestingsgiften aangepast moeten worden aan de groeiomstandigheden en de potentiële productie van de locatie. De huidige teeltmethoden voor cassave in WA, inclusief Nigeria, dragen bij aan de lage opbrengsten. In de praktijk hangt het tijdstip van planten af van de start van het regenseizoen. Inzichten uit onze studie laten zien dat een dergelijk strategie met planten in de periode van april tot juni en een oogst na 12 maanden leidt tot groeivertraging tijdens de periode van wortelvulling door droogte en een verminderde opbrengst door de korte groeiperiode na de droogteperiode. Zonder beregening geeft een latere tijdstip van planten in het midden van het regenseizoen (augustus-september) een adequate eerste groei en een periode van sterke groei na de droogte met een hogere lichtbenutting als het gewas 7-8 maanden in het veld staat. Deze strategie geeft het gewas voldoende tijd om te herstellen van de droogte en daardoor een hogere opbrengst, zoals we hebben waargenomen in het groeiseizoen van 2016 in Benue.

Resultaten van mijn studie verbeterden het LINTUL-Cassava model onder water gelimiteerde condities en vormden de empirische basis en een theoretische fundering van nutriëntbeperkte gewasgroeimodellering. Het LINTUL-Cassava-NPK model geeft inzicht in de interacties tussen N, P en $\mathrm{K}$ bemestingen en de optimale bemestingsmomenten in het groeiseizoen. Dit is belangrijk omdat hiermee de nutriëntverliezen beperkt kunnen worden bij een verbeterde gewasopbrengst, door de juiste hoeveelheid meststoffen op het goede moment toe te dienen. De verkregen inzicht kunnen de adviezen ter ondersteuning van de cassaveteelt ondersteunen en verbeteren. Cassave met hoge opbrengsten kan een sleutelrol spelen om aan de groeiende toekomstige vraag naar voedsel en landbouwproducten te voldoen vanwege de hoge nutriëntefficiëntie en een grote energetische waarde van cassavewortels. Bij een beperkte $\mathrm{N}$ beschikbaarheid geeft cassave veel meer energie per kg gegeven $\mathrm{N}$ dan mais. Cassave wordt in Nigeria vooral geteeld voor de eigen markt. De verwachtingen voor een toenemende cassaveproductie zijn veelbelovend, omdat door de productie en export van hoogwaardige cassavezetmeel en chips buitenlandse valuta worden verdient en de rurale en economische ontwikkelingen worden versneld. De sterke respons op bemesting laten zien dat de Nigeriaanse economie nog sterk zou kunnen verbeteren door een verhoogde productie en verwerking van cassave. Cassave kan als grondstof dienen voor een reeks aan producten waarmee zowel de binnen- en buitenlandse vraag vergroot wordt, en kan bijdragen aan economische groei en de lang nagestreefde transformatie in de landbouw van Nigeria. 


\section{Acknowledgements}

During my fellowship period with African Women in Agriculture Research and development (AWARD), I received an offer for advanced science training/knowledge sharing in good agronomic practices for cassava, with International Fertilizer Development Center (IFDC) CATALIST-Uganda Project. Then, I was gifted the PhD thesis of Dr. Anneke Fermont by Dr. John Wendt. This piece of work caused me to start dreaming of learning from those that taught and supervised Dr. Fermont, which included Prof. Ken Giller. In June 2014, I approached Prof Giller, for admission into PhD program in plant production systems group of Wageningen University. He granted me provisional acceptance letter on the basis that my application for funding would be successful and connected me to my daily supervisor Dr. AGT Schut. Fortunately, with the support of Dr. Schut, I received a 4-year PhD fellowship award from Netherlands Fellowship Programme (NUFFIC). These two believed in me and painstakingly coached and mentored me to ensure that I obtain all required advanced scientific, personal and professional development skills and knowledge for the completion of my studies. I am most grateful to you. My work with Dr. Schut exposed me to an exceptional work ethic that is only geared towards excellence. He kept raising the bar, sharing very insightful ideas and knowledge, especially in the novel nutrient-limited crop growth aspect of light interception and utilization (LINTUL-Cassava) model, of which, I am thankful for.

I highly appreciate my in-country supervisors, Dr. Anthony O. Ano and Prof C.N Egesi. Also, Dr. Adeyemi Olojede for the immense support towards the success of the elaborate fieldwork. I remain grateful to Prof. Dr. ir. M. van Ittersum, for his readiness to share his wealth of knowledge whenever contacted and show of kindness, especially when I lost my beloved father. Big thanks to Prof. Dr R. Merckx, KU Leuven, Belgium for the encouragements, Karla Moore and family for your support and kindness when I visited KU Leuven to facilitate my plant sample analysis. Thanks to the Head PE\&RC $\mathrm{PhD}$ Programme Dr. Claudius van de Vijver for the very useful orientation meeting that kept me going. Thank you Marcel Lubbers, Bert Rijk, Charlotte Schilt, Karen Hendricks and Linda Kaster for your support with computer checks, comfortable office environment, heads up with needful information and most especially financial stability. I was blessed to know Rob van den Beuken and Bastiaen Boekelo, who graciously helped me paddle across the storms of statistical analysis using R. I am grateful with smiles for the beautiful friendship of my colleagues in the PPS group. Thank you for the support and assuring kind words, checking up to know about one another's welfare is much more than the gift of gold. Katrien Descheemaeker, Pytrik Reidsma, Gerrie van de Ven, Maja Slingerland, Joost van Heerwaarden, Eva Thuijsman, Eva Goudsmit, Eva Huet, Esther Mugi, Arouna Dissa,

Antoine Languillaume, Joao Nunes Vieira da Silva, Renske Hijbeek, Comfort Ojo, Jiska van Vliet, Inge van de Wiel, Lotte Woittiez, Wim Paas, Wytze Marinus, Hanna Kool, Na Wang, Marloes van Loon, Urcil Kenfack Essougong and many others.

Certainly there is no good $\mathrm{PhD}$ thesis in agronomy without comprehensive field research. The African Cassava Agronomy Initiative (ACAI project), provided the funding and the enabling environment for my field studies and completion of my PhD program. Thank you the entire ACAI team, especially. Bernard Vanlauwe, Pieter Pypers, Stefan Hauser, Christine Kreye, Meklit Chernet, and Guillaume Ezui. My special thanks goes to the Executive director National Root Crops Research Institute, Umudike (NRCRI) Prof. U.J Ukpabi and my colleagues that assisted me in various capacities during the fieldwork, Chinaza Ironkwe, Ngozi Onyeji Ihejirika, Kenny, Shola Eja, Charles C. Nwokoro, Dr. Innocent Onyekwere, Joseph Mbe, etc. Also, I deeply appreciate the encouragements and inspirations from TNC Echendu, Uchenna E. Okoroafor, Flourish Awobajo, Ngozi Edoh, Maureen E. Chris-Nwokocha etc. I must not forget the dedication of the farmers and extention agents (EAs) I worked it, especially John Ohunyon from Edo, who assisted with the management of the experiments on-farm and maintaining weed-free farms all through. Others included sir Gregory, Afolabi Bernard, Pst. Elvis and Papa.

A big heartfelt gratitude to Rob van den Beuken's family. The parents, Joan and Riet found me very interesting and took me as a family. Thanks to Rob's brother, Bas and Grandma for contributing to the fun I had with this sweet family. A profound gratitude to the African Community of Wageningen, especially my fellow Nigerians. Ibrahim Jibril, Micheal Babatunde, Ranti Sanni-Lawal, Georgina Abiola etc., who showed direct care and understanding. To my other brothers and sisters including Isaac Omwenga, Christella Uwineza, and Shapan Yong Chia, Thank you for your immense supports. I appreciate the friendship and spiritual support from the International Christian Fellowship (ICF), 
especially Karen and Daniel. Big thanks to my lovely sister in-law, Victoria Ngozi Iwuoha for the unrelenting care given to me and my family during the whole study period away from family. I extend my gratitude to the entire Uwadilekes and Adieles for their fervent prayers and believe in me, especially to my siblings for their continuous supports. My eternal appreciations go to my besties Azunna and Kelechi for helping to care for my children while I was away in school.

In this life, I was gifted with two persons that valued education even without attaining it. My most cherished late grandmother (Matilda F. Uwadileke) and very inspiring father, late Mr. Harcourt G. Uwadileke. The pains of losing them transmuted into an unquenchable fire for unalloyed success in my educational pursuit. I guess they are smiling now, this achievement is one of my tributes to them. Now, to my darling husband Pst. Samuel C. Adiele and my children, Favour and Abundance Adiele; this pursuit would not have seen the light if you did not give your support and maintained it. You sacrificed a lot, denying yourselves deserved comforts and pleasures. As you can see, the battle is won with nothing broken - nothing missing! Thank you a multi-million times. Most especially, I give all praises to God the Creator, who knew my name before I was conceived, kept and sustained me on the path of my destiny. 


\section{PE\&RC Training and Education Statement}

With the training and education activities listed below the PhD candidate has complied with the requirements set by the C.T. de Wit Graduate School for Production Ecology and Resource Conservation (PE\&RC) which comprises of a minimum total of 32 ECTS (= 22 weeks of activities)

\section{Review of literature (6 ECTS)}

- Fertilizers for improved cassava production

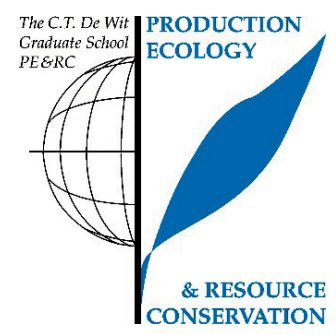

Writing of project proposal (4.5 ECTS)

- Improved crop management systems for sustainable cassava production in sub-Saharan Africa

\section{Postgraduate courses (4.5 ECTS)}

- $\quad$ Linear models; PE\&RC (2015)

- $\quad$ Generalized linear models; PE\&RC (2015)

- $\quad$ Mixed linear models; PE\&RC (2015)

- $\quad$ Soil ecology; PE\&RC (2019)

- $\quad$ GIS in practice; PE\&RC (2019)

- $\quad$ Dynamic models in R; PE\&RC (2019)

Laboratory training and working visits (1.5 ECTS)

- $\quad$ Laboratory and equipment use (2017)

Invited review of (unpublished) journal manuscript (1 ECTS)

- Agronomy Journal: intensification options of small holders' cassava production in south-west Nigeria

Deficiency, refresh, brush-up courses (12 ECTS)

- $\quad$ Research methods in crop science; CSA/PE\&RC (2015)

- $\quad$ System analysis; PPS/PE\&RC (2015)

Competence strengthening / skills courses (2.7 ECTS)

- Enhancing negotiation skills for women; AWARD Fellowship (2015)

- $\quad$ Introduction to R; ACAI Project (2017)

- $\quad$ Ethics in field research and data collection; ACAI Project (2018)

- $\quad$ Proposition writing; PE\&RC (2019)

- $\quad$ Brain training; PE\&RC (2019)

PE\&RC Annual meetings, seminars and the PE\&RC weekend (1.8 ECTS)

- $\quad$ PE\&RC Weekend for first year PhD candidates (2015)

- PE\&RC Weekend for last year PhD candidates (2018)

- PE\&RC Day (2019)

Discussion groups / local seminars / other scientific meetings (7.5 ECTS)

- Weekly lunchtime seminars; PPS \& CSA (2015)

- $\quad$ Planning and review workshops for ACAI Project meetings (2016-2018)

- Weekly lunchtime seminars; PPS \& CSA (2018-2020)

- $\quad$ Modelling and simulation; PE\&RC (2019-2020)

- $\quad$ R Users; PE\&RC (2019-2020)

International symposia, workshops and conferences (5 ECTS)

- $\quad$ ASA-CSSA-SSSA International annual meeting; San Antonio, USA (2019)

- $\quad$ ACAI Annual review meeting; Zanzibar, Tanzania (2019)

Lecturing / supervision of practicals / tutorials (1.2 ECTS)

- Crop physiology and environment (2019)

Supervision of MSc students (3 ECTS)

Water availability and potassium uptake of cassava in Nigeria 


\section{Peer reviewed articles in scientific journals}

Adiele, J.G., Schut, A.G.T., van den Beuken, R.P.M., Ezui, K.S., Pypers, P., Ano, A.O., Egesi, C.E., Giller, K.E., 2020. Towards closing cassava yield gap in West Africa: Agronomic efficiency and storage root yield responses to NPK fertilizers. Field Crops Res. Published online https://doi.org/10.1016/j.fcr.2020.107820.

Onyekwere, I.N., Ethan, S., Adiele, J.G., Mbe, J.O., Nwokoro, C.C., 2017. Micronutrients characterization of soils of basalt parent material in Ikom, Cross River State Nigeria, for sustainable crop production. Direct Res. J. Agric. Food Sci. 5(10):348-352.

https://doi.org/10.26765/DRJAFS.2017.8125.

Adiele, J. G., Chukwu, L.I, Ano, A.O., Echendu, TNC., 2014. Management of short fallows using two different cover crops. Greener J. Agric. Sci. 4(2): 058-066.

Adiele, J. G., Volk, T.A., 2013. Developing live cover crop systems for willow (Salix spp.) bioenergy crop. Sky Journal of Soil Sc. and Environ. Mgt. 2(9):88-97.

\section{Articles under review}

Adiele, J.G., Schut, A.G.T., van den Beuken, R.P.M., Ezui, K.S., Pypers, P., Ano, A.O., Egesi, C.E., Giller KE., 2020. Evaluating cassava yield potential using the LINTUL-Cassava model. Submitted to Eur. J. Agron.

Adiele, J.G., Schut, A.G.T., Ezui, K.S., Pypers, P., Giller, K.E. Dynamics of nutrient uptake, dilution and nutrition indices for cassava. Submitted to Agron. Sustain. dev.

Adiele, J.G., Schut, A.G.T., Ezui, K.S., Giller, K.E. LINTUL-Cassava-NPK: a simulation model for nutrient-limited cassava growth. Submitted to Field Crops Res.

\section{Proceedings}

Adiele, J.G., Schut, A.G.T., Ezui, K.S., Pypers, P., Ano, A.O., Egesi, C.E., Giller, K.E., 2020.

Agronomic Efficiency and Nutrient Recovery from Fertilizers By Cassava on Fields with Low Soil Fertility in West Africa. ASA, CSSA, and SSSA International Annual Meetings. November $10-13$, 2019. San Antonio, Texas USA.

https://scisoc.confex.com/scisoc/2019am/meetingapp.cgi/Paper/121765.

Adiele, J.G., Schut, A.G.T., Ezui, K.S., Pypers, P., Ano, A.O., Egesi, C.E., Giller, K.E., 2020.

Simulating Cassava Growth Under Rain-Fed Conditions in Nigeria. ASA, CSSA, and SSSA

International Annual Meetings. November 10 - 13, 2019. San Antonio, Texas USA.

https://scisoc.confex.com/scisoc/2019am/meetingapp.cgi/Paper/121768.

Adiele, J.G., Hauser, S., Egesi, C.N., Nwaogu, A., Ano, A.O., Chukwu, L.I., Echendu, T.N.C., 2013. Management of short fallows using two different cover crops. ASA, CSSA, and SSSA International Annual Meetings. November 3 - 6, 2013. Tampa, Florida.

https://dl.sciencesocieties.org/publications/meetings/2013am/11220/

Edoh, N. L., Adiele, J., Okogbenin, E., Akinbo, O.A. and Egesi, C.N., 2012. Overcoming challenges of climatic change in cassava production in Nigeria. GCP21-II, June 18-22, 2012. Kampala Uganda.

Adiele, J., Volk, T.A., 2011. Developing spring cover crop systems for willow biomass crop establishment. Aspects of Applied Biology 112: 113-119. 


\section{About the author}

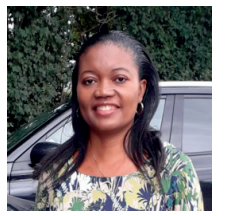

Joy Adiele was born on $19^{\text {th }}$ September 1975 , in Umuako Nsirimo, Ubakala South LGA of Abia State Nigeria. She grew up in the same place and attended her primary education at Community Primary School, Umuako and secondary education at Community Secondary School, Nsirimo. She enrolled for a bachelor's degree in Geography at Abia State University, Uturu in 1994. In 2005, she was employed as an agric. meteorologist at National Root Crops Research Institute, Umudike. There she developed research interest in soil fertility and crop management for sustainable root and tuber crop production. In 2009, she received a scholarship from Ford Foundation International Fellowship Program (IFP), for MSc in Natural Resources Management at State University of New York, College of Environmental Science and Forestry, Syracuse New York (SUNY ESF). For her MSc research, she developed living cover crop systems for willow (Salix spp) bioenergy crop. She completed her MSc studies in May 2011. Upon her return to Nigeria, she continued with her job at NRCRI, Umudike as an Agronomist. Then, she embarked on a research for short fallow management with legumes - Mucuna and Pueraria). In 2013, Joy received a fellowship award from African Women in Agricultural Research and Development Fellowship (AWARD), to undergo advanced training on scientific research and leadership skills development. As part of the fellowship, she worked as a research fellow at International Fertilizer Development Center (IFDC) CATALIST-Uganda Project. Her research focused on Conservation farming (Minimum tillage) and improved crop management systems in cassava production. In June 2015, She was admitted as a PhD student in the Plant Production Systems Group of Wageningen University under a scholarship award from Netherlands Fellowship Program (NUFFIC). Her PhD focused on exploring the yield potential of cassava and the dynamics of nutrients limitations in relation to water availability, in order to obtain better insight and a theoretical understanding of how the crop responds to nutrient availability and application of fertilizers in different agro-ecologies.

Email address: joyadiele@yahoo.com 


\section{Funding}

This study was funded by Netherlands Fellowship Programme (NUFFIC). The field work was funded by Bill \& Melinda Gates Foundation through the African Cassava Agronomy Initiative project (ACAI).

Financial support from Wageningen University for the printing of this thesis is gratefully acknowledged. 



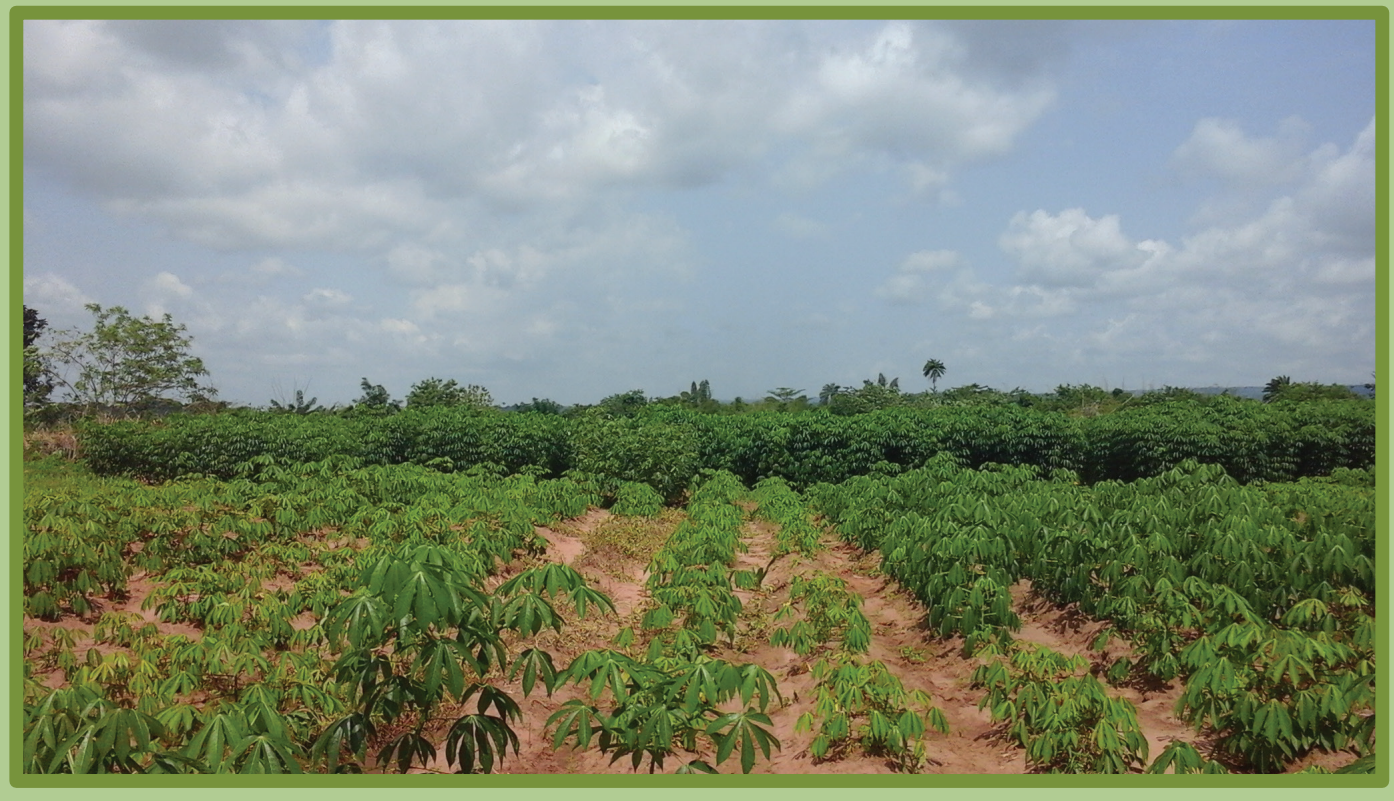

